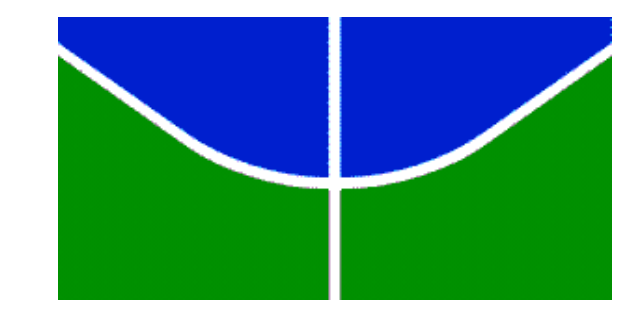

Universidade de Brasília - UnB

Instituto de Ciências Humanas

Departamento de Geografia

Pós-Graduação em Geografia

Missifany Silveira

\title{
A IMPLANTAÇÃO DE HIDRELETRICAS NA AMAZÔNIA BRASILEIRA, IMPACTOS SOCIOAMBIENTAIS E À SAÚDE COM AS TRANSFORMAÇÕES NO TERRITÓRIO: O CASO DA UHE DE BELO MONTE.
}

Brasília 
Missifany Silveira

\title{
A IMPLANTAÇÃO DE HIDRELETRICAS NA AMAZÔNIA BRASILEIRA, IMPACTOS SOCIOAMBIENTAIS E À SAÚDE COM AS TRANSFORMAÇÕES NO TERRITÓRIO: O CASO DA UHE DE BELO MONTE.
}

\author{
Tese de Doutorado apresentada ao Programa \\ de Pós-Graduação em Geografia, do \\ Instituto de Ciências Humanas da \\ Universidade de Brasília, como requisito \\ para obtenção do título de Doutora em \\ Geografia.
}

Orientador: Dr. Mário Diniz de Araújo Neto

Coorientadora: Dra. Helen da Costa Gurgel

Brasília 


\section{A IMPLANTAÇÃO DE HIDRELETRICAS NA AMAZÔNIA BRASILEIRA, IMPACTOS SOCIOAMBIENTAIS E À SAÚDE COM AS TRANSFORMAÇÕES NO TERRITÓRIO: O CASO DA UHE DE BELO MONTE.}

Tese de Doutorado apresentada ao Programa de Pós-Graduação em Geografia, do Instituto de Ciências Humanas da Universidade de Brasília, como requisito para obtenção do título de Doutora em Geografia.

Banca Examinadora:

Prof. Dr. Mário Diniz de Araújo Neto (Orientador)

Departamento de Geografia - UnB

Prof. Dr. Christovam, de Castro Barcellos Neto

Fundação Oswaldo Cruz (FIOCRUZ)

Prof. Dr. Perci Coelho de Souza

Departamento de Serviço Social - UnB

Profa. Dra. Anne-Elisabeth Laques

Institut de Recherche pour le Développement - IRD

Prof. Dr. Valdir Adilson Steinke

Departamento de Geografia - UnB

Prof. Dr. Osmar Abílio de Carvalho Júnior (Suplente)

Departamento de Geografia - UnB

Brasília 


\section{FICHA CATALOGRÁFICA}

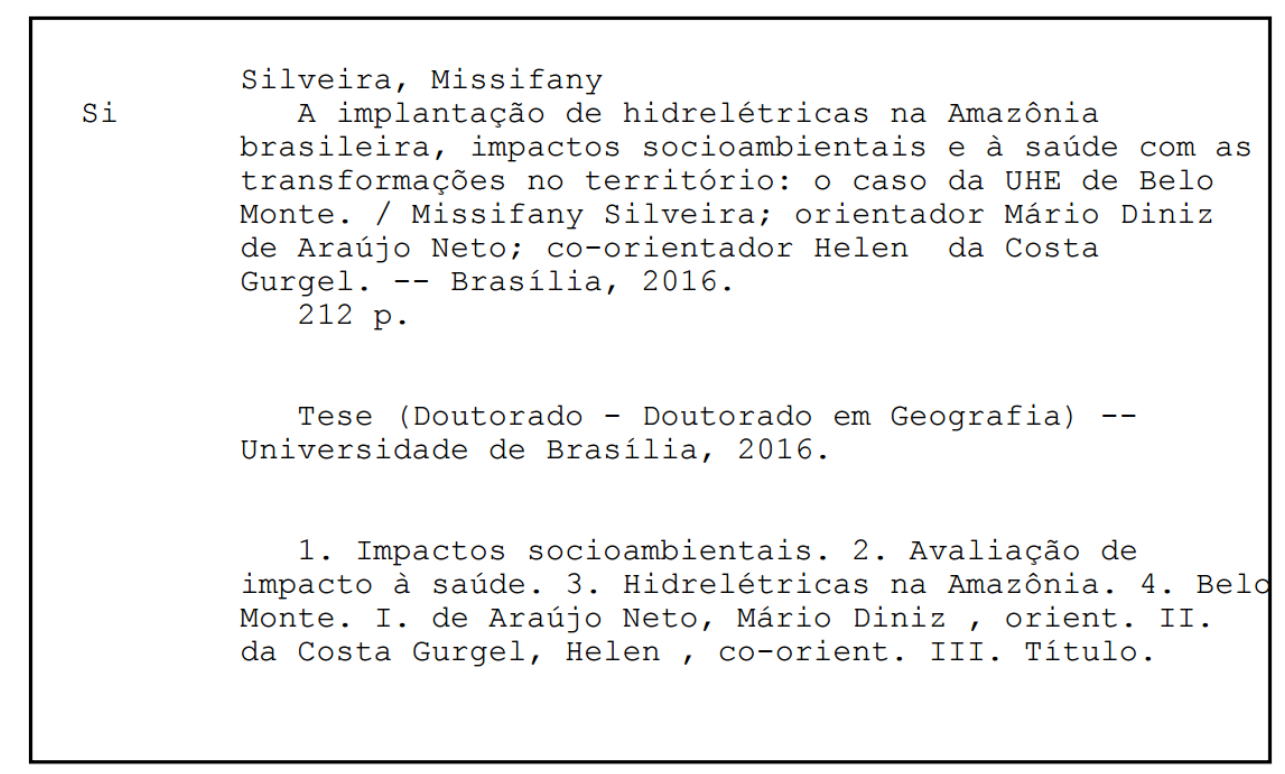


Dedico este trabalho aos meus pais. 


\section{AGRADECIMENTOS}

Agradeço a todas as pessoas e às instituições que colaboraram de alguma maneira para a realização deste trabalho:

Ao Programa de Pós-Graduação em Geografia da UnB, pela oportunidade de realização do curso de Doutorado.

Ao Dr. Mário Diniz de Araújo Neto, pelo importante papel de orientador, pelas nossas conversas e seus questionamentos sempre tão enriquecedores durante esse percurso.

Aos colegas da Secretaria de Vigilância em Saúde, pelo reconhecimento deste trabalho e pelo apoio durante os primeiros anos do Doutorado.

Ao Conselho Nacional de Pesquisas (CNPq), pela concessão da bolsa sanduiche no exterior.

Ao Institut de Recherche pour le Développement (IRD), especialmente à Maison de la Télédétection (MTD) - Espace DEV, em Montpellier, pelo acolhimento e troca de conhecimentos. Aos amigos que compartilharam essa passagem pela França: André Fenner; Marcus Fuckner; Paulo Peiter; Cláudio Almeida; Alexandre Weifels; Audrey Bochaton; Juliette Longchamp, e Alexandre Bena, pelo apoio e amizade.

À Dra. Helen Gurgel, pelo apoio e convite para participar do Projeto Regional Epidemiological Landscape Amazon System (RELAIS), sob a coordenação da Dra. Denise Pires de Carvalho (UFRJ) e do Dr. Laurent Durieux (IRD), de quem recebi o incentivo para participação em reuniões, congressos e seminários.

A todos que me ajudaram a conhecer um pouco da realidade da Usina Hidrelétrica de Belo Monte, pela contribuição e por possibilitarem o acesso aos dados, em especial o Dr. José Brito Ladislau; o enfermeiro Osvaldo Damasceno; o Dr. Mário Franco; o Instituto Socioambiental (ISA); a Fundação Getúlio Vargas, a Fundação Viver Produzir e Preservar (FVPP); a D. Gracinda Magalhaes, do Movimento de Mulheres Trabalhadoras de Altamira, Campo e Cidade (MMTAC); os técnicos da Secretaria Municipal de Saúde de Altamira, pela contribuição e pelo acesso aos dados.

À Dra. Anne Elizabeth Laques e a Adriana Moellmann, pelas contribuições.

À Gislaine Disconzi, em nome de todos os amigos que, de alguma maneira, colaboraram e torceram para a realização deste trabalho.

À Vera Beatriz, pela hospitalidade, incentivo e apoio constante, todo o meu reconhecimento e gratidão.

À minha família, em especial à minha irmã Jeanete, pela generosidade e solidariedade. 


\section{RESUMO}

SILVEIRA, Missifany. A implantação de hidrelétricas na Amazônia brasileira, impactos socioambientais e à saúde com as transformações no território: o caso da UHE de Belo Monte. 2016. 212f. Tese (Doutorado em Geografia) - Pós-Graduação em Geografia, Universidade de Brasília-UnB, Brasília, 2016.

A Região da Amazônia brasileira, onde historicamente ocorreram processos de colonização e uso intensivo dos recursos naturais, é emblemática no tocante às tensões relativas ao uso do território. Atualmente, é o espaço de maior expansão do potencial energético e de futuros projetos hidrelétricos, característica que lhe confere uma (re)valorização nacional. De modo geral, as localidades onde se instalam grandes empreendimentos, como as hidrelétricas têm seus espaços transformados em um contexto de marcadas contradições. De um lado, há os efeitos positivos, traduzidos por benefícios apresentados como um legado à população, além da geração temporária de emprego e renda. De outro, estão os impactos negativos, que, com o imperativo afluxo populacional tanto de trabalhadores como de pessoas atraídas pela obra, acarretam modificações profundas no território. A construção de usinas hidrelétricas requer um planejamento rigoroso para a utilização dos recursos naturais, assim como ações na região para mitigar os principais conflitos e compensar seus impactos, particularmente ambientais e sociais. Nesse aspecto, faz parte do escopo da Avaliação de Impacto Ambiental (AIA), por meio dos estudos e planos, a responsabilidade pelas proposições de mitigação dos principais impactos socioambientais, neles considerados a saúde. A avaliação de impactos à saúde, no âmbito dos grandes empreendimentos no Brasil, é comumente realizada de forma pontual nos processos de licenciamento ambiental. Existem ainda poucas iniciativas no País para o uso da metodologia de Avaliação de Impacto à Saúde, preconizada pela OMS, e disseminada em diversos países. Diante desse quadro, este trabalho objetivou discutir as interfaces entre desenvolvimento, meio ambiente e saúde no contexto da implantação dos grandes empreendimentos na Amazônia brasileira, em estudo de caso que teve por objeto a usina de Belo Monte. A pesquisa se deteve na abordagem teórico-conceitual. Em seguida, houve a análise das relações entre as dinâmicas no território e as ações aplicadas na região, resultantes das transformações locais com a construção das usinas hidrelétricas. Para tal, foram utilizados dados gerais de natureza socioambiental, assim como informações relativas à saúde das áreas de influência da usina de Belo Monte. Os resultados apontam para uma tendência na mudança do perfil de saúde na região, em que as doenças transmissíveis surgem em menor grau quando comparadas às não transmissíveis, aqui representadas pelos acidentes e violências, que apresentaram um aumento significativo ao longo da série histórica. Resultados pouco expressivos diante do aporte de recursos pelo poder público e pela empresa Norte Energia não foram eficientes o bastante para solucionar os conflitos na região e as frequentes paralisações da obra, bem como para atender plenamente o acesso à saúde. As políticas de desenvolvimento estabelecidas decorrem de interesses diversos externos à região e, quando implantadas, desestruturam a lógica de organização local, aumentando os conflitos ambientais e sociais na área, com reflexos sobre a saúde e a qualidade de vida. Concluiu-se, dessa forma, que o enfrentamento dos problemas de modo a garantir a integração das iniciativas para a resolução de conflitos e outras externalidades impostas pela implantação das hidrelétricas demanda visão ampliada e políticas públicas integradas de saúde, meio ambiente e desenvolvimento ético, para a construção de territórios mais saudáveis.

Palavras-chave: Impactos socioambientais. Avaliação de impacto à saúde. Hidrelétrica. Amazônia. Belo Monte 


\begin{abstract}
SILVEIRA, Missifany. The implantation of hydropower plants in the Brazilian Amazon and the social, environmental and health impacts from the transformations on the territory: the case of Belo Monte. 2016. 212p. Thesis (Ph.D on Geography) - Post Graduated Studies in Geography, University of Brasilia-UnB, Brasília/Brazil, 2016.
\end{abstract}

The Brazilian Amazon, place of historical colonization processes and intensive use of natural resources, is an emblematic spot in regards to the tense relations related to land use. Currently it is the site of the greatest expansion of energy potential and future hydroelectric plant projects, a characteristic that gives it a nationwide (re)appreciation. In a general aspect, the areas where are located the largest settlements such as dams witness their spaces being turned into an environment marked by multiple contradictions. On one hand, there are positive effects, translated by benefits presented as a legacy to the population, as well as temporary employment and income opportunities. On the other, the negative impacts caused by population influx of both workers and people attracted by work offers entail profound changes on the territory. The building of hydroelectric power plants requires rigorous planning about the use of natural resources and actions in the area in order to mitigate the major conflicts and compensate its impacts, particularly the environmental and social ones. Concerning this aspect, it is a part of the Environmental Impact Assessment established through many studies and plans, the responsibility for mitigation proposals about the main social and environmental impacts, among which are those regarding health issues. The assessment about health impacts in the context of large projects in Brazil is performed mainly by the environmental licensing process. In this country there is only a few initiatives using the methodology of Impact Assessment to Health, as recommended by WHO and disseminated in several nations. To this end, the goal here was to discuss the interfaces between development, environment and health in the scope of implementing big projects in the Brazilian Amazon, through a case study about the hydroelectric plant in Belo Monte. This search presents a theoretical and conceptual approach. Plus, there was the analysis about the relations between the territory's dynamics and the actions implemented in the area, a result of the local changes due to the construction of hydroelectric power plants. In order to achieve this goal, were used general demographic and environmental data, as well the information about health aspects in the site covered by Belo Monte hydroelectric power plant. The results indicate a trend in the area's health profile changing, where communicable diseases show a lesser extent when compared to non-communicable, represented here by accidents and violence, with a significant increase over the time series. The inexpressive results obtained from the resources allocated by the government and by the Norte Energia Company were not enough to solve the conflicts in the area and neither the frequent stoppages of work, as well as to fulfill the health infrastructure needs. The established development policies are a result of many interests unrelated to the area's particularities, and are able to disrupt the local organizing logic in a manner that increases environmental and social conflicts, affecting the health and quality of life. Therefore, the final conclusion is that, to ensure the integration between the initiatives of conflict resolution and other externalities imposed by the implementation of hydroelectric power plants, it is required an expanded vision and the correlation of health policies, environmental and ethical development, in order to build healthier territories.

Keywords: Social and environmental impacts. Health impact assessment. Hydroelectric. Amazônia. Belo Monte. 


\section{SUMÁRIO}

INTRODUÇÃ

CAPÍTULO 1 - AMAZÔNIA: TERRITÓRIO DE ENERGIA ..............................................26

1.1 O OLHAR GEOGRÁFICO SOBRE O TERRITÓRIO NO CONTEXTO DAS NOVAS

ESPACIALIDADES

1.2 O TERRITÓRIO AMAZÔNICO COMO INSTRUMENTO ESTRATÉGICO DE POLÍTICAS PÚBLICAS NO ÂMBITO DO PLANEJAMENTO DE EMPREENDIMENTOS HIDRELÉTRICOS NO BRASIL

1.2.1 A organização do setor elétrico brasileiro diante do potencial energético da Amazônia...................35

1.2.2 Os atores envolvidos no planejamento das usinas hidrelétricas em face do cumprimento do

licenciamento ambiental no Brasil......

1.3 A REALIDADE DA ENERGIA “LIMPA, RENOVÁVEL E BARATA” PRODUZIDA PELAS HIDRELÉTRICAS. .46

1.4 OS IMPACTOS SOCIOAMBIENTAIS GERADOS PELA IMPLANTAÇÃO DE HIDRELÉTRICAS 50

\section{CAPÍTULO 2 - SAÚDE E AMBIENTE NO CONTEXTO DOS PROJETOS DE} DESENVOLVIMENTO

2.1 DESENVOLVIMENTO, AMBIENTE E SAÚDE: FATORES RELEVANTES PARA A

SUSTENTABILIDADE DOS GRANDES PROJETOS DE INFRAESTRUTURA 57

2.1.1 Relação entre os processos de desenvolvimento, ambiente, saúde e as situações de risco 59

2.2 O PAPEL DA SAÚDE AMBIENTAL NAS POLÍTICAS PÚBLICAS E NO DESENVOLVIMENTO SUSTENTÁVEL

2.2.1 Avaliação de Impacto Ambiental (AIA): conexão possível entre saúde e meio ambiente ................. 66

2.2.2 O setor saúde e os processos de licenciamento ambiental de grandes empreendimentos no Brasil: instrumentos, limitações e desafios

2.2.3 A avaliação dos impactos à saúde em projetos de desenvolvimento no Brasil e sua importância estratégica para a sustentabilidade socioambiental

\section{CAPÍTULO 3 - AVALIAÇÕES DE IMPACTO À SAÚDE EM PROJETOS} HIDRELÉTRICOS: UMA REALIDADE POUCO EXPLORADA

3.1 IDENTIFICANDO OS EFEITOS DE PROJETOS HIDRELÉTRICOS SOBRE A SAÚDE, A PARTIR DO MODELO CONCEITUAL FPEEEA: POSSIBILIDADES E FRAGILIDADES

3.2 MALÁRIA COMO ÚNICO INDICADOR DE SAÚDE NA AVALIAÇÃO DE IMPACTO

AMBIENTAL DE EMPREENDIMENTOS NA REGIÃO DA AMAZÔNIA LEGAL

3.3 AVALIAÇÃO DE IMPACTOS À SAÚDE (AIS): CONCEITOS, NOÇÕES E PERSPECTIVAS ..........91

3.3.1 Aplicação da metodologia AIS no Brasil: perspectivas e desafios 
CAPÍTULO 4 - ESTUDO DE CASO: UHE DE BELO MONTE, IMPACTOS SOCIOAMBIENTAIS E AS QUESTÕES RELATIVAS À SAÚDE NO CONTEXTO DAS TRANSFORMAÇÕES DO TERRITÓRIO ....................................................................... 104

4.1 PERSPECTIVAS GEOGRÁFICAS E METODOLÓGICAS 104

4.2. TRANSFORMAÇÕES ECONÔMICAS, AMBIENTAIS E SOCIAIS PROVOCADAS PELA UHE DE BELO MONTE: OS DESCOMPASSOS DAS MEDIDAS COMPENSATÓRIAS E O AFLUXO POPULACIONAL NA REGIÃO.

4.2.1. Saneamento e mobilidade urbana

4.2.2 Deslocamentos compulsórios: um fator de desestrutura social para as comunidades tradicionais rurais e urbanas

4.2.3 Povos indígenas: conflitos, desestruturação social das aldeias e reflexos para a saúde.......

4.3 DIAGNÓSTICO DA SITUAÇÃO DE SAÚDE NA ÁREA DE INFLUÊNCIA DA UHE DE BELO MONTE, NO CONTEXTO DAS PRINCIPAIS DOENÇAS RELACIONADAS À IMPLANTAÇÃO DE HIDRELÉTRICAS.

4.3.1. Situação de saúde no contexto das doenças sexualmente transmissíveis: HIV-Aids, hepatites e sífilis 133 4.3.2 A situação de saúde no contexto das doenças não transmissíveis: causas externas, uma epidemia em evidência 141

4.3.3 O paradoxo entre a infraestrutura de saúde ofertada e o acesso aos serviços prestados na área: altos investimentos e resultados pouco expressivos.

4.4 OS PLANOS E PROGRAMAS NO ÂMBITO DO GOVERNO FEDERAL PARA O CUMPRIMENTO DE CONDICIONANTES E RITOS LEGAIS DO LICENCIAMENTO DA UHE DE BELO MONTE, COM FOCO NOS ASPECTOS DA SAÚDE

4.4.1 Plano de Desenvolvimento Regional Sustentável do Xingu (PDRS-X): perspectivas para as ações socioambientais e de saúde na região da UHE de Belo Monte.

4.4.2 Programa Nacional de Controle da Malária (PNCM): impacto positivo para a saúde no contexto de uma política, programa e projeto.

4.5 CONSIDERAÇÕES: ASSIMETRIAS E AVANÇOS NA EFETIVIDADE DAS AÇÕES COMPENSATÓRIAS NO CONTEXTO DOS PLANOS E PROGRAMAS NA REGIÃO DA UHE DE BELO MONTE.

\section{CAPÍTULO 5 - ASPECTOS RELEVANTES NO CONTEXTO DA AVALIAÇÃO DE} IMPACTOS DE PROJETOS HIDRELÉTRICOS ..............................................................172

5.1 DELIMITAÇÃO DOS IMPACTOS NO TERRITÓRIO .

5.2 PARTICIPAÇÃO SOCIAL COMO VALOR ESSENCIAL À SUSTENTABILIDADE DOS PROJETOS 177

5.3 CAPACIDADE POLÍTICA E INSTITUCIONAL LOCAL 


\section{LISTA DE FIGURAS}

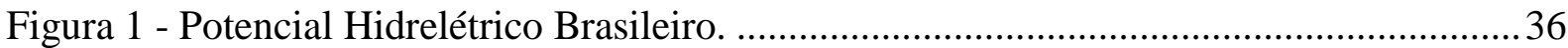

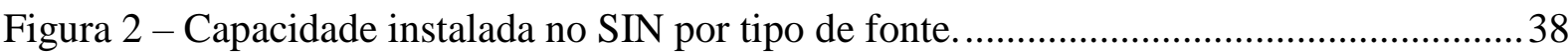

Figura 3 - Amazônia como a "nova fronteira de energia" ....................................................... 39

Figura 4 - Integração Eletroenergética do SIN no BRASIL ................................................... 42

Figura 5 - As fases do Licenciamento Ambiental de uma Usina Hidrelétrica ......................... 43

Figura 6 - Documentos necessários ao licenciamento de projetos de grande porte na área de

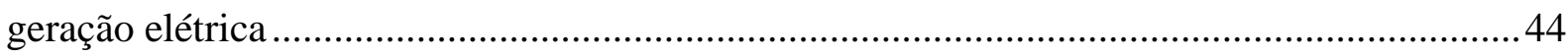

Figura 7 - Produção e consumo de energia elétrica no Brasil (2012)..................................... 47

Figura 8 - Estudos ambientais analisados pelo setor saúde por solicitação do Ibama, no

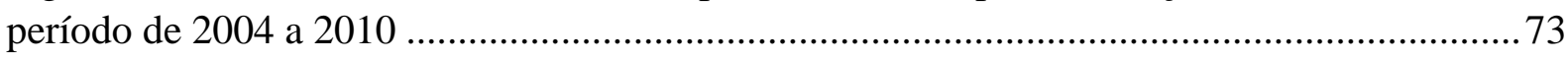

Figura 9 - Cadeia Ambiente e Saúde (Matriz FPEEEA) …............................................... 81

Figura 10 - Matriz Causa-Efeito a partir do modelo FPEEEA para avaliação dos impactos à

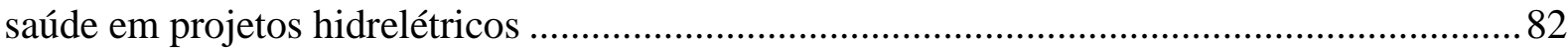

Figura 11 - Média do IPA da malária por municípios da Região Norte, no período de 2008 a 2011

Figura 12 - IPA da malária por município da área de influência das hidrelétricas do Complexo Madeira, Belo Monte e Complexo do Tapajós, entre os anos de 2007 a 2011 88

Figura 13 - Fluxo do PNCM para avaliação da saúde em áreas de risco ou endêmicas de malária, conforme Portaria MS/SVS No 1, de 13/01/2014

Figura 14 - Tomada de decisão nos diferentes níveis hierárquicos considerando a AAE e AIA 98

Figura 15 - Influência dos determinantes da saúde na AIS .............................................. 101

Figura 16 - Localização da Usina de Belo Monte................................................................ 105

Figura 17 - A cronologia da implantação da Usina de Belo Monte, de 1975 a 2015............ 106

Figura 18 - Estimativa da população atraída pela obra de construção da usina de Belo Monte entre 2010 e 2020 para áreas de influência (direta e indireta).

Figura 19 e 20 - Rua no centro de Altamira com esgoto a céu aberto e lançamento do esgoto diretamente no Rio Xingu.

Figura 21 - Circulação de ônibus dos canteiros de obras da Usina de Belo Monte para Altamira

Figura 22 - Circulação de caminhões na UHE de Belo Monte 
Figura 23 - Vista da UHE de Belo Monte.

Figura 24 - Crescimento da frota veicular em Altamira, no período de 2010 a 2015

Figura 25 -Número de acidentes entre 2010 a 2015

Figura 26 - Percentual de motocicletas em comparação aos demais veículos.

Figura 27 e 28 - Imagem antes e após o início da urbanização da orla à beira do Rio Xingu

Figura 29 e 30 - Reassentamento Urbano Coletivo (RUC) no bairro Jatobá, em Altamira .. 120

Figura 31 - Terras Indígenas e Unidades de Conservação na Área de Influência da UHE Belo Monte

Figura 32 - A caiapó Tuíra aponta facão para o presidente da Eletronorte, Muniz Lopes, 1989.

Figura 33 - Taxa de incidência parasitária anual (IPA), por mil hab., segundo a variável raça/cor nas Unidades da Federação e Amazônia Legal em 2013.

Figura 34 - Casos novos de AIDS notificados pelo CTA (Região da AID da usina de Belo Monte)

Figura 35 - Frequência de casos novos de Aids notificados pela SES, por município de residência e ano de diagnóstico (Região da AID da usina de Belo Monte) ...........134

Figura 36 - Frequência de casos de Aids notificados pelo Datasus, por ano segundo município de residência e ano de diagnóstico (Região da AID da usina de Belo Monte)

Figura 37 - Casos positivos de hepatites B e C confirmados pelo CTA de Altamira136 Figura 38 - Casos notificados de hepatites B e C pela SMS, para a Região de AID da UHE de Belo Monte

Figura 39 - Casos confirmados de hepatites B e C pelo Datasus, para a região AID da UHE de Belo Monte

Figura 40 - Casos notificados de sífilis em gestante notificados pela SMS, por município de residência na região AID da UHE de Belo Monte

Figura 41 - Casos notificados de sífilis em gestante, notificados pelo Datasus, por município de residência, na região AID da UHE de Belo Monte.

Figura 42 - Casos notificados de sífilis congênita, notificados pela SMS, por município de residência

Figura 43 - Casos notificados de sífilis congênita, notificados pelo Datasus, por município de residência

Figura 44 - Óbitos decorrentes das principais doenças relacionadas à implantação de hidrelétricas no município de Altamira no período de 2006 a 2015.

Figura 45 - Número de óbitos por acidentes e violências no município de Altamira no período de 2006 a 2014 
Figura 46 e 47 - Percentual de óbitos por grupos de causas relacionadas à implantação de hidrelétricas no município de Altamira, nos períodos de 2006 a 2010 e de 2011 a 2015 ...... 144

Figura 48 - Número de internações referentes a todas as causas para os municípios da

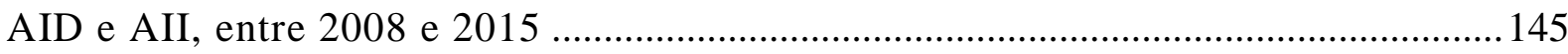

Figura 49 - Números de internações pelos principais agravos em Altamira ........................ 146

Figura 50 - Figura- Número de internações por causas externas, de acordo com o local de internação, nos municípios da AID e AII da usina de Belo Monte ........................................ 146

Figura 51 - Taxa de mortalidade hospitalar por causas externas de acordo com o sexo, no municipio de aAltamira

Figura 52 - Valores totais por internação em eventos de intenção indeterminada, para o Estado do Pará, Altamira e AII de Belo Monte 149

Figura 53 - Hospital Municipal São Rafael (Altamira, PA) 151

Figura 54 - Hospital Regional Público da Transamazônica de Altamira. 152

Figuras 55 e 56 - Novo Hospital Geral de Altamira, no Bairro Mutirão 153

Figura 57 - Área de Influência Direta (AID) e Área de Influência Indireta (AII) da Usina de Belo Monte

Figura 58 - Localização das unidades de saúde notificadoras da malária na região da área de influência de Belo Monte.

Figura 59 - Total de notificações na área urbana de Altamira no período de 2003 a 2014

Figura 60 - Total de casos positivos na área urbana de Altamira no período de 2003 a 2014164 Figura 61 - Total de notificações comparado ao número de casos positivos na área urbana de Altamira, entre 2003 e 2014

Figura 62 - Total de notificações comparado aos casos positivos na área urbana de Anapu, entre 2003 e 2014

Figura 63 - Total de notificações comparado aos casos positivos de malária na área urbana de Vitória do Xingu, entre 2003 e 2014 166

Figuras 64 e 65 - Cenário para o Rio Xingu antes e depois do enchimento do Reservatório

Figura 66 - Instrumentos de avaliação de impacto no contexto das Políticas, Planos e Projetos no Brasil

Figura 67 - Modelo de participação social na tomada de decisão e gerenciamento de conflitos em projetos hidrelétricos

Figura 68 - Representação dos vários aspectos envolvidos na tomada de decisões, em escala espacial e temporal, para a gestão de recursos naturais.... 184

Figura 69 - Etapas da evolução de uma política e o grau de influência dos atores envolvidos 
Figura 70 - Determinantes estruturais no âmbito das políticas públicas sustentáveis 188

\section{LISTA DE QUADROS}

Quadro 1 - Agentes do setor elétrico que detêm a maior capacidade instalada de energia elétrica das usinas em operação no país

Quadro 2 - Principais intervenções nas etapas de implantação de uma hidrelétrica e os impactos/riscos à saúde

Quadro 3 - Participação do setor saúde nos processos de licenciamento ambiental de empreendimentos, no âmbito federal, no período de 2004 a 2007

Quadro 4 - Matriz de ações preventivas durante a avaliação de projetos hidrelétricos

Quadro 5 - Indicadores de vulnerabilidade social, condições de moradia, renda e pobreza, no período de 2000 a 2010

Quadros 6 e 7- Terras Indígenas (Tis) e populações diretamente e indiretamente afetadas.. 123

Quadro 8 - Taxas de mortalidade por causas externas de acordo com a região de saúde do Pará.

Quadro 9-Custo dos serviços hospitalares por causas externas na Região de Saúde Xingu (em reais)

Quadro 10 - Equipamentos de saúde e hospitais planejados e concluídos como condicionantes de saúde para a AID de Belo Monte

Quadro 11 - Recursos da Norte Energia para o PDRS--X, no período de 2011 a 2014 ....... 158

Quadro 12 - Repasses do Fundo Nacional de Saúde para os municípios da AID da Usina De Belo Monte

Quadro 13- Recursos da Vigilância em Saúde decorrentes do aumento populacional na Área de Influência Direta da Usina de Belo Monte 


\section{LISTA DE ABREVIAÇÕES E SIGLAS}

ANA

ANEEL

AHE

ABRASCO

ATCS

AIA

APM

BASA

BNDES

CT Saúde

CAPS

CEO

CTA

CVE

CENEPI

$\mathrm{CIDH}$

CIMI

CGDEX

CONDISI

CNUMAD

CEBDS

CNPE

CNS

CCBM

CGVAM

DSAST

Demutran
Agência Nacional das Águas

Agência Nacional de Energia Elétrica

Aproveitamento Hidrelétrico

Associação Brasileira de Pós-graduação em Saúde Coletiva

Atestado de Condição Sanitária

Avaliação de Impacto Ambiental

Avaliação do Potencial Malarígeno

Banco da Amazônia S/A

Banco Nacional de Desenvolvimento Econômico

Câmara Técnica de Saúde

Centro de Assistência Psicossocial

Centro de Especialidade Odontológica

Centro de Testagem e Aconselhamento

Centro de Vigilância Epidemiológica

Centro Nacional de Epidemiologia

Comissão Interamericana de Direitos Humanos

Conselho Indigenista Missionário

Comitê Gestor do Plano de Desenvolvimento Regional Sustentável do Xingu

Conselho Distrital de Saúde Indígena

Conferência das Nações Unidas sobre o Meio Ambiente e Desenvolvimento

Conselho Empresarial Brasileiro para o Desenvolvimento Sustentável

Conselho Nacional de Política Energética

Conselho Nacional de Saúde

Consórcio Construtor de Belo Monte

Coordenação Geral de Vigilância Ambiental em Saúde

Departamento de Vigilância em Saúde Ambiental e Saúde do Trabalhador

Departamento Municipal de Transporte e Trânsito 
DSS

DSEI

EIA

EPE

ENSP/Fiocruz

FPSEEA

FGV

Funai

FVPP

HIA

IBGE

INESC

ISA

IPA

LAPM

LI

LO

LP

MAB

MS

MME

MMA

MPF

MMTAC

NESA

NUVS

ODMS

ONU

OEA

OMS

ONS

ONG

OPAS
Determinantes Sociais à Saúde

Distrito Sanitário Especial de Saúde Indígena

Estudo de Impacto Ambiental

Empresa de Pesquisa Energética

Escola Nacional de Saúde Pública (Ensp/Fiocruz

Força-Pressão-Situação-Exposição-Efeito-Ação

Fundação Getúlio Vargas

Fundação Nacional do Índio

Fundação Viver Preservar e Produzir

Health Impact Assessment

Instituto Brasileiro de Geografia e Estatística

Instituto de Estudos Socioeconômicos

Instituto Socioambiental

Indice Parasitário Anual

Laudo de Avaliação do Potencial Malarígeno

Licença de Instalação

Licença de Operação

Licença Prévia

Movimento dos Atingidos por Barragem

Ministério da Saúde

Ministério de Minas e Energia

Ministério do Meio Ambiente

Ministério Público Federal

Movimento de Mulheres Trabalhadoras de Altamira, Campo e Cidade

Norte Energia S/A

Núcleo de Vigilância em saúde

Objetivos do Desenvolvimento do Milênio

Organização das Nações Unidas

Organização dos Estados Americanos

Organização Mundial de Saúde

Operador Nacional do Sistema

Organização Não Gorvenamental

Organização Pan-Americana da Saúde 
OCDE

PBA

PACM

PAC

PDRS-X

PPCDAm

PDE

PNMC

PNMA

PNSA

PEIR

PER

Prodes

PNCM

PISF

PBA

RUCs

RIMA

SVS

SESAI

SES

SMS

SINAN

SIM

SIPOT

$\mathrm{SIH}$

SIN

SUS

SOPHIA

SUDAM

TAC
Organização para a Cooperação e o Desenvolvimento Econômico

Plano Básico Ambiental

Plano de Ação para o Controle da Malária

Plano de Aceleração do Crescimento

Plano de Desenvolvimento Regional Sustentável do Xingu

Plano de Prevenção e Controle do Desmatamento na Amazônia Legal

Planos Decenais de Expansão de Energia

Plano Nacional Sobre Mudança do Clima

Política Nacional de Meio Ambiente

Política Nacional de Saúde Ambiental

Pressão Estado Impacto Resposta

Pressão Estado Resposta

Programa de Monitoramento da Cobertura Florestal da Amazônia Brasileira por Satélite

Programa Nacional para o Controle da Malária

Projeto de Transposição do São Francisco

Projetos Básicos Ambientais

Reassentamentos Urbanos Coletivos

Relatório de Impacto Ambiental

Secretaria de Vigilância em Saúde

Secretaria Especial de Saúde Indígena

Secretaria Estadual de Saúde

Secretaria Municipal de Saúde

Sistema de Informação de Agravos de Notificação

Sistema de Informação de Morbidade

Sistema de Informações do Potencial Hidrelétrico Brasileiro da Eletrobrás

Sistema de Informações Hospitalares

Sistema Interligado Nacional

Sistema Único de Saúde

Society of Practioners of Health Impact Assessment

Superintendência de Desenvolvimento da Amazônia)

Termo de Ajuste de Conduta 
TR

TIs

TCU

TRF

UE

UBS

$\mathrm{UC}$

UPAs

UHE

VAS

VIGIAGUA

Viva

VIGIPEQ

VIGIDESASTRES

WCD

WHO

YHEC
Termos de Referência

Terras Indígenas

Tribunal de Contas da União

Tribunal Regional Federal

União Europeia

Unidades Básicas de Saúde

Unidades de Conservação

Unidades de Pronto Atendimento

Usinas Hidrelétricas

Vigilância Ambiental em Saúde

Vigilância da Qualidade da Água para Consumo Humano

Vigilância de Violências e Acidentes

Vigilância em Saúde de Populações Expostas a Contaminantes Químicos

Vigilância em Saúde em Situação de Desastres

World Commission Dams (Comissão Mundial de Barragens)

World Health Organization

York Health Economics Consortium 


\section{INTRODUÇÃO}

A compreensão do papel exercido pelos grandes projetos na Amazônia, desde a época dos planos de colonização, perpassa a argumentação de que tais empreendimentos se mostram fundamentais para o desenvolvimento socioeconômico da região. Sob o entendimento de que se trata de uma área de livre exploração de recursos naturais, esses projetos foram e continuam a ser responsáveis pela organização e controle do território, com a consequente mobilização de capital e mão de obra na região.

É inegável a importância do planejamento estratégico para alavancar o desenvolvimento social e econômico do país, o qual cria oportunidades para que outros setores possam se ampliar. Nesse contexto, a implantação de hidrelétricas, como geradoras de energia elétrica, se apresenta como fator essencial para o funcionamento da sociedade, no âmbito das populações de maneira geral, mas, sobretudo, para os setores de atividade econômica.

Contudo, a instalação dos grandes empreendimentos no Brasil, principalmente na região amazônica, é marcada historicamente pelas repercussões de cunho ambiental, intimamente vinculadas ao desmatamento das áreas de floresta e à execução de planos de desenvolvimento econômico da região. As discussões atuais em torno de uma nova forma de gestão dos planos e projetos no Brasil que transforme o paradigma estabelecido no país desde a década de 70, onde a construção de grandes obras, a exemplo de Tucuruí, foi responsável por grandes impactos ambientais e sociais, ainda é incipiente.

Nesse aspecto, as hidrelétricas se apresentam como empreendimentos de relevante análise. Assim se considera tendo em vista que, no processo de transformação das áreas em que são construídas, instauram-se dinâmicas socioeconômicas diversas, com o surgimento de novos grupos sociais sob interesses distintos, numa configuração que resulta em problemas e conflitos na região. Contudo, a implantação dos planos de desenvolvimento invariavelmente acarreta importantes alterações ambientais, econômicas e socioculturais, que envolvem os mais dissonantes aspectos da dinâmica regional, interferindo no cotidiano das populações e modificando seus modos de subsistência, sobretudo no tocante às condições de saúde e à qualidade de vida. 
É relevante explicitar também que tal percepção decorreu da minha trajetória profissional, especialmente quando exerci a função de Consultora no Ministério da Saúde (MS), no período de 2008 a 2011. A partir dos caminhos trilhados na saúde pública, desde de 2003, ocorreu uma maior aproximação com a área da saúde ambiental, o que me levou a observar a importância do entrelaçamento entre as questões de saúde, ambiente e desenvolvimento. Nesse sentido, esse caminho percorrido motivou de forma destacada a realização da pesquisa apresentada nesta tese.

Vale ainda ressaltar que a passagem pelo campo da saúde ambiental me permitiu compartilhar as discussões e formulações de estratégias da saúde para alguns planos e projetos governamentais, como o Plano Sustentável da BR-163, o Complexo do Rio Madeira e os mais recentes Complexo do Rio Tapajós e a Usina Hidrelétrica de Belo Monte. No mais, a oportunidade de coordenar e participar de seminários e oficinas sobre o desempenho do setor saúde nos processos de licenciamento ambiental conduziu à descoberta de uma temática nova, que requer um debate maior entre os dois setores. Essas experiências se mostraram fundamentais para uma compreensão mais ampla dos processos produtivos e suas inter-relações com os aspectos ambientais, sociais e de saúde, no contexto dos projetos de desenvolvimento.

No cenário específico dos grandes empreendimentos da área no Brasil, a produção de energia elétrica ocorre, predominantemente, por meio de usinas hidrelétricas, que representam 64\% da totalidade de energia produzida no país. Em 2014 já se somavam 1.093 fontes hidroelétricas em operação, com perspectivas de mais 219 usinas hidrelétricas até 2015, sendo que sete delas, destacadamente grandes obras, já se encontram em construção, todas na Região Norte do país (ANEEL, 2014). Apesar de a matriz energética no Brasil se fundamentar em fontes renováveis, com destaque para as hidrelétricas - consideradas uma forma de produção de "energia limpa" -, o modelo de desenvolvimento vigente provoca numerosos e frequentes conflitos sociais e ambientais, com a violação, em alguns casos, dos direitos humanos.

O planejamento dos programas e planos para a implantação de hidrelétricas, particularmente na Amazônia, é objeto de inúmeros questionamentos sobretudo pela não participação dos atores locais nas decisões que objetivam identificar melhores estratégias de ação diante das diferentes necessidades sociais. Apesar de elaborado em uma atmosfera abrangente, racional e isolado, o planejamento, por ser desprovido de emoção, não abarca uma visão pluralista da sociedade. As alocações e usos dos recursos naturais são decididos, em grande parte, segundo um modelo normativo ou prescritivo. 
Atualmente, o Brasil enfrenta o desafio de implantar obras de infraestrutura por intermédio do Plano de Aceleração do Crescimento (PAC), com vistas a suprir as demandas de energia, transporte, habitação, entre outras. (BRASIL, 2011b). Contudo, esses empreendimentos de larga escala vêm acompanhados de repercussões proporcionalmente impactantes, sejam elas positivas ou negativas. Nesse sentido, a maior preocupação de determinados setores da sociedade civil é que o PAC não repita os ciclos já presenciados no país com o uso intensivo de recursos naturais e com a reprodução de desigualdades regionais e sociais.

No entanto, quando se observam as avaliações de impactos ambientais, sob a jurisdição de um setor que possui forte atuação institucional, os aspectos socioambientais, bem como aqueles relacionados à saúde humana, nem sempre são considerados nos processos de licenciamento ambiental. Esse fato demonstra a lacuna decorrente da ausência de articulação entre as políticas públicas setoriais diante dos impactos socioambientais gerados pelos grandes empreendimentos.

Portanto, os estudos ambientais como um requisito à implantação de projetos potencialmente poluidores têm se mostrado de fato pouco eficientes em apontar os impactos e a inexistência dos riscos à saúde inerentes a esses empreendimentos, limitando-se prioritariamente aos aspectos biofísicos. Pesquisas sobre o tema apontam que a pouca inserção dos aspectos relativos à saúde durante a Avaliação de Impacto Ambiental (AIA) decorre da falta de articulação entre os diferentes setores e de legislação ou instrumentos específicos (SILVEIRA, 2008; BARBOSA et al, 2012). Desse modo seria necessária a implementação de instrumentos normativos que incorporem a abordagem socioambiental no escopo da avaliação, com foco na manutenção da qualidade de saúde das populações atingidas.

Em que pese a ausência de mecanismos institucionais, técnicos e políticos, diversas instâncias do setor saúde concentram esforços para a inserção dos aspectos próprios dessa área nos processos de licenciamento ambiental de grandes empreendimentos. Sob essa perspectiva, o campo da saúde ambiental tem cumprido com a sua função de acompanhar sistematicamente os processos relativos aos grandes projetos, com a proposição de instrumentos e metodologias para avaliar os impactos à saúde que possam contribuir para formação de territórios com a adequada sustentabilidade ambiental e social.

Num cenário em que se evidencia o pequeno número de estudos relacionados aos impactos sobre a saúde no âmbito dos grandes empreendimentos, bem como no contexto das 
inúmeras discussões acadêmicas e profissionais sobre o tema, surgem as seguintes questões: Em que medida os aspectos socioambientais e de saúde são consideradas nos planos e programas direcionados à concepção dos projetos hidrelétricos? A Avaliação de Impacto Ambiental (AIA) é suficiente para contemplar os principais problemas e conflitos observados no território mediante a implantação de grandes empreendimentos? Em que medida ocorrem as articulações entre os atores envolvidos, principalmente dos tomadores de decisão com os atores em esfera local, nesse contexto?

O tema exigiu uma abordagem teórico-metodológica, dentro do objetivo proposto neste estudo de observar e compreender as diversas dinâmicas presentes nos processos e ações aplicadas ao território afetado frente os possíveis impactos socioambientais e à saúde advindos das transformações locais com a construção das usinas hidrelétricas (UHE) na Região Amazônica. Para tanto, buscou-se analisar e discutir as interfaces entre desenvolvimento econômico, meio ambiente e saúde no contexto da implantação dos grandes empreendimentos na Amazônia brasileira. Desde já é possível afirmar que tais projetos, ao mesmo tempo em que são indutores do desenvolvimento, causam impactos socioambientais que, via de regra, se configuram como intrínsecos a esse processo.

Nesse contexto, com vistas à discussão e compreensão a respeito de como os grandes empreendimentos repercutem sobre as populações dos territórios modificados, o presente estudo tem como objetivo analisar os impactos socioambientais e à saúde originados pelas transformações no território com a implantação de usinas hidrelétricas na Amazônia, investigando os efeitos dos planos e programas na região no que concerne ao atendimento das ações mitigadoras e compensatórias.

Nesse sentido, para se possibilitar a execução da proposta inicial, delinearam-se os seguintes objetivos específicos: i) identificar de que forma são avaliados os aspectos de saúde no âmbito dos processos de licenciamento ambiental de grandes empreendimentos; ii) verificar como são realizadas as ações de mitigação e compensação dos impactos socioambientais e de saúde no contexto das implantação das hidrelétricas; iii) discutir e propor parâmetros de avaliação de impactos com a construção das Usinas Hidrelétricas (UHE).

Considerando-se que, no âmbito dos programas e planos da política energética, os aspectos socioambientais e relativos à saúde permanecem em segundo plano nas decisões de planejamento, destaca-se a necessidade de uma análise realizada em maior proximidade com o território. À vista desses fatores, a UHE de Belo Monte foi escolhida como objeto do estudo de 
caso sobretudo pela sua magnitude e pelas complexas relações entre as diferentes populações que habitam as adjacências da área de construção da terceira maior usina hidrelétrica do mundo, a qual se encontra em fase final.

Trata-se de estudo de natureza analítica, realizado sob a ótica metodológica da pesquisa qualitativa. De caráter exploratório, o trabalho contou com revisão temática por meio de extenso levantamento bibliográfico e de documentos governamentais e não governamentais, além de dados secundários provenientes de sistemas de informações oficiais. Para o estudo de caso, a delimitação do período de tempo para a realização dessa etapa da pesquisa ocorreu em função das fases do licenciamento ambiental. Este está caracterizado pelas principais etapas do processo, determinando o início das obras a partir da emissão da Licença de Instalação (LI), em 2011. As áreas de influência da usina fazem parte do recorte espacial para a coleta de dados socioambientais e de saúde, com vistas a observar as principais ações dos planos e programas na região.

A pesquisa de campo visou observar os principais impactos socioambientais e à saúde a partir da coleta de dados e da percepção das dinâmicas entre os atores locais. Objetivou-se também analisar as ações implementadas pelas instituições públicas e privadas, apontando-se assim os aspectos positivos e as principais limitações, mediante a observação de como a população das áreas de influência do projeto reagem à implantação do empreendimento em seu território. A partir de entrevistas informais e das declarações verbais de atores das diferentes instituições locais na cidade de Altamira, no Estado do Pará, foi possível registrar aspectos fundamentais à compreensão dos processos e das dinâmicas locais. Identificou-se, dessa maneira, os principais impactos positivos e negativos das ações compensatórias preconizadas nos planos e programas para a região da usina.

A tese está estruturada em cinco capítulos. O primeiro apresenta uma discussão sobre a noção de território como instrumento estratégico de políticas públicas para o planejamento de empreendimentos hidrelétricos na Amazônia. Aborda, também, a influência da geografia nas modificações territoriais e as novas espacialidades, configurando a região Amazônica como a "nova fronteira" de energia pelo seu potencial em hidroeletricidade. Visa apontar os principais impactos originados com a construção e instalação desses empreendimentos, ressaltando a importância da matriz energética baseada em fontes renováveis, em contraste com seus impactos ou riscos a determinados grupos populacionais. 
O segundo capítulo apresenta o tripé desenvolvimento, ambiente e saúde no sentido de debater sobre a importância dessa integração no contexto do desenvolvimento sustentável. Com o intento de destacar o papel exercido pela saúde ambiental como elo entre os campos das políticas públicas de saúde e do meio ambiente, apresentam-se resultados de pesquisas anteriores que consolidam a importância do setor saúde para a concessão de licenciamento ambiental a grandes empreendimentos.

A terceira parte se refere à avaliação de impactos na saúde em projetos hidrelétricos. Ressalta-se que, no Brasil, essa prática é ainda restrita. Nessa perspectiva, o Ministério da Saúde propôs recentemente documento norteador, visando aplicar a Avaliação de Impacto à Saúde (Health Impact Assesment - HIA, em inglês) por meio do licenciamento ambiental, denominado: AIS: Metodologia adaptada para aplicação no Brasil. Cabe, nesse ponto, ressaltar a importância da exposição de conceitos, noções e perspectivas a respeito da metodologia AIS, preconizada pela OMS e empregada em diversos países. Apresenta-se também a proposição de ações preventivas, na dimensão econômica, ambiental e social, a partir do modelo conceitual FEPEEA. Destaca-se, ainda, o debate a respeito da importância da malária como indicador de avaliação da saúde na região amazônica.

O quarto capítulo é dedicado ao estudo de caso, com a análise sobre os impactos socioambientais e à saúde mediante a implantação das obras da UHE de Belo Monte. A pesquisa de campo procurou aproximar as consequências marcantes da obra com seus efeitos negativos e positivos, diante de uma gestão marcantemente corporativa do empreendimento. Uma investigação dessa natureza se tornou possível por meio da coleta de dados oficiais das organizações governamentais e não governamentais. No entanto, é importante lembrar que sua realização se deveu sobretudo à percepção da dinâmica local, com visitas aos locais afetados e a captura de relatos por meio de entrevistas informais com a população e os gestores locais.

O quinto capítulo aponta aspectos relevantes a serem observados durante a avaliação de projetos de desenvolvimento no país, a exemplo das hidrelétricas, tendo em vista a propositura e discussão de questões importantes, negligenciadas durante a avaliação de impactos. Entendese que a natureza do processo social deflagrado pelo empreendimento condiz simultaneamente com o processo econômico, político, ambiental e cultural.

Por fim, são apresentadas as conclusões e considerações finais, seguidas da inserção de dois artigos científicos já publicados, anexados a esta tese por se configurarem também como parte dos resultados da pesquisa aqui apresentada. 


\section{CAPÍTULO 1 - AMAZÔNIA: TERRITÓRIO DE ENERGIA}

\subsection{O OLHAR GEOGRÁFICO SOBRE O TERRITÓRIO NO CONTEXTO DAS NOVAS ESPACIALIDADES}

Tradicionalmente, os estudos realizados no âmbito da Geografia mostram um especial empenho na abordagem da categoria espaço. Assim ocorre porque essa categoria específica apresenta múltiplas possibilidades, as quais, em suas várias vertentes, contribuiu para a explicação da realidade e para o entendimento das questões sociais no mundo atual. Segundo Lefebvre (1974), a determinação principal das relações de produção é o próprio espaço. Para o autor, a construção do conceito de espacialidade geográfica perpassa a proposição do espaço social como produto das relações sociais de produção e reprodução, organizadas a partir da apreensão de elementos da realidade (LEFEBVRE, 1974).

Os fenômenos geográficos passaram a explorar a construção social das relações espaciais a partir do estabelecimento da Geografia Crítica, que considera a sociedade sob a perspectiva de seu movimento histórico mediante a sua dimensão espacial. Ou seja, o espaço é abordado como um produto social, nas esferas econômica, política e cultural. Para Christofoletti (1982), essa corrente foi marcada pelo interesse em analisar os modos de produção e as formas socioeconômicas em vinculação a um objetivo político predeterminado.

De acordo com Milton Santos (1985), a estrutura espacial também se caracteriza como social: esta última se situa em algum lugar do espaço temporal, num determinado período. Cabe, porém, à sociedade definir se a estrutura social deve existir ou não, por conta da forte interferência que ela exerce nos processos, sejam eles temporais ou históricos. Segundo Santos (1985), a globalização se configura como um grande processo hegemônico e contemporâneo. O autor a denominou de período técnico informacional, pelo qual ocorre a crescente substituição do meio natural por um ambiente gradativamente mais artificializado. Prova disso são os objetos, edificações e monumentos construídos nas sociedades atuais, os quais restringem progressivamente os espaços apontados como naturais.

No entendimento de Massey (2008), a globalização necessita de espacialização, pois “é uma estória contada como universal a partir de uma fala posicionada geograficamente, ignorando as desigualdades, rupturas e divisões sobre a qual ela é construída". Nesse sentido, a 
fim de se compreender a relação entre o espaço e sociedade no contexto da globalização, é preciso o reconhecimento da importância da dinâmica decorrente das relações sociais, que podem ser construídas e reconstruídas por intermédio de subjetividades políticas, econômicas e sociais (MASSEY, 2008).

Sendo assim, as modificações do território nos processos sociais é um ponto fundamental, exercendo um papel importante no espaço geográfico, pois a Geografia precisa abordar os processos sociais, situando suas investigações nas mediações desses processos. Para Harvey (2005), a apropriação do espaço geográfico, que é extremamente diversificado, não mais depende apenas da natureza, mas sim das inúmeras configurações das relações sociais.

Segundo Cidade (2001), de acordo com a perspectiva desenvolvida pela orientação neopositivista de pensamento e pesquisa, a natureza tende a ser abordada como um objeto, um recurso passível de análise e de exploração pelos diferentes agentes da sociedade. O desenvolvimento social e econômico que ocorreu sob essa concepção se caracterizou fortemente pela utilização dos recursos naturais como objeto de exploração para obtenção de lucros progressivamente maiores.

A expressão "o que é de todos não é de ninguém”, utilizada por Hardin, resume a racionalidade do espaço privado sobre a racionalidade do ambiente, revelando as dificuldades de se abordarem, por exemplo, as questões relacionadas à degradação socioambiental (HAUGHTON; HUNTER, 2004). Para Haughton e Hunter (2004), mercados livres são úteis aos interesses de curto prazo para benefício próprio, ao mesmo tempo em que sabotam interesses coletivos a longo prazo.

O planejamento regional tem como objetivo principal diminuir ou atenuar as desigualdades regionais; no entanto, é utilizado como instrumento político de intervenção e controle. Como reordenadora de recursos e oportunidades, porém, a ideia de região desempenha um papel importante, tendo em vista que apresenta a base para a legitimação de espaços, por meio da sua população (BEZZI, 2004),

Normalmente cabe ao Estado definir a aplicação de medidas políticas que permitam a diminuição das desigualdades entre regiões, mediante o seu planejamento. No Brasil, diante da necessidade de modernização da economia brasileira, ocorreu, a partir da década de 1950, a criação de diversas empresas estatais, com o objetivo de promover uma política de planejamento e desenvolvimento regional (BEZZI, 2004). A lógica da reestruturação e 
adequação do território, nesse contexto, atuou continuamente como suporte e objeto de reprodução, na medida em que, nos processos capitalistas, a multiplicação do capital se vincula necessariamente à sua localização geográfica.

A Dra. Berta Becker ${ }^{1}$ explicita que, se não houver agregação de valores pelas instituições detentoras de megaprojetos na região, o cenário para a Amazônia continuará marcado por grandes impactos socioambientais. Esse alerta permite chegarmos à conclusão de não haver de fato uma diferença significativa entre as políticas implementadas nas décadas passadas e as propostas atuais para a Amazônia. Assim se observa porque, por mais que reestruturem o sistema produtivo na região, as políticas existentes objetivam sobretudo a "produção capitalista do espaço regional". Ou seja, verificamos que os grandes novos projetos continuamente trazem consigo mais dos velhos problemas.

Sendo assim, o território deve ser rediscutido enquanto espaço sobre o qual seu domínio não deve ser construído por grupos ou classes resultando em desigualdades sociais, mas que se construam identidades territoriais para o fortalecimento do diálogo e para a construção de laços de identidade social e não apenas para o seu controle físico (HAESBAERT, 2002).

Atualmente, o Plano de Aceleração do Crescimento (PAC), último grande projeto do governo federal brasileiro, se apresenta como iniciativa prioritária. Entretanto, não é possível determinar em que medida se discute a participação de fato dos diversos setores envolvidos.

Conforme Aguiar (2011) "os primeiros anos de implementação do PAC motivaram acordos polêmicos e pressões internas ao governo para viabilizar o andamento das obras do programa, flexibilizando normas e instrumentos ambientais".

[...] Pela primeira vez em décadas, o País teria um plano estratégico capaz de resgatar o planejamento em infraestrutura, retomar investimentos em setores estruturantes, fazer crescer o emprego e a renda, incentivar o investimento público e privado e, principalmente, construir a infraestrutura necessária para sustentar o crescimento no Brasil (AGUIAR, 2011).

Após o lançamento do PAC, com a consequente atenção proveniente de inúmeros setores do governo federal, assim como por se tratar de obras de grandes impactos sociais, o setor da saúde intensificou suas ações para incluir as questões relacionadas aos impactos das

\footnotetext{
${ }^{1}$ Palestra proferida pela Dra. Berta Becker no Centro de Desenvolvimento Sustentável da Universidade de Brasília, em outubro de 2012, durante o programa intitulado Quarta Sustentável.
} 
medidas propostas nessa área específica, sob a perspectiva do território afetado, pois a organização social e política nesses espaços geográficos pode influir decisivamente no modo como os riscos à saúde são distribuídos entre os diferentes grupos sociais (MIRANDA et al, 2008).

A fim de se investigar o planejamento em determinada região, a noção de território é premissa fundamental. Quando se utiliza o conceito de território mais especificamente na área da saúde, é indispensável a reflexão sobre o "território utilizado", aquele que não pode ser considerado como uma simples delimitação de uma área (região). Dessa forma, é preciso conhecê-lo mais detalhadamente, assim como a população que o habita e os processos que ali se desenvolvem (GONDIM et al, 2008).

De acordo com Barcellos (apud GONDIM et al, 2008), se o "território é o resultado de acumulação e situações históricas, ambientais e sociais que promovem condições particulares para a produção de doenças", reconhecê-lo para diferenciar determinadas populações e saber os problemas que as afetam se apresenta como uma etapa importante.

Como advertem Barcellos e Monken (2008), “o território não é um depósito de objetos (indústria, propriedades rurais, população etc.), ele é formado por redes sociais, culturais e econômicas, e precisamos reconhecer estas redes para atuar sobre elas".

A partir do diálogo sobre as relações entre saúde, ambiente e territorialidades, Ramos e Machado (2010) propõe uma discussão que considere o território como uma categoria de análise que oferece o entendimento dos contextos históricos-sociais das relações da sociedade com seu meio, permitindo assim compreender os mecanismos que geram os riscos ambientais e à saúde humana (RAMOS; MACHADO, 2010).

Desse modo, no campo do planejamento das ações de saúde, destacamos como fundamental a elaboração de uma agenda conjunta entre os diversos setores para o estabelecimento de conexões na busca de conhecimento e técnicas adequadas para a avaliação da necessidade de preservação dos recursos naturais e da qualidade de vida das populações inseridas nos espaços socioambientais.

O papel do espaço geográfico no planejamento para o desenvolvimento regional e sua relação com os fatores de degradação ambiental, decorrentes do modelo de desenvolvimento vigente, torna-se, dessa maneira, uma questão central para o enfrentamento das dissonâncias e 
para as discussões que envolvam os impactos socioambientais. É importante destacar como estes últimos são muitas vezes negligenciados no planejamento de políticas públicas.

Nesse sentido, a implantação de usinas hidrelétricas pode promover profundas mudanças nas formas de apropriação e uso do território sendo responsáveis por redefinir os espaços locais e a estrutura espacial e demográfica, modificando as relações sociedade e natureza.

\subsection{O TERRITÓRIO AMAZÔNICO COMO INSTRUMENTO ESTRATÉGICO DE POLÍticas PÚblicas NO ÂMBITO DO PLANEJAMENTO DE EMPREENDIMENTOS HIDRELÉTRICOS NO BRASIL}

O movimento para o fortalecimento de políticas territoriais, que centraliza todos os esforços para a ocupação econômica da Amazônia e do Centro-Oeste, teve início na década de 1970. Tendo em vista a expansão da "fronteira econômica" do país a partir da região CentroSul, foram criados o I PND e II PND - I Plano Nacional de Desenvolvimento Econômico e Social (1975-1979) (ARAÚJO, 1993).

Durante esse período, o Brasil se encontrava em um cenário de declínio com poucos investimentos, em que planos dessa natureza poderiam contribuir para o crescimento das exportações, por meio de grandes empreendimentos estatais e privados. Nessa perspectiva, criam-se programas especiais como o POLOAMAZÔNIA (Programa Especial de Polos Agropecuários e Agrominerais da Amazônia), a SUDAM (Superintendência de Desenvolvimento da Amazônia), e o BASA (Banco da Amazônia S/A) (COSTA, 2000).

Depois de um longo período de estagnação, entre as décadas de 1980 e 1990, os programas Brasil em Ação (PPA 1996-1999) e Avança Brasil (PPA 2000-2003) surgiram com o intento de alavancar uma nova estratégia para a integração da região Amazônica ao espaço produtivo brasileiro. Dentre os principais projetos desenvolvidos por esses dois projetos, destacam-se: a recuperação das BR 364 (Brasília-Acre) e BR 163 (Cuiabá-Santarém); o asfaltamento da BR 174 (Manaus-Boa Vista); a implementação das hidrovias AraguaiaTocantins e Madeira; o gasoduto de Urucu, e a linha de alta tensão conectando Tucuruí a Altamira (THÉRY, 2005). 
A partir da noção de ocupação e integração da região, com a implantação de empreendimentos que interferem na dinâmica territorial e social, foi possível compreender a influência dos grandes projetos na Amazônia, assim como a dimensão de seus impactos socioambientais (ARAÚJO; BELO, 2009).

Na década de 1970, a ampliação dos grandes projetos de mineração na Amazônia, reforçando o papel dessa região como fornecedora de insumos minerais, influenciou e ainda influencia marcadamente a organização socioeconômica dos povos e comunidades tradicionais, acarretando impactos e transformações socioambientais (ASSIS; ZHOURI, 2011).

Diante de um novo ciclo de incremento econômico e social no Brasil, o governo federal lançou, em 2007, o Plano de Aceleração do Crescimento (PAC), para suprir três eixos de desenvolvimento no País: Infraestrutura Logística (rodovias, ferrovias, portos, aeroportos, entre outros); Infraestrutura Energética (geração e transmissão de energia hidrelétrica, petróleo, gás natural e combustível renovável), e Infraestrutura Social e Urbana (habitação, saneamento, recursos hídricos e metrôs).

Atualmente, o PAC representa um projeto prioritário para o governo federal. No entanto, segundo Aguiar (2011), "os primeiros anos de implementação do PAC motivaram acordos polêmicos e pressões internas ao governo para emissão de licenças ambientais e autorizações que viabilizassem o andamento das obras do programa, flexibilizando normas e instrumentos ambientais" (AGUIAR, 2011).

As ações governamentais de planejamento e gestão do território - incluídas medidas específicas para o meio ambiente e os grupos sociais - se encontram condicionadas ao contexto socioeconômico e cultural, em que as alterações ambientais, as reações sociais e produtivas podem gerar novas práticas socioespaciais. Nesse contexto, o planejamento passa a se configurar como instrumento técnico de decisão governamental, submetido a pressões políticas e à gestão do território. Dessa forma, as ações adotadas se configuram necessariamente de acordo com o espaço e envolvem conflitos de poder (JATOBÁ, 2006). Para Becker (1990), a gestão do território é estratégica e tem finalidade econômica, pois se utiliza das relações de poder e de instrumentos táticos e técnicos para definir e executar suas finalidades específicas.

No tocante às políticas territoriais, há de se destacar que, desde a década de 1950, "tais políticas vêm se tornando políticas econômico-territoriais, transformando o território, com suas 
regiões e lugares, em suporte e, em alguns casos, objeto de investimentos estatais e privados" (COSTA, 2000).

A configuração do território no planejamento de ações públicas, no que diz respeito ao desenvolvimento regional e seu enfrentamento diante das dissonâncias, principalmente entre os setores produtivos, mostra-se central para a discussão das questões relacionadas aos fatores de degradação socioambiental decorrentes do modelo de desenvolvimento vigente, pois se trata de aspecto comumente negligenciado no planejamento de políticas públicas.

A construção de barragens, por exemplo, a partir da implantação de usinas hidrelétricas é considerada pelos setores governamental e empresarial como o vetor de desenvolvimento para determinadas regiões, sobretudo pela oferta de energia, que atrai novos investimentos, com o consequente movimento da economia local (KATSURAGAWA et al, 2009). Contudo, a ausência de planejamento aliado ao tratamento conferido à região amazônica como provedora de estoque de recursos naturais inesgotáveis, com a prevalência da sua exploração sobre qualquer outra possibilidade de desenvolvimento a ser implementado, acarreta a multiplicação de assentamentos humanos sem a suficiente infraestrutura social - transporte, saneamento, educação, saúde (ARAÚJO e BELO, 2009).

O conjunto de reservatórios hidrelétricos construídos no Brasil nos últimos cinquenta anos gerou profundas alterações nos mecanismos de funcionamento dos rios, lagos, áreas alagadas e pântanos. As grandes alterações ambientais a montante e a jusante, durante a construção das grandes represas como a de Balbina, Samuel e Tucuruí, na Amazônia brasileira, são conhecidas por meio de diversos estudos pela destruição dos ecossistemas locais e regionais, gerando efeitos até mesmo para a saúde humana (TUNDISI, 2007).

Em pesquisa realizada sobre o licenciamento ambiental de usinas hidrelétricas em Minas Gerais, entre os anos de 2002 e 2006, com foco nos conflitos desencadeados pela sua construção, evidenciou-se que os projetos são licenciados apesar de os estudos que os embasam serem insuficientes, havendo a ocorrência de restrições legais e de manifestada resistência pelas populações atingidas durante a implantação do empreendimento. Se, de um lado, observamos populações ribeirinhas que consideram a terra como um patrimônio da família e da comunidade, com regras para o compartilhamento dos recursos, de outro, há o setor elétrico, nas figuras do Estado e dos empreendedores públicos e privados, os quais, dentro da lógica de mercado, entendem o território como propriedade, qual seja, uma mercadoria de valoração monetária (ZHOURI; OLIVEIRA, 2007). 
Para Zhouri e Oliveira (2007), as ações políticas sob a ótica econômica tendem a resolver os problemas de degradação ambiental por meio de medidas mitigadoras e compensatórias, conforme o denominado pelas duas autoras como modelo dominante de "paradigma da adequação ambiental” em oposição a um "paradigma da sustentabilidade”. Por esse padrão, o ambiente é visto como externalidade, qual seja, a "paisagem que deve ser modificada e adaptada aos objetivos do projeto técnico" (ZHOURI; OLIVEIRA, 2007).

Ainda segundo Zhouri e Oliveria, as populações ribeirinhas acabam por se tornarem invisíveis enquanto sujeitos sociais e atores políticos dotados de desejos e direitos, o que induz ao aumento da violência e dos conflitos, caracterizando-se, assim, um desenvolvimento desigual e excludente nesses territórios. O mesmo estudo aponta para os países exportadores de insumos ou produtos intermediários de alto consumo energético e baixo valor agregado, cuja instalação no Brasil intensifica a utilização de áreas economicamente marginais. Dessa forma, observa-se a expansão da fronteira econômica do mercado em territórios historicamente ocupados por agricultores familiares e minorias étnicas. A partir dessa dinâmica, instauram-se áreas de conflito social, com a consequente desapropriação das populações locais.

Conforme entendimento dos economistas do Fórum Econômico Mundial, o nível de produção de energia hidrelétrica de um país constitui um indicador de sustentabilidade ambiental. Acredita-se, então, que o Brasil caminha na direção de um 'desenvolvimento sustentável', visto que $70,5 \%$ da capacidade instalada no país provêm de fonte hidráulica (ZHOURI; OLIVEIRA, 2007). Porém, há dados de que as barragens construídas já inundaram 3,4 milhões de hectares de terras produtivas, desalojando mais de um milhão de pessoas no país (ZHOURI; OLIVEIRA, 2007). Segundo Manyari (2007), a modificação natural do rio, em consequência da construção de grandes hidrelétricas, com profundas alterações nas características do canal e da planície, afeta adversamente a biodiversidade, bem como a exploração econômica dos recursos naturais.

O conceito de desenvolvimento sustentável, como utilizado, por exemplo, pelas empresas do setor elétrico, assume caráter hegemônico como uma alternativa para atravessar a lacuna existente entre exploração capitalista de recursos naturais e a preservação ambiental. Portanto, tal noção, sob a ótica econômica, utiliza-se da mitigação e da compensação, mostrando-se incapaz de contabilizar outros valores como equidade social, diversidade cultural, autonomia e autogestão (ASSIS; ZHOURI, 2011). Observa-se uma reorientação desse discurso ao longo dos últimos anos. Num primeiro momento, ele considerava a natureza como espaço 
de geração de riquezas; com o passar do tempo, incorporou elementos da noção de desenvolvimento sustentável, sob a mesma perspectiva que visa renovar os pilares de sustentação do progresso econômico.

Segundo Assis e Zhouri (2011), o discurso publicitário de muitas empresas tanto do setor elétrico, químico e petroquímico substitui a realidade vivenciada e estabelece o uso de caracteres simbólicos com o intuito de ilustrar a ideia de desenvolvimento sustentável, desconstruindo a imagem de uma natureza alterada. Ao afirmar os preceitos hegemônicos no campo ambiental, esse discurso oculta a existência dos custos ambientais e corrobora a apropriação desigual dos recursos territorializados, não contabilizando os impactos sociais e ambientais; no mais, afeta os modos de vida comprometidos pela instalação dos empreendimentos (ASSIS; ZHOURI, 2011).

Na análise do Ecological Footprint Method ${ }^{2}$, Van Bellen observou os preceitos de que a pressão sobre a integridade ecológica e a saúde humana continua a aumentar. Argumenta sobre a necessidade de iniciativas mais efetivas para o alcance da sustentabilidade, entre as quais deve constar o desenvolvimento de ferramentas que estimulem o envolvimento da sociedade civil e avaliem as estratégias de desenvolvimento (VAN BELLEN, 2004).

A criação de mecanismos de inclusão participatória junto às decisões para implantação de projetos, sob o ponto de vista ambiental, é um fator essencial para conferir visibilidade às comunidades tradicionais, transformando-as em atores da própria realidade, em condição de partícipes e sabedores dos seus direitos (ARAÚJO; BELO, 2009).

Em entrevista a respeito da Usina de Belo Monte, Ricardo Verdum, professor do Instituto de Estudos Socioeconômicos (Inesc) ${ }^{3}$, manifestou-se de modo enfático quanto aos interesses do capitalismo pelas riquezas da região Amazônica, os quais abarcam fatores para além da própria usina geradora de energia:

É mais uma manifestação do que chamamos de colonialismo interno, expansão do processo de ocupação dessa região pela economia capitalista. É uma expansão geográfica que está chegando àquela região com um grande

\footnotetext{
${ }^{2}$ Sistema desenvolvido por Wackernagel e Rees, fundamenta-se basicamente no conceito de capacidade de carga. Para efeito de cálculo, a capacidade de carga de um sistema corresponde à máxima população que pode ser suportada indefinidamente no sistema (VAN BELLEN, 2004).

${ }^{3}$ Assessor do Instituto de Estudos Socioeconômicos (Inesc), Ricardo Verdum participou do seminário que ocorreu em Brasília para discutir as obras de Belo Monte e os impactos que a usina causará nas comunidades indígenas no Xingu. Disponível em: http://www.ihu.unisinos.br/entrevistas/40735-belo-monte-e-seus-impactos-sobre-ospovos-indigenas-entrevista-especial-com-ricardo-verdum. Acesso em: 26/01/2012.
} 
projeto e impactos significativos. Mas esse processo não se dá isolado, está conectado com um plano maior de ocupação, de geração de energia, principalmente para o setor mineral (IHU, 2012).

Harvey (1993) destaca que a espacialidade tradicional do capitalismo é aquela das concentrações espaciais do capital e do trabalho, dos desequilíbrios regionais, das migrações desterritorializantes, da degradação socioambiental, das periferias das cidades, do urbanismo que segrega, da involução das pequenas cidades, da modernização predatória do campo. Nessa espacialidade se assenta a reprodução desse sistema (HARVEY, 1993).

Vale lembrar que o problema não surge dos grandes projetos de infraestrutura em si, mas sim da maneira como são construídos e para quem se destinam.

\subsubsection{A organização do setor elétrico brasileiro diante do potencial energético da Amazônia}

A implantação de grandes projetos de infraestrutura, especialmente na região amazônica, é marcada historicamente pelos impactos socioambientais, os quais estão intimamente vinculados ao desmatamento das florestas e à execução, desde a década de 60, dos planos de desenvolvimento econômico da região.

Entre as décadas de 1970 e 1980, a população urbana da Amazônia aumentou de 37,7\% para $51,8 \%$, crescimento que se deveu sobretudo aos incentivos do governo aos grandes projetos. No que se refere ao desmatamento, desde a implantação do Plano de Prevenção e Controle do Desmatamento na Amazônia Legal (PPCDAm), em 2004, a taxa anual na região, medida pelo Programa de Monitoramento da Cobertura Florestal da Amazônia Brasileira por Satélite (Prodes), tem apresentado redução (ESCADA et al, 2013).

Entretanto, apesar da tendência de queda, alguns estudos apontam para a elevação do desmatamento em áreas onde são construídas Usinas Hidrelétricas (UHE). É o caso de Porto Velho, em Rondônia, em que se verificou um aumento de $237 \%$ no desmatamento da região no ano de 2011 em comparação a 2010. Para os autores, não se pode atribuir o incremento às obras em si, pois é preciso observar o contexto em que ocorre a sua instalação (ESCADA et al, 2013).

A exploração atual da região Amazônica se refere não só à sua riqueza mineral e biodiversidade, mas também ao seu imenso potencial energético, tendo em vista que a região 
reúne os maiores mananciais do planeta. Os altos índices da relação entre a demanda total e a disponibilidade hídrica encontrados no Brasil se devem principalmente à Região Hidrográfica Amazônica, que detém 73,6\% dos recursos hídricos superficiais, contribuindo, no entanto, com apenas $4 \%$ da demanda de retirada do Brasil. De acordo com o Sistema de Informações do Potencial Hidrelétrico Brasileiro (SIPOT) da Eletrobrás, a Região Norte detém o maior potencial, com 99.292 MW (BRASIL, 2012a) (Figura 1).

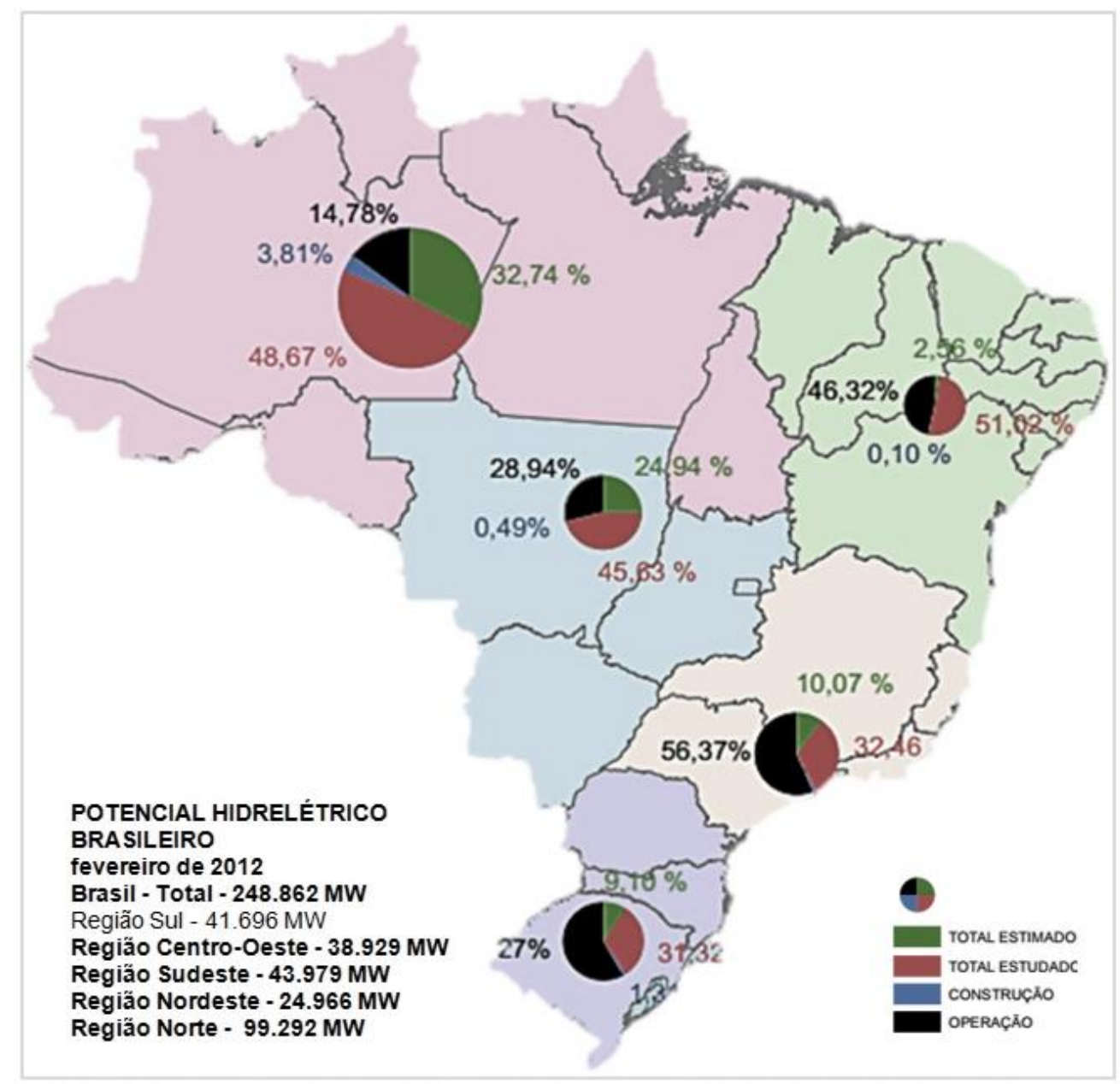

Figura 1 - Potencial Hidrelétrico Brasileiro.

Fonte: Brasil, 2012a.

Conforme o Instituto Socioambiental (ISA), a expansão da hidroeletricidade nessa região nas próximas décadas será exponencial. Considera que a produção de energia elétrica no Sul e Sudeste do país, onde se concentram os grandes centros consumidores, dependerá desses recursos, tendo em vista que a Bacia do Paraná e as Bacias do Tocantins e São Francisco juntas já exploraram praticamente a metade do seu potencial (ISA, 2010). A Região Hidrográfica do 
Paraná, que possui o maior aproveitamento desse potencial hidrelétrico com 46.806 MW, corresponde a $58 \%$ do total instalado.

Em 2014, o Brasil possuía 3.055 empreendimentos em operação para gerar energia; 1.093 eram fontes hidroelétricas, que representavam 62,53\% dos 134.912.947 KW de potência instalada. Prevê-se, para os próximos anos, a adição de $36.422 .675 \mathrm{KW}$ na capacidade de geração do país, proveniente dos 219 empreendimentos atualmente em construção, com a outorga de mais 483 (ANEEL, 2014).

No Brasil, um dos principais instrumentos de planejamento para a expansão eletroenergética do país são os Planos Decenais de Expansão de Energia (PDE), elaborados pelo setor elétrico. Compete ao Conselho Nacional de Política Energética (CNPE) o estabelecimento de políticas e diretrizes para a área, assim como o planejamento da expansão de oferta de energia elétrica, realizado com base em normas estabelecidas por ele e subsidiado por estudos da Empresa de Pesquisa Energética (EPE).

De acordo com o PDE 2020, estima-se uma maior expansão da hidroeletricidade na região norte, sobretudo por conta de grandes empreendimentos, com destaque para a usina hidrelétrica de belo monte (BRASIL, 2012b).

Há previsão de que a capacidade de geração hidráulica aumentará de 84 GW para 117 GW, no período de 2012 até 2021. Novos projetos ainda serão viabilizados, como a construção das usinas hidrelétricas São Luiz do Tapajós e Jatobá, dois projetos que fazem parte das sete usinas previstas para o Complexo do Tapajós, no Estado do Pará, consideradas "estratégicas de interesse público, estruturantes e prioritárias para efeito de licitação e implantação, conforme Resolução CNPE No 3 de maio de 2011” (BRASIL, 2012b).

Nos últimos estudos apresentados, o PDE 2023 destacou uma capacidade instalada relativa aos empreendimentos de geração constantes do Sistema Interligado Nacional (SIN), incluindo a parcela de Itaipu importada do Paraguai, que totalizava 124,6 mil MW em 31/12/2013. É importante considerar que, para a distribuição da capacidade instalada por tipo de fonte do parque gerador existente, a energia hidráulica representava 64\% do total em 2013 (BRASIL, 2014b) (Figura 2).

De acordo com o PDE 2023, a composição da oferta de geração de energia teve como base os "empreendimentos com viabilidade técnica, econômica e socioambiental, em diversos estágios de desenvolvimento, e com reais possibilidades de início de operação no horizonte do 
estudo" (BRASIL, 2014b). Entretanto, no caso da Usina de Belo Monte, ela irá compor um subsistema à parte, com previsão de conexão ao subsistema Norte a partir de abril de 2016.

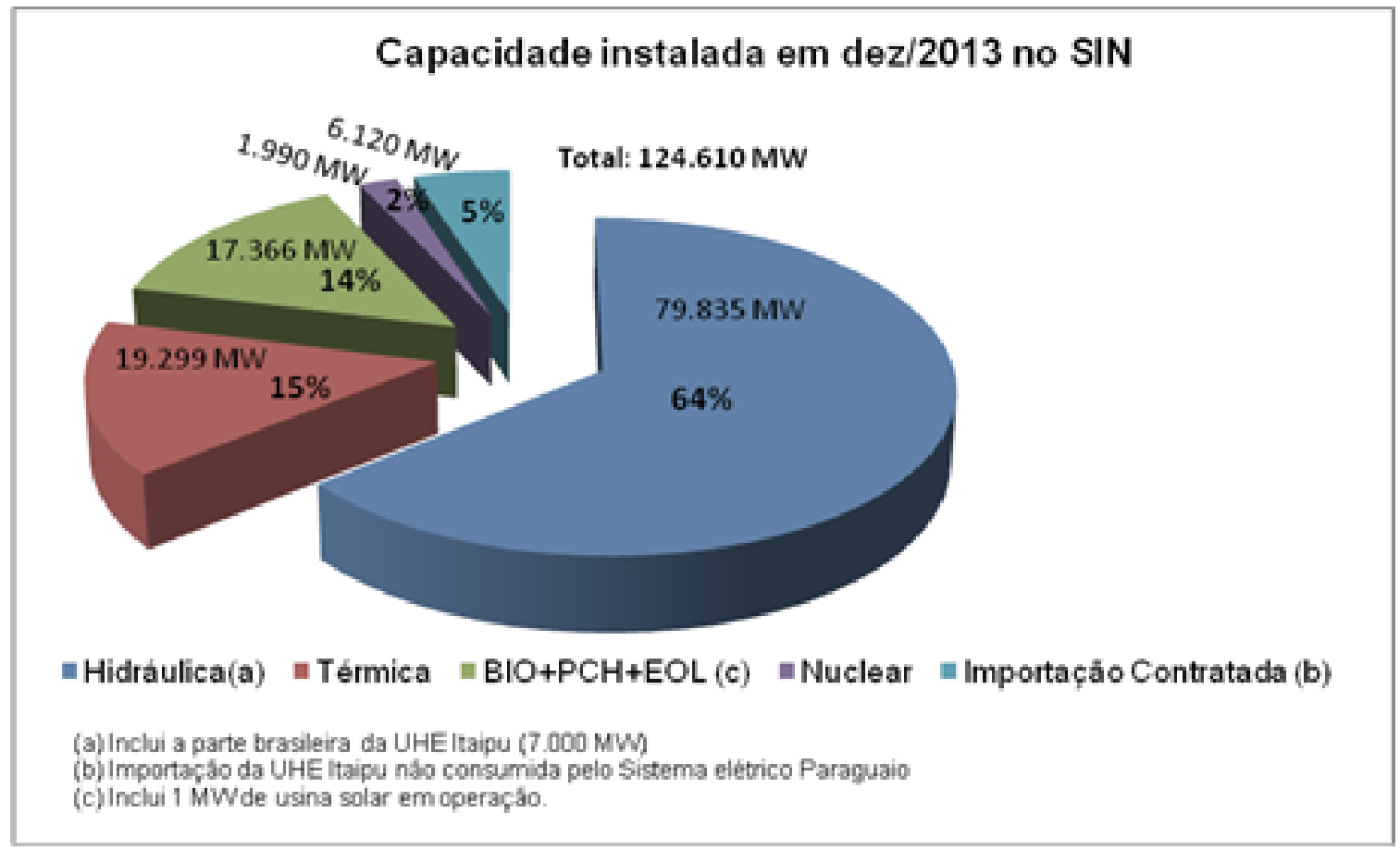

Figura 2 - Capacidade instalada no SIN por tipo de fonte.

Fonte: Brasil, 2014b

Conforme previsto, a participação da Região Norte na expansão de projetos de geração de energia elétrica passará de 12\%, em 2013 para 23\% da capacidade instalada no SIN em 2023, totalizando 30.504 MW de expansão. Diante desse cenário, a Amazônia se destaca como o território "consumido" pelas dezenas de grandes hidrelétricas a serem implantadas nos próximos anos, passando a ser considerada pelos órgãos de governo como a nova "fronteira elétrica", em conformidade com os planos e políticas do Governo Federal (Figura 3).

De acordo com o Ministério do Meio Ambiente (MMA), apesar do maior potencial hidrelétrico remanescente se localizar na Amazônia, levando-se em conta a grande importância dos aspectos ambientais dessa região, caracterizada pela marcada presença de unidades de Conservação e de Terras Indígenas, é possível que significante parte do potencial estimado não se mostre ambientalmente viável (BRASIL, 2006a). 


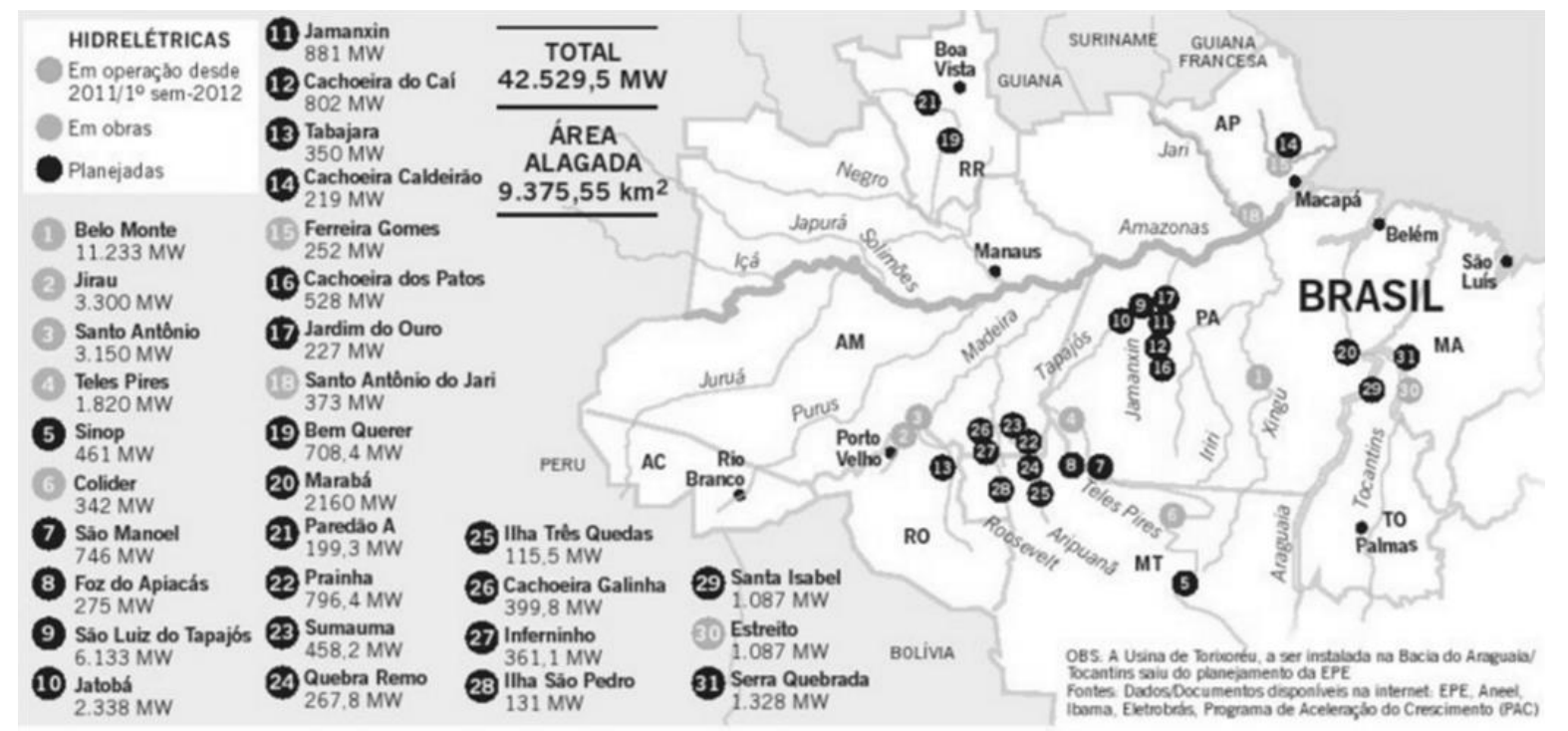

Figura 3 - Amazônia como a "nova fronteira de energia"

Fonte:http://oglobo.globo.com/economia/de-23-novas-hidreletricas-planejadas-na-amazonia-sete-seraoconstruidas-em-areas-intocadas-6173007

Alvo de críticas de muitos ambientalistas, a construção de barragens na bacia do rio Tapajós causará o alagamento de áreas situadas em parques nacionais. Apesar do movimento contrário a essa implantação, o governo federal, no intuito de "contornar" a controvérsia, editou em 2012 uma medida provisória (MP-558) para a redução da área de quatro Unidades de Conservação (UC), alterando ainda outras duas na região (WWF, 2012).

A partir de casos como esses, os organismos internacionais de cooperação, como o Banco Mundial por exemplo, decidiram adotar instrumentos de planejamento e gestão ambiental, acarretando a elaboração dos primeiros Estudos de Impacto Ambiental no Brasil (MORETTO et al, 2012) e, posteriormente, a criação da Política Nacional de Meio Ambiente (PNMA).

O principal marco regulatório da agenda ambiental à época, a PNMA subsidiava o planejamento e a gestão ambiental brasileira com outros importantes instrumentos de política ambiental em âmbito nacional, tais como o zoneamento e o licenciamento ambiental, a avaliação de impacto no meio ambiente, as áreas protegidas, entre outros (SÁNCHEZ, 2006).

Vale destacar que a Avaliação de Impacto Ambiental (AIA) foi regulamentada no Brasil apenas para a escala de projetos, apesar de haver sido instituída como um processo metodológico vinculado ao licenciamento ambiental de empreendimentos e de se enquadrar na 
dimensão ambiental do planejamento e da gestão de políticas, planos, programas e projetos na área (SÁNCHEZ, 2006).

Entendemos que, para um país retomar o desenvolvimento nacional nos patamares esperados, é necessária a execução de grandes projetos de infraestrutura. No entanto, as formas de superação dos "entraves ao desenvolvimento" não perpassam apenas a desapropriação e o licenciamento ambiental, mas sim a capacidade de planejamento e gestão do Estado.

\subsubsection{Os atores envolvidos no planejamento das usinas hidrelétricas em face do cumprimento do licenciamento ambiental no Brasil}

O período que abrangeu a criação da Eletrobrás até o ano de 1993 se caracterizou por uma forte intervenção estatal no setor elétrico brasileiro, baseada em um modelo não totalmente centralizado. A partir desse momento, o Brasil iniciou a reforma de sua indústria de energia elétrica com o Plano Nacional de Desestatização. Ocorreu uma reestruturação vertical e horizontal da indústria de energia elétrica com a privatização das empresas distribuidoras e da maioria das geradoras, com exceção daquelas com fonte de energia nuclear e de uma parte da binacional de Itaipu. O Estado passou, então, a coordenar o setor elétrico por meio do Operador Nacional do Sistema (ONS) (MALAGUTI, 2009)

O Estado assumiu a função de fiscalizar o setor elétrico a partir de 1996, com a criação da Agência Nacional de Energia Elétrica (ANEEL), instituída pela Lei 9.427/96. As reformas setoriais ocorreram de forma concomitante e paralela à privatização de ativos federais e estaduais. Essa agência foi instituída com o intuito de gerenciar as questões pertinentes à indústria de energia elétrica brasileira, como a definição de regras de entrada, tarifas e estrutura de mercado (D’ARAÚJO, 2009).

Outro órgão importante no processo de regulação é a Agência Nacional das Águas (ANA), instituído pela Lei n ${ }^{\circ} 9.984$ de 2000. É responsável por analisar, outorgar e fiscalizar os aproveitamentos hidrelétricos antes da licitação da concessão ou da autorização de uso do potencial de energia hidráulica pela ANEEL (ANA, 2014).

Em 2001, com a determinação federal no sentido do racionamento de energia elétrica e partir da consequente queda do consumo de eletricidade, a questão da eficiência energética e a 
introdução de novas fontes alternativas tornaram-se relevantes. A matriz energética fortemente dependente da energia hidráulica veio a contribuir com o colapso físico do sistema elétrico brasileiro (MALAGUTI, 2009).

Em 2004, instituiu-se a Empresa de Pesquisa Energética (EPE), entidade pública federal vinculada ao Ministério de Minas e Energia, a qual tem por finalidade subsidiar o planejamento do setor energético. A EPE consolidou a implementação de leilões no setor de energia elétrica e estabeleceu contratos conjuntos entre a iniciativa privada e pública, o que permitiu novos investimentos, (MALAGUTI, 2009).

Atualmente, o Operador Nacional do Sistema Elétrico (ONS) é o órgão responsável pela coordenação e controle da operação das instalações de geração e transmissão de energia elétrica no Sistema Interligado Nacional (SIN), sob a fiscalização e regulação da Agência Nacional de Energia Elétrica (ANEEL).

O Sistema Interligado Nacional (SIN), encarregado da produção e transmissão de energia elétrica no Brasil, é uma estrutura hidrotérmica de grande porte, em que predominam as usinas hidrelétricas e múltiplos proprietários. É formado pelas empresas das regiões Sul, Sudeste, Centro-Oeste, Nordeste e parte da região Norte. Apenas 1,7\% da energia requerida pelo país encontra-se fora do SIN, em pequenos sistemas isolados, localizados sobretudo na região amazônica (ANEEL, 2015) (Figura 4).

Considerado um dos maiores potenciais de energia elétrica do mundo, o Brasil tem sua matriz energética assegurada pelas fontes hidroelétricas, provedoras da maior parte desse tipo de energia no país - o restante é distribuído entre as outras fontes de geração, quais sejam, térmica, eólica e solar.

Em 2005, a Agência Nacional de Águas (ANA) considerava o grande potencial hidrelétrico como "uma fonte abundante, limpa e renovável”, além de apresentar uma vantagem comparativa quanto às matrizes elétricas adotadas por outros países, que utilizam como fontes de energia os combustíveis fósseis e/ou centrais nucleares para a geração de energia elétrica. Entretanto, a sua obtenção se dá em longos prazos, até que se alcance o resultado final desejado, tanto em termos dos estudos envolvidos (inventário, viabilidade, projeto básico e executivo) quanto relativamente ao tempo necessário para a construção de uma usina. Essa peculiaridade temporal implica a necessidade de um planejamento antecipado da expansão da oferta de energia (ANA, 2005). 


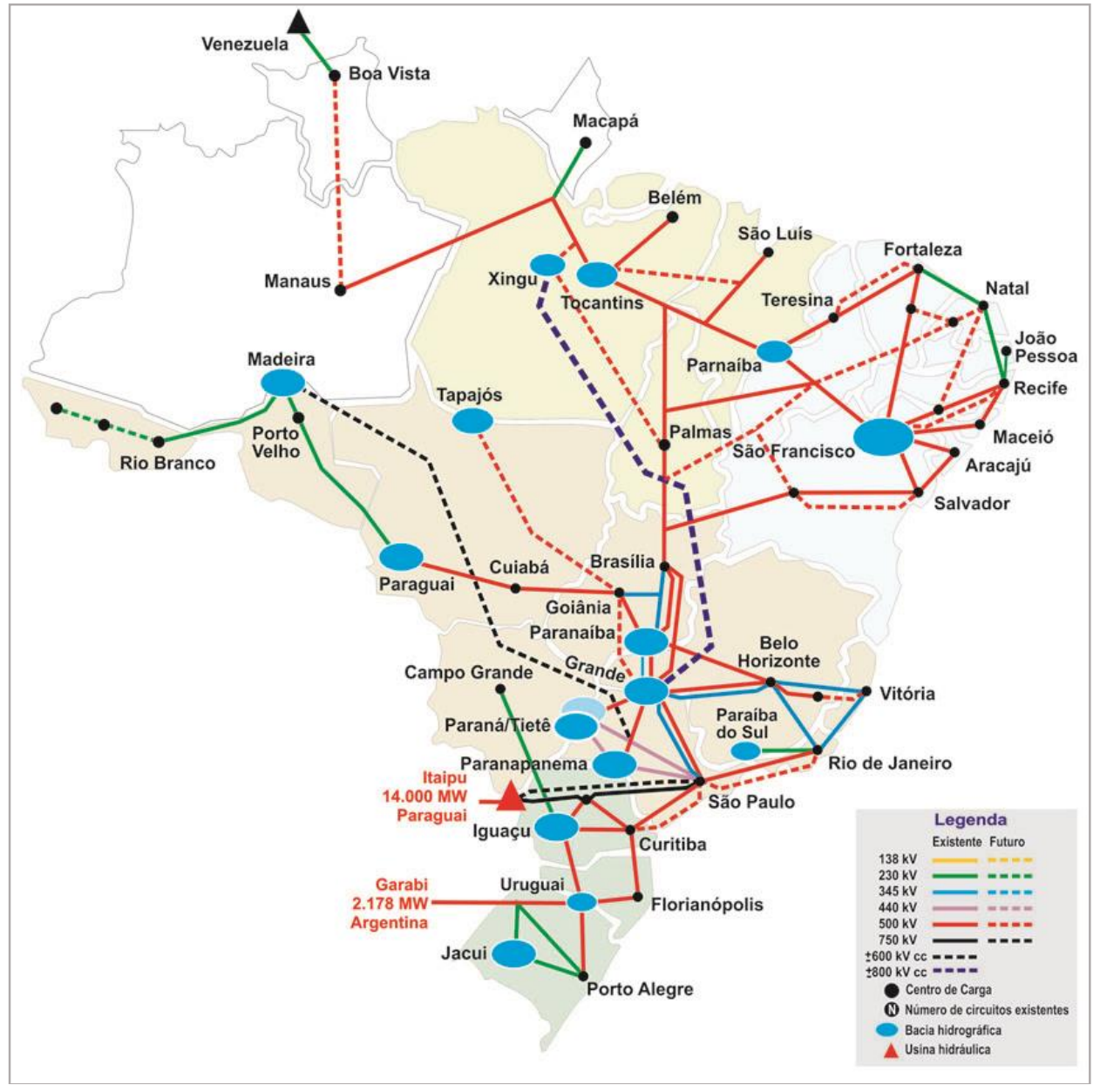

Figura 4 - Integração Eletroenergética do SIN no BRASIL

Fonte: Aneel, 2015.

Ainda que consideradas como um importante provedor de energia elétrica limpa, as usinas hidrelétricas também se situam no patamar dos grandes empreendimentos que provocam efeitos negativos sobre as áreas sensíveis, tanto do ponto de vista ambiental como social, particularmente em áreas de expansão, como a região amazônica.

De acordo com a ANA, os agentes do Setor Elétrico Brasileiro precisam entender o licenciamento como instrumento de controle e gestão ambiental, assegurando os objetivos e as diretrizes da Política Nacional de Meio Ambiente. Assim, os estudos ambientais devem ser aprimorados de forma a atenderam os requisitos para a obtenção das licenças ambientais (ANA, 2005).

[...] Destacam-se os impactos das usinas hidrelétricas, com especial destaque para a área inundada pelos reservatórios e suas consequências sobre o meio físico-biótico e sobre as populações atingidas. As preocupações com essas questões são agravadas pelo fato da maior parte do potencial hidrelétrico hoje 
remanescente estar localizado em áreas de condições socioambientais delicadas, por suas interferências sobre territórios indígenas, sobretudo na Amazônia, nas áreas de preservação e nos recursos florestais, ou em áreas bastante influenciadas por ocupações antrópicas. São também fundamentais os estudos e equacionamentos associados aos usos múltiplos e, eventualmente, concorrenciais desses recursos hídricos, em suas feições socioeconômicas, ambientais e estratégicas, relativas à pesca, abastecimento urbano, saneamento básico, irrigação, transporte, uso industrial, lazer e etc. (ANA, 2005).

Responsável pelo licenciamento ambiental das grandes hidrelétricas, o Ibama, órgão executor da Política Nacional de Meio Ambiente (PNMA), atua conforme a Resolução CONAMA 237/97, que dispõe sobre o licenciamento dos empreendimentos que geram significativo impacto ambiental e se encontram localizados ou que geram impactos diretos em dois ou mais Estados da federação, em áreas indígenas ou unidades de conservação do domínio da União.

Sendo assim, para a viabilização de todo e qualquer empreendimento, exige-se a realização de estudos ambientais preliminares como condição prévia à sua implantação, de acordo com a legislação ambiental vigente. A seguir, destacamos as principais fases para a obtenção das licenças ambientais por parte dos grandes empreendimentos de geração elétrica (Figura 5).

\begin{tabular}{|l|c|c|}
\hline \multicolumn{1}{|c|}{ Fase da Usina } & Licença Ambiental & Documento Principal \\
\hline Viabilidade & Prévia -LP & EIA/RIMA \\
\hline Projeto Básico & Instalação - LI & PBA \\
\hline Comissionamento & Operação - LO & Vistoria e testes \\
\hline Operação Comercial & Renovação da LO & Vistoria e testes \\
\hline
\end{tabular}

Figura 5 - As fases do Licenciamento Ambiental de uma Usina Hidrelétrica Fonte: Stamm, 2003.

Além da legislação básica para o licenciamento ambiental - como a resolução CONAMA n ${ }^{\circ}$ 001/86, que instituiu o Estudo de Impacto Ambiental (EIA) e o respectivo Relatório de Impacto Ambiental (RIMA) -, há também a Resolução CONAMA nº 006/87, que regulamenta os documentos a serem apresentados em cada fase do licenciamento ambiental para os projetos de grande porte na área de geração elétrica (Figura 6). 


\begin{tabular}{|c|l}
\hline \multicolumn{2}{|c}{ Documentos necessários ao licenciamento de Usinas Hidrelétricas } \\
\hline Tipos de Licença & \multicolumn{1}{c}{ Documentos } \\
\hline \multirow{2}{*}{ Licença Prévia (LP) } & $\begin{array}{l}\text { Requerimento de Licença Prévia } \\
\text { Portaria Ministério Minas e Energia (MME) autorizando o Estudo da Viabilidade } \\
\text { Relatório de Impacto Ambiental (RIMA) sintético e integral, quando necessário } \\
\text { Cópia da publicação de pedido na LP }\end{array}$ \\
\hline \multirow{5}{*}{ Licença de Instalação (LI) } & $\begin{array}{l}\text { Relatório do Estudo de Viabilidade. } \\
\text { Requerimento de licença de Instalação. } \\
\text { Cópia da publicação da concessão da LP } \\
\text { Cópia da Publicação de pedido de LI } \\
\text { Cópia do Decreto de outorga de concessão do aprovei-tamento hidrelétrico } \\
\text { Projeto Básico Ambiental }\end{array}$ \\
\hline \multirow{2}{*}{ Licença de Operação (LO) } & $\begin{array}{l}\text { Requerimento de Licença de Operação } \\
\text { Cópia da Publicação da Concessão da LI } \\
\text { Cópia da Publicação de pedido de LO. }\end{array}$ \\
\hline
\end{tabular}

Figura 6 - Documentos necessários ao licenciamento de projetos de grande porte na área de geração elétrica Fonte: Elaborado por Missifany Silveira a partir da Resolução Conama nº 006 de 1987.

O Brasil possui atualmente 3.479 Agentes de Geração que investem no mercado de geração de energia elétrica, a partir de diversas fontes de energia, com predominância das hidrelétricas. Os dez principais agentes de geração detêm uma capacidade de aproximadamente $71.000 .000 \mathrm{~kW}$ de potência instalada, considerando-se todos as fontes de energia elétrica. No total, são 4.165 empreendimentos em operação, que, somados, chegam a $136.249 .368 \mathrm{~kW}$ de potência instalada no país (Quadro 1). Destes, 201 empreendimentos são usinas hidrelétricas (UHE) em operação no país (ANNEL, 2015).

Contudo, com a implantação de mais três UHE em construção, novos agentes entrarão no ranking dos maiores geradores de energia elétrica. É o caso da Norte Energia S.A., responsável pela construção da Usina de Belo Monte, que representará 8,24\% da capacidade de geração do país. Além de Belo Monte, estão em construção a UHE de Teles Pires (Companhia Hidrelétrica Teles Pires) e a de São Manoel (Empresa de Energia São Manoel S.A), todas no Estado do Pará; juntas, elas representarão um acréscimo de 13.755 .860 kW na capacidade de geração de energia elétrica (ANEEL, 2015). 
Quadro 1 - Agentes do setor elétrico que detêm a maior capacidade instalada de energia elétrica das usinas em operação no país

\begin{tabular}{|c|c|c|}
\hline \multicolumn{3}{|c|}{ Agentes do setor elétrico e a capacidade instalada de energia elétrica no País } \\
\hline $\mathbf{N}^{\mathbf{0}}$ & Agentes do Setor & Potência Instalada $(\mathrm{kW})$ \\
\hline $\mathbf{1}^{\mathbf{o}}$ & Companhia Hidro Elétrica do São Francisco CHESF & $10.615 .131,00$ \\
\hline $\mathbf{2}^{\mathbf{o}}$ & Furnas Centrais Elétricas S/A.FURNAS & $9.907 .492,00$ \\
\hline $\mathbf{3}^{\mathbf{o}}$ & Centrais Elétricas do Norte do Brasil S/A.ELETRONORTE & $9.191 .214,10$ \\
\hline $4^{\circ}$ & Tractebel Energia S/ATRACTEBEL & $7.323 .817,73$ \\
\hline $\mathbf{5}^{\mathbf{o}}$ & Itaipu Binacional ITAIPU & $7.000 .000,00$ \\
\hline $\mathbf{6}^{\mathbf{0}}$ & Petróleo Brasileiro S/APETROBRAS & $6.715 .074,60$ \\
\hline $7^{\mathbf{o}}$ & Companhia Energética de São Paulo CESP & $6.649 .820,00$ \\
\hline $\mathbf{8}^{\mathbf{o}}$ & CEMIG Geração e Transmissão S/ACEMIG-GT & $5.987 .594,40$ \\
\hline $9^{\mathbf{o}}$ & Copel Geração e Transmissão S.A. COPEL-GT & 4.929.407,00 \\
\hline $10^{\circ}$ & AES Tietê S/A & $2.652 .050,00$ \\
\hline \multicolumn{2}{|c|}{$\begin{array}{r}\text { Total } \\
\text { Obs.: } 1 \mathrm{GW}=1.000 .000 \text { de } \mathrm{kW} \text { de potência. }\end{array}$} & 70.971.600,83 \\
\hline
\end{tabular}

Fonte: Aneel, 2015.

Até 2013, a estimativa é de que as grandes hidroelétricas serão as principais responsáveis por significativa parte expansão do setor elétrico, com a sua capacidade total instalada, de acordo com o PDE (BRASIL, 2014b). Nesse cenário, a Região Amazônica se configura como território de exploração dos recursos hídricos para a geração de energia elétrica, da mesma forma como ocorreu anteriormente com os Estados de São Paulo, Paraná, Minas Gerais e Bahia, os quais, juntos, ainda detêm a maior capacidade instalada do país. Entretanto, é importante ressaltar que, justamente na Amazônia dos grandes rios e florestas, encontram-se também, além da energia "limpa e barata" oferecida para os grandes agentes do setor energético, os conflitos socioambientais de naturezas diversas.

Nesse contexto, uma das críticas ao procedimento de licenciamento de usinas hidrelétricas no Brasil é o fato de que ele se fundamenta na avaliação dos impactos ambientais de empreendimentos pautados no controle e mitigação dos impactos do projeto de forma isolada, sem a devida avaliação dos efeitos cumulativos dos empreendimentos na área (ANDRADE, 2011). 


\subsection{A REALIDADE DA ENERGIA "LIMPA, RENOVÁVEL E BARATA" PRODUZIDA PELAS HIDRELÉTRICAS}

De acordo como o Plano Nacional Sobre Mudança do Clima (PNMC) de 2008, o setor energético brasileiro é considerado "extremamente limpo" comparado aos demais países, já que sua a matriz energética conta com uma participação de $45,8 \%$ de fontes renováveis, enquanto a média mundial é de 12,9 \% (BRASIL, 2008a). As hidrelétricas contribuem para esse quadro, já que a energia hidráulica representa $64 \%$ da capacidade instalada de produção no país (BRASIL, 2014b).

Contudo, o MME acredita que, mesmo que "os projetos hidroelétricos utilizem uma fonte renovável e limpa, resultando em melhoria de qualidade de vida pela disponibilização da energia elétrica, não se pode ignorar os impactos significativos causados por alguns empreendimentos hidroelétricos, tanto do ponto de vista da sustentabilidade dos ecossistemas quanto da sustentabilidade social" (BRASIL, 2007a).

Uma das justificativas para que os grandes empreendimentos hidrelétricos permaneçam nos planos do governo federal é a oportunidade diante do rico potencial existente na região amazônica, assegurando-se que apenas 74 mil MW (28,6\% do total) estão efetivamente aproveitados relativamente ao estimado pela Empresa de Pesquisa Energética (EPE) (MORETTO et al, 2012).

Contudo, há de se destacar que a energia produzida nessa região se destina a abastecer os mercados sobretudo das regiões Sudeste e Nordeste. De acordo com a Norte Energia ${ }^{4}$, empresa encarregada da implantação da UHE de Belo Monte, a energia ali gerada será comercializada para atender consumidores em dezessete Estados. Destes, São Paulo será o maior consumidor, com aproximadamente 30\%, seguido por Minas Gerais, com 14,5\%, e Bahia, com 13,8\%. O restante será dividido por outros catorze Estados em parcelas menores.

A produção e o consumo de energia elétrica no Brasil compõem uma rede complexa. Como ilustra a figura a seguir, o consumo na região Sul e Sudeste supera as demais regiões (Figura 7). Os maiores produtores de energia elétrica em 2012 foram Paraná, São Paulo, Minas Gerais, Rio de Janeiro e Pará; os maiores consumidores, São Paulo, Rio de Janeiro, Minas

\footnotetext{
4 Norte Energia. Hidrelétrica de Belo Monte. Disponível em: http://norteenergiasa.com.br/site/wpcontent/uploads/2015/01/Paper-Belo-Monte-Dezembro.pdf. Acesso em: 10/04/2014.
} 
Gerais, Rio Grande do Sul e Paraná. Portanto, a demanda de energia pelas regiões do Sudeste e Sul é enorme, e a energia a ser produzida na Região Norte continuará a atender a essas mesmas localidades.

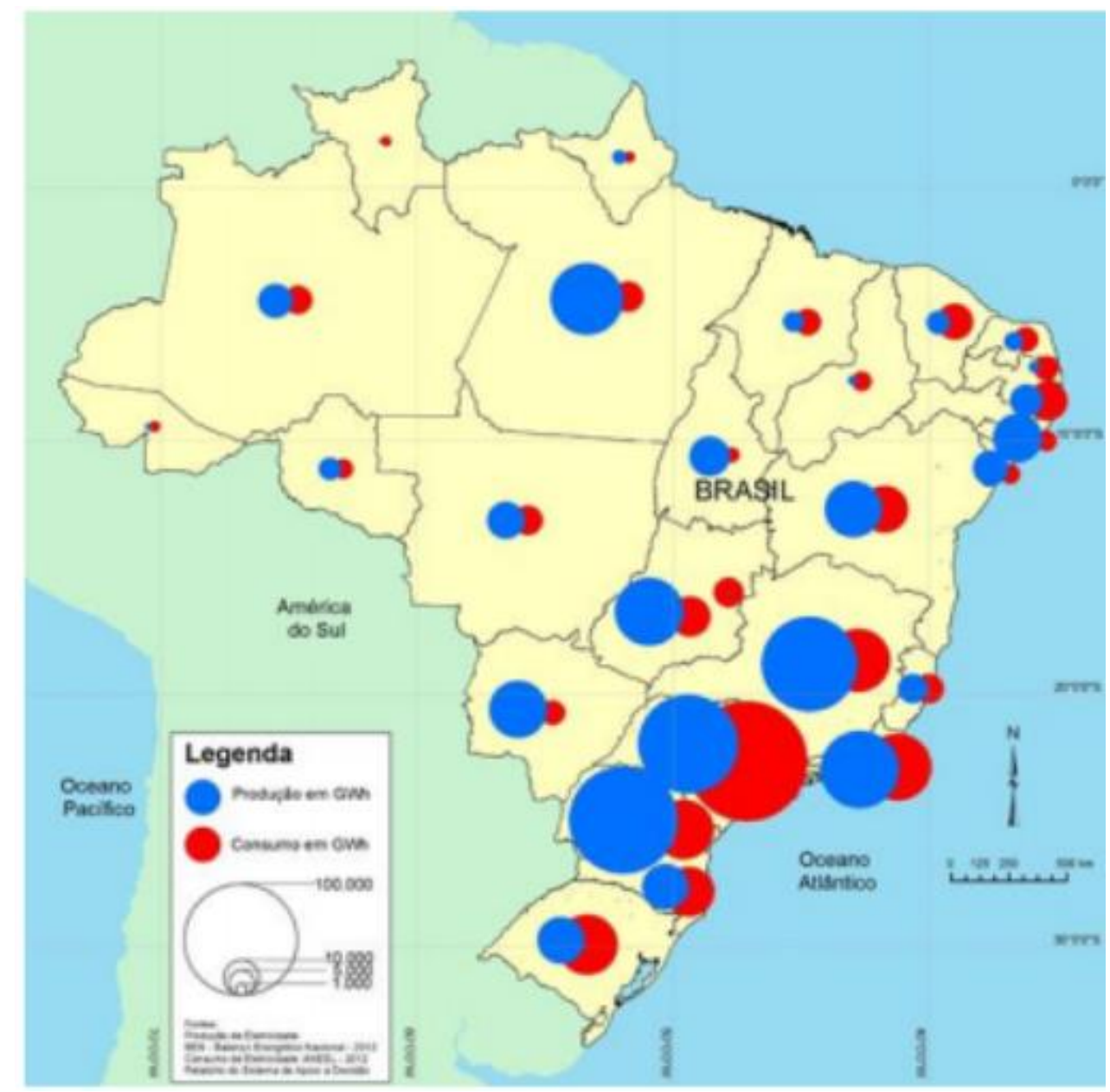

Figura 7 - Produção e consumo de energia elétrica no Brasil (2012)

Fonte: Moreira, 2015.

Segundo informações presentes no documento do Painel de Especialistas quanto ao uso da energia produzida pela UHE de Belo Monte, a maior parte se destinaria a usinas de alumina e alumínio no próprio Pará, além de abastecer uma linha de transmissão para a região Sudeste, com capacidade menor do que a prevista originalmente no planejamento elétrico. Para os autores do estudo, o setor de alumínio no Brasil consome expressivas quantidades de energia para uso em commodity, produzindo alumínio e outros produtos eletro-intensivos para exportação, marcadamente nas indústrias instaladas na região Norte do País, sendo essa "a principal razão da construção de Belo Monte" (FEARNSIDE, 2009). 
Castro (2012) sustenta que o PAC, programa direcionado à logística de transporte, energia e comunicação, adota um modelo de modernização com base em megaprojetos de investimentos. Para o autor, esse modelo reproduz o que ocorreu durante a expansão da fronteira amazônica nos anos de 1970, responsável por “conflitos sócio-territoriais envolvendo diferentes atores locais com exploração de recursos naturais e o desmatamento" (CASTRO, 2012).

Outro aspecto importante apontado por especialistas da área de energia são os acordos que "preveem que as emissões de dióxido de carbono devem diminuir pela metade, e cuja solução passa por ter mais eficiência energética" (PELLEGRINI, 2015). Para a maioria desses profissionais, o governo precisa definir e incentivar uma política de eficiência energética, com diferentes matrizes de energia por meio de tecnologias, e não apenas "continuar investindo na expansão da oferta de energia" (PELLEGRINI, 2015). Afirmam ainda que há muitas perdas na rede de distribuição brasileira. O setor elétrico deveria otimizar sua rede de transmissão com a utilização de outras fontes de energia, como a solar, para alimentá-la, priorizando energias limpas de origem alternativa e não apenas a hidroeletricidade. Esses especialistas argumentam também que "hoje $6 \%$ da energia produzida no Brasil é roubada no caminho entre a usina e o consumidor" (PELLEGRINI, 2015).

Além da eficiência energética, o modelo adotado no Brasil pela hidroeletricidade, apesar de ser uma matriz de energia limpa, passa por fragilidades como a eficiência das redes de distribuição e sua suscetibilidade às mudanças climáticas, como esclarecido recentemente pelo Conselho Empresarial Brasileiro para o Desenvolvimento Sustentável (CEBDS). Segundo a entidade, o setor elétrico possui unidades produtivas bastante sensíveis a variações extremas de clima, com vulnerabilidades significativas decorrentes de mudanças hidrológicas causadas pelo aumento de temperatura; destaca-se também a variabilidade natural, característica marcante do Brasil, a qual pode afetar qualquer atividade econômica (CEBDS, 2014).

Umas das obras mais caras e emblemáticas do PAC, a UHE de Belo Monte, segue como um dos empreendimentos mais criticados do atual governo. É marcada pela ocorrência de inúmeros processos judiciais, todos em andamento, acarretando atrasos na sua conclusão da obra e no fornecimento de energia pelas compradoras.

Pesquisa realizada em 2013 sobre os conflitos em Belo Monte contabilizou mais de cinquenta processos judiciais movidos contra a obra de construção da hidrelétrica. Neles, apontavam-se as violações de direitos humanos estabelecidos pelos tratados internacionais, bem como infrações da legislação ambiental e dos direitos constitucionais, em denúncias realizadas 
pelas instituições da sociedade civil e defensorias públicas como os Ministérios Públicos Federal e Estaduais. Não obstante, apesar das inúmeras ações ajuizadas entre 2001 a 2013, tendo em vista o não cumprimento de medidas que visem assegurar a proteção ambiental e sociais, a construção da usina de Belo Monte segue em andamento (FLEURY, 2013).

De acordo com o Tribunal de Contas da União (TCU), o custo da Hidrelétrica de Belo Monte, umas das principais obras do PAC, com financiamento do Banco Nacional de Desenvolvimento Econômico (BNDES), foi estimado em 33 bilhões de reais. Trata-se de um incremento significativo quando comparado aos dezenove bilhões orçados à época do leilão da usina, em 2010.

O professor Célio Bermann $(2014)^{5}$ afirma que a obra de Belo Monte foi superdimensionada, pois a quantidade de água necessária para que a usina se mantenha em funcionamento estará disponível apenas por um período de três meses ao ano, o que, na prática, permite sua operação apenas nos meses de setembro e outubro, no período das chuvas, não produzindo mais do que 1 mil MW. Constata-se, assim, que o retorno econômico-financeiro dessa usina é relativamente baixo, com custos muito elevados. Para esse crítico do setor, além da limitada eficiência, os maiores beneficiários da energia gerada na região Norte, como Tucuruí, são, principalmente, as fábricas de aço e de alumínio utilizados para exportação.

O Painel de Especialistas ${ }^{6}$, formado por 38 pesquisadores voluntários que questionavam a qualidade e confiabilidade do Estudo de Impacto Ambiental (EIA) apresentado em 2009 pelo empreendedor responsável pela construção da usina para a obtenção da Licença Prévia (LP), dentre os vários artigos compilados, questionou a eficiência energética do projeto, apresentando dúvidas acerca da sua viabilidade técnica, econômica e social (MAGALHÃES; HERNANDEZ, 2009).

Assim sendo, apesar de a matriz energética resultar em grande parte de fontes renováveis, em especial a hidroeletricidade, o cenário atual aponta na direção de graves

\footnotetext{
${ }^{5}$ Conforme sustentado por Célio Bermann em entrevista ao sítio Viomundo: “A energia hidrelétrica não é limpa, nem barata". Publicada em 03 de junho de 2010. Disponível em: http://www.viomundo. com.br/entrevistas/bermann-a-energia-hidreletrica-nao-e-limpa-nem-barata.html. Acesso em: 10/04/2014.

${ }^{6}$ Em 2009, especialistas vinculados a diversas instituições de Ensino e Pesquisa identificaram e analisaram, de acordo com a sua especialidade, graves problemas e sérias lacunas no EIA de Belo Monte. O documento com a compilação de diversos artigos foi denominado PAINEL DE ESPECIALISTAS - Análise Crítica do Estudo de Impacto Ambiental do Aproveitamento Hidrelétrico de Belo Monte.
} 
impactos socioambientais, gerando inúmeros conflitos nas regiões onde são implantadas novas usinas hidrelétricas (BAINES, 2003).

A construção de grandes usinas hidrelétricas tem sido, apesar de tentativas de maquiagem pelas empresas com campanhas publicitárias, uma violência social e ambiental, que viabiliza um modelo perverso de lucros para as empresas construtoras e as empresas que utilizam a energia gerada sob tarifas subsidiadas. Aumentando, portanto, a concentração de capital e a exclusão social (BAINES, 2003).

Diante dos elementos até aqui ressaltados, observa-se que as populações locais, em suas práticas sociais e saberes, se encontram em situações de desequilíbrio em seu próprio território. Enfatizamos a percepção de que as obras do PAC se transformaram em um grande palco de ações governamentais e empresariais, transgredindo, em grande medida, direitos sociais e étnicos.

\subsection{OS IMPACTOS SOCIOAMBIENTAIS GERADOS PELA IMPLANTAÇÃO DE HIDRELÉTRICAS}

Conforme o Relatório da Comissão Mundial de Barragens (WCD), a construção de represas hidrelétricas em diversas partes do mundo e na Amazônia brasileira tem causado impactos sociais e ambientais significativos (WCD, 2000).

Diversos estudos apontam que o aumento das áreas desmatadas e da degradação dos ecossistemas em torno dos lagos de suas barragens incorrem em consequências imediatas para a população local, exacerbando conflitos fundiários, causando impactos diretos sobretudo para as condições de vida das populações mais vulneráveis, como as comunidades tradicionais, indígenas, ribeirinhas e quilombolas (KOIFMAN, 2001; ZHOURI; OLIVEIRA, 2007; KATSURAGAWA et al, 2009; QUEIROZ; MOTTA-VEIGA, 2012).

Sob a perspectiva ambiental, estudo realizado por Tundisi (2007) demonstra que a conectividade entre áreas alagadas, canais naturais, lagos, rios e pântanos possuem interações diretas e indiretas e de grande importância ecológica e econômica, com reflexos no ciclo social, impulsionando as principais atividades econômicas como a pesca, a exploração florestal, a aquicultura e a pecuária. Ainda segundo essa pesquisa, as pescarias artesanais na Amazônia 
empregam aproximadamente setenta mil trabalhadores, são a principal fonte de subsistência de 250 mil pessoas e produzem entre cem e duzentos milhões de dólares por ano (TUNDISI, 2007).

Tundisi (2007) sustenta também que os mecanismos de funcionamento dos ecossistemas terrestres e aquáticos na Amazônia apresentam um comportamento diferente de outros; algumas das suas funções próprias promovem alterações nas comunidades vegetais e animais, fator que requer uma atenção maior quando se implantam, na região, reservatórios para a geração de energia. Desse modo, a construção de grandes reservatórios pode alterar o transporte de sedimentos dos rios para os oceanos em grande escala, aumentando consideravelmente o tempo de retenção dos ecossistemas continentais; contribui também para o aumento da eutrofização e contaminação dos ambientes aquáticos, modificando as cadeias alimentares e produzindo uma diminuição do volume de água disponível (TUNDISI 2007).

De acordo com Schaeffer (1986), além do impacto gerado pelo barramento do rio, há mudanças advindas de seu planejamento, construção, operação e manutenção, mediante a modificação da estrutura socioeconômica e cultural regional. A consequência são desequilíbrios no mercado de trabalho, na infraestrutura e na organização geral da comunidade, ocasionados pelo fluxo migratório de pessoas à procura de emprego, pela especulação imobiliária, pela elevação dos preços, além de outros problemas (SCHAEFFER, 1986).

Outro grave distúrbio apontado em estudos sobre os impactos gerados pelas hidrelétricas é o deslocamento compulsório de populações. A realocação de povos que deixam seus locais de origem tem como consequências fortes alterações nos seus modos de vida. Vale destacar que a maior parte das famílias afetadas por esses empreendimentos pertence às áreas rurais: são ribeirinhos, posseiros, pequenos proprietários; uma menor parte, mas não menos importante, pertence aos núcleos urbanos (BESSA et al, 2011).

Bulcão (1994) sustenta que a construção de projetos hidrelétricos, com a consequente formação de um lago artificial, particularmente em região tropical, introduz importantes modificações no meio ambiente e, paralelamente, pode acarretar diversos riscos para a saúde das comunidades do entorno. Tais modificações à jusante do barramento provocam alterações no ecossistema, devido à modificação do fluxo do rio, ocasionando possíveis prejuízos à agricultura e ao abastecimento de água para comunidades ribeirinhas, além do processo de eutrofização do lago a montante, resultando na má qualidade da água potável (BULCÃO, 1994). 
Inúmeras transformações socioeconômicas e demográficas ocorrem simultaneamente aos impactos ambientais provocados pela implantação das hidrelétricas. Relativamente à saúde, os impactos que atingem diretamente a população local se vinculam diretamente ao advento de um extenso contingente de trabalhadores e familiares, atraídos pela possibilidade de emprego e aquisição de renda. Na medida em que se encontram expostos à precária infraestrutura, como a falta de saneamento básico, de assistência e de acesso à saúde, além do aumento da prostituição, essas populações se veem frequentemente acometidas por doenças sexualmente transmissíveis, num cenário que tende a se agravar (BULCAO, 1994; FERRETE et al, 2004).

Em consequência da pressão exercida pelo crescente fluxo migratório de trabalhadores, que resulta em uma maior demanda no fornecimento de serviços públicos - o que poderia ser equacionado por um melhor planejamento anteriormente ao início de tais empreendimentos -, observa-se um exacerbado agravamento do estado de saúde das populações locais diretamente atingidas (BULCÃO, 1994).

Katsuragawa et al (2009) ressaltam que a implantação das grandes usinas hidrelétricas gera inúmeros impactos - ambientais, socioeconômicos e epidemiológicos. Este último se relaciona estreitamente com o aumento das áreas alagadas permanentemente, em que a proliferação de vetores, principalmente a malária, se torna um sério problema de saúde na Região Norte.

Além dos agravos como a proliferação de doenças transmissíveis, relacionada ao crescimento populacional, é premente que se dê uma atenção especial a um dos mais graves problemas de saúde pública no Brasil, qual seja, as doenças crônicas não transmissíveis, assim como a exacerbação da violência e o aumento da ocorrência de acidentes. Esses prejuízos à saúde têm causado um alto impacto sobre a morbimortalidade da população, repercutindo em elevados custos sociais, econômicos, familiares e pessoais (BRASIL, 2013b).

Verificam-se destacados impactos sob a perspectiva ambiental, os quais podem impactar indiretamente a saúde, tais como os efeitos da decomposição da vegetação terrestre inundada, que deteriora a qualidade da água e ocasiona a perda de serviços ecossistêmicos. Outro aspecto debatido, e ainda controverso, no tocante à "energia verde" das hidrelétricas, diz respeito às emissões de gases de efeito estufa. Muitos consideram as hidrelétricas como uma fonte de energia livre de emissões gasosas. No entanto, estudos sobre o tema têm comprovado que as barragens emitem gases de efeito estufa em várias formas ao longo da execução desses projetos (FEARNSIDE, 2015). 
Até mesmo a construção das hidrelétricas de Santo Antônio e Jirau, em Porto Velho, no Estado de Rondônia, que utiliza tecnologias de ponta na área da construção civil, com a redução de alguns dos impactos sociais e ambientais mais frequentes, provoca importantes alterações ambientais, com consequentes impactos para a saúde humana. Segundo Ganem et al (2014), os impactos cumulativos e efeitos sinérgicos na região não foram considerados, resultando em condicionantes socioeconômicas insuficientes para compensar os prejuízos a que se submetem as populações locais. Para os autores, os impactos se potencializaram em virtude da cheia histórica ocorrida em 2014; argumentam que, sem uma avaliação estratégica para a região, os impactos e conflitos tendem a aumentar a cada novo empreendimento.

Como exposto, a implantação de grandes projetos hidrelétricos apresenta repercussões danosas tanto antes quanto durante e após a construção das usinas. As principais transformações ocorrem de fato durante a execução do projeto, tais como alterações culturais; desestruturação social das comunidades urbanas e rurais; flutuações econômicas; mudanças no uso do solo com a perda da biodiversidade das terras inundadas; prejuízo da boa qualidade das águas, com impactos sobre a pesca de subsistência e a agricultura, assim como diversas outras transformações, com efeitos sobre o local da obra e seu entorno (Quadro 2).

Quadro 2 - Principais intervenções nas etapas de implantação de uma hidrelétrica e os impactos/riscos à saúde

\begin{tabular}{|c|c|c|}
\hline Etapa & Intervenções / Ocorrências & Impactos / Riscos \\
\hline $\begin{array}{c}\text { Construção } \\
\text { (vias de acesso, canteiros } \\
\text { de obras, escavações) }\end{array}$ & 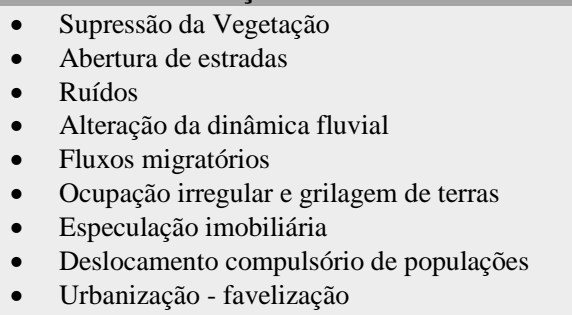 & $\begin{array}{l}\text { - Riscos de doenças de transmissão vetorial: } \\
\text { Malária, Leishmaniose, Febre Amarela, } \\
\text { Dengue, Esquistossomose } \\
\text { •Riscos de doenças sexualmente transmissíveis: } \\
\text { DSTs- Aids, Sífilis, Hepatites Virais } \\
\text {-Aumento de morbimortalidade por causas } \\
\text { externas } \\
\text {-Desestruturação social }\end{array}$ \\
\hline $\begin{array}{l}\text { Enchimento do } \\
\text { reservatório }\end{array}$ & $\begin{array}{l}\text { - } \quad \text { Captura de animais- Perturbação da Fauna } \\
\text { - } \quad \text { Inundação: áreas urbanas, áreas agricultáveis } \\
\text { - } \quad \text { Alteração nas espécies de peixes } \\
\text { - } \quad \text { Migração de peixes } \\
\text { - } \quad \text { Remoção forçada de populações }\end{array}$ & $\begin{array}{l}\text {-Riscos de epidemias pela proliferação de } \\
\text { vetores: malária, dengue, Febre Amarela } \\
\text { • Alteração na qualidade da água } \\
\text { •Inundação de sítios arqueológicos e sagrados } \\
\text { •Limitação na navegabilidade pelas populações } \\
\text { indígenas, ribeirinhos e outras }\end{array}$ \\
\hline Operação & $\begin{array}{l}\text { - } \quad \text { Formação de lagos } \\
\text { - } \quad \text { Inundação de florestas } \\
\text { - } \quad \text { Perda da biodiversidade } \\
\text { - } \quad \text { Perda de emprego e renda }\end{array}$ & $\begin{array}{l}\text { - Riscos de epidemias pela proliferação de } \\
\text { vetores: malária, dengue, Febre Amarela } \\
\text { • Alteração da qualidade da água }\end{array}$ \\
\hline
\end{tabular}

Fonte: elaborado por Missifany Silveira a partir de Britto (2014) e Rovere et al (2009). 
Todas as fases que compõem os projetos de construção das usinas se mostram igualmente importantes sob o ponto de vista do planejamento e das medidas de prevenção, que representam a base para o futuro das comunidades situadas nas localidades modificadas pela “desterritorialização" provocada por esses empreendimentos.

A respeito, vale destacar que é justamente nos impactos sociais que se cruzam as questões de qualidade de vida e bem-estar, e no espaço socioambiental se revelam as situações concernentes à saúde das populações que vivem nesses territórios (re)construídos pela implantação das hidrelétricas. Diversos estudos sobre os impactos socioambientais da implantação de hidrelétricas, no Brasil e no mundo, comprovam sua repercussão para a saúde individual e coletiva (QUEIROZ; MOTA-VEIGA, 2012).

Normalmente, as medidas mitigatórias de compensação dos impactos gerados pelos grandes projetos hidrelétricos são realizadas pelos empreendedores, que assumem o papel institucional para a resolução do problema. Essa situação, na maioria das vezes, gera conflitos por conta de as ações implementadas não incluírem a participação da sociedade na tomada de decisões (ZHOURI; OLIVEIRA, 2007).

Apesar da experiência negativa de Tucuruí no Pará, onde se verificaram inúmeros impactos socioeconômicos e epidemiológicos, os quais afetaram aldeias indígenas e outras populações tradicionais, a exploração do potencial hidrelétrico segue na Amazônia, com a instituição de novos projetos. Mesmo os empreendimentos hidrelétricos mais recentes, na região amazônica, ainda desconsideram os aspectos sociais, priorizando os interesses políticos e econômicos (QUEIROZ; MOTA-VEIGA, 2012).

Berta Becker, em seu livro A Urbe Amazônida, descreve as cidades como vetores de transformação na floresta "urbanizada" da Amazônia. Ressalta a autora que os pequenos núcleos, característicos da região, local em que convivem diferentes culturas do saber indígena, caboclo e grupos camponeses, constituem um contingente diferenciado e resistente da população, com características próprias. Esses núcleos se apresentam como locais de pouca infraestrutura, carecendo de atividades econômicas, o que os separam dos grandes movimentos de transformação na área. No entanto, alguns grupos camponeses se caracterizam pela resistência e, a despeito da expropriação de terras e das mudanças provocadas pela modernização, continuam com suas atividades em sistemas agroflorestais, mantendo assim a economia local em bases sustentáveis (BECKER, 2013). 
A respeito, Becker (2013) também sustenta que se deve atribuir valor econômico às florestas, mediante uma reorganização da base econômica da região, considerando as cidades amazônicas como redes para a criação de cadeias produtivas. Essas "Redes de cidades" podem implementar um novo padrão de desenvolvimento, "não predatório, e não mais em intensificações de riscos das tendências globais" (BECKER, 2013). Segundo a estratégia defendida pela autora, trata-se de "produzir para preservar". Assume-se como base logística as cidades, com fundamento na ciência e na tecnologia, de forma a se alcançar uma utilização social e econômica sustentável da Amazônia, resultando em grandes benefícios às populações regionais e ao país (BECKER, 2013). Para Vargas (2006) a questão central passa por compatibilizar a expansão da infraestrutura com o uso sustentável dos recursos naturais e o bem-estar das populações no sentido de superar conflitos entre as demandas nacionais e os direitos da população que vivem na região (VARGAS, 2006).

O cenário futuro para a Região Norte do país se pauta no planejamento e na construção de novas usinas hidrelétricas para a geração de eletricidade. Esse quadro apresenta prováveis efeitos negativos, sobretudo para as comunidades indígenas, já que as áreas demarcadas e as populações nelas residentes são afetadas diretamente por esses empreendimentos, que não respeitam as limitações instituídas, ocasionando a reprodução do mesmo modelo de desenvolvimento aplicado em décadas passadas (KOIFMAN, 2001).

Para Koifman (2001), os benefícios para o país, decorrentes da ampliação de recursos energéticos mediante empreendimentos do setor elétrico - crescimento da oferta de emprego e outros benefícios sociais -, caminham juntos com as ameaças cada vez mais evidentes ocasionadas por esse processo - perda da biodiversidade, prejuízo à qualidade de vida, saúde, cultura e sobrevivência das populações, sobretudo das comunidades indígenas (KOIFMAN, 2001).

Rosa (1989) argumenta que os prejuízos às comunidades indígenas da região é um dos graves problemas advindos da implantação de projetos hidrelétricos na Amazônia, pois as "terras indígenas ultrapassam os aspectos sociais e envolve o cultural e o ético". Para o autor, a energia elétrica específica para a região Amazônia poderia ser obtida por meio de outras formas alternativas, já que a energia produzida na área atende prioritariamente as regiões Sudeste e Nordeste (ROSA, 1989).

Considerando que a implantação de projetos de infraestrutura acarreta transformações significativas, consideramos que o planejamento das grandes hidrelétricas na Amazônia precisa 
estabelecer uma combinação da expansão da energia elétrica com a conservação dos processos ecológicos, sociais e econômicos. Vale ressaltar que os processos ecológicos nessa região são complexos e devem ser mantidos como força produtiva social e econômica da região (TUNDISI, 2007).

Vale destacar que há autores segundo os quais a avaliação dos elementos que permitem às comunidades tradicionais o exercício de sua capacidade de reorganização política e econômica, diante dos impactos gerados pelos grandes projetos, poderá "criar perspectivas para a sua existência e permitirá a contínua redefinição de sua identidade política" (ARAÚJO; BELO, 2009).

A reflexão sobre a dimensão da "invisibilidade e da intangibilidade nos estudos espaciais", dentre os vários discursos sobre a geografia cultural, é abordado por Almeida (2013) quanto à compreensão do espaço geográfico na contemporaneidade. Destacamos a importância desse aspecto para a compressão dos fatores analíticos que permeiam o discurso geográfico e, de certa forma, se conectam com o território. Para a autora, as "geografias emocionais", consideradas como intangíveis, são aquelas geradas, por exemplo, pelas migrações, e são "materializadas em um imaginário coletivo dos grupos por meio de recordações de paisagens e de lugares deixados sem qualquer relação com seus novos destinos” (ALMEIDA, 2013).

Essa "nova" perspectiva pode representar uma alternativa para compreensão dos espaços marginais impostos pelos poderes que cercam as mais diversas populações, transformando-as em atores invisíveis e sem protagonismo diante da complexidade dos impactos visíveis e latentes sobre o território.

Tendo em vista todos os aspectos abordados, a visão direcionada apenas ao desenvolvimento econômico, distante das questões sociais e ambientais das regiões que sofrem tais impactos, não é suficiente para viabilizar projetos de desenvolvimentos dessa magnitude em um cenário de sustentabilidade. Assim sendo, um modelo de desenvolvimento que não assume a devida responsabilidade social e ambiental se consolida como indutor de externalidades socioambientais, as quais são deduzidas das mesmas populações que cedem seus territórios aos grandes empreendimentos. 


\section{CAPÍTULO 2 - SAÚDE E AMBIENTE NO CONTEXTO DOS PROJETOS DE DESENVOLVIMENTO}

\subsection{DESENVOLVIMENTO, AMBIENTE E SAÚDE: FATORES RELEVANTES PARA A SUSTENTABILIDADE DOS GRANDES PROJETOS DE INFRAESTRUTURA}

A partir da década de 1970, as questões relativas à conservação e à preservação dos recursos naturais obtiveram maior destaque nas discussões sobre a qualidade de vida. Somente então determinados aspectos como o dilema do desenvolvimento em contraponto à preservação e conservação, no contexto do fenômeno do crescimento demográfico, passaram a ser foco das discussões de forma mais ampla (COSTA, 2005).

A expressão "desenvolvimento sustentável” assumiu uma esfera global, circulando no mundo a partir do Relatório da Comissão de Brundtland, apresentado à Assembleia Geral da Organização das Nações Unidas (ONU), em 1987. Nesse momento, a gestão ambiental se desenvolveu de modo a se configurar como que atualmente se entende por gestão da sustentabilidade (ALMEIDA, 2002).

A busca por um consenso e conciliação entre a crítica ambiental e a sociedade industrial, no âmbito de seus diversos interesses, atingiu o ápice com a proposta da Agenda 21, principal documento resultante da Conferência Rio-92, que, ao longo dos seus quarenta capítulos, propõe bases para ações no âmbito global (CORDANI et al, 1997). Após mais de vinte anos do lançamento da Agenda 21, definida na ocasião como marco importante no cenário mundial em que, como vale ressaltar, conferiu-se ênfase à saúde como tema fundamental no que se refere à proteção e à promoção da saúde humana -, ainda persiste a busca por compromissos que reiterem e avancem a relação essencial da saúde com o desenvolvimento sustentável.

Após a Rio+10, realizada na África do Sul em setembro de 2002, um balanço sobre as condições socioambientais do planeta revelou o agravamento da degradação ambiental e da expropriação dos recursos humanos e naturais (COSTA, 2005). Confirmou-se, desse modo, a premência de se repensarem os conceitos consagrados na década de 1990. Entre eles, encontram-se aqueles entrelaçados pela ideia de desenvolvimento sustentável, como biodiversidade, justiça social, direitos humanos e desenvolvimento social. 
A Organização Mundial da Saúde (OMS) criou, em 2005, a Comissão para os Determinantes Sociais da Saúde (Comission on Social Determinants of Health), com o fim de orientar ações no âmbito de um movimento global, combinando políticas e programas, com vistas à diminuição das iniquidades no campo da saúde entre os diferentes grupos sociais (OMS, 2011).

A Declaração da Conferência Mundial sobre Determinantes Sociais da Saúde, realizada no Rio de Janeiro em outubro de 2011, destacou a necessidade de uma atuação precisa sobre os determinantes sociais para a redução das iniquidades em saúde. Para tanto, consideramos urgente a implementação de políticas no sentido de aperfeiçoar as condições de saúde, com a concomitante promoção de coesão social e de desenvolvimento econômico.

Há uma maior compreensão de que a saúde contribui para outras questões, como a coesão social e o desenvolvimento econômico, e de que é preciso coordenar esforços dos diferentes setores para melhorar as condições de saúde (OMS, 2011).

Nas últimas décadas, apesar do forte crescimento econômico e do sucesso de alguns países em alcançar os Objetivos do Desenvolvimento do Milênio (ODMs), observamos a continuidade do aumento das disparidades e desigualdades sociais e de gênero, além da deterioração crescente do ambiente (WHO, 2012).

No entendimento de diversos pesquisadores, é importante prosseguir na implementação dos princípios de desenvolvimento sustentável. Nesse movimento, inúmeros países, representados pelo meio acadêmico e pelos tomadores de decisão, já conseguiram avançar no sentido da criação de mecanismos que visem um ajuste ao modelo de desenvolvimento até então vigente. O chamado “Objetivos do Desenvolvimento Sustentável” (Sustainable Development Goals, no original em inglês) se apresenta como um conjunto de metas complementares aos ODMs, com a proposta de ações tanto para países em desenvolvimento como para as nações mais desenvolvidas, sob a finalidade comum de se atingirem as metas acordadas na Rio+10 (BUSS et al, 2012).

As políticas sociais e econômicas são determinantes para a qualidade de vida de uma população. Assim, é possível afirmar que o patamar de desenvolvimento de uma sociedade depende da qualidade da saúde de sua população, da distribuição do espaço social e da qualidade de assistência e proteção em situações nas quais a saúde é deficitária (CDSS, 2010). Para o enfrentamento das conjunturas negativas decorrentes de mudanças ambientais faz-se 
necessária a articulação conjunta de medidas no âmbito do meio ambiente, da saúde e do desenvolvimento socioeconômico com vistas à implementação das ações fundamentais à sustentabilidade.

O movimento em prol da intersetorialidade entre as áreas da saúde, meio ambiente e desenvolvimento, presente nas agendas governamentais, em fóruns de discussões, conferências e no meio acadêmico, requer a existência de maiores articulações para no sentido de se configurar uma visão mais ampla dos fatores ambientais de risco, decorrentes das atividades humanas, com o objetivo de prevenir e controlar os efeitos ambientais adversos à saúde humana.

\subsubsection{Relação entre os processos de desenvolvimento, ambiente, saúde e as situações de risco}

Ao longo das últimas décadas, observou-se o progressivo aumento em escala global das pressões sobre os ecossistemas, os quais têm se exaurido, numa configuração de ameaças à capacidade de suporte do que até então a natureza poderia prover às atividades humanas. A Organização Mundial da Saúde (OMS) alerta constantemente sobre como a utilização não sustentável dos ecossistemas eleva o potencial de mudanças ecológicas para um quadro negativo e prejudicial à saúde humana. Não obstante, os Objetivos de Desenvolvimento do Milênio (ODMs), centrados na redução da pobreza, da fome e das doenças, sofrerão sério comprometimento se não houver uma reversão das perdas nos serviços providos pelos ecossistemas (OPAS, 2005).

Há autores segundo os quais o crescimento econômico, normalmente desenvolvido em bases insustentáveis, acarreta pressões frequentes sobre os estoques naturais dos serviços ecossistêmicos sobretudo pela degradação dos recursos naturais e pelo aumento das desigualdades sociais (PHILIPPI; MALHEIROS, 2005).

As modificações ambientais provocadas pela ação do homem - consumo exacerbado, alteração e poluição contínua dos recursos naturais sem critérios adequados e o devido planejamento - ampliam o risco de exposição das populações às doenças, com reflexos diretos sobre a qualidade de vida em esfera global (PHILIPPI; MALHEIROS, 2005). As mudanças sobre as condições de trabalho e os modos de vida provocam o aumento dos perfis de exposição 
humana a substâncias químicas e outros processos destrutivos, expressos no surgimento de novas patologias (BREILH, 2008).

Em especial nas grandes cidades, tanto no Brasil como no mundo, a degradação das condições ambientais, sociais e da qualidade de vida crescem de forma alarmante, no contexto de incertezas científicas, consequências irreversíveis dos danos ambientais e conflitos de interesses (LUCENA, 2005). Em 2005, conforme pesquisa do Instituto Brasileiro de Geografia e Estatística (IBGE), 2.263 (41\%) dos 5.560 municípios brasileiros informaram a ocorrência de alteração ambiental que afetou as condições de vida da população (IBGE, 2006).

No que diz respeito a esse aspecto, a gestão ambiental assumiu papel de destaque nas discussões das agendas e pautas governamentais, universidades e instituições de pesquisa relativamente aos processos produtivos e os riscos socioambientais, na busca de instrumentos que minimizem os impactos das atividades envolvidas nesses processos (LUCENA, 2005).

No âmbito das características próprias da modernidade, do desenvolvimento e do conhecimento científico e tecnológico estabelecido, e a partir das pressões exercidas pelos movimentos socioambientais, o conceito de externalidades deixou de ser considerado como a "não incorporação de bens ambientais nos cálculos econômicos das empresas, por serem considerados bens livres e gratuitos" (LUCENA, 2005), para ser discutido então sob a perspectiva dos danos provocados pela sociedade industrial. Os custos da utilização desenfreada dos recursos ambientais e a consequente diminuição da capacidade de suporte dos ecossistemas nem sempre são computados pelo sistema econômico. Assim sendo, o custo ambiental não é distribuído pelo mercado, ou seja, nele não é incorporada a deterioração e o esgotamento dos recursos naturais. Desse modo, são geradas as externalidades ambientais (HAUGHTON; HUNTER, 2004).

Os problemas concernentes à saúde também são tratados como externalidades, uma vez que os custos sociais, ambientais e sanitários permanecem ocultos nos preços de produtos e serviços para, por fim, serem socializados. Diante dessa circunstância, a discussão sobre o tema tem alcançado mais espaço no campo da saúde pública (SOARES; PORTO, 2007). Trata-se de um contexto que nos permite ampliar o olhar sobre a relação saúde-ambiente a partir dos processos sociais e econômicos de desenvolvimento, no intuito de minimizar o entrave à sustentabilidade. 
Diversos estudos e pesquisas que se debruçam sobre os problemas à saúde, ao trabalho e ao meio ambiente, particularmente no campo da saúde pública no Brasil, se defrontam com grupos populacionais vulneráveis e expostos a diversos e graves riscos ocupacionais e ambientais (PORTO; FREITAS, 1997). Relativamente a esses perigos, destacam-se os acidentes de trabalho, os desastres ambientais e, ainda, os efeitos crônicos provocados pela exposição a substâncias químicas perigosas em áreas de risco, como os ambientes de trabalho, ou moradias em áreas contaminadas por resíduos perigosos. Sob essa ótica, as populações consideradas vulneráveis são as maiores vítimas de um modelo de desenvolvimento marcado pela injustiça ambiental (PORTO; FREITAS, 1997).

A respeito, Lucena (2005) argumenta que, na sociedade industrial, ocorre a minimização dos riscos por meio de alternativas com foco apenas na diminuição das possibilidades de ocorrência de acidentes em indústrias consideradas de alto impacto ambiental. Nesse contexto, não existe esforço satisfatório quando se trata de minimizar os danos socioambientais, pois o que normalmente se observa é a inexistência de informações suficientes sobre os possíveis impactos para diferentes áreas, como ocorre na saúde (LUCENA, 2005).

O tema justiça ambiental se tornou objeto de maior atenção por parte dos movimentos sociais em prol do desenvolvimento de ações coletivas que divulguem informações ao público sobre as fontes dos riscos ambientais, com o objetivo de enfrentar as situações que provoquem injustiças ambientais no país (DAMASCENO; SANTANA JUNIOR 2011). Nesse sentido, há de se destacar que o termo justiça ambiental surgiu nos Estados Unidos a partir dos movimentos de luta por direitos civis contra a apropriação desigual dos recursos ambientais e contra o tratamento injusto e danoso das populações marginalizadas e vulneráveis. Estas passaram a compreender que há uma relação direta e estreita entre a qualidade do seu local de trabalho, da sua comunidade e da sua saúde (DAMASCENO; SANTANA JUNIOR, 2011).

Nessa mesma perspectiva, Acselrald et al. (2009) reafirmam o conceito de Justiça Ambiental como "o nexo inovador entre a questão social e a questão ambiental". A noção, assim, apresenta-se como estratégia de combate contra as injustiças ambientais, em que os riscos ambientais recaem sobre "populações menos dotadas de recursos financeiros, políticos e informacionais" (ACSELRALD et al., 2009). A concepção de Justiça Ambiental, considerada a partir de um conjunto de princípios e práticas, surge com o intento de superação das formas variadas de injustiça e desigualdade, na procura de modelos alternativos de desenvolvimento 
não excludentes, assegurando o acesso e o uso sustentável dos recursos naturais (ACSELRAD et al, 2009).

Quando se referem aos conflitos socioambientais e à proteção da sociobiodiversidade, marcada pela interação entre bens ambientais, sociais, culturais e étnicos, bem como pela busca da garantia de justiça ambiental, determinados autores ressaltam que o próprio Direito Ambiental ainda apresenta limitações e insuficiências para abarcar a complexidade da questão (CAVEDON; VIEIRA, 2011). Dessa forma, considerando-se as fragilidades socioeconômicas e informacionais para uma maior proteção socioambiental, destacamos a premência de uma abordagem mais ampla, que integre os fatores socioeconômicos, políticos, culturais e étnicos.

De acordo com pesquisadores das questões socioambientais e seus conflitos, diversos empreendimentos, industriais ou não, podem gerar "injustiças ambientais", na medida em que, ao serem implementados, acarretam riscos e danos às camadas mais vulneráveis da sociedade, que são então excluídos do processo de desenvolvimento (ZHOURI et al, 2005). Nessa perspectiva, a construção de hidrelétricas, que ocupa grandes extensões territoriais, quase sempre transferindo os prejuízos aos segmentos sociais mais vulneráveis como as populações ribeirinhas e comunidades étnicas, tem provocado impactos socioambientais, com custos que incidem diretamente sobre os povos locais. Ou seja, nessas localidades, os atores sociais não são considerados sujeitos ativos no processo de decisão a respeito dos usos dos recursos naturais ali existentes (ZHOURI et al, 2005).

Ab’Sáber e Muller-Plantenberg (2006) ressaltam que, durante a implantação desses grandes projetos de desenvolvimento, o cenário é constituído por diversos conflitos socioambientais, o que se reflete nos graves impactos sobre as comunidades locais e sobre um significativo contingente de povos indígenas. Os autores destacam ainda que "para estas comunidades a demarcação de terras e os programas de saúde são uma precondição para a sua sobrevivência" (AB'SABER; MULLER-PLANTENBERG, 2006).

Os problemas decorrentes da degradação ambiental, assim como sua interferência na qualidade de vida da população, requerem uma ampla discussão e reflexão a respeito, na medida em que a expansão dos projetos de desenvolvimento pode colocar em risco a saúde das comunidades nas áreas afetadas e até mesmo em âmbito global. A implantação de grandes empreendimentos é um dos fatores indutores de externalidades, tendo em vista o aumento dos custos dos serviços públicos de saúde, bem como das mudanças culturais e sociais enfrentadas pelas populações nos territórios onde se instalam tais projetos (SILVEIRA, 2010). 
Apesar dos avanços identificados, os princípios de proteção ambiental e do desenvolvimento sustentável ainda se configuram como um entrave para o crescimento econômico (JACOBI, 2007). Na ideologia do crescimento sustentável, compreende-se que o desenvolvimento socioeconômico pode e precisa continuar, mas de forma politicamente compatibilizada com a sustentabilidade ecológica e a justiça social (CARNEIRO, 2005). No entendimento de Oliveira e Câmara (2004), os processos de desenvolvimento social e econômico repercutem sobre as relações que ocorrem nos ecossistemas, ocasionando impactos na saúde dos seres humanos. Portanto, se as principais atividades responsáveis por tais desdobramentos se referem aos processos de produção, requer-se um maior comprometimento dos responsáveis na execução de ações referentes à prevenção, ao controle dos riscos e à promoção da saúde.

Segundo a OPAS (2005), uma proposta de inserção de questões inerentes à saúde humana nos projetos, planos e programas de governo, como uma ação sistemática, pode contribuir para o movimento estabelecido em âmbito global. Dessa maneira, o processo de desenvolvimento encontra-se vinculado à proteção do meio ambiente e da saúde, com o objetivo de se alcançar a devida sustentabilidade socioambiental.

\subsection{O PAPEl Da SAúde ambiental Nas políticas públicas e No DESENVOLVIMENTO SUSTENTÁVEL}

O modelo de desenvolvimento socioeconômico vigente representa uma das causas mais expressivas dos problemas sociais da humanidade, atualmente observados sobretudo no que concerne ao meio ambiente e à saúde, áreas que são particularmente reveladoras dessas causas. Estima-se que $24 \%$ da carga de doença e $23 \%$ de todas as mortes, no mundo, podem ser atribuídas a fatores ambientais. Esse impacto se acentua em grupos nos quais a desigualdade se reflete com maior intensidade na saúde. Segundo a OMS, seria possível prevenir um quarto dessas ocorrências pela redução dos fatores dos riscos ambientais (WHO, 2014).

A complexidade dos problemas socioambientais e a múltipla determinação social da saúde - questões básicas como moradia, saneamento, trabalho, a renda, educação e acesso aos serviços de saúde - dependem de uma abordagem sistêmica, interdisciplinar e intersetorial das questões referentes ao desenvolvimento. Esse quadro permite analisar as inter-relações causais 
entre os impactos ambientais e seus efeitos sobre a saúde humana, rompendo com o modelo clássico do processo saúde/doença. Nesse sentido, para se reforçar a exigência de um movimento integrador na construção de consensos e na execução de agendas, a fim de se estabelecerem políticas públicas cada vez mais favoráveis à promoção da saúde e da vida, fazse necessária a reflexão atenta sobre o papel do desenvolvimento sustentável diante das dissonâncias entre os setores produtivos e as relações do meio ambiente com a saúde humana.

Em se tratando da inter-relação entre saúde, meio ambiente e desenvolvimento, nas décadas de 1970 e 1980 observam-se períodos de marcada importância para o estabelecimento de discussões importantes a respeito do tema no mundo. É o caso da Conferência de Estocolmo na Suécia, que se destacou pelas críticas ao processo de industrialização e seus impactos; a Declaração de Alma-Ata, um marco para a incorporação das dimensões sociais, políticas, culturais e econômicas e sua relação com a saúde; a Conferência Internacional sobre Promoção da Saúde - com a Carta de Ottawa. e o Relatório de Brundtland, que apresentou críticas ao modelo de desenvolvimento adotado e aos padrões de produção e consumo. No Brasil, a VIII Conferência Nacional de Saúde, com foco na reforma sanitária, redefiniu o conceito de saúde como direito social e universal.

A década de 1990 no Brasil foi marcada por dois momentos significativos no âmbito da saúde e do desenvolvimento sustentável: a aprovação da Lei Orgânica do Sistema Único de Saúde e a Conferência das Nações Unidas sobre o Meio Ambiente e Desenvolvimento (CNUMAD), conhecida como Rio-92.

Vale ressaltar que todos os movimentos apontados acima contribuíram para a elaboração de políticas e estratégias referentes à saúde e ao ambiente, configurando o que hoje se conhece por saúde ambiental. Formalizado pela OMS em 1993, no encontro realizado na cidade de Sofia, na Bulgária, o campo da Saúde Ambiental foi reconhecido no documento final, denominado de Carta de Sofia, em que se definia o conceito da seguinte maneira:

Todos aqueles aspectos da saúde humana, incluindo a qualidade de vida, que estão determinados por fatores físicos, químicos, biológicos, sociais e psicológicos no meio ambiente. Também se refere à teoria e prática de valorar, corrigir, controlar e evitar aqueles fatores do meio ambiente que, potencialmente, possam prejudicar a saúde de gerações atuais e futuras (OPS/OMS, 1993).

Posteriormente, em revisão da Organização Mundial de Saúde para a Europa WHO/EURO, apresentou-se uma nova definição: 
Saúde ambiental é o que abarca aqueles aspectos da saúde e enfermidades humanas que são determinadas por fatores ambientais. Também se referem a teoria e prática da avaliação e controle dos fatores ambientais que podem afetar a saúde (ORDÓÑEZ, 2000).

No Brasil, as ações na esfera da saúde ambiental eram operacionalizadas pelo antigo Centro Nacional de Epidemiologia (CENEPI), ocasião em que se constituiu uma área especifica denominada "vigilância ambiental em saúde" (VAS), com a finalidade de identificar medidas de prevenção e controle dos fatores de risco ambientais que interferem na saúde humana.

A vigilância em saúde ambiental consiste em um conjunto de ações que proporcionam o conhecimento e a detecção de mudanças nos fatores determinantes e condicionantes do meio ambiente que interferem na saúde humana, com a finalidade de identificar as medidas de prevenção e controle dos fatores de risco ambientais relacionados às doenças ou a outros agravos à saúde (BRASIL, 2007b).

A atuação específica para a saúde ambiental, atualmente, encontra-se a cargo do Ministério da Saúde, que, desde 2003, é responsável pelas ações elaboradas para a área. Cabe ao MS também a condução do processo para a instituição da Política Nacional de Saúde Ambiental, por meio da Coordenação Geral de Vigilância Ambiental em Saúde (CGVAM), na Secretaria de Vigilância em Saúde (SVS). Nesse contexto, o setor saúde no Brasil define saúde ambiental como:

Área da saúde pública afeta ao conhecimento científico e a formulação de políticas públicas relacionadas à interação entre a saúde humana e os fatores do meio ambiente natural e antrópico que a determinam, condicionam e influenciam, com vistas a melhorar a qualidade de vida do ser humano, sob o ponto de vista da sustentabilidade (BRASIL, 2007b).

As principais ações e diretrizes para a consolidação da política nacional no âmbito do SUS se iniciaram a partir dos anos 2000. O primeiro seminário sobre a Política Nacional de Saúde Ambiental (PNSA), realizado em 2005, teve como objetivo abordar a saúde ambiental como um campo de práticas intersetoriais e transdisciplinares, a fim de orientar políticas públicas formuladas por intermédio da utilização do conhecimento e com a participação social (RADICCHI; LEMOS, 2009). Com a finalidade de trabalhar o tema de forma ampliada e em consonância com os princípios e as diretrizes do Sistema Único de Saúde (SUS), em 2007, o Conselho Nacional de Saúde, em parceria com a CGVAM, lançou o documento "Subsídios para a construção da Política Nacional de Saúde Ambiental” (RADICCHI; LEMOS, 2009). 
Inúmeras outras iniciativas no campo da saúde ambiental no Brasil têm recebido maior destaque, por meio de programas já consolidados, com ênfase para os Programas de Vigilância da Qualidade da Água para Consumo Humano (VIGIAGUA); Vigilância em Saúde de Populações Expostas a Contaminantes Químicos (VIGIPEQ), e Vigilância em Saúde em Situação de Desastres (VIGIDESASTRES) - apenas para citar os mais destacados. No entanto, esse documento reafirma a posição do Ministério da Saúde em empenhar a implantação do Sistema de Vigilância em Saúde Ambiental, visando o aprimoramento do modelo de atuação nos Estados brasileiros, com ações voltadas para a saúde no tocante à degradação e à contaminação ambiental (BRASIL, 2011a).

Nesse sentido, as discussões também se ampliaram no contexto dos projetos de desenvolvimento e saúde, no âmbito do Departamento de Vigilância em Saúde Ambiental e Saúde do Trabalhador (DSAST), do Ministério da Saúde, e na esfera dos processos de licenciamento ambiental (SILVEIRA, 2010). Com atuação nesses processos desde 2005, o DSAST, antiga CGVAM, é o órgão responsável em propor e recomendar os aspectos da saúde relacionados à implantação de empreendimentos no âmbito federal, por solicitação do Ibama. Entretanto, seu desempenho se mostra ainda marcadamente pontual (SILVEIRA, 2008), como será abordado a seguir.

\subsubsection{Avaliação de Impacto Ambiental (AIA): conexão possível entre saúde e meio ambiente}

A avaliação e a gestão de riscos ambientais para a saúde são de fundamental importância e deveriam ser consideradas como base para o desenvolvimento de políticas na área da saúde, estendendo-se sua aplicação para os demais setores prioritários, como energia, transportes, agricultura e indústria. No Brasil, no entanto, as discussões sobre a possibilidade de uma avaliação multidisciplinar, que considere os impactos da modificação do meio ambiente sobre a saúde da população, sobretudo durante a implantação de projetos de desenvolvimento potencialmente poluidores são ainda bastante incipientes (SILVEIRA, 2008).

Apesar de inúmeras e claras disposições relativas à saúde humana na legislação ambiental infraconstitucional - principalmente no tocante à Lei $\mathrm{n}^{\circ} 6.938 / 81$, que dispõe sobre a Política Nacional de Meio Ambiente (PNMA), e à Resolução CONAMA nº 001/86, que versa 
acerca dos critérios básicos e diretrizes gerais para a avaliação de impacto ambiental (BRASIL, 2008c) -, a negligência das questões relacionadas à saúde humana, durante os processos de licenciamento de grandes projetos de desenvolvimento, é evidente (SILVEIRA, 2008).

Sob essa perspectiva, apesar das fragilidades institucionais e técnicas, o setor saúde tem procurado estar presente nos processos de licenciamento ambiental de grandes empreendimentos, com participação ativa no sentido de inserir ações e medidas relativas à saúde quando da implementação desses projetos. Visa-se, desse modo, a construção de territórios mais sustentáveis ambiental e socialmente (SILVERA, 2010). Com base nesse pressuposto, alguns estudos no âmbito do licenciamento ambiental de grandes empreendimentos apontam para o fato de que a participação do setor saúde nesses processos ainda requer discussões mais abrangentes e propostas metodológicas suficientes para avaliar os aspectos específicos da saúde. Consideram, assim, que os instrumentos legais e institucionais necessitam de aperfeiçoamento, para que tais aspectos sejam abarcados de forma mais abrangente.

\subsubsection{O setor saúde e os processos de licenciamento ambiental de grandes empreendimentos no Brasil: instrumentos, limitações e desafios}

A Avaliação de Impacto Ambiental (AIA) foi a primeira ferramenta específica na área em uso corrente no Brasil. Implantada como um dos instrumentos da Política Nacional de Meio Ambiente (PNMA), pela Lei $n^{\circ}$ 6.938/81, somente a partir da Resolução CONAMA n ${ }^{\circ}$ 01, de 23 de janeiro de 1986, estabeleceram-se as definições, responsabilidades, critérios e diretrizes gerais para seu uso e implementação. Essa resolução vinculou a AIA ao licenciamento ambiental de atividades potencialmente poluidoras, definindo como um dos instrumentos de avaliação de impactos o Estudo de Impacto Ambiental e seu Respectivo Relatório (EIA/RIMA) (BRASIL. 2008c). A obrigatoriedade desses estudos representou um marco para o desenvolvimento do ambientalismo brasileiro, dado que, até meados da década passada, nos projetos de empreendimentos apenas eram consideradas as variáveis técnicas e econômicas, sem qualquer preocupação mais elaborada com o meio ambiente, em contraste com o interesse público (MILARÉ, 2006). 
Há de se ressaltar a forma como os debates e as discussões sobre os problemas causados mediante os impactos de grandes empreendimentos marcaram a preparação e a institucionalização do licenciamento ambiental, entre os anos de 1970 e 1980, consolidando-o como um dos principais instrumentos da PNMA. Apesar de não consistir em um mecanismo satisfatório para a sustentabilidade, esse instrumento representou um marco histórico importante e de extrema relevância para as medidas de prevenção dos impactos sociais e ambientais decorrentes do desenvolvimento (ZHOURI et al, 2005).

O licenciamento ambiental é uma obrigação legal prévia à instalação de qualquer empreendimento ou atividade potencialmente poluidora ou degradadora do meio ambiente em determinado território; possui como uma de suas mais expressivas características a participação social na tomada de decisão, por meio da realização de Audiências Públicas como parte do processo (SILVEIRA, 2008). Trata-se de dispositivo que compreende um processo de três etapas, nas quais são estabelecidas condicionantes a serem cumpridas pelo empreendedor para a obtenção das licenças ambientais, ou seja, a Licença Prévia (LP), a Licença de Instalação (LI) e a Licença de Operação (LO) (BRASIL, 2008c).

O modelo de Avaliação de Impacto Ambiental (AIA) tem sua estrutura concebida para obtenção das três licenças, como mencionado, para as fases de planejamento, construção e operação de grandes projetos de infraestrutura, prevendo assim, as consequências futuras sobre a qualidade ambiental com a implantação de uma obra e as possíveis medidas de mitigação e compensação dos impactos gerados.

A difusão da AIA teve repercussão internacional com a Conferência das Nações Unidas sobre Meio Ambiente, na Rio -92, estabelecendo como princípio na Declaração do Rio seu conceito, além de reconhecer, por meio da Agenda 21, AIA como instrumento para estimular o desenvolvimento sustentável (SÁNCHEZ, 2013).

A importância dos aspectos ambientais no âmbito da saúde recebeu destaque na III Conferência Nacional de Saúde, realizada no Brasil em 1963. O foco na questão se ampliou na VIII Conferência Nacional de Saúde, em 1986. A coparticipação entre os setores saúde e meio ambiente está especificada na Constituição Federal de 1988 (Art. 200, inciso VIII), encontrando-se inserida no campo de atribuições do Sistema Único de Saúde (SUS). Ressaltamos ainda a existência de outros instrumentos normativos a respeito, como as Resoluções do Conselho Nacional de Meio Ambiente (CONAMA) (SILVEIRA, 2008). Nesse aspecto, um importante instrumento é a Resolução CONAMA nº. 01, de 23 de janeiro de 1986, 
que explicita de forma clara a importância dos impactos ambientais quando "das alterações causadas por qualquer atividade que direta ou indiretamente afetam a saúde humana" (BRASIL, 2008c).

A participação do setor saúde nos processos de licenciamento ambiental é discricionária, com fundamento no $\S 1^{\circ}$ do Art. $4^{\circ}$ da Resolução CONAMA n ${ }^{\circ} .237 / 97$, segundo o qual o Ibama realizará o licenciamento:

[...] após considerar o exame técnico procedido pelos órgãos ambientais dos Estados e Municípios, em que se localizar a atividade ou empreendimento, bem como, quando couber, o parecer dos demais órgãos competentes da União, dos Estados, do Distrito Federal e dos Municípios, envolvidos no procedimento de licenciamento" (BRASIL, 2008c - grifo nosso).

É importante salientar que a Resolução CONAMA n 001/1986 já versava sobre o impacto ambiental:

\footnotetext{
Artigo $1^{\circ}$ - Para efeito desta Resolução, considera-se impacto ambiental qualquer alteração das propriedades físicas, químicas e biológicas do meio ambiente, causada por qualquer forma de matéria ou energia resultante das atividades humanas que, direta ou indiretamente, afetam:

I - a saúde, a segurança e o bem-estar da população;

II - as atividades sociais e econômicas;

III - a biota;

IV - as condições estéticas e sanitárias do meio ambiente;

$\mathrm{V}$ - a qualidade dos recursos ambientais. Com esta definição, podem-se entender como impacto (BRASIL, 2008c - grifo nosso).
}

Entretanto, no âmbito do SUS, o primeiro marco legal a evidenciar a inserção das questões de saúde no licenciamento ambiental é a Resolução CONAMA nº. 286/2001, que "dispõe sobre o licenciamento ambiental de empreendimentos nas regiões endêmicas de malária" (BRASIL, 2008c). Além desse dispositivo, outros dois instrumentos normativos vinculam a participação do setor saúde ao licenciamento ambiental, quais sejam: a Resolução CONAMA n". 387/2006, que "Estabelece procedimentos para o Licenciamento Ambiental de Projetos de Assentamentos de Reforma Agrária” (BRASIL, 2008c), e atualmente a Portaria nº 1, de 13 de janeiro de 2014, que:

Estabelece diretrizes, procedimentos, fluxos e competência para obtenção do Laudo de Avaliação do Potencial Malarígeno (LAPM) e do Atestado de Condição Sanitária (ATCS) de projetos de assentamento de reforma agrária e outros empreendimentos sujeitos ao licenciamento ambiental em áreas de risco ou endêmica para malária (BRASIL, 2014a). 
Vale ressaltar que a referida portaria exige do empreendedor a elaboração do Plano de Ação para o Controle da Malária (PACM) como requisito para a obtenção da Licença Prévia e de Instalação (LP e LI), quando da implantação de empreendimentos na região de risco ou endêmica de malária, limitando-se, portanto, à região da Amazônia Legal. Essa peculiaridade expõe a fragilidade do setor saúde para atuar em empreendimentos localizados em outras regiões brasileiras.

Destaca-se ainda que a primeira aproximação entre os setores de meio ambiente e saúde em âmbito federal, apesar do marco regulatório exposto acima, ocorreu somente em 2004, após o órgão de controle federal questionar a ausência do setor saúde no processo de licenciamento ambiental de empreendimentos licenciados pelo Ibama (BRASIL, 2004) ${ }^{7}$. A partir desse marco, o órgão ambiental passou a reconhecer o setor saúde como "instituição envolvida no processo de licenciamento" (SILVEIRA, 2008) a fim de se posicionar pontualmente nos processos de licenciamento ambiental de empreendimentos, por meio das análises elaboradas nos Estudos de Impacto Ambiental (EIA/RIMA), nos Planos Básicos Ambientais (PBA), além dos Termos de Referência (TR) e das complementações pertinentes. Cabe destacar também que não existe ferramenta de avaliação de impacto na saúde especificamente dirigida aos processos de licenciamento ambiental. Quando solicitado o parecer técnico pelo Ibama, o setor saúde apresenta suas recomendações nos TR, EIA/RIMA e PBA, com a finalidade de subsidiar as licenças ambientais (SILVEIRA, 2010).

Os resultados da pesquisa realizada por Silveira (2008), com base nos dados do MS/DSAST durante o período de 2004 a 2007, demonstraram a forma como o setor saúde tem participado dos processos de licenciamento ambiental em esfera federal (SILVEIRA, 2008). O estudo permitiu identificar, a partir do cruzamento dos dados analisados com o Sistema de Informação de Licenciamento Ambiental (Sislic) do Ibama, se as recomendações do setor saúde eram incorporadas como requisitos prévios das Licenças Ambientais emitidas pelo Ibama.

O estudo identificou 22 empreendimentos de diferentes tipologias, dos quais foram examinadas 36 análises ambientais pelo setor saúde, incluindo: TR, EIA/RIMA, PBA e complementações. A partir do diagnóstico obtido, verificou-se que, do total do que examinado pelo setor saúde, apenas em dezoito empreendimentos (50\%) se incorporou algum tipo de

\footnotetext{
${ }^{7}$ O Ministério Público Federal do Mato Grosso do Sul solicita posição técnica do Ministério da Saúde sobre o Relatório de Impacto Ambiental (RIMA) relativo à presença de mercúrio no Gasoduto que estava em processo de licenciamento pelo Ibama em 2004 (BRASIL, 2004).
} 
recomendação como condicionante às licenças ambientais emitidas pelo órgão ambiental federal (Quadro 3). De acordo com a pesquisa, uma das razões - ou limitações - a explicar essa porcentagem, já que as recomendações relativas à saúde não são consideradas como requisitos para a concessão das licenças ambientais, foi a falta de critérios definidos pelo Ibama para a solicitação de posicionamento técnico ao setor saúde.

Quadro 3 - Participação do setor saúde nos processos de licenciamento ambiental de empreendimentos, no âmbito federal, no período de 2004 a 2007

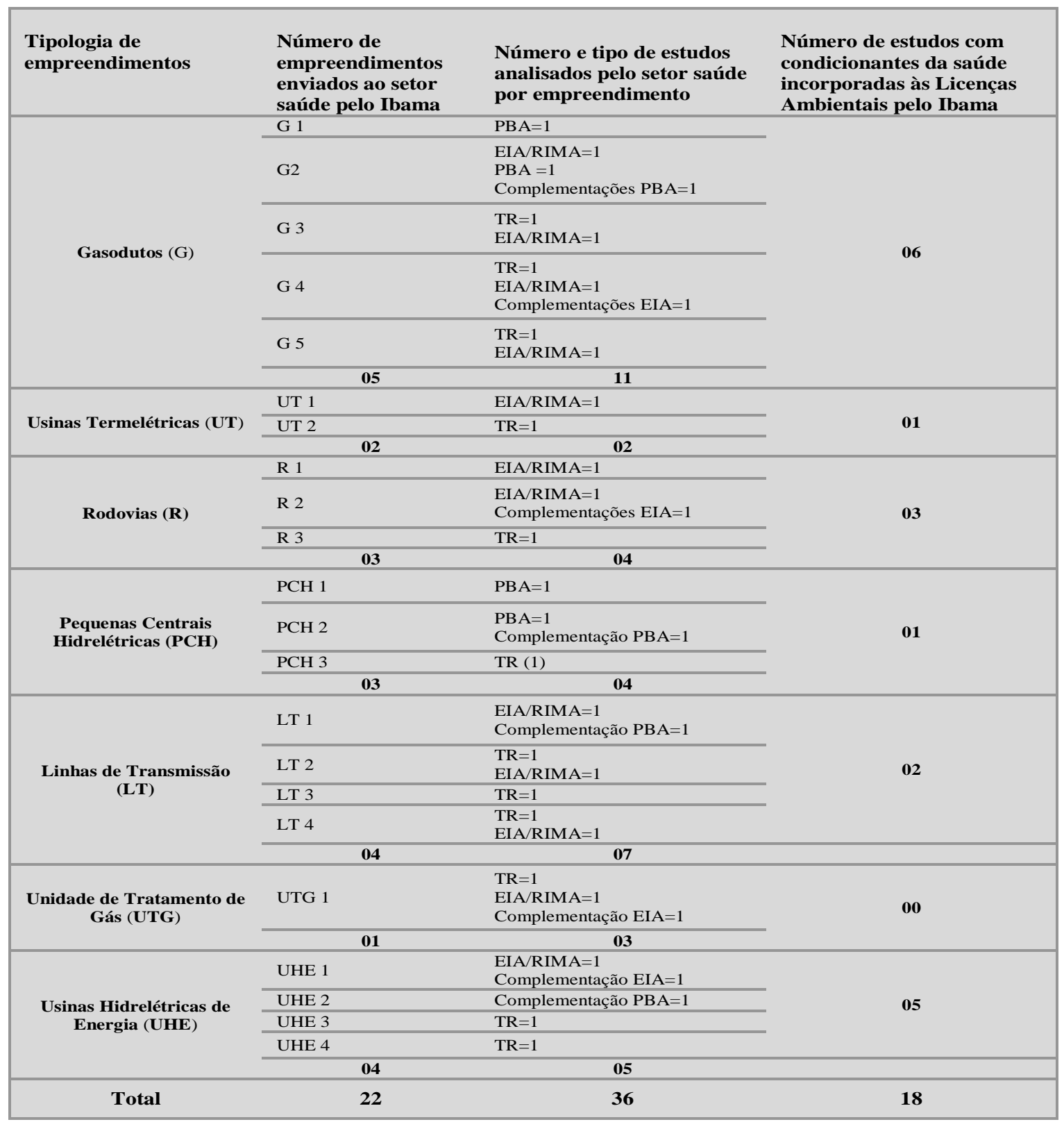

Fonte: Silveira, 2008. 
Além das questões elencadas, verificou-se também que as demandas estabelecidas pelo órgão ambiental partem apenas de determinadas áreas técnicas do licenciamento, sendo que outras áreas não consideram o setor saúde como instituição imprescindível ao processo. Assim ocorre exceto quando o empreendimento se localiza em áreas endêmicas de malária, em função do cumprimento obrigatório pela portaria ministerial (SILVEIRA, 2008).

Outro fator a ser ressaltado se refere ao fato de se considerar o envolvimento de mais um órgão no processo como um “entrave ao desenvolvimento", já que a pressão, normalmente exercida pelo empreendedor para obter as licenças ambientais em tempo hábil, é recorrente durante as avaliações efetuadas pelo Ibama. Verifica-se, desse modo, que as questões relacionadas à saúde são consideradas em caráter secundário durante o processo de licenciamento; consequentemente, a elas não se confere a relevância devida a um condicionante para as licenças ambientais emitidas ao empreendedor.

Eventualmente, por ocasião das audiências públicas destinadas ao licenciamento de empreendimentos considerados estratégicos, o setor saúde é convocado a participar, tendo em vista que eventuais questões específicas não são passíveis de serem respondidas pela área técnica do Ibama.

Apesar de o licenciamento ambiental se constituir como uma obrigação legal, prévia à instalação de qualquer empreendimento ou atividade potencialmente poluidora, além de possuir como uma de suas mais expressivas características a "participação social na tomada de decisão", por meio da realização de Audiências Públicas, muitos destes empreendimentos têm sido questionados por resultarem em inúmeros conflitos socioambientais (BRASIL, 2007e).

Não obstante as dificuldades e limitações apresentadas, o setor saúde trabalha com o órgão ambiental federal durante o licenciamento de forma a subsidiá-lo pontualmente. Conforme o gráfico a seguir, é possível corroborar a ocorrência de um aumento significativo na participação do setor saúde nos processos de licenciamento ambiental de empreendimentos, com um expressivo número em 2008 (Figura 8). 


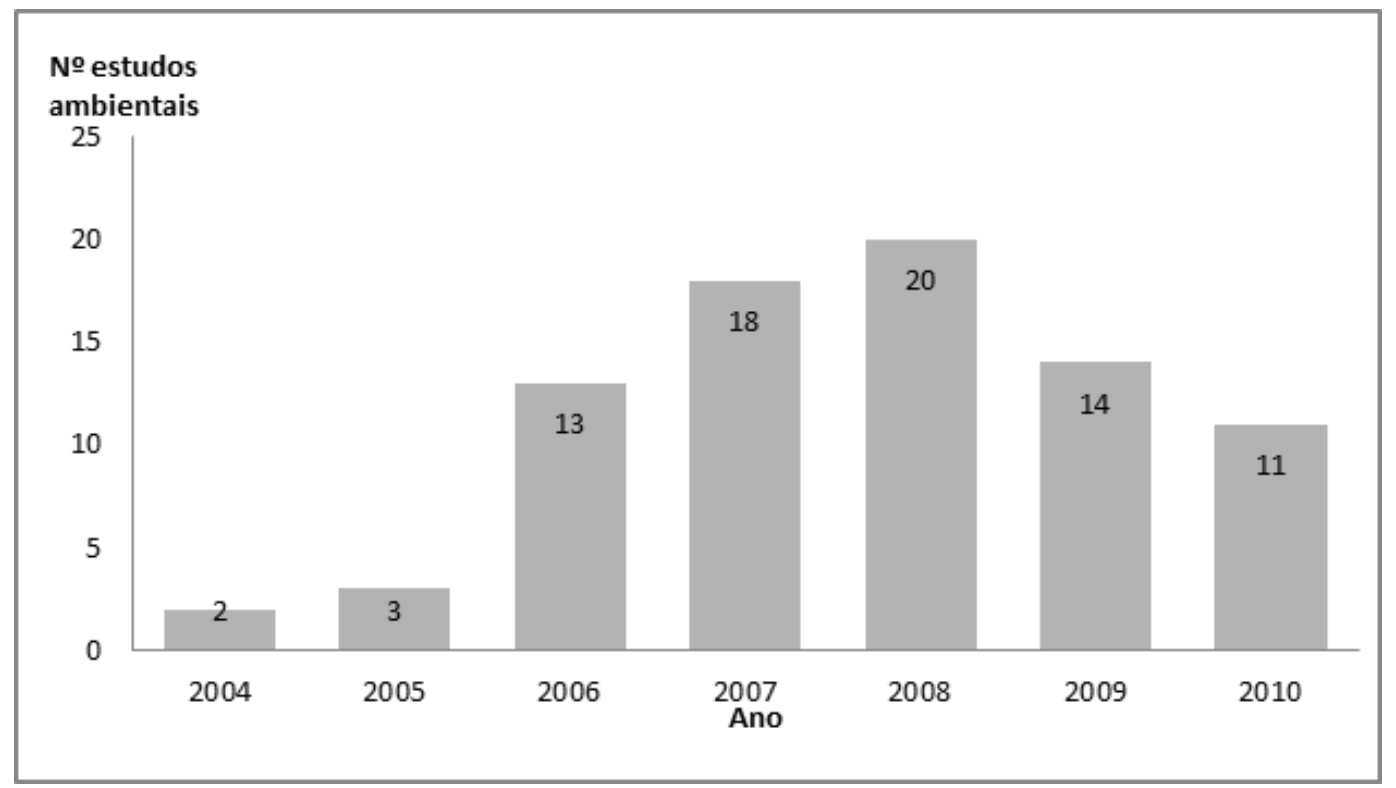

Figura 8 - Estudos ambientais analisados pelo setor saúde por solicitação do Ibama, no período de 2004 a 2010

Fonte: Dsast, 2011.

Diante do que aqui exposto, espera-se que a participação do setor saúde continue a crescer, tanto como indutor da inserção das questões relativas a essa área específica, com vistas ao fortalecimento de ações preventivas em projetos de desenvolvimento, quanto como decorrência das obras de infraestrutura do PAC, a exemplo das novas Usinas Hidrelétricas de Energia (UHE) na Amazônia, dos polos petroquímicos, das grandes rodovias, dentre outros empreendimentos (BRASIL, 2011b).

É importante destacar que as avaliações sobre os impactos ambientais em tais empreendimentos não contemplaram a saúde de forma sistemática e em consonância com os princípios da promoção da saúde e da sustentabilidade socioambiental, como demonstrado em vários estudos a respeito (BARBOSA et al, 2012). Contudo, para se obter uma avaliação que se refira de fato à realidade do que proposto, o licenciamento de viabilidade do projeto não deve ser concedido antes da devida conclusão dos estudos de impacto socioambiental, com a implementação das ações mitigadoras e compensatórias a fim de remediar os efeitos dos efeitos negativos (QUEIROZ; MOTA-VEIGA, 2012).

Para haver uma atuação conjunta entre as políticas de saúde e de meio ambiente, é essencial a busca de conhecimento e técnicas adequadas que avaliem a necessidade de preservação dos recursos naturais e a qualidade de vida das populações nos espaços sob a perspectiva socioambiental. É imperativo que se estabeleça como prerrogativa prioritária, em 
planos e programas de governo, a elaboração de agendas que possibilitem abordagens integradas dos problemas de saúde, frente aos potenciais riscos oriundos dos processos produtivos e dos projetos de desenvolvimento, a fim de compreendê-los e enfrentá-los, com a finalidade de encontrar soluções para os problemas identificados, estabelecendo-se conexões entre os diversos setores envolvidos.

No Brasil, embora haja a menção, no referencial normativo, a respeito da importância da participação do setor saúde no planejamento dos projetos de desenvolvimento, apontando para a obrigatoriedade das ações preventivas, ainda não há legislação específica que regule a participação sistemática do setor saúde nos processos de licenciamento ambiental. A exceção se encontra nos procedimentos referentes às áreas endêmicas de malária e em projetos de assentamentos e reforma agrária.

Diante desse panorama, enfatizamos a necessidade de previsão de mecanismos institucionais e técnicos mais eficazes, para assegurar, de forma sistemática e mais efetiva, a participação do setor saúde nos processos de licenciamento ambiental de empreendimentos. Esses instrumentos devem considerar também, além da Amazônia Legal, os projetos previstos para as demais regiões do país, visando ações de prevenção e promoção da saúde.

Considerando-se a magnitude dos impactos gerados pelas grandes obras no contexto de um novo ciclo de desenvolvimento econômico e social do país, a discussão sobre esse conceito deve estar pautada nas agendas governamentais, a fim de se viabilizar a construção de um processo de sustentabilidade socioambiental.

\subsubsection{A avaliação dos impactos à saúde em projetos de desenvolvimento no Brasil e sua importância estratégica para a sustentabilidade socioambiental}

Mediante o novo ciclo de desenvolvimento econômico e social no Brasil, o Governo Federal lançou, em 2007, o Plano de Aceleração do Crescimento (PAC) com o objetivo de suprir três eixos de desenvolvimento no País: Infraestrutura Logística (rodovias, ferrovias, portos, aeroportos, entre outros); Infraestrutura Energética (geração e transmissão de energia hidrelétrica, petróleo, gás natural e combustível renovável), e Infraestrutura Social e Urbana (habitação, saneamento, recursos hídricos e metrôs). Até 2011, somavam-se 3.212 ações 
distribuídas em todo o País com recursos da ordem de $\mathrm{R} \$ 503,9$ bilhões de reais (BRASIL, 2011b).

Para o PAC-2 os investimentos alcançavam R\$ 955 bilhões até 2014, sendo seu principal agente financiador o Banco Nacional de Desenvolvimento Econômico e Social (BNDES), que participa com 53\% para investimentos no Eixo Energia é 53\% e no Eixo Logístico 62\%. Para Verdum (2012) monitorar e garantir o acesso às informações sobre a atuação do BNDES é fundamental para democracia do país, já que as obras do PAC podem ser questionadas sobre sua efetividade e seus efeitos ambientais, sociais e culturais (VERDUM, 2012)

Ao se levar em consideração a magnitude e o impacto do PAC nos aspectos econômicos e sociais, em 2007, o Ministério da Saúde (MS), em parceria com a Associação Brasileira de Pós-graduação em Saúde Coletiva (ABRASCO), realizou um seminário com atores de diversos setores para debater a necessidade de uma agenda de caráter orientador, a fim de construir um processo de sustentabilidade socioambiental no âmbito do PAC.

Na ocasião, apontaram-se as ações necessárias à garantia do direito à saúde, a serem desencadeadas no âmbito do Estado, do meio acadêmico e dos movimentos sociais (BRASIL, 2007d). Durante o seminário, houve relato a respeito da preocupação no sentido de o PAC não repetir ciclos recorrentes de crescimento socioeconômico rápido do país, acompanhados de concentração de renda, utilização desenfreada de recursos naturais, reprodução de desigualdades regionais e sociais, seguidos do consequente colapso econômico, social e ambiental. Defendeu-se que o pais, ao contrário do que se observa comumente, deveria enfrentar "os desafios econômicos, sociais e ambientais de forma includente, democrática e justa, protegendo os grupos populacionais mais vulneráveis" (BRASIL, 2007d).

A exemplo do PAC, os casos mais emblemáticos são identificados na construção de grandes usinas hidrelétricas, que ocasionam o aumento de áreas desmatadas, a degradação ambiental nas áreas em torno dos lagos das barragens, o aumento do contingente populacional, além da emissão de gases que contribuem para o aquecimento global.

No tocante à expansão da matriz da bioenergia, sobretudo no plantio da monocultura da cana-de-açúcar, os impactos observados se relacionam predominantemente ao aumento da carga de poluentes no ar, na água e no solo por fertilizantes e agrotóxicos e a expansão das áreas 
devastadas pelas queimadas. Trata-se de circunstâncias que também interferem nos ecossistemas por conta dos prejuízos que causam à biodiversidade.

Também a construção de extensas rodovias acarreta grandes impactos nas dinâmicas sociais e culturais das populações localizadas nas proximidades, requerendo, portanto, cuidados no planejamento a fim de minimizar os danos caudados. Além do mais, é fundamental que haja o devido investimento na infraestrutura social e urbana, especialmente o destinado ao saneamento, o qual precisa estar acompanhado do fortalecimento dos aspectos regulatórios decorrentes da Lei Federal do Saneamento Básico ${ }^{8}$. Nesse sentido, torna-se prioritária a busca de alternativas tecnológicas que possibilitem a sustentabilidade local (BRASIL, 2007f).

O incremento da qualidade de vida e de saúde das populações se vincula intrinsecamente ao desenvolvimento de processos ecologicamente sustentáveis. De acordo com a Organização Pan-Americana da Saúde (OPAS), o enfrentamento das situações negativas decorrentes de mudanças ambientais depende de ajustes e reformas nos processos de tomada de decisões. Objetiva-se, assim, a integração dos diversos fatores econômicos aos sociais e ambientais (OPAS, 2005).

A OMS sustenta que os impactos na saúde deveriam ser considerados pela legislação em que se aplica a Avaliação de Impacto Ambiental (AIA), ou seja, durante o licenciamento ambiental. No entanto, observa-se mais comumente que tais impactos são mal avaliados, quando o são, o que nem sempre ocorre. Conclui-se, então, que os aspectos da saúde e seus potenciais impactos raramente são incluídos no escopo do licenciamento (OMS, 2001).

Porto e Freitas (1997) argumentam que, ao se pensar em processos produtivos de forma sustentável, é fundamental a exigência de uma análise prévia dos grandes empreendimentos ou projetos tecnológicos, antes da sua construção e operação, com o exame dos padrões ambientais, de segurança e de saúde, incluindo a dos trabalhadores.

O Conselho Nacional de Saúde (CNS) foi enfático ao afirmar que há “dissociações entre empreendimentos econômicos e de infraestrutura, seus impactos ambientais e a saúde da população" (BRASIL, 2007c). Recomendou, em moção, “que a legislação seja cumprida e

\footnotetext{
${ }^{8}$ Lei $\mathrm{n}^{\circ} 11.445$, de 5 de janeiro de 2007, que estabelece as diretrizes nacionais para o saneamento básico e para a política federal de saneamento básico no Brasil. Disponível em: http://www.planalto.gov.br/ ccivil_03/_ato20072010/2007/lei/l11445.htm. Acesso em: 25/04/2014
} 
aperfeiçoada no sentido de incluir a participação do setor saúde nos processos de licenciamento ambiental" (BRASIL, 2007c).

No Brasil, o setor saúde participa pontualmente do licenciamento ambiental de grandes empreendimentos. Contudo, destaca-se a inexistência, ainda hoje, de instrumentos jurídicos satisfatórios que estabeleçam a obrigatoriedade da inserção dos aspectos de saúde na maior parte dos processos, com exceção dos concernentes à malária. Dessa forma, faz-se necessário ampliar a discussão a respeito da elaboração de uma avaliação multidisciplinar, no sentido de contribuir para o aperfeiçoamento de instrumentos que fortaleçam as políticas públicas setoriais, o que somente deverá ocorrer, no entanto, quando houver a compreensão de como os processos produtivos impactam o ambiente natural e, consequentemente, a saúde de determinadas populações.

Vale lembrar que a Organização Mundial da Saúde (OMS) define saúde como um estado completo de bem-estar físico, mental e social, e não meramente a ausência de doença. Esse conceito abarca a concepção de que a saúde é influenciada por diversos fatores. Segundo Finkelman (2002), "a saúde não mais se explica pela ausência de doença, mas como resultado de ações de caráter intersetorial que a considerem como produto e, ao mesmo tempo, como insumo ao desenvolvimento" (FINKELMAN, 2002).

Sob essa perspectiva, consideramos que cabe ao Sistema Único de Saúde (SUS) a tarefa de reconhecer e promover ações de melhoria da qualidade de vida, reduzindo as vulnerabilidades e os riscos à saúde, os quais se configuram como fundamentais na busca da equidade social. Nessa perspectiva, o setor saúde se mostra disposto a intensificar suas ações para se incluírem os aspectos da saúde nos processos de licenciamento ambiental de grandes empreendimentos.

No capitulo a seguir, discutiremos as iniciativas do Ministério da Saúde para a incorporação da metodologia de Avaliação de Impacto à Saúde (AIS) nos processos de licenciamento ambiental. 


\section{CAPÍTULO 3 - AVALIAÇÕES DE IMPACTO À SAÚDE EM PROJETOS HIDRELÉTRICOS: UMA REALIDADE POUCO EXPLORADA}

A realização de estudos a respeito da avaliação de impacto à saúde na região Amazônica, na qual se concentram, atualmente, os maiores projetos de grandes hidrelétricas, se caracteriza como um desafio. Assim ocorre, em primeiro lugar, por não existir um número significativo de estudos sobre o tema (BALBY, 2012). Em segundo, observa-se uma contradição entre os interesses envolvidos no desenvolvimento do país e os impactos decorrentes desse processo. O proponente do projeto, muitas vezes o poder público, alega possuir instrumentos suficientes de avaliação - como o licenciamento, por exemplo -, e qualquer proposição de novos instrumentos de avaliação pode ser recebida como um "entrave" ao desenvolvimento.

No Brasil, como destacado anteriormente, a avaliação de impacto à saúde ainda é restrita. Há, contudo, pesquisadores que atualmente realizam análises pontuais. É o caso do projeto desenvolvido pela Escola Nacional de Saúde Pública (Ensp/Fiocruz), ${ }^{9}$ que tem por objetivo avaliar o risco ao ecossistema da bacia do Rio Madeira e à saúde humana das populações no tocante às mudanças socioambientais.

De acordo com a pesquisadora Sandra Hacon, coordenadora do projeto e uma das principais referências sobre o tema no Brasil, a pesquisa não se limita somente à avaliação dos efeitos à saúde, mas também ao bem-estar humano: "O projeto pretende contribuir diretamente para a inserção da dimensão da saúde na avaliação dos impactos socioambientais em projetos de desenvolvimento por meio de abordagem integrada com atores sociais do território, desde o início do projeto" (AGENCIA FIOCRUZ, 2013). A pesquisa visou principalmente traçar um perfil de saúde das comunidades ribeirinha e urbana antes da ocorrência dos impactos provenientes do desenvolvimento local.

Outro projeto de destaque quanto à avaliação de impacto à saúde desenvolvido por Hacon tem como foco a exposição de mercúrio sofrida pela população ribeirinha do Rio Madeira em decorrência da hidrelétrica de Santo Antônio, localizada no município de Porto

\footnotetext{
${ }^{9}$ Agência Fiocruz de Notícias: "Ensp/Fiocruz inicia projeto que integra saúde, ambiente e educação em Rondônia", projeto da pesquisadora da Escola Nacional de Saúde Pública (Ensp/Fiocruz) Sandra Hacon, junto com o vicecoordenador, Salvatore Siciliano. Disponível em: http://www.fiocruz.br/ccs/. Acesso em: 12/12/2013.
} 
Velho, Rondônia. A pesquisa avalia as condições de saúde e os níveis de contaminação de mercúrio nos ribeirinhos do Rio Madeira na área de influência direta do reservatório da UHE de Santo Antônio (HACON, 2014).

Pelo exposto, a avaliação de impacto à saúde deveria ser considerada como instrumento importante e de utilização sistemática pelos tomadores de decisão, no âmbito das políticas públicas, com o fim de apontar, preventivamente, caminhos para mitigar e compensar de forma eficiente os impactos socioambientais e na saúde. No entanto, identificam-se dificuldades para inserir novos instrumentos de avaliação diante dos impactos identificados frequentemente nos grandes empreendimentos, como é o caso das hidrelétricas. O principal obstáculo é a forma pela qual ocorre o enfrentamento dos setores governamentais, que ainda abordam a avaliação de impacto à saúde como mais um "instrumento burocrático" a emperrar os projetos de infraestrutura no País, e não uma medida essencial de proteção à saúde humana e ao meio ambiente.

\subsection{IDENTIFICANDO OS EFEITOS DE PROJETOS HIDRELÉTRICOS SOBRE A SAÚDE, A PARTIR DO MODELO CONCEITUAL FPEEEA: POSSIBILIDADES E FRAGILIDADES}

Apesar de não haver muitos indicadores que relacionem o efeito direto da degradação ambiental sobre a saúde humana, sua aplicação exerce papel fundamental tanto na identificação e no estabelecimento de prioridades como na formulação de políticas e na avaliação do estado do meio ambiente, provendo informações adequadas ao público e aos tomadores de decisão (HACON et al, 2005).

O modelo conceitual Força-Pressão-Situação-Exposição-Efeito-Ação (FPSEEA, acrônimo em português), adaptação literal da denominação em inglês Driving Force-PressureState-Exposure-Effect-Action (DPSEEA), foi proposto pela OMS para orientar os gestores na tomada de decisões no campo da saúde, com a análise das conexões entre saúde, meio ambiente e desenvolvimento sustentável (CORVALÁN et al, 1999).

Esse modelo conceitual se originou da adaptação de outros dois padrões antecedentes. O primeiro, denominado de Pressão Estado Resposta (PER), elaborado pela Organização para 
a Cooperação e o Desenvolvimento Econômico (OCDE), está embasado no conceito de causalidade. O segundo, Pressão Estado Impacto Resposta (PEIR), desenvolvido pelo Programa das Nações Unidas para o Meio Ambiente (PNUMA), destina-se ao monitoramento dos efeitos das pressões das atividades humanas sobre o meio ambiente e os possíveis impactos sobre a saúde humana (PNUMA, 2004).

A metodologia FPSEEA organizou indicadores que ampliassem as dimensões das metodologias precedentes (PER e PEIR), incorporando a relação entre a exposição e os efeitos diretos e indiretos sobre a saúde, que se expressam por problemas originados das forças motrizes. Esse modelo se mostrou bastante útil para a identificação e construção de indicadores na área da Saúde Ambiental no Brasil, desde a criação da Vigilância em Saúde Ambiental no âmbito do SUS (OPAS, 2014).

De acordo com os argumentos encontrados na literatura, o modelo FPSEEA possibilita uma análise integrada da saúde ambiental no contexto econômico e social; sua aplicação pode auxiliar o monitoramento das condições de sustentabilidade ambiental e de saúde (SOBRAL; FREITAS, 2010). Classificado como uma das categorias de avaliação de sustentabilidade, esse modelo utiliza relações de causa e efeito; estabelece, assim, ligações entre cada componente da estrutura por meio da definição de indicadores para cada componente e do reconhecimento das ações efetivas de controle e prevenção dos possíveis impactos (WHEED et al, 2009).

Na matriz FPEEEA, as forças motrizes geram as pressões que modificam o estado no ambiente, o qual, em condições adversas, fica exposto aos riscos, ocasionando, então, efeitos nocivos sobre a saúde. Segundo Kligerman et al (2007), no âmbito de um sistema de indicadores de saúde ambiental criado para monitorar a qualidade do meio ambiente e atuar na proteção da saúde, esse modelo pode subsidiar a tomada de decisão de gestores (KLIGERMAN et al, 2007).

Desse modo, essa metodologia permite a construção de uma matriz de análise para um determinado problema, podendo ser adaptada para aspectos específicos de uma política, plano ou programa que possam afetar a saúde. Trata-se de um marco conceitual no sentido da compreensão das forças condutoras das mudanças ambientais (crescimento populacional ou inovações tecnológicas), das pressões (produção, consumo, emissão de poluentes), das alterações de estado do meio ambiente (níveis de contaminação), da exposição (externa, interna, dose absorvida) e dos efeitos para a saúde de todos esses fatores de transformação (avançados, moderados ou precoces). Sua estrutura analítica, composta por elementos da cadeia ambiente e saúde, possibilitou uma primeira aproximação no sentido de se observar como os elementos se 
conectam de modo a causarem efeitos positivos ou negativos na saúde em um determinado empreendimento (Figura 9).

Com o intuito de discutir a relação entre a saúde ambiental e o desenvolvimento de grandes projetos, como hidrelétricas, esse modelo, como já afirmado anteriormente, representou uma primeira aproximação com o tema, por permitir a discussão das questões de saúde, do ambiente e do desenvolvimento sustentável, incorporando as relações de causa e efeito. Por meio desse método, é possível compreender como os grandes empreendimentos, além de vetores de desenvolvimento e de ocupação do território, interferem no ambiente e nos aspectos socioeconômicos, com reflexos na saúde e na qualidade de vida da população.

\section{CADEIA AMBIENTE E SAUDE}

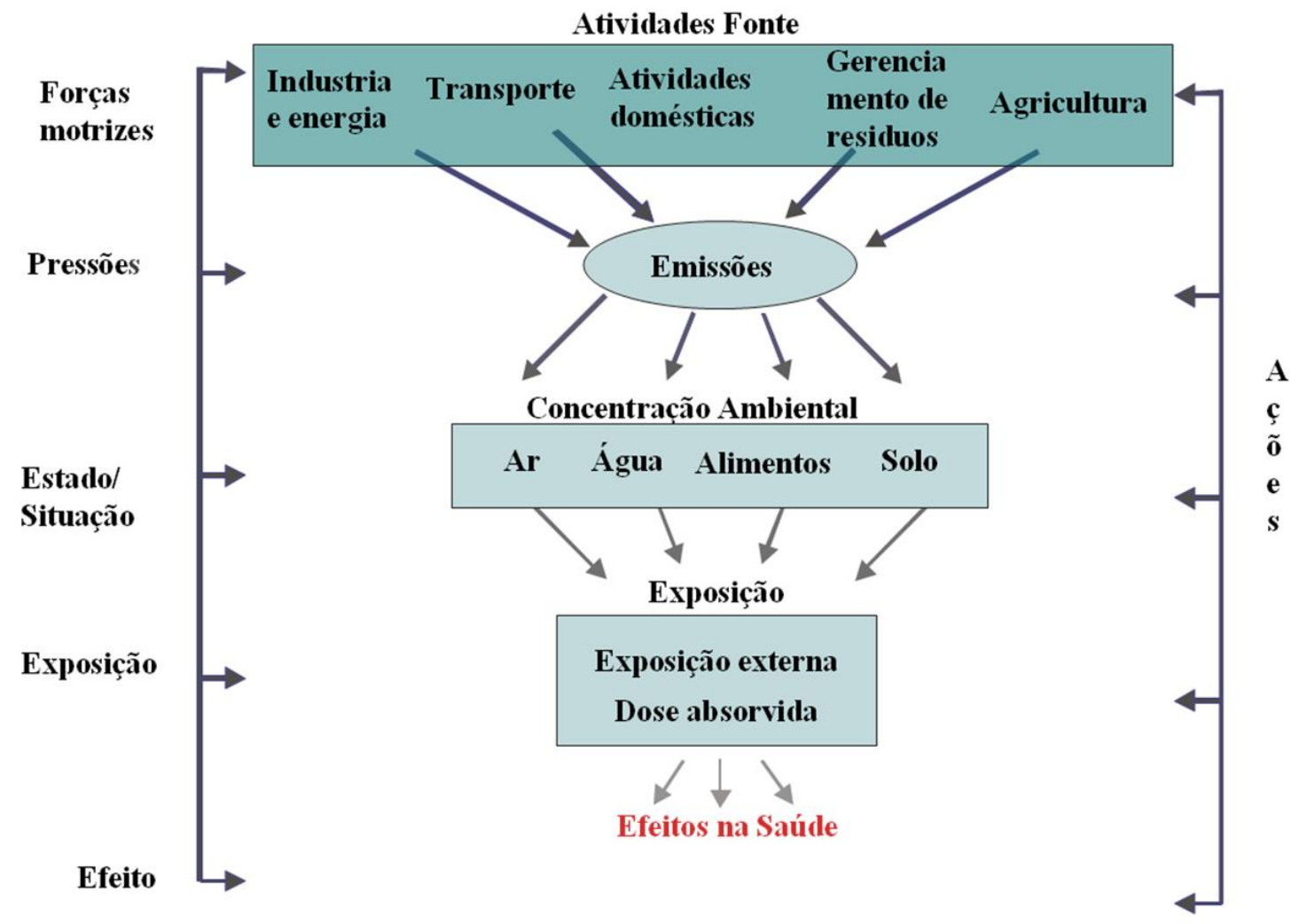

Figura 9 - Cadeia Ambiente e Saúde (Matriz FPEEEA)

Fonte: Corvalán et al, 1999.

Essa primeira aproximação permitiu que se elaborasse uma matriz pela qual se observam os possíveis efeitos à saúde no âmbito de projetos de infraestrutura, com base na política energética e no plano de construção das hidrelétricas na Amazônia. A partir dessas 
forças motrizes, geradoras de pressão que modificam o meio ambiente e expõem a população a fatores de risco epidemiológicos e a outras formas de exposição, revelam-se os possíveis efeitos sobre a saúde (Figura 10).

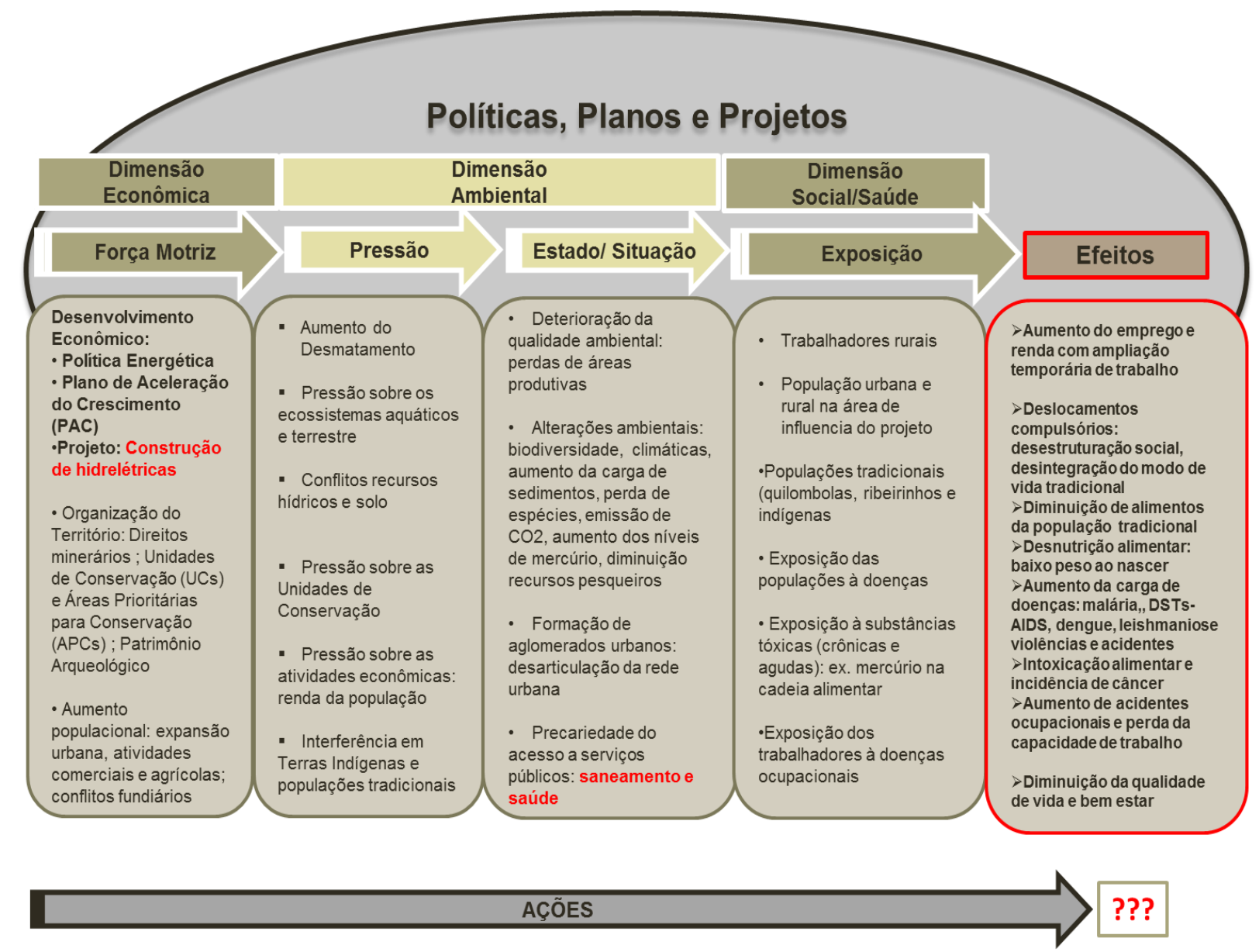

Figura 10 - Matriz Causa-Efeito a partir do modelo FPEEEA para avaliação dos impactos à saúde em projetos hidrelétricos

Fonte : elaborada por Missifany Silveira com base no modelo conceitual de Corvalán et al, 1999.

A composição da matriz se fundamenta em revisão de literatura e pesquisa de campo sobre os principais impactos provenientes da construção de hidrelétricas, considerando-se o contexto das políticas, planos e projetos governamentais no Brasil, alinhados às dimensões econômica, ambiental e social.

Com fundamento no modelo apresentado, emergem elementos que possibilitam conferir materialidade às principais ações estratégicas, sobretudo na área da vigilância ambiental, para atuação nas áreas de desenvolvimento dos projetos hidrelétricos. As diversas possibilidades de 
atuação são complexas e, portanto, requerem um planejamento das ações para a tomada de decisão no território, permitindo um olhar crítico sobre as questões socioambientais sob a ótica preventiva. Dessa maneira, o processo de avaliação se apresenta mais retrospectivo do que prospectivo, como normalmente ocorre nas avaliações de saúde.

Vale lembrar que a aplicação da estrutura FPEEEA é limitada. Uma das críticas a respeito sustenta que a dependência de ligações unidirecionais em cadeia pode não ser suficiente para compreender a complexidade dos processos envolvidos em uma avaliação mais detalhada. Por simplificar as interligações nos casos em que, por exemplo, a questão medida por um indicador representado por força motriz também pode ser averiguada pela pressão, esse método é passível de ambiguidades, podendo dificultar a identificação de indicadores (WAHEED et al, 2009).

Apesar do uso limitado, uma das vantagens dessa estrutura é a possibilidade de selecionar as variáveis ou indicadores para cada etapa da cadeia, representando as alterações ambientais e de saúde e permitindo maior flexibilidade na análise das inter-relações nos diferentes níveis. Como esse método permite uma comunicação clara, compacta, com os indicadores organizados, ele facilita a tomada de decisão pelos gestores (WAHEED et al, 2009), apresentando-se como instrumento de subsídios à elaboração de ações de vigilância em saúde ambiental.

Contudo, a análise do modelo conceitual permitiu algumas proposições, as quais, dentro de uma abordagem ampla, podem conduzir à observação de como as forças (macro) de uma política, um plano e projeto pressionam o ambiente e, consequentemente, expõem determinadas populações a agravos que afetam sua qualidade de vida e bem-estar. A fim de mitigar os efeitos negativos ou potencializar os que se mostram positivos, são necessárias ações estratégias e efetivas, em âmbito político e institucional, para a obtenção de resultados sustentáveis nos territórios modificados pelos grandes empreendimentos.

A matriz a seguir demonstra uma proposição de ações preventivas, nas dimensões econômicas, ambiental e social, a ser seguida pelas políticas públicas (saúde, ambiente, educação) como base para uma avaliação inicial durante a implementação de grandes projetos de infraestrutura, a exemplo das Usinas Hidrelétricas (Quadro 4). 


\begin{tabular}{|c|c|c|}
\hline Dimensão & Elementos de avaliação & Ações \\
\hline Econômica & $\begin{array}{l}\text { Desenvolvimento econômico: } \\
\text { - Política de Energia: Aumento do número de obras do PAC/ } \\
\text { Hidrelétricas } \\
\text { - Planejamento territorial: uso e necessidade de áreas para } \\
\text { produção de energia } \\
\text { - Fluxo populacional: expansão urbana, atividades } \\
\text { comerciais, demanda por serviços de infraestrutura de saúde, } \\
\text { especulacãao imobiliária e aumento da procura por áreas para } \\
\text { expansão agrícola e pecuária }\end{array}$ & 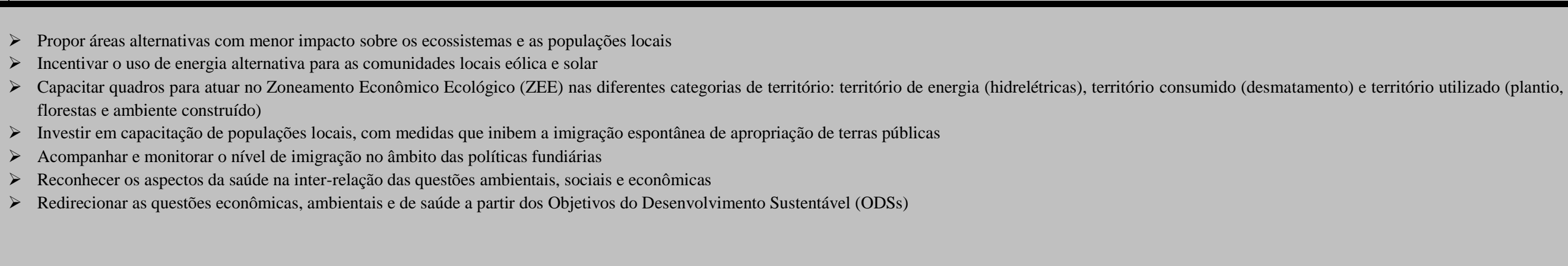 \\
\hline Social/Saúde & 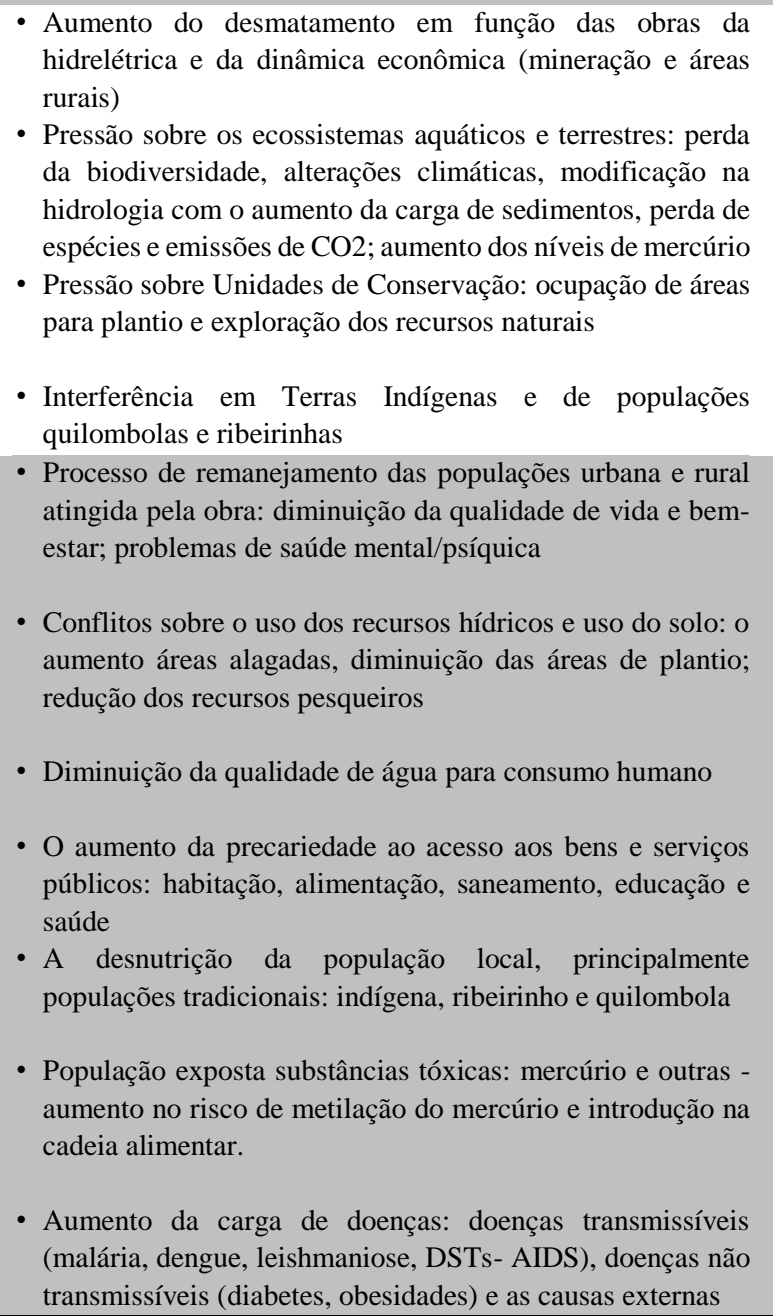 & 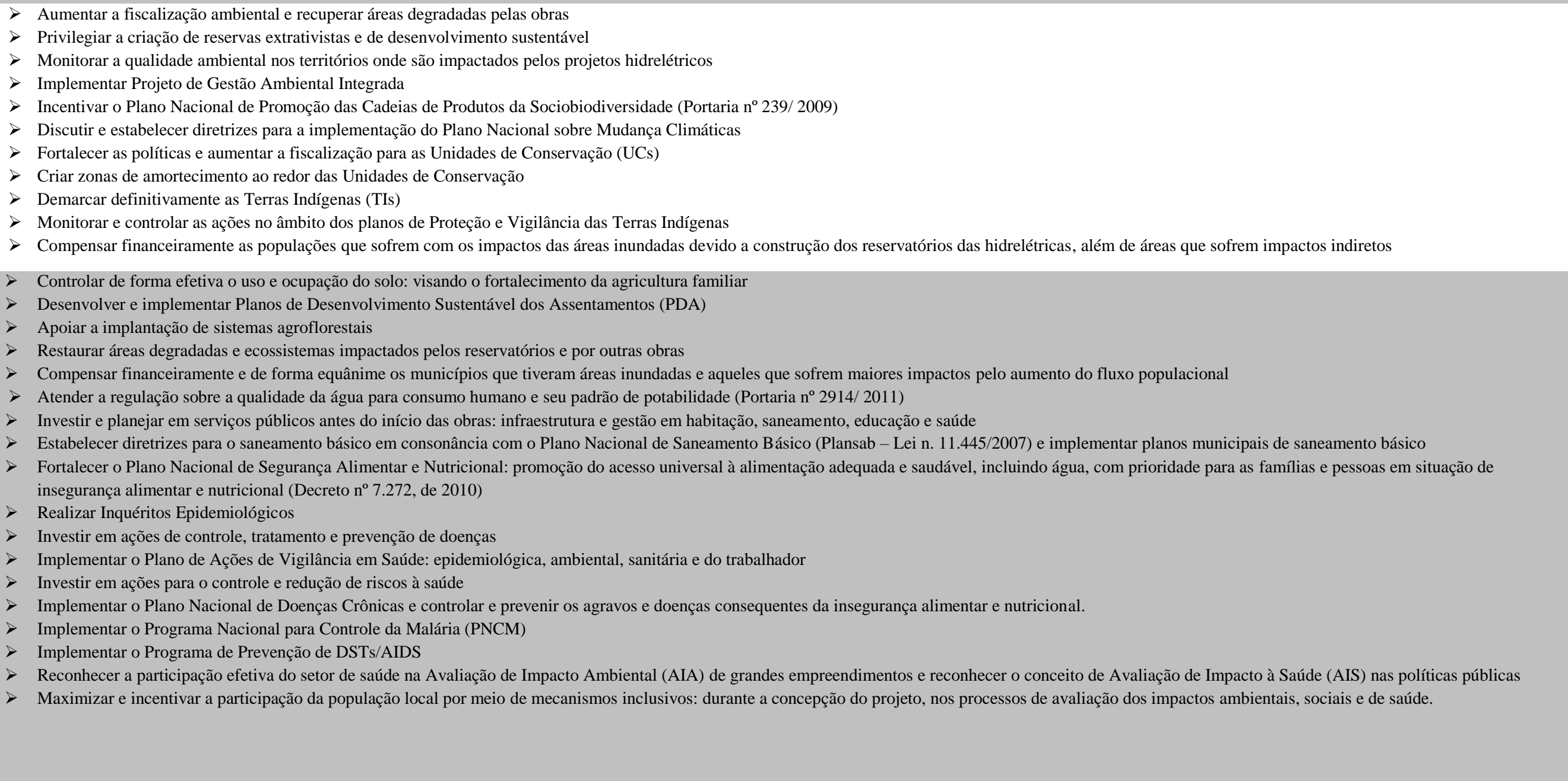 \\
\hline
\end{tabular}




\subsection{MALÁRIA COMO ÚNICO INDICADOR DE SAÚDE NA AVALIAÇÃO DE IMPACTO AMBIENTAL DE EMPREENDIMENTOS NA REGIÃO DA AMAZÔNIA LEGAL ${ }^{10}$}

A malária ainda é, sem dúvida, um dos mais graves problemas de saúde pública no Brasil e no mundo. De acordo com dados da Organização Mundial de Saúde (OMS), em 2013 ocorreram 198 milhões de casos de malária no mundo, levando a 584.000 óbitos, sobretudo na África. Na região das Américas, três países foram responsáveis por 72\% dos casos em 2013, sendo $42 \%$ no Brasil, que responde também por metade dos óbitos na região. No entanto, apesar do número alarmante, o relatório da OMS estima uma redução de 75\% na incidência os casos para a Colômbia e o Brasil (WHO, 2014).

Nesse contexto, os setores da saúde no Brasil dedicam especial atenção à malária, por se tratar um agravo de espectro epidemiológico pela elevada incidência na região amazônica. Esse quadro é especialmente problemático nos Estados da Amazônia Legal, considerada área endêmica e na qual se situa maioria dos casos de malária (BRASIL, 2008b).

No âmbito do Ministério da Saúde (MS), o Programa Nacional para o Controle da Malária (PNCM) dispõe de instrumentos normativos e técnicos que compõem um sistema de informações para a vigilância epidemiológica da malária. O Sivep-Malária é responsável por estabelecer diretrizes e procedimentos para a elaboração, em conjunto com o SUS, do Plano de Ação do Controle da Malária (PACM) como condicionante para a obtenção das licenças ambientais e, por conseguinte, para a construção do empreendimento (BRASIL, 2014a).

Por se configurar como doença de notificação compulsória, todos os casos suspeitos de malária devem ser registrados às instituições de saúde locais (BRASIL, 2006b). Esse procedimento é aplicado tanto em áreas endêmicas, pelo SIVEP-Malária, quanto nas localidades não endêmicas, pelo Sistema de Informação de Agravos de Notificação (SINAN) (BRASIL, 2014a).

\footnotetext{
${ }^{10}$ A Amazônia Legal é uma área de 5.217.423 km², que corresponde a $61 \%$ do território brasileiro. Segundo o IBGE, a Amazônia Legal foi criada inicialmente como área de atuação da Superintendência do Plano de Valorização Econômica da Amazônia (SPVEA), em 1953. Atualmente, ela corresponde à área dos Estados da Região Norte (Acre, Amapá, Amazonas, Pará, Rondônia, Roraima e Tocantins), acrescidos da totalidade do Estado de Mato Grosso e dos municípios do Estado do Maranhão situados a oeste do meridiano $44^{\circ} \mathrm{O}$. Em sua configuração atual, equivale à área de atuação da SUDAM (IBGE, 2015).
} 
O Ministério da Saúde determina como parâmetros de risco para a malária o Índice Parasitário Anual (IPA) com os valores correspondentes a baixo risco (IPA < 10), médio risco (IPA 10 - 49) e alto risco (IPA >=50) (BRASIL, 2010a). Segundo os dados Sivep-Malária, os municípios classificados como de alto risco se concentram principalmente nos Estados do Pará e Amazonas. De acordo com o Boletim Epidemiológico do Ministério da Saúde, no período de 2000 a 2011, 99,7\% dos casos de malária foram notificados nessa região. Nos últimos doze anos, registrou-se uma média de 422.858 casos por ano (BRASIL, 2013a).

A transmissão da doença no país ocorre em três espécies de parasitos da malária: Plasmodium vivax, Plasmodium falciparum e Plasmodium malariae, predominando as infecções causadas pelo P. Vivax. Os graus de risco são classificados de acordo com o IPA, que expressa o número de exames positivos de malária por mil habitantes em determinado lugar e período. As áreas são classificadas como de alto risco (IPA $\geq 50 / 1.000$ hab.), médio risco (IPA entre 10 e 49/1.000 hab.) e baixo risco (IPA <10/1.000 hab.) (BRASIL, 2013a).

A figura a seguir ilustra o mapa de risco, elaborado com a finalidade de observar o comportamento da malária na Região da Amazônia Legal de acordo com a média do IPA no período de 2008 a 2011 (Figura 11).

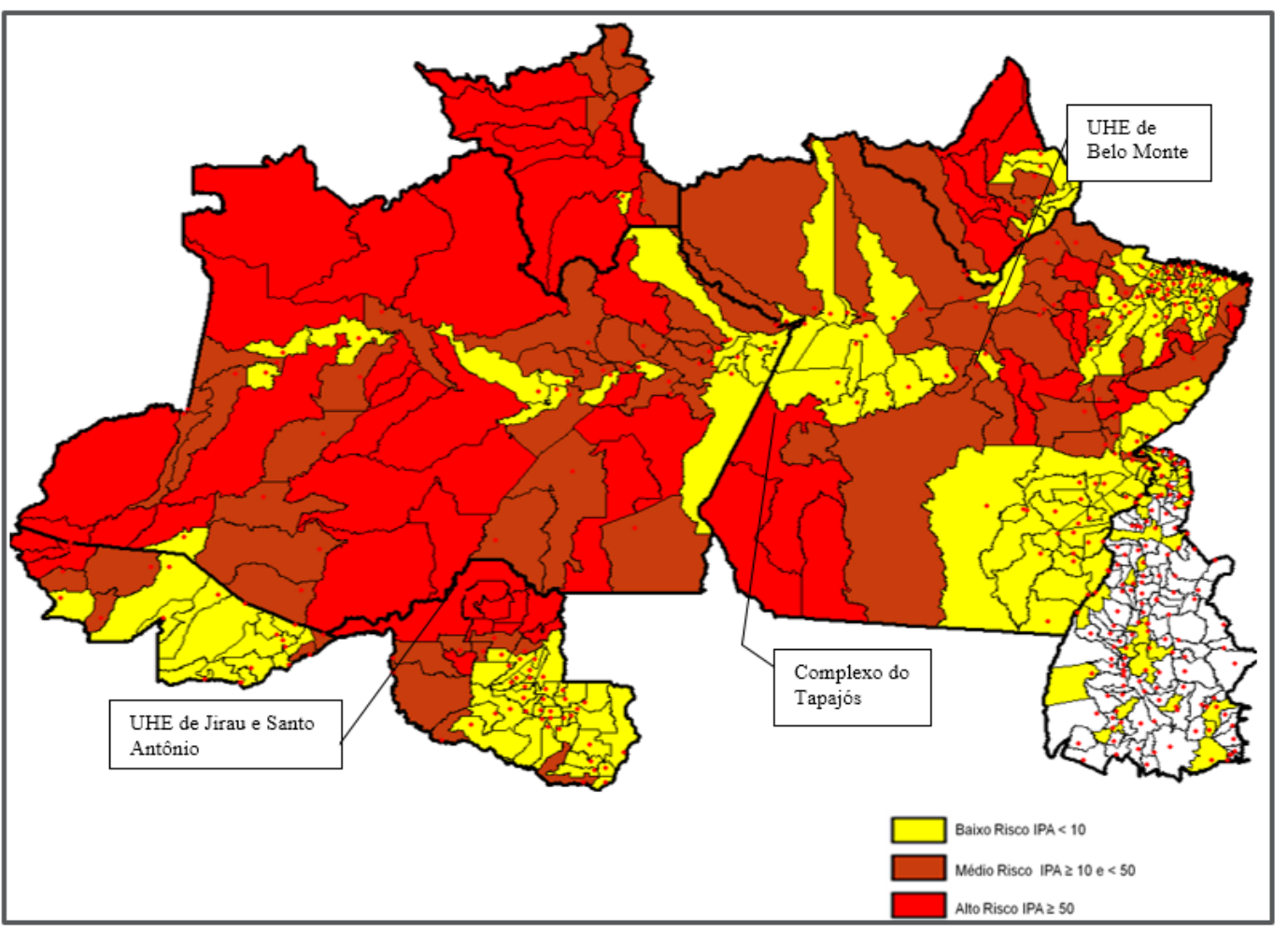

Figura 11 - Média do IPA da malária por municípios da Região Norte, no período de 2008 a 2011 Fonte: elaborado por Missifany Silveira a partir de dados Datasus, 2012 
Nessa mesma região se concentram as maiores obras de hidrelétricas em construção no Brasil: uma das obras está localizada no município de Porto Velho (UHE de Jirau), no Estado de Rondônia; outra, em Altamira (UHE de Belo Monte), no Estado do Pará. Há, ainda, o Complexo do Tapajós, que contempla sete novas usinas, com plano de viabilidade aprovado pelo governo federal.

Os mapas de risco a seguir (Figura 12) retratam o Índice Parasitário Anual (IPA) da malária por município, nas áreas de influência dos três projetos, entre os anos de 2007 a 2011. Observa-se ocorrência da doença em quase todos os municípios onde se localizam as usinas em construção. No entanto, o elevado número de casos de malária não pode ser atribuído apenas a esse fator. Há outras variáveis a serem consideradas, visto que a área onde está previsto o futuro Complexo do Tapajós já apresenta um IPA bastante elevado.

Os IPA para os municípios da área de influência direta e indireta das três localidades nesse período variavam entre médio a alto risco. Portanto, se ao longo da série histórica esses municípios já se configuravam como áreas de médio e alto risco, não é possível inferir que o empreendimento é o fator principal do impacto observado.

Conforme pesquisadores da área, há uma provável influência direta das mudanças ambientais causadas por atividades humanas, como a formação dos lagos das grandes barragens, sobre a ocorrência de malária nessas regiões. Vasconcelos et al. (2006) destacam que essa interferência foi observada na década de 1980, com a formação do lago de Tucuruí, no Pará, onde a ocorrência de malária prevaleceu em alguns municípios situados à margem do reservatório.

O incremento populacional decorrente da construção da barragem de Tucuruí e a dinâmica de alteração do uso do solo ocasionaram um impacto sobre a dispersão da malária na localidade, com um aumento significativo dos números de casos. Também a proliferação de plantas aquáticas, mediante a formação do lago, contribuiu para novos criadouros de mosquitos, que, somado aos problemas sociais como a falta de infraestrutura dos serviços de abastecimento de água, assistência médico-sanitária, precariedade das habitações, dificultou o controle dos vetores da malária pelos serviços de saúde local (VASCONCELOS et al,2006). 


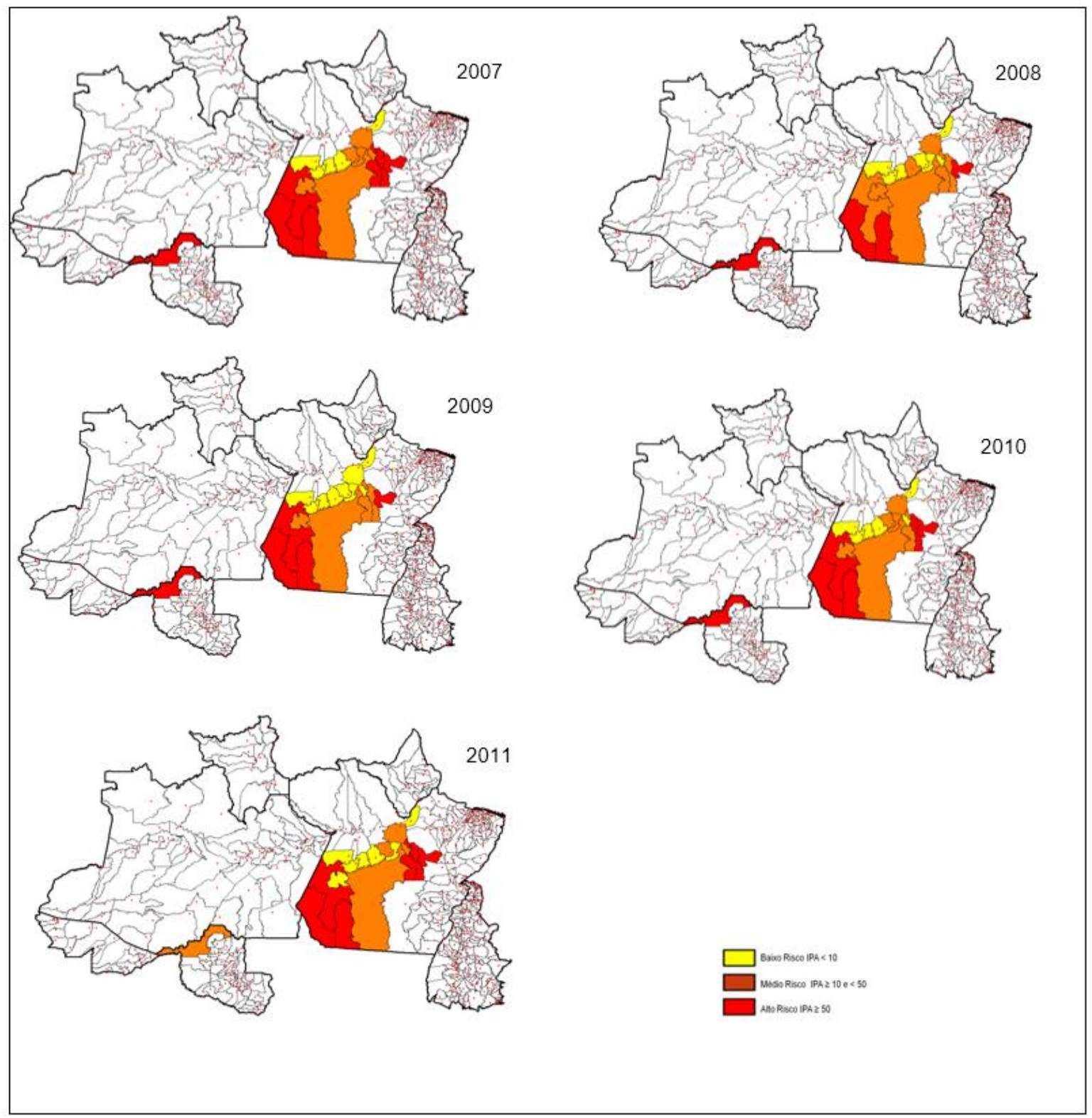

Figura 12 - IPA da malária por município da área de influência das hidrelétricas do Complexo Madeira, Belo Monte e Complexo do Tapajós, entre os anos de 2007 a 2011

Fonte: elaborada por Missifany Silveira a partir de dados do Datasus, 2012.

Um estudo realizado entre 2004 e 2005, nas localidades onde de construção das Usinas Hidrelétricas (UHE) de Santo Antônio e Jirau, no Município de Porto Velho, em Rondônia, demonstrou que a prevalência da malária antes do início das obras acarretou um grande impacto na população e em algumas áreas indígenas, nos Estados de Rondônia e Amazonas (KATSURAGAWA et al, 2009). Por meio desses dados, é possível observar que os efeitos da migração não controlada para uma área endêmica de malária, associada à falta de infraestrutura adequada, representam fatores de risco à saúde da população. 
Para Rovere et al (2009), o risco associado à implantação de projetos hidrelétricos tende a aumentar em virtude das condições sanitárias desfavoráveis, tanto no ambiente urbano quanto nas áreas rurais. $\mathrm{O}$ incremento dos riscos decorre também da ausência de medidas preventivas e as condições precárias para o tratamento da população que sofrem os impactos da implantação do empreendimento (ROVERE et al, 2009).

No entanto, a fim de possa dar início a qualquer empreendimento de grande porte na área da Amazônia Legal, ou em outras regiões suscetíveis à malária, o empreendedor deve aprovar o PACM. Para que assim ocorra, alguns parâmetros devem ser considerados, de acordo com a normatização do Ministério da Saúde, como exigência do órgão ambiental. Dessa forma, antes da aprovação do PACM, é necessário seguir alguns passos conforme o estabelecido pela Portaria MS/SVS n ${ }^{\circ}$ 1, de janeiro de 2014. O primeiro deles é a elaboração de um plano para a realização da Avaliação do Potencial Malarígeno (APM), requisito para a emissão do Laudo de Avaliação do Potencial Malarígeno (LAPM). Ao final desse processo, o empreendedor receberá o Atestado de Condição Sanitária (ATCS) a fim de, somente então, dar prosseguimento à obra.

Vale destacar que, conforme o art. $3^{\circ}$ da Portaria MS/SVS n ${ }^{\circ}$, a APM deve incluir:

Avaliação da estrutura de saúde dos municípios impactados pelo projeto de assentamento de reforma agrária ou outro empreendimento, análises epidemiológicas da malária, análises entomológicas dos vetores transmissores da malária, características do empreendimento e impactos socioeconômicos decorrentes de sua implantação, acompanhados de cópia de mapas com a localização georreferenciada do empreendimento e suas vias de acesso, conforme disposto no Anexo I a esta Portaria (BRASIL, 2014a).

Somente após a aprovação da APM, o licenciamento (LAPM) é emitido pelo órgão de saúde competente, passando a ser o documento condicionante para a Licença Prévia (LP). A Licença de Instalação (LI) se condiciona à aprovação do PACM para obtenção do Atestado de Condição Sanitária (ATCS). Caso não seja cumprido o Plano para Controle da Malária, o órgão de saúde competente pode cancelar o ATCS.

A figura a seguir (Figura 13) sintetiza a importância da malária como indicador de avaliação de impacto à saúde em áreas de risco ou endêmicas, no contexto de políticas pública, planos de desenvolvimento e demais projetos. Sua importância epidemiológica para a vigilância é de relevância ainda maior para o empreendedor, na medida em que o cumprimento da Portaria SVS/MS n ${ }^{\circ} 1$ assume caráter de ação compulsória para a concessão do licenciamento ambiental de empreendimentos na região Amazônica. 


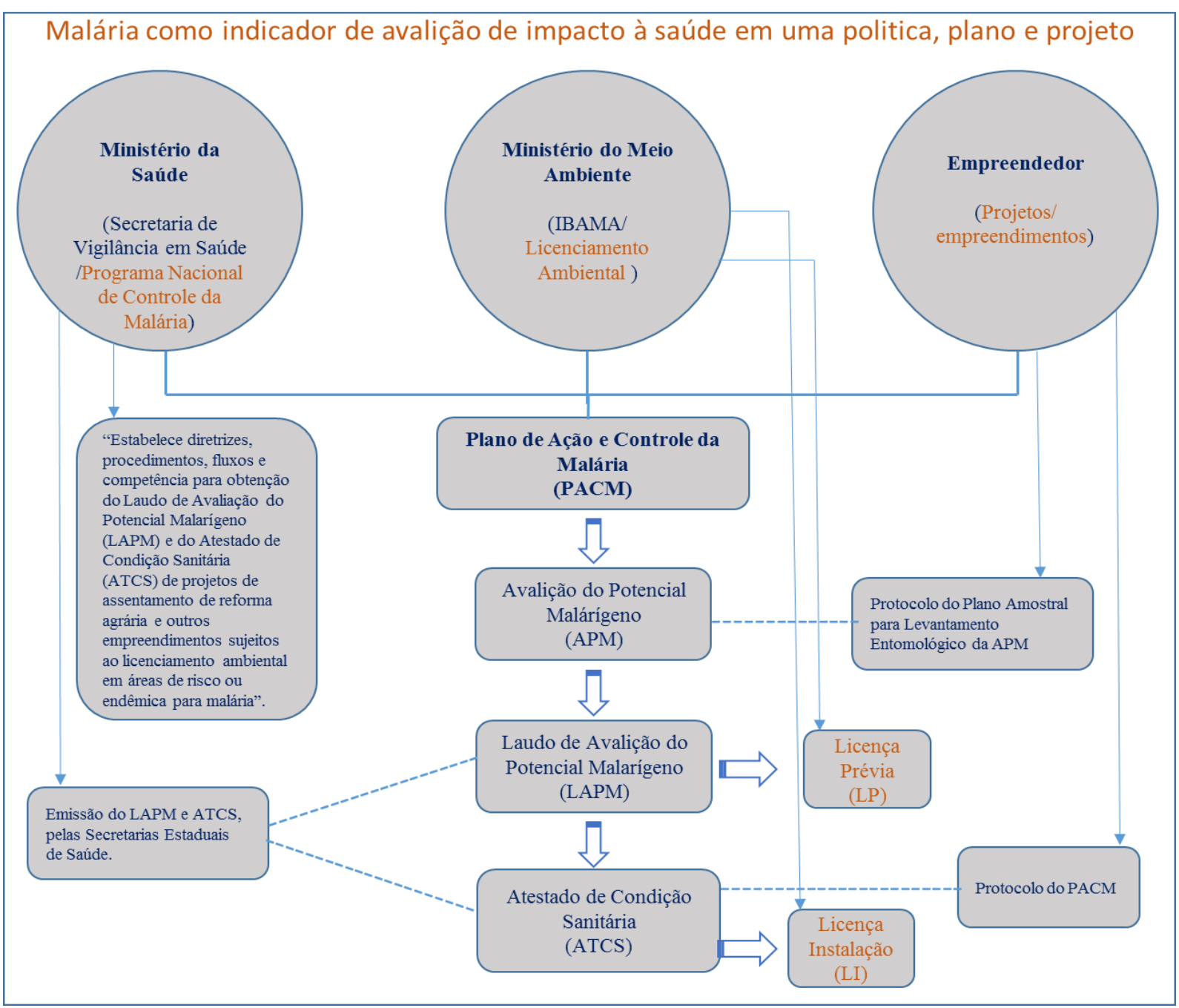

Figura 13 - Fluxo do PNCM para avaliação da saúde em áreas de risco ou endêmicas de malária, conforme Portaria MS/SVS No 1 , de 13/01/2014

Fonte: elaborado por Missifany Silveira, 2015.

O PACM é, portanto, um indicador de avaliação de impacto à saúde, tendo em vista que ele estrutura as ações nas Áreas de Influência Direta e Indireta (AID e AII) dos empreendimentos, incluindo os alojamentos e canteiros de obras, antes do seu início, caracterizando-se, assim, como ação preventiva da saúde.

Destaca-se, ainda, que parágrafo único da referida Portaria SVS/MS n ${ }^{\circ} 1$ determina que o PACM:

Deve ser reajustado e readequado de acordo com o monitoramento e avaliação promovidos nas diversas fases do empreendimento, observados nas vistorias e em conjunto com os entes envolvidos, incluindo os investimentos necessários para dar sustentabilidade ao controle da malária, previstos no documento (BRASIL, 2014a). 
A relevância desse indicador assume caráter inquestionável mediante a gravidade da doença. O setor saúde exerce papel fundamental no processo de licenciamento de grandes empreendimentos de infraestrutura no país. Entretanto, a limitação institucional persiste. Com a emissão da Portaria Interministerial no 419/2011, que regulamenta a atuação dos órgãos e entidades da administração pública federal envolvidos no licenciamento ambiental, definindo prazos e escopo de atuação, o processo tende a se simplificar. Como consequência, os impactos se limitam apenas às áreas de riscos e endêmicas de malária, diminuindo o espaço para a aplicação da Avaliação de Impacto à Saúde (AIS) como estratégia de integração à AIA.

\subsection{AVALIAÇÃO DE IMPACTOS À SAÚDE (AIS): CONCEITOS, NOÇÕES E PERSPECTIVAS}

A Organização Mundial da Saúde (OMS) definiu, pela primeira vez, a Avaliação de Impacto à Saúde (AIS) como uma combinação de procedimentos, métodos e ferramentas que permitem avaliar uma proposta de política, plano ou programa quanto aos seus potenciais impactos à saúde, bem como a ocorrência desses efeitos na população (WHO, 1999). Essa definição representou um marco para a AIS, quando lançada pela OMS, em 1999, no documento Ghotenburg Consensus ${ }^{11}$ (Consenso de Gotemburgo, em português)

Segundo International Association for Impact Assessment (IAIA - Associação Internacional para a Avaliação de Impacto, em português), os princípios orientadores da AIS baseiam-se no Consenso de Ghotemburg, que tem como valores a democracia, a equidade, o desenvolvimento sustentável, o uso ético da evidência e a abordagem global da saúde. Trata-se de consenso pertinente também por reforçar a necessidade de a AIS avaliar os efeitos sobre os determinantes sociais da saúde (IAIA, 2006).

Observa-se uma escassa presença dos aspectos relativos à saúde durante as avaliações ambientais na década de 1970. Por conta desse fator, e após intensas campanhas da Organização Mundial da Saúde (OMS) por meio de programas como "Saúde para todos no século XXI” e, mais recentemente, a estratégia da "Rede de Cidades Saudáveis", a Avaliação de Impacto à

\footnotetext{
${ }^{11}$ Resultado das discussões do documento "Health impact assessment: From theory to practice", no seminário "Health impact asssessment: From theory to practice" preparado pela European Centre for Health Policy (ECHP) da Organização Mundial da Saúde (OMS), em Gothenburg, Suécia, de 28 a 30 de outubro de 1999.
} 
Saúde (AIS) adquiriu maior visibilidade como instrumento de ação intersetorial de promoção da saúde e de redução das desigualdades, sendo apreendida por diversos países (BACIGALUPE et al, 2009).

Diversos países utilizam a Health Impact Assessment (HIA - Avaliação de Impacto à Saúde, em português) com o objetivo de introduzir a perspectiva da saúde na elaboração de políticas públicas que tenham por objetivo identificar sistematicamente as potenciais desigualdades originadas da sua implementação, com a consequente proposta de mudanças que promovam a equidade para a saúde nas regiões afetadas (SILVEIRA et al, 2012).

Com base nos compromissos assumidos pela União Europeia (UE), desenvolveu-se a metodologia da Avaliação de Impacto à Saúde (AIS) para aplicação no desenvolvimento de políticas de países da UE, originalmente denominada de European Policy Health Impact Assessment Methodology, ou Metodologia EPHIA. Seu o objetivo era informar e influenciar o processo de elaboração de uma política, programa ou projeto, levando-se em consideração suas implicações sobre as iniquidades em saúde (ABRAHAMS et al, 2004).

Segundo Abrahams et al (2004), esse método adota como referência básica o "modelo social de saúde", que extrapola a ausência de doença e aborda o bem-estar físico, mental, social e espiritual das pessoas. Para tanto, reconhece que a saúde e o bem-estar são afetados por complexas interações entre fatores sociais e econômicos, desenvolvimento físico e comportamento individual, assim como fatores hereditários.

A análise a respeito das iniquidades em saúde é considerada um dos princípios-chave dessa metodologia, na qual se aponta a existência de indivíduos e grupos de pessoas que apresentam condições melhores ou piores de saúde, ressaltando-se as desigualdades existentes. Este fator reflete a exposição diferenciada a riscos de saúde associados a fatores como condições socioeconômicas, etnia e gênero, ao longo do tempo de vida dos indivíduos (ABRAHAMS et al, 2004).

Dessa forma, portanto, a AIS engloba a identificação, predição e avaliação das esperadas alterações nos riscos à saúde - que podem ser tanto negativas quanto positivas, individuais ou coletivas -, causadas por uma política, plano, programa ou projeto de desenvolvimento que afetem uma determinada população. Vale destacar ainda que tais mudanças podem ser diretas e imediatas, indiretas ou tardias (WHO, 1999). 
Os "praticantes"12 da AIS sustentam que, em virtude de seu caráter preditivo, multidisciplinar, intersetorial e participativo, com foco nas desigualdades sociais, essa metodologia, além de utilizada para auxiliar a tomada de decisões, tem a finalidade de maximizar os ganhos de saúde por meio de uma intervenção (QUIGLEY, 2006; ABRAHAMS et al 2004; BHATIA E WERNHAM, 2009; MIRKO, 2013). Pressupõe-se, por conseguinte, que a AIS é capaz de otimizar as condições e a qualidade de vida de determinada população que venha a sofrer algum tipo de intervenção no seu território. Para a maior parte dos especialistas ou "praticantes de AIS", esse instrumento visa alcançar os seguintes resultados:

- Maximizar ganhos na saúde por meio de investimento relativamente pequeno no contexto do desenvolvimento;

- Melhorar a situação de saúde nas comunidades locais, assegurando a sustentabilidade do projeto;

- Estabelecer as bases para uma integração estratégica entre os setores de saúde e meio ambiente, possibilitando a colaboração das duas partes em questões interligadas.

A AIS propõe, em seu desenho, a sistematização de informações, incorporando evidências científicas, com o olhar dirigido aos problemas identificados e aos impactos previstos para a saúde. Constitui, desse modo, uma ferramenta de sustentação técnica e política para os tomadores de decisão. Vale destacar que um dos aspectos mais importantes dessa metodologia é sua abordagem integrada, com a participação dos atores sociais no território desde o início do projeto, em torno dos problemas que possam surgir com o novo empreendimento.

De acordo com estudos apresentados pelo York Health Economics Consortium (YHEC), a AIS pode se integrar a outras formas de avaliação de impacto para determinar, com base em evidencias, o impacto sobre os determinantes da saúde passíveis de serem afetados por uma política, plano ou programa. Essa integração seria benéfica por disponibilizar informações e orientações aos profissionais que desconhecem os impactos na saúde causados por empreendimentos potencialmente poluidores (YHEC, 2006).

\footnotetext{
12 Essa denominação é comumente utilizada pela maioria dos pesquisadores e especialistas em AIS em âmbito internacional, como nos foi possível observar durante dois Seminários Internacionais sobre Health Assessment Impact, realizados no Canadá e na Itália, em 2012 e 2015 respectivamente.
} 
Segundo Noble e Bronson (2005), a inclusão dos impactos à saúde na Avaliação de Impacto Ambiental (AIA) dos projetos tem recebido maior destaque por parte dos profissionais e instituições de saúde, incluindo a Organização Mundial de Saúde (OMS) e a Health Canada, num reconhecimento da necessidade e dos benefícios de uma abordagem no âmbito da saúde na AIA (NOBLE; BRONSON, 2005).

Essa experiência do Canadá em projetos de mineração permitiu que se concluísse como os processos que avaliam os impactos dos respectivos projetos não têm conferido a devida importância à questão da saúde humana. O mesmo estudo identificou oportunidades de aprendizagem no sentido de se avançar para uma abordagem mais inclusiva da saúde na AIA, conforme destacam Noble e Bronson (2005). Para os dois autores, integrar a saúde em avaliações de impactos ambientais exige inúmeras considerações, tais como avaliar os efeitos dos projetos na saúde, tendo como base o reconhecimento de que a saúde humana, o bem-estar e o ambiente são indissociáveis. Nesse aspecto, as repercussões sociais e para a saúde deveriam ser consideradas com o mesmo rigor científico que se confere aos fatores biofísicos durante a avaliação de impactos ambientais.

A AIS, apesar de adotada há quase duas décadas - desde o Consenso de Gotemburgo, em 1999 -, continua a atrair a atenção de diferentes setores, tanto públicos quanto privados, além do meio acadêmico e de organizações da sociedade civil. Pesquisa realizada por Balby (2012) apontou um significativo número de publicações - artigos científicos, manuais, guias, livros - e conferências internacionais a respeito da questão. Ressalta-se também que, em 2011, houve a criação da Society of Practioners of Health Impact Assessment (SOPHIA), com o objetivo de reunir os profissionais envolvidos com a prática da AIS (BALBY, 2012).

De acordo com a mesma pesquisa, a AIS apresenta vantagens e limitações. Assim sendo, deve atender a determinados pré-requisitos, tais como: os principais motivos para se adotar uma AIS; o contexto em que se insere a proposta; tipo de instituições responsável pelos custos e tomada de decisão; a existência de avaliadores capacitados; os métodos e ferramentas utilizados na avaliação; o engajamento das partes interessadas; a possibilidade de recursos humanos e financeiros, entre outros fatores (BALBY, 2012).

Constatou-se também que, no Brasil, são poucos os trabalhos que apresentam a variável saúde em avaliações prévias (ex ante) dos impactos relacionados a uma política, plano ou projeto. Mais comum é a participação em estudos retrospectivos (ex post), ou seja, em avaliações durante ou após a implantação de um projeto. Assim se evidenciou no capítulo 
anterior, no qual demonstramos que a avaliação da variável saúde é empregada especialmente em projetos específicos ou nos programas específicos - como é o caso da malária - no decorrer das avaliações de impacto ambiental.

\subsubsection{Aplicação da metodologia AIS no Brasil: perspectivas e desafios}

Conforme ressaltado no capítulo anterior, o Departamento de Vigilância em Saúde Ambiental e Saúde do Trabalhador (DSAST) atua, desde 2005, nos processos de licenciamento ambiental de grandes empreendimentos, com análise dos estudos ambientais mediante solicitação do Ibama. No entanto, essa perspectiva de avaliação retrospectiva, que aborda a saúde nos estudos ambientais, ainda apresenta lacunas.

Com o objetivo de definir as diretrizes e propor a realização de estudos e pesquisas para implementar a metodologia de Avaliação de Impacto à Saúde (AIS) de forma a garantir ações que vislumbrem a saúde e a qualidade de vida de populações expostas aos impactos gerados pelos grandes projetos de desenvolvimento, o DSAST disponibiliza iniciativas nesse campo. Nesse sentido, houve a elaboração de normativas e portarias para estruturar o campo da saúde ambiental no país, aproximando profissionais dos dois setores no âmbito do licenciamento ambiental, além da realização de oficinas para capacitação em AIS e a integração de agendas para a inclusão da saúde nos planos e projetos. Dentre as iniciativas, destacam-se:

- $\quad 1^{a}$. Oficina de Trabalho sobre Avaliação de Empreendimentos pelo Sistema Único de Saúde (SUS) para discutir Avaliação de Risco à Saúde decorrente de Empreendimentos Críticos e Ações Antrópicas (BRASIL, 2005);

- Portaria nº 47, de 29 de dezembro de 2006, que dispõe sobre a Avaliação do Potencial Malarígeno e o Atestado de Condição Sanitária para os projetos de assentamento de reforma agrária e para outros empreendimentos, nas regiões endêmicas de malária;

- $1^{a}$. Reunião sobre licenciamento ambiental de empreendimentos, com base nas experiências das esferas federal, estadual e municipal, no âmbito da Vigilância em Saúde Ambiental, realizada em 2007 (SILVEIRA, 2008);

- Seminário sobre Saúde Ambiental e Saúde do Trabalhador e suas interfaces com o Programa de Aceleração do Crescimento (PAC), realizado pelo Ministério da Saúde 
(MS) e pela Associação Brasileira de Pós-graduação em Saúde Coletiva (Abrasco) (BRASIL, 2007d);

- Portaria n ${ }^{\circ} 822$, de 30 de abril de 2008, que estabelece diretrizes para cooperação entre o Ministério da Saúde e o Ministério do Meio Ambiente, visando a integração e a implementação de ações comuns e a consolidação de agenda bilateral (SILVEIRA, 2008);

- Participação do Ministério da Saúde nos processos de licenciamento ambiental nas Hidrelétricas do Rio Madeira (Santo Antônio e Jirau) e no Projeto de Transposição do São Francisco (PISF);

- "Oficina de trabalho sobre AIS" com colaboradores da OMS e das Universidades de Liverpool e do Canadá, realizado pelo Ministério das Saúde em parceria com a Abrasco, em 2008;

- Portaria MS n 2.241, de setembro de 2009, que institui o Grupo Técnico de Saúde e Licenciamento Ambiental, com a finalidade de estruturar a participação do setor saúde nos processos de licenciamento ambiental de empreendimentos;

- Representação no Comitê Gestor do Plano de Desenvolvimento Regional Sustentável do Xingu (CGDEX), sob coordenação da Casa Civil da Presidência da República, criado pelo Decreto $\mathrm{n}^{\circ} 7.340$, de 2 de outubro de 2010, com o objetivo de subsidiar as decisões e acompanhar as ações de planejamento das ações de saúde na Região do Xingu pela Câmara Técnica de Saúde;

- Portaria Interministerial $n^{\circ} 419$, de 26 de outubro de 2011, que regulamenta a atuação dos órgãos e entidades da administração pública federal envolvidos no licenciamento ambiental (BRASIL, 2011c);

- Portaria MS/SVS no 1, de janeiro de 2014, que estabelece diretrizes, procedimentos, fluxos e competência para a elaboração do Plano para o Controle da Malária (PACM) para o licenciamento ambiental de empreendimentos (BRASIL, 2014a);

- Realização, em 2013, do $1^{\circ}$ Seminário Brasileiro sobre Avaliação de Impacto à Saúde (AIS) e atuação do setor saúde no Licenciamento Ambiental;

- Elaboração, em 2014, do documento Avaliação de Impacto à Saúde (AIS): Metodologia adaptada para aplicação no Brasil (BRASIL, 2014c). 
Sob essa perspectiva, a busca por novos instrumentos e metodologias capazes de avaliar os impactos sobre a saúde se evidencia como prerrogativa do setor saúde, reforçando seu papel nas políticas sociais de modo a garantir arranjos institucionais e capacidade de resposta mais efetivos.

Diante desse quadro, o modelo AIS se tornou objeto de estudo no Brasil, a partir das experiências relatadas por outros países, por meio dos "praticantes de AIS". A primeira iniciativa ocorreu em 2008, quando da realização da "Oficina de trabalho sobre AIS", que contou com colaboradores da OPAS/OMS e das Universidades de Liverpool e do Canadá. A oficina teve por objetivo a capacitação dos profissionais do setor saúde a fim de se lançaram as bases para a operacionalização da AIS no Brasil.

Com base nessa experiência e nas muitas reuniões de trabalho e seminários, a discussão sobre a metodologia AIS adquiriu contornos mais abrangentes no âmbito do SUS, com a elaboração do documento: Avaliação de Impacto à Saúde - AIS: Metodologia adaptada para aplicação no Brasil. Essa é a referência mais atual nos dias de hoje, publicada pelo Ministério da Saúde com a finalidade de induzir o desenvolvimento de atividades específicas para a adaptação e desenvolvimento da AIS no país (BRASIL, 2014c). Essa publicação objetivou contribuir para o aperfeiçoamento da política de saúde e de meio ambiente. Sua aplicação deveria atuar como guia para a política ambiental em curso, já que se configura como documento propositivo que "tratará da atuação do setor saúde nos processos de licenciamento ambiental" (BRASIL, 2014c). Vale destacar ainda que esse documento tem sua importância reconhecida como primeiro relatório no país que preconiza a importância dos impactos à saúde decorrentes, principalmente, da construção e implantação de grandes empreendimentos.

Nesse sentido, as inter-relações causais entre os impactos ambientais e os possíveis efeitos sobre a saúde humana passam por uma reorientação para se incluir a dimensão da saúde na Avaliação de Impacto Ambiental (AIA), visando o fortalecimento de ações que instiguem as empresas a mitigar e compensar impactos sobre a saúde da população. No entanto, a AIA não consegue por si só assegurar que a saúde e seus determinantes sejam contemplados na avaliação dos impactos de grandes empreendimentos, como as hidrelétricas, necessitando-se ainda de uma avaliação mais abrangente.

O documento Avaliação de Impacto à Saúde - AIS: Metodologia adaptada para aplicação no Brasil poderia inserir em sua concepção, de acordo com nosso entendimento, além da Avaliação de Impacto Ambiental (AIA), a Avaliação Ambiental Estratégica (AAE). Este 
último é um instrumento que possibilita "enfoques analíticos e participativos que visam integrar as considerações ambientais nos planos, políticas e programas, avaliando as interligações com as considerações econômicas e sociais" (OCDE, 2006).

Para o MMA, as avaliações de impacto preditivas são fundamentais para subsidiar a fase de formulação de uma política pública e, no caso da Avaliação Ambiental Estratégica (AAE), são apresentadas como um instrumento de suporte às decisões; aplicam-se às políticas, planos ou programas em fase de concepção, e não na avaliação durante a etapa de implementação, como ocorre com a AIA (MMA, 2002).

A figura a seguir demonstra que uma AAE se posiciona na hierarquia dos diferentes níveis de tomada de decisão. As políticas se situam no topo da pirâmide e, assim, determinam os planos, os programas e os projetos futuros a serem colocados em prática. Dessa forma, a AAE se aplica nos três primeiros níveis por serem os mais estratégicos, já que orientam os grandes objetivos (Figura 14).

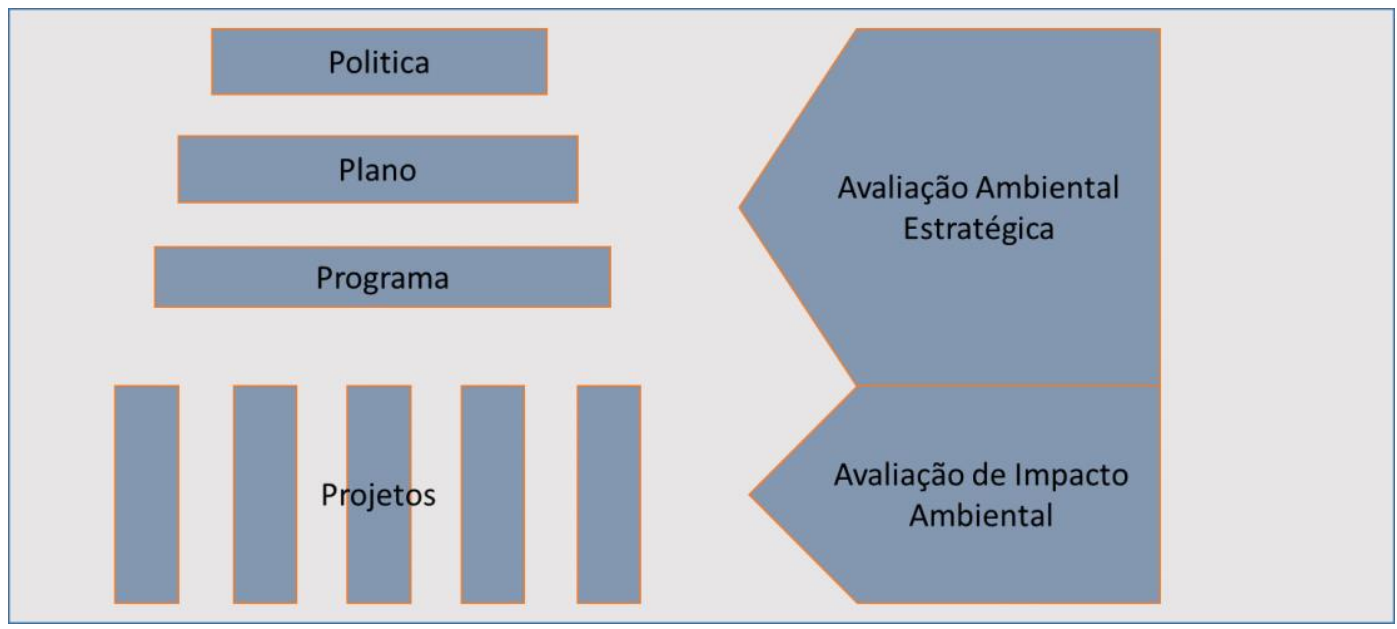

Figura 14 - Tomada de decisão nos diferentes níveis hierárquicos considerando a AAE e AIA Fonte: OCDE, 2006.

Segundo a OCDE (2006), apesar de se situarem no grau mais alto da tomada de decisão, as políticas tendem a ter proposições mais flexíveis que os projetos, pois estes comportam geralmente especificações e normas bem definidas. Essa afirmação se evidencia na AIA, por meio do Estudo de Impacto Ambiental (EIA), obrigatório nos processos de licenciamento ambiental de empreendimentos específicos. A respeito, faz-se necessária uma discussão mais ampla, que direcione a abordagem metodológica no sentido de integrar a Avaliação de Impacto 
à Saúde (AIS) a outras avaliações, como a AIA e AAE, compreendendo como estratégia de fortalecimento as políticas setoriais, principalmente na fase de implementação de um determinado projeto. Para Sánchez (2008), a AEE é considerada um instrumento catalizador, tendo em vista que poderia facilitar a integração entre as PPPs nas diversas instituições responsáveis pelas articulações, promovendo assim a coordenação entre elas.

Por se configurar como ferramenta que permite estimar os impactos causados por uma política, plano ou programas sobre a saúde, estimando principalmente as iniquidades sociais, a metodologia de AIS no Brasil é concebida atualmente a partir de sua integração com a AIA. Porém, como se sabe, a abordagem sobre a saúde humana nos estudos ambientais apresenta um escopo limitado. Desse modo, a AIS se mantém como um instrumento metodológico frágil no sentido de "minimizar os impactos negativos e maximizar os impactos positivos, nos diferentes contextos sociais, econômicos e geográficos", como explicitado no documento publicado pelo Ministério da Saúde (BRASIL, 2014c).

Nessa perspectiva, há autores que dialogam na direção da integração da AIS com a AIA, possibilitando uma nova categoria de análise, voltada para promover melhores condições de vida e saúde à população da área de abrangência de um projeto. Entretanto, para Bhatia e Wernham (2009), essa integração depende:

- De um proponente do projeto que reconheça a Avaliação de Impacto Ambiental (AIA) como uma estratégia regulatória disponível à saúde pública;

- Da receptividade da agência que conduz a Avaliação de Impacto Ambiental (AIA);

- Do envolvimento das instituições de saúde pública;

- Dos objetivos complementares entre os interessados da comunidade e profissionais de saúde;

- Da colaboração entre as instituições responsáveis pela Avaliação de Impacto Ambiental (AIA), as instituições de saúde pública e os interessados afetados, além de diretrizes, recursos e treinamento para a prática integrada da Avaliação de Impacto à Saúde (AIS) e da Avaliação de Impacto Ambiental (AIA).

Destaca-se ainda que a regulamentação atual para os projetos de desenvolvimento ancorados apenas na AIA, com o EIA e o PBA atuando como seus instrumentos - pode ser 
insuficiente para avaliações mais abrangentes como a AIS. Essa peculiaridade acaba por se tornar uma fragilidade, porque, na maioria dos casos, as decisões estratégicas já foram tomadas, havendo pouca margem para alternativas de menor risco à saúde. Além do mais, consideramos a dificuldade em se dar seguimento à avaliação ou ao monitoramento das recomendações de saúde nas avaliações de impacto ambiental após a conclusão do processo de licenciamento.

Para a maior parte dos "praticantes", a AIS é aplicada às políticas públicas como instrumento de planejamento, com a propositura de ações específicas de saúde com o objetivo de melhorar a qualidade de vida das populações das áreas afetadas por meio da predição de possíveis riscos. Contudo, um dos princípios do modelo conceitual da AIS é a incorporação dos determinantes sociais, o que confere maior abrangência para a sua avaliação.

A respeito, apontamos como relevante que, no documento publicado pelo Ministério da Saúde, se explicitassem os determinantes sociais de saúde. Assim, o instrumento se tornaria mais robusto por considerar a complexidade e a interdependência dos fatores socioeconômicos e os conflitos decorrentes de sua interação com o ambiente e, essencialmente, com os determinantes sociais da saúde, como aponta Winkler (2011) (Figura 15). No mais, poderia contribuir na identificação dos impactos sobre grupos vulneráveis de forma diferenciada, já que abordaria as desigualdades e iniquidades em saúde.

A AIS é citada também como componente da Health in All Policies (HiAP - Saúde em Todas as Políticas, em Português) no sentido de alcançar melhores resultados em saúde com a diminuição das desigualdades identificadas nessa área. Em 2013, Helsinque, na Finlândia, sediou a Conferência Mundial sobre Promoção da Saúde, que indicava, entre seus principais objetivos, a implementação da HiAP.

A HiAP é uma abordagem que visa integrar a saúde em todas as políticas públicas, no âmbito de todos os setores que se incorporem sistematicamente a saúde e os sistemas de saúde nas decisões. Suas principais características se fundamentam nos Direitos Humanos e na justiça social como foco da formulação de políticas (LEPPO et al, 2013). Uma aproximação dessa natureza, que inclua a saúde no contexto de outras políticas sociais - como transporte, habitação, educação, agricultura -, representa uma influência significativa sobre os fatores determinantes da saúde (GULIS et al, 2014). 


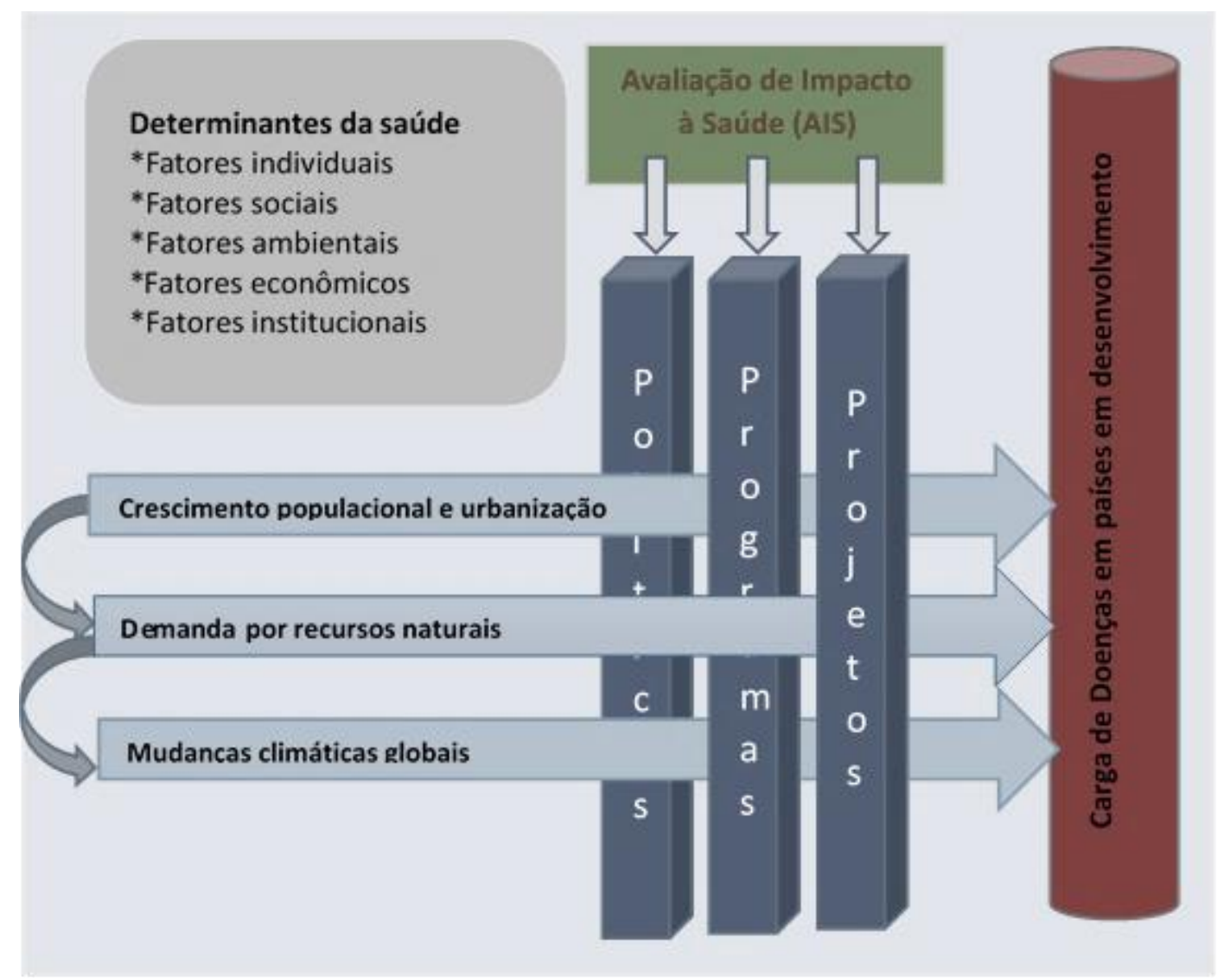

Figura 15 - Influência dos determinantes da saúde na AIS

Fonte: WINKLER, 2011.

Considerando-se que as desigualdades em saúde resultam não apenas de múltiplos fatores econômicos, ambientais e estilo de vida, mas também dos problemas relativos ao acesso aos cuidados de saúde, "é essencial que a redução dessas desigualdades seja considerada como prioridade fundamental em todos níveis de uma ação política, prosseguindo assim com a estratégia 'saúde em todas as políticas' e pela realização de avaliações de impacto eficazes, que tenham em conta os resultados em termos de equidade no campo da saúde"13.

Cabe ressaltar que o documento de discussão para a Conferência Mundial sobre Determinantes Sociais da Saúde, realizada no Brasil em 2011, ressalta que a maior parte da carga de doenças ocorre por conta das condições em que as pessoas nascem, vivem, crescem, trabalham e envelhecem. Portanto, esse conjunto de condições denominado de "determinantes sociais da saúde", no qual se resumem os determinantes sociais, econômicos, políticos, culturais

\footnotetext{
${ }^{13}$ Parlamento Europeu (2009/2014). Relatório: Reduzir as desigualdades no domínio da saúde na EU. Comissão do Ambiente, da Saúde Pública e da Segurança Alimentar. A7-0032/2011. Disponivel em: http://www.europarl. europa.eu/sides/getDoc.do?pubRef=-//EP//NONSGML+REPORT+A7-2011-0032+0+DOC+PDF+V0//PT.
} Acesso em: 12/12/2015. 
e ambientais da saúde, é de suma importância para avaliar as condições relativas a esse aspecto em uma determinada população (OMS, 2011).

Considerada como uma das vantagens da AIS, a abordagem dos Determinantes Sociais à Saúde (DSS) é tarefa complexa que envolve inúmeros fatores. Nesse sentido, é fundamental o empenho para que ocorra a integração dos diferentes órgãos e instituições responsáveis por políticas, programas e projetos, com a finalidade de seleção dos principais determinantes, por meio dos dados e informações mais relevantes e acessíveis para análise das desigualdades em saúde e, consequentemente, para a diminuição das iniquidades.

Contudo, apesar de se observarem avanços quanto ao tema, é necessário identificar quem, como e quando se deve realizar uma AIS, já que não existe legislação especifica para sua aplicação. Como exposto pelo Professor Mirko Winkler em palestra recente na Fiocruz ${ }^{14}$, apesar de existirem trabalhos que apontam caminhos para aplicação da AIS no Brasil, é preciso que as instituições de pesquisa se interessem por essa metodologia. Winkler enfatiza também ser preciso sensibilizar os profissionais do setor saúde na direção de propor e divulgar a importância do instrumento. Ademais, não há disponibilidade de capacitação em AIS, sendo necessário que as instituições de saúde proponham uma linha de treinamento e formação de corpo técnico específico para trabalhar nesse campo.

Outro ponto destacado pelo pesquisador se refere à qualidade da AIS quando integrada à AIA. Ele considera que os profissionais envolvidos nas avaliações normalmente são especialistas em meio ambiente; por possuírem foco apenas sobre os determinantes ambientais na saúde, eles desconhecem os demais aspectos como, por exemplo, o perfil epidemiológico de outras doenças que podem causar impacto em diferentes populações (WINKLER, 2015).

Como exposto por Balby (2012) em sua pesquisa sobre AIS no Brasil, uma das fragilidades da avaliação de impacto à saúde é que os projetos analisados no licenciamento ambiental seguem um escopo predefinido pelo empreendedor e pelo órgão ambiental e a ser negociado entre as partes. Nesse caso, não se atende a uma das premissas da AIS, qual seja, a inclusão das partes afetadas no processo. A pesquisadora aponta caminhos para superar essa

\footnotetext{
${ }^{14}$ Palestra proferida pelo Professor Mirko Winkler, do Instituto de Medicina Tropical e Saúde Pública da Suíça, sobre "Avaliação de Impacto à saúde em grandes empreendimentos em Países Tropicais", realizada pela Fiocruz e a Escola Nacional de Saúde Pública Sérgio Arouca (ENSP) em 14/04/2015.
} 
limitação, no sentido de haver maior envolvimento dos órgãos de saúde na definição do escopo da AIA, de forma a possibilitar a integração entre saúde e ambiente desde o início do processo.

Sendo assim, a AIS não deve ser vista como um instrumento para substituir a AIA nos processos de licenciamento, mas poderá se configurar como instrumento complementar. O setor ambiental, responsável por analisar as questões de saúde nesses processos, não dispõe de corpo técnico capacitado para a tarefa. Dessa maneira, as análises são comumente contestadas pelos órgãos de controle por conta da ausência de resposta efetiva das condicionantes impostas pelo projeto. Contudo, até que novas metodologias sejam construídas e institucionalmente aceitas no âmbito das políticas públicas, as poucas alternativas de inclusão dos elementos relativos à saúde nos processos de desenvolvimento devem prosseguir.

No caso da UHE de Belo Monte, não se propôs avaliação de impacto à saúde independente, que analisasse especificamente os aspectos de saúde antes e durante sua construção. A avaliação desses aspectos ocorreu no âmbito de determinados programas e planos pontuais, como condicionante do licenciamento ambiental. Os desafios para se avaliarem os riscos à saúde dentro do processo de licenciamento ambiental têm demonstrado ser tão complexos quanto o empreendimento em si e serão observados no estudo de caso apresentado no próximo capítulo. 


\section{CAPÍTULO 4 - ESTUDO DE CASO: UHE DE BELO MONTE, IMPACTOS SOCIOAMBIENTAIS E AS QUESTÕES RELATIVAS À SAÚDE NO CONTEXTO DAS TRANSFORMAÇÕES DO TERRITÓRIO}

\subsection{PERSPECTIVAS GEOGRÁFICAS E METODOLÓGICAS}

Considerada a terceira maior do mundo, a Usina Hidrelétrica (UHE) de Belo Monte terá capacidade instalada de 11.233,1 MW, com dois reservatórios que, somados, compreendem uma área total de $516 \mathrm{~km}^{2}$ no rio Xingu. Sua barragem principal se localiza a aproximadamente $40 \mathrm{~km}$ a jusante da cidade de Altamira, no Estado do Pará.

Sua concepção abrange um barramento principal no rio Xingu (denominado Sítio Pimental), de onde derivam as vazões por canal que segue até a Casa de Força Principal ( $3^{\circ} 07^{\prime} 35^{\prime}$ 'S , 51 46 $36^{\prime}$ 'W), no Sítio Belo Monte, com a formação de um trecho de cerca de 100 km de extensão no rio Xingu a ser submetido a uma vazão residual. A Casa de Força

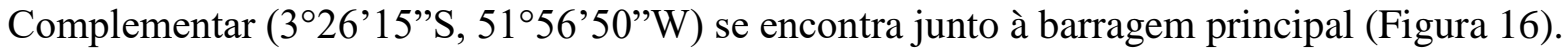

Segundo o RIMA (2009), a maior parte da área de abrangência do reservatório onde será construída a barragem se situa no município de Altamira, com 51,9\%; 48\% está localizada em Vitória do Xingu, e 0,1\% em Brasil Novo. Além dessas localidades, o empreendimento terá influência direta nos municípios de Anapu e Senador José Porfirio, por abrigarem localidades com as obras de Belo Monte (povoado de Belo Monte do Pontal e Vila de Santo Antônio).

Neste estudo de caso, delimitou-se o recorte temporal em função das fases do licenciamento ambiental. O marco foi o ano de 2011, quando da emissão da Licença de Instalação (LI), que concretizou o início das obras da usina. Esse parâmetro permitiu a correlação dos principais dados socioambientais e de saúde coletados na região, com a avaliação das informações em dois momentos, ou seja, antes e após o início das obras. Vale enfatizar que esse período também marcou o começo do processo migratório para a região, com grande afluxo populacional para a cidade de Altamira.

No tocante ao recorte espacial, a escolha recaiu sobre as Áreas de Influência Direta e Indireta (AID e AII), indicadas pelo Estudo de Impacto Ambiental (EIA) da UHE de Belo Monte. A ênfase recaiu sobre a AID, que engloba cinco municípios: Altamira, Vitória do Xingu, Anapu, Brasil Novo e Senador José Porfírio. Além de Altamira, que se caracteriza como o município com maior contingente populacional e conta com infraestrutura melhor desenvolvida 
em comparação com os demais, Anapu e Vitória do Xingu se situam nas proximidades dos canteiros de obra. A análise da Área de Influência Indireta (AII) ocorreu no âmbito da sua inserção no Plano de Desenvolvimento Regional Sustentável do Xingu (PDRS-X), no qual muitas das ações de saúde, como a construção, ampliação e equipamentos de saúde foram contempladas. A AII abarca outros cinco municípios: Placas, Uruará, Medicilândia, Pacajá e Porto de Moz.
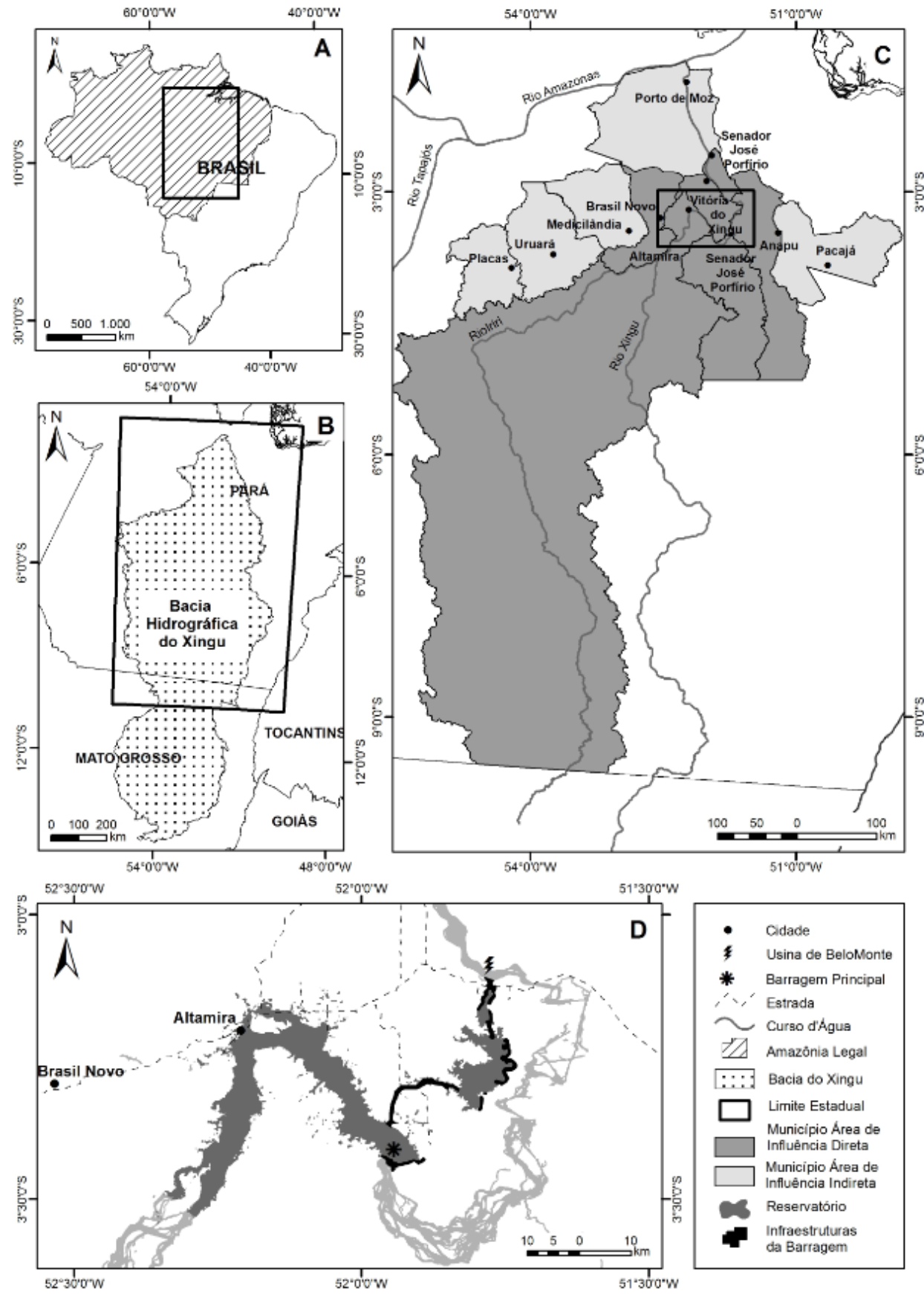

Figura 16 - Localização da Usina de Belo Monte

Fonte: Elaborado por Missifany Silveira a partir de dados do IBGE; ANA; OPEN STREET MAP, 2014. 
A escolha do objeto neste estudo de caso ocorreu em função de Belo Monte se configurar como uma das maiores obras do PAC, que além de ser uma obra reconhecida pela sua magnitude, é onde se concentram diversos conflitos socioambientais no âmbito de seu planejamento, desde décadas, até a sua construção, os quais foram, frequentemente, questionados por instituições nacionais e internacionais da área de meio ambiente e direitos humanos, movimentos sociais e organizações não governamentais (ONGs). A cronologia da obra da Usina de Belo Monte contou com cenas públicas, de conquistas políticas e perdas, em um processo de avanços e recuos dos movimentos sociais ao longo do tempo, que fizeram parte da história da idealização desse grande projeto de infraestrutura no país (Figura 17).

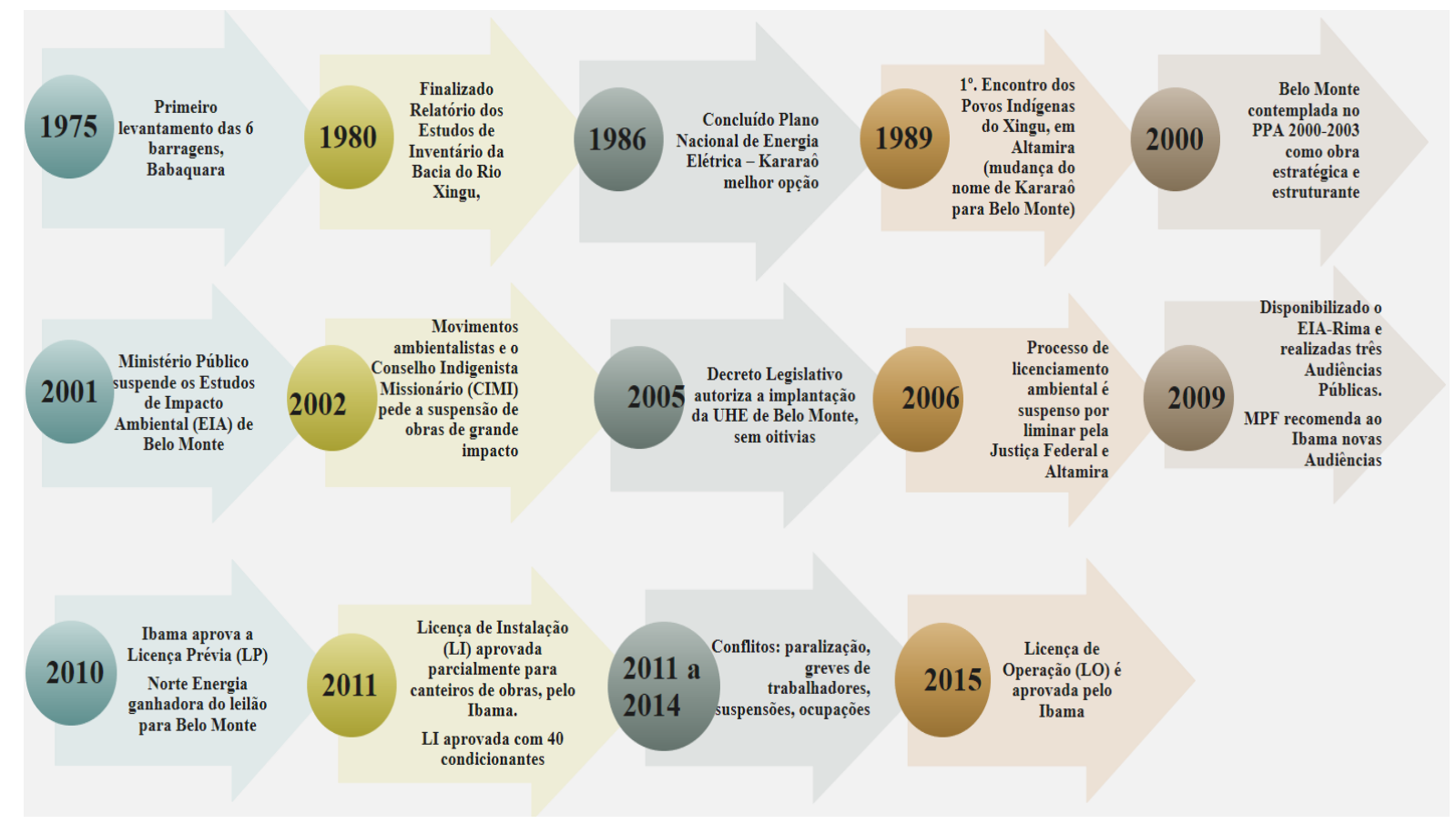

Figura 17 - A cronologia da implantação da Usina de Belo Monte, de 1975 a 2015.

Fonte: Elaborado por Missifany Silveira, 2015.

A pesquisa de campo visou, no entanto, verificar e analisar os principais impactos socioambientais e à saúde nas diferentes populações afetadas pela obra, a partir de dados e da percepção dos atores locais. Objetivou-se, na materialização das ações realizadas pelas instituições públicas e privadas nesses territórios, apontar os principais entraves, observando como a população "afetada" dialoga com os atores que "geram" o impacto. 
A abordagem qualitativa da pesquisa de campo se estabeleceu como o suporte metodológico para a realização de entrevistas abertas e o registro de declarações de atoreschave das instituições locais na cidade de Altamira. A escolha por esses dois métodos de coleta de dados se mostrou importante no sentido de registrar aspectos fundamentais à compreensão dos processos e das dinâmicas locais, acrescentando elementos e dimensões múltiplas à tarefa de identificar os principais impactos positivos e negativos para saúde nas obras da UHE de Belo Monte, bem como as limitações existentes.

No tocante à análise da situação relativa à saúde, selecionaram-se alguns dos principais indicadores de impacto relacionados à implantação de hidrelétricas, com destaque para as doenças transmissíveis, como malária, HIV-Aids, hepatites virais e sífilis, além das doenças não transmissíveis, como as causas externas. Os elementos alusivos a esses agravos, durante o período de investigação proposto neste estudo, foram disponibilizados pela Secretaria Municipal de Saúde (SMS) de Altamira e a 10 ${ }^{\text {a }}$ Regional de Saúde da Secretaria Estadual de Saúde (SES), com base em dados fornecidos pelos Sistemas de informações do Datasus do Ministério da Saúde (MS).

Além da coleta de dados, também ocorreram visitas, em Altamira, à empresa Norte Energia, responsável pelo empreendimento e pelas ações de mitigação dos impactos socioambientais na Área de Influência Direta (AID) e Indireta (AII); aos movimentos sociais como a Fundação Viver Preservar e Produzir (FVPP); ao Instituto Socioambiental (ISA); à Fundação Getúlio Vargas (FGV), responsável pelo monitoramento das condicionantes da Licença de Instalação (LI) da UHE de Belo Monte.

Cabe ressaltar que a empresa Norte Energia é a responsável pela mitigação dos impactos previstos nos estudos ambientais. Assim sendo, os recursos investidos visam atender as condicionantes das licenças ambientais que constam no Plano Básico Ambiental (PBA) e no Plano de Desenvolvimento Regional Sustentável do Xingu (PDRS-X). De acordo com o $10^{\circ}$ Centro Regional de Saúde ${ }^{15}$, esses recursos foram fundamentais para o fortalecimento dos três principais programas de saúde: 1) Programa Nacional para o Controle da Malária (PNCM); 2) Programa de Vigilância das Doenças (com foco nas patologias transmissíveis); 3) Programa de

\footnotetext{
${ }^{15} \mathrm{O} 10^{\circ}$ Centro Regional de Saúde é uma das treze Regionais de Saúde do Estado do Pará. Atende nove municípios, os quais coincidem com a área de Influência da UHE de Belo Monte. Em reunião realizada em agosto de 2015, foram disponibilizados dados e relatos sobre os aspectos da saúde relacionados à usina de Belo Monte. As Regiões de Saúde são instituídas pelo Estado, em articulação com os Municípios, respeitadas as diretrizes gerais pactuadas na Comissão Intergestores Tripartite (CIT).
} 
Fortalecimento da Atenção à Saúde (com foco na construção e equipamentos de Unidades de Saúde e Hospitais).

É importante esclarecer que a malária se destaca como o indicador de saúde mais visado tanto pelo setor ambiental quanto pelos empreendedores, tendo em vista se tratar de condição imperativa para obtenção das licenças. Por essa razão, esse parâmetro recebe, neste estudo, abordagem específica em um subcapítulo parte.

\subsection{TRANSFORMAÇÕES ECONÔMICAS, AMBIENTAIS E SOCIAIS PROVOCADAS PELA UHE DE BELO MONTE: OS DESCOMPASSOS DAS MEDIDAS COMPENSATÓRIAS E O AFLUXO POPULACIONAL NA REGIÃO}

De modo geral, as localidades onde se instalam grandes empreendimentos, como as hidrelétricas, têm seus espaços transformados em um contexto de marcadas contradições. De um lado, há os efeitos positivos, traduzidos por "benefícios" apresentados como um legado à população, além da geração temporária de emprego e renda. De outro, estão os impactos negativos, que, com o imperativo afluxo populacional tanto de trabalhadores como de pessoas atraídas pela obra, acarretam modificações profundas no território. Os últimos representam uma pressão sobre os serviços públicos locais, especialmente para o sistema de saúde, normalmente despreparado para suportar um aumento na demanda de serviços que requer a expansão dos recursos humanos e financeiros.

Segundo o Estudo de Impacto Ambiental (EIA), no caso da UHE de Belo Monte, previase inicialmente um aumento populacional, ao final dos dois primeiros anos da obra, de cerca de 96.000 pessoas na região. O mesmo documento apontava que, a partir do quarto ano, as taxas de crescimento da população atraída para a região sofreriam um declínio até o término da implantação da usina (BRASIL 2014d) (Figura 18).

Por ser o centro das dinâmicas locais, Altamira é o município com o maior afluxo populacional, composto tanto de trabalhadores para a construção da obra como de pessoas atraídas em busca melhores oportunidades de trabalho e renda. Além da extensão territorial, a cidade também apresenta o maior número de habitantes da Região de Saúde do Xingu ${ }^{16}$.

\footnotetext{
${ }^{16}$ A Região de Saúde do Xingu compreende nove municípios dos dez localizados nas AID e AII da usina de Belo Monte.
} 
Segundo censo do IBGE de 2010, sua população era de 99.075. No entanto, há divergências quanto a esse total. Para os atores locais, a população já alcança 150.000, enquanto a estimativa do IBGE em 2014 foi de 106.768 habitantes (IBGE, 2014d). Atualmente, apesar de enormes deficiências apontadas pelos moradores e gestores, é também considerada uma referência em atendimentos de urgência e emergência para os nove municípios da Região de Saúde, por apresentar as melhores infraestruturas para o acesso à saúde comparativamente aos demais.

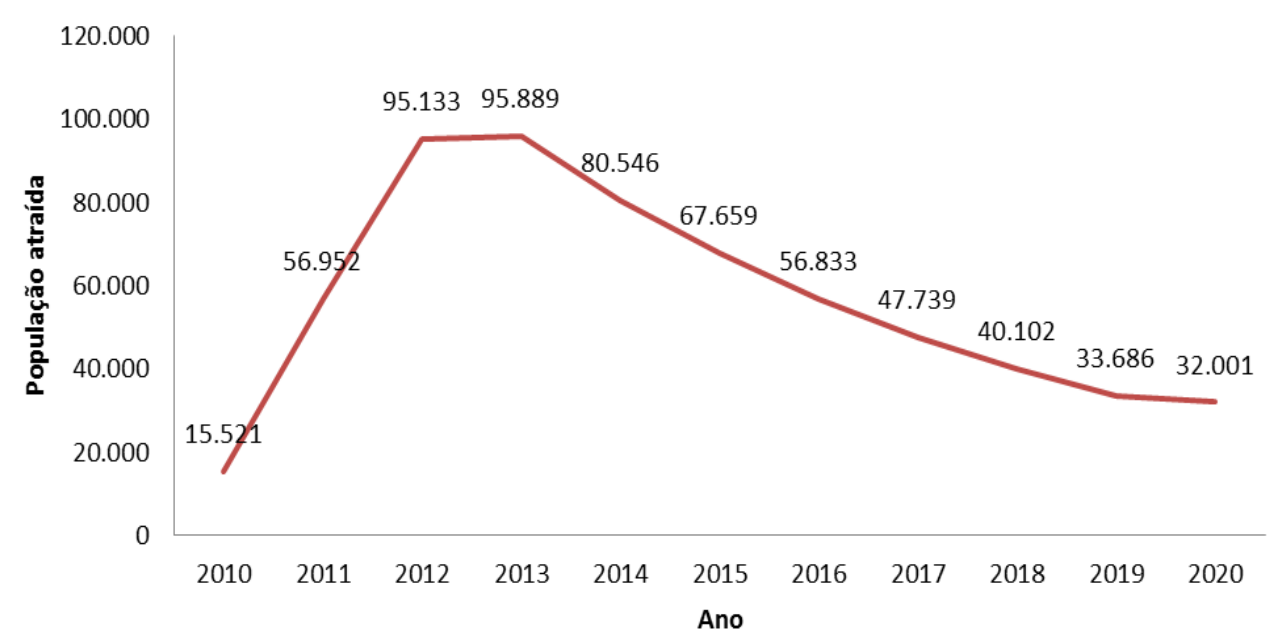

Figura 18 - Estimativa da população atraída pela obra de construção da usina de Belo Monte entre 2010 e 2020 para áreas de influência (direta e indireta)

Fonte: Brasil, 2014d.

Somada à obra da usina, houve a construção de quatro canteiros principais, nos sítios definidos, para uma população estimada pelo EIA de 20.109 trabalhadores (Quadro 5). De acordo com a Norte Energia, durante o pico da obra, foram contabilizados aproximadamente 45.000 trabalhadores contratados pelo Consórcio Construtor Belo Monte (CCBM), entre 2013 a 2014. Porém, atualmente, a usina conta, sem considerar a mão de obra terceirizada de outras empresas, com catorze mil trabalhadores, dos quais dez mil estão alojados nos canteiros e quatro mil residem na cidade de Altamira (NORTE ENERGIA, 2015).

O grande contingente populacional foi responsável, em parte, pela dinamização da região, principalmente na cidade de Altamira, onde houve aumento na procura pelo comércio e serviços, ocasionando circulação maior de pessoas e veículos. Esse fator se intensificou pelo trajeto diário dos trabalhadores entre o percurso dos canteiros de obra e as cidades vizinhas. A contratação de quarenta mil trabalhadores provocou pressões sobre o atendimento dos serviços 
básicos para a maioria da população dos municípios da Área de Influência Direta e Indireta (AID e AII) da UHE de Belo Monte.

Quadro 5 - localização dos canteiros de obras e capacidade de trabalhadores previstos durante a implantação da usina de belo monte (EIA-RIMA, 2009)

\begin{tabular}{|l|l|l|l|}
\hline Estrutura & Localização & Município & $\begin{array}{l}\text { No de } \\
\text { Funcionários }\end{array}$ \\
\hline Vila residencial & Altamira & Altamira & 500 \\
\hline Vila residencial & Santo Antônio do Belo Monte & Vitória do Xingu & 2.500 \\
\hline Alojamento & Santo Antônio do Belo Monte & Vitória do Xingu & 8.701 \\
\hline Alojamento & Sítio Bela Vista & Vitória do Xingu & 2.078 \\
\hline Alojamento & Sítio Ilha Pimental & Vitória do Xingu & 5.145 \\
\hline $\begin{array}{l}\text { Acampamentos/ } \\
\text { alojamentos provisórios }\end{array}$ & Sítio Canais e Diques & Vitória do Xingu & 1.185 \\
\hline Total & & & \\
\hline
\end{tabular}

Fonte: Brasil, 2014d.

As mudanças ocasionadas na região pela movimentação da economia local, com a implantação de redes para o comércio, construção de novas lojas, projetos de infraestrutura de lazer, entre outras iniciativas, são consideradas positivas para alguns setores da região. No entanto, essas modificações acarretaram também uma série de novas demandas e inúmeros problemas sociais e ambientais para a região.

Os dados do Atlas do Desenvolvimento Humano no Brasil a seguir (Quadro 6) apontam que os municípios da AID apresentaram melhoras significativas quanto aos indicadores de vulnerabilidade social, condições de moradia, renda e pobreza, entre 2000 e 2010. Porém, quando comparados à média nacional, esses números ainda estão inferiores ao desejado para a região.

No caso de Altamira, a situação tem se agravado em virtude do crescimento constante da população, resultando em uma mobilidade urbana caótica de acordo com os padrões da cidade. No mais, uma das principais queixas da população se refere à violência urbana, decorrente dos altos índices de criminalidade e do aumento do número de acidentes fatais, ocasionado pelo intenso trânsito de veículos. 
Quadro 5 - Indicadores de vulnerabilidade social, condições de moradia, renda e pobreza, no período de 2000 a 2010

\begin{tabular}{|c|c|c|c|c|c|c|c|c|c|c|c|c|}
\hline \multirow[t]{2}{*}{$\begin{array}{l}\text { Municípios AID da } \\
\text { UHE de Belo } \\
\text { Monte/ Indicadores }\end{array}$} & \multicolumn{2}{|c|}{ Mortalidade infantil * } & \multicolumn{2}{|c|}{$\begin{array}{c}\text { Mortalidade até } 5 \\
\text { anos de idade** }\end{array}$} & \multicolumn{2}{|c|}{$\begin{array}{c}\% \text { de } \\
\text { extremamente } \\
\text { pobres }\end{array}$} & \multicolumn{2}{|c|}{$\%$ de pobres } & \multicolumn{2}{|c|}{\begin{tabular}{|c|} 
\% pessoas em \\
domicílios com \\
abastecimento de água \\
e esgotamento sanitário \\
inadequados \\
\end{tabular}} & \multicolumn{2}{|c|}{$\begin{array}{c}\text { Renda per capita } \\
\text { (R\$) }\end{array}$} \\
\hline & 2000 & 2010 & 2000 & 2010 & 2000 & 2010 & 2000 & 2010 & 2000 & 2010 & 2000 & 2010 \\
\hline Brasil & 30,57 & 16,70 & 36,98 & 18,83 & 12,48 & 6,62 & 27,90 & 15,20 & 8,91 & 6,12 & 592,46 & 793,87 \\
\hline Altamira & 27,56 & 17,27 & 29,69 & 18,55 & 10,44 & 11,25 & 32,47 & 22,38 & 37,49 & 24,32 & 401,93 & 492,05 \\
\hline Anapu & 35,11 & 20,60 & 37,81 & 22,17 & 34,02 & 26,31 & 52,07 & 44,80 & 35,61 & 48,31 & 226,80 & 266,28 \\
\hline Brasil Novo & 36,05 & 17,40 & 38,82 & 18,72 & 20,42 & 26,63 & 40,05 & 41,29 & 53,09 & 27,73 & 289,98 & 408,55 \\
\hline Senador José Porfírio & 38,32 & 26,20 & 41,26 & 28,16 & 35,34 & 25,82 & 63,52 & 53,06 & 59,93 & 47,38 & 193,78 & 219,97 \\
\hline Vitória do Xingu & 35,11 & 20,00 & 37,81 & 21,51 & 32,03 & 18,88 & 55,86 & 42,76 & 59,81 & 34,83 & 261,41 & 323,18 \\
\hline
\end{tabular}

Fonte: Atlas de Desenvolvimento Humano, 2015.

Diante desse cenário, as medidas compensatórias são de responsabilidade própria do empreendedor, previstas nos Estudos de Impacto Ambiental e definidas no Plano Básico Ambiental (PBA), que respondem por praticamente todas as ações para mitigar e compensar os impactos estimados na área de influência da usina, em face das transformações ambientais e sociais decorrentes da sua construção.

Segundo relatório da Norte Energia publicado em dezembro de 2014, foram destinados mais de 1,9 bilhões de reais para ações socioambientais nos municípios das áreas de Influência Direta (AID) e Indireta (AII) da Usina Hidrelétrica Belo Monte. Como parte do Plano Básico Ambiental (PBA), encontram-se em desenvolvimento "117 projetos nas áreas ambiental, econômica, social e cultural para os cinco municípios da AID” (NORTE ENERGIA, 2014). Há de se destacar que, nesse montante, contemplam-se os recursos destinados ao Projeto Básico Ambiental (PBA), ao Componente Indígena (PBA-CI) e ao Plano de Desenvolvimento Regional Sustentável do Xingu (PDRS-X), propostos pelo governo federal (NORTE ENERGIA, 2014).

De acordo com os dados obtidos nesta pesquisa, juntamente com o que registrado a partir dos depoimentos da população local, há um longo caminho à frente até que sejam observadas tanto as ações compensatórias implementadas quanto aquelas em curso, de forma a apresentarem os efeitos desejados pelo empreendedor e, principalmente, pelas populações afetadas pelo empreendimento. Nos relatos de moradores de Altamira a respeito da usina de Belo monte, recolhidos em agosto de 2015 , as manifestações demonstraram a insatisfação com as mudanças ocorridas: 
No momento ainda estamos com a parte ruim, a cidade está passando pela estruturação toda. A gente não acompanha esse benefício de imediato" '[...] A gente ainda sofre muito, todo o trânsito que a gente tem no deslocamento para o trabalho. [...] Vim de lá pra cá de moto, é um verdadeiro rally! A cidade que não tem estrutura para esse 'enchimento' de carro e de gente". (INFORMAÇÃO VERBAL ${ }^{17}$ ).

Apesar de todo o aporte financeiro, os dados a seguir apontam para os problemas que ainda persistem na região.

\subsubsection{Saneamento e mobilidade urbana}

Apesar de o saneamento básico se vincular intimamente às questões de saúde, esse indicador é analisado separadamente, pois se trata de condicionante própria do PBA, no âmbito do qual se estabeleceu que a implantação de estruturas de saneamento básico atenderia os três municípios da AID da usina, a saber: Altamira, por ser a área de maior impacto populacional; Vitória do Xingu, e Anapu, município que abriga a construção da usina principal, os canteiros e alojamentos.

De acordo com a Fundação Getúlio Vargas (FGV), até o início do ano de 2015, o Ibama havia considerado essa condicionante como "parcialmente atendida". Apesar do município de Altamira contar com rede de abastecimento de água e esgoto, um Sistema de Tratamento de Esgoto, que ainda está em fase de testes, a rede não poderá ser operada pela falta de ligações domiciliares, o que ficou a cargo da prefeitura (Figuras 19 e 20).

Todas as localidades contempladas, conforme as condicionantes, com o recebimento de saneamento básico enfrentam o mesmo problema da falta de ligações domiciliares (onze mil novas conexões de agua e dezesseis mil de esgoto), situação que impede seu amplo funcionamento, bem como a definição da gestão desses sistemas por parte das instancias institucionais locais, principalmente devido ao alto custo de manutenção (FGV, 2015). O atraso também tem causado transtornos à população, que havia sofrido com a realização das obras realizadas quando um grande contingente populacional já ocupava Altamira. Hoje não se sabe

\footnotetext{
${ }^{17}$ Informações coletadas verbalmente em agosto de 2015, na cidade de Altamira, no Estado do Pará.
} 
ao certo quem irá arcar com os custos dessas ligações e tampouco se será instituída uma tarifa diferenciada para a população de baixa renda (FGV, 2015).
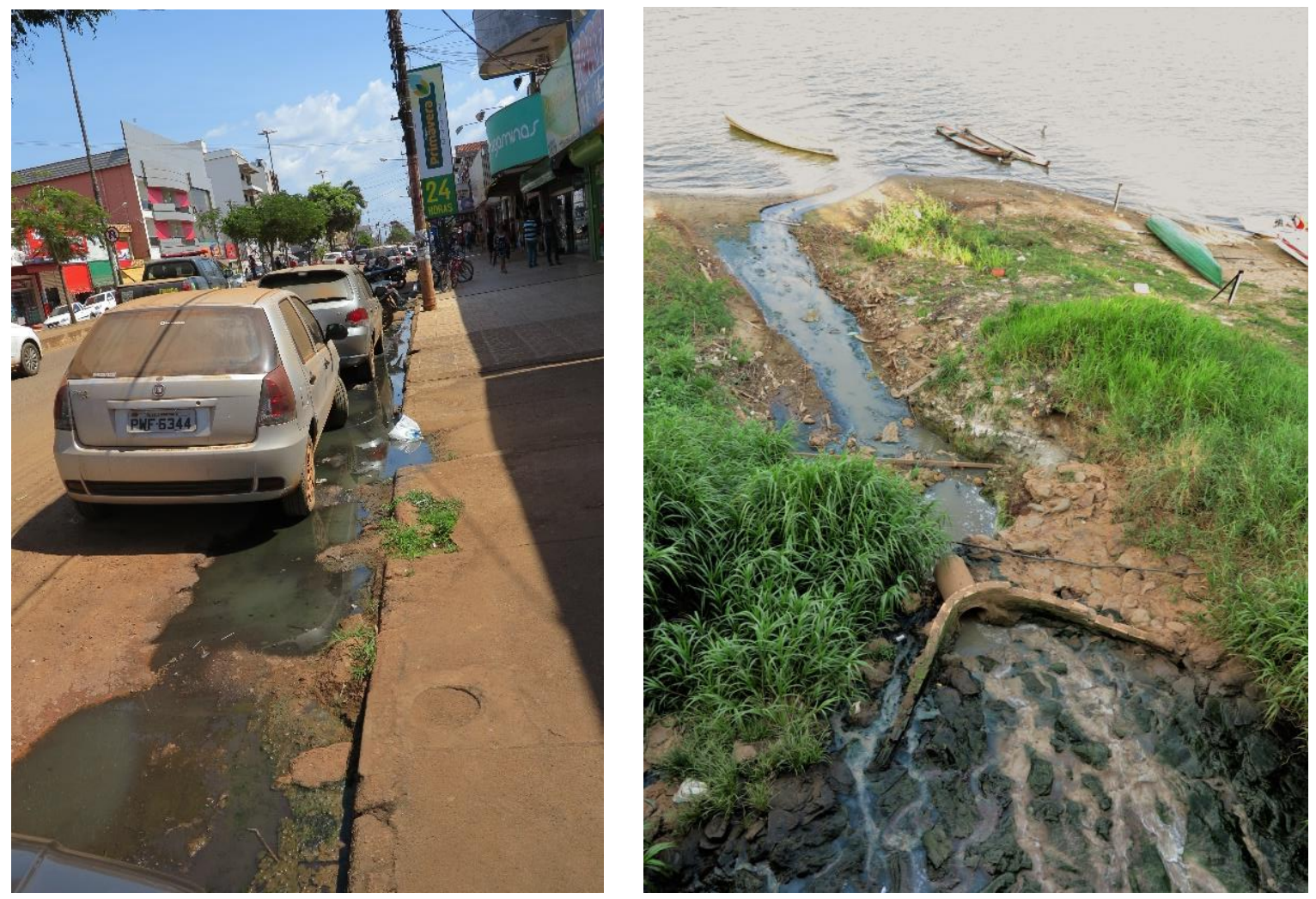

Figura 19 e 20 - Rua no centro de Altamira com esgoto a céu aberto e lançamento do esgoto diretamente no Rio Xingu.

Fonte: Por Missifany Silveira, 2015.

No tocante à mobilidade urbana, a situação do tráfego associada aos acidentes de trânsito na região se tornou um problema grave de saúde pública. De acordo com os dados do Departamento Municipal de Transporte e Trânsito (Demutran), Altamira registrou um aumento significativo no número de veículos automotores a partir de 2010. De acordo com o diretor desse Departamento, "a cidade passou, e ainda passa, por uma transformação" (Informação verbal) por conta da construção da usina de Belo Monte. Afirma ainda que esse foi um fator decisivo para o atual trânsito caótico que, consequentemente, contribuiu para o aumento de acidentes.

Diariamente, há um fluxo constante de ônibus, veículos, caminhões, máquinas pesadas e motocicletas entre os municípios de Altamira, Vitória do Xingu e Anapu, vias de acesso aos canteiros das principais obras (Pimental, Canal e Belo Monte), com o transporte de pessoas e cargas para erguer a maior obra do PAC (Figuras 21, 22 e 23). Apesar da movimentação de 
quase oitocentos ônibus por dia, na região dos canteiros de obras, para transportar os trabalhadores, mais da metade da frota veicular é representada por motocicletas. Vale destacar que estas são as principais responsáveis pelos acidentes de trânsito na área.

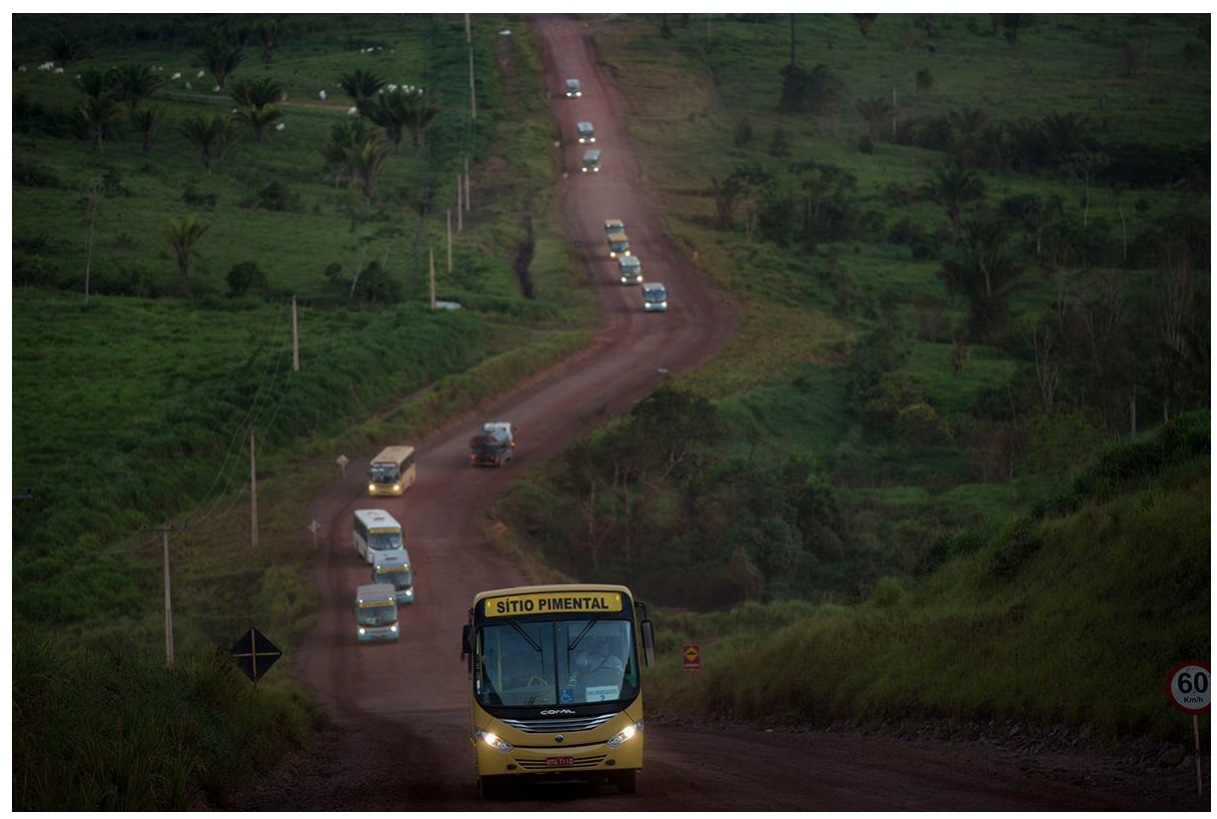

Figura 21 - Circulação de ônibus dos canteiros de obras da Usina de Belo Monte para Altamira Fonte: http://www.lalodealmeida.com.br/site_pt/editorial/belo-monte-a-obra/\#!prettyPhoto

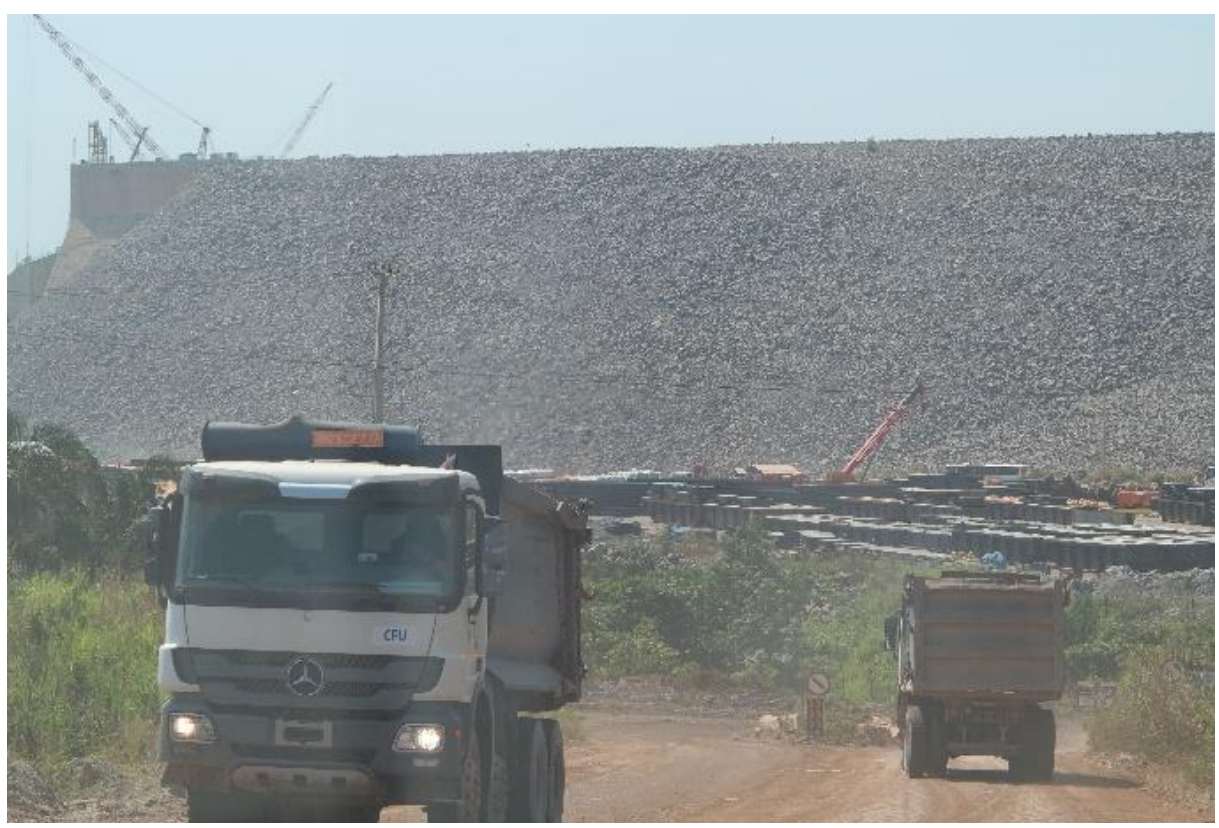

Figura 22 - Circulação de caminhões na UHE de Belo Monte

Fonte: Por Missifany Silveira, 2015. 


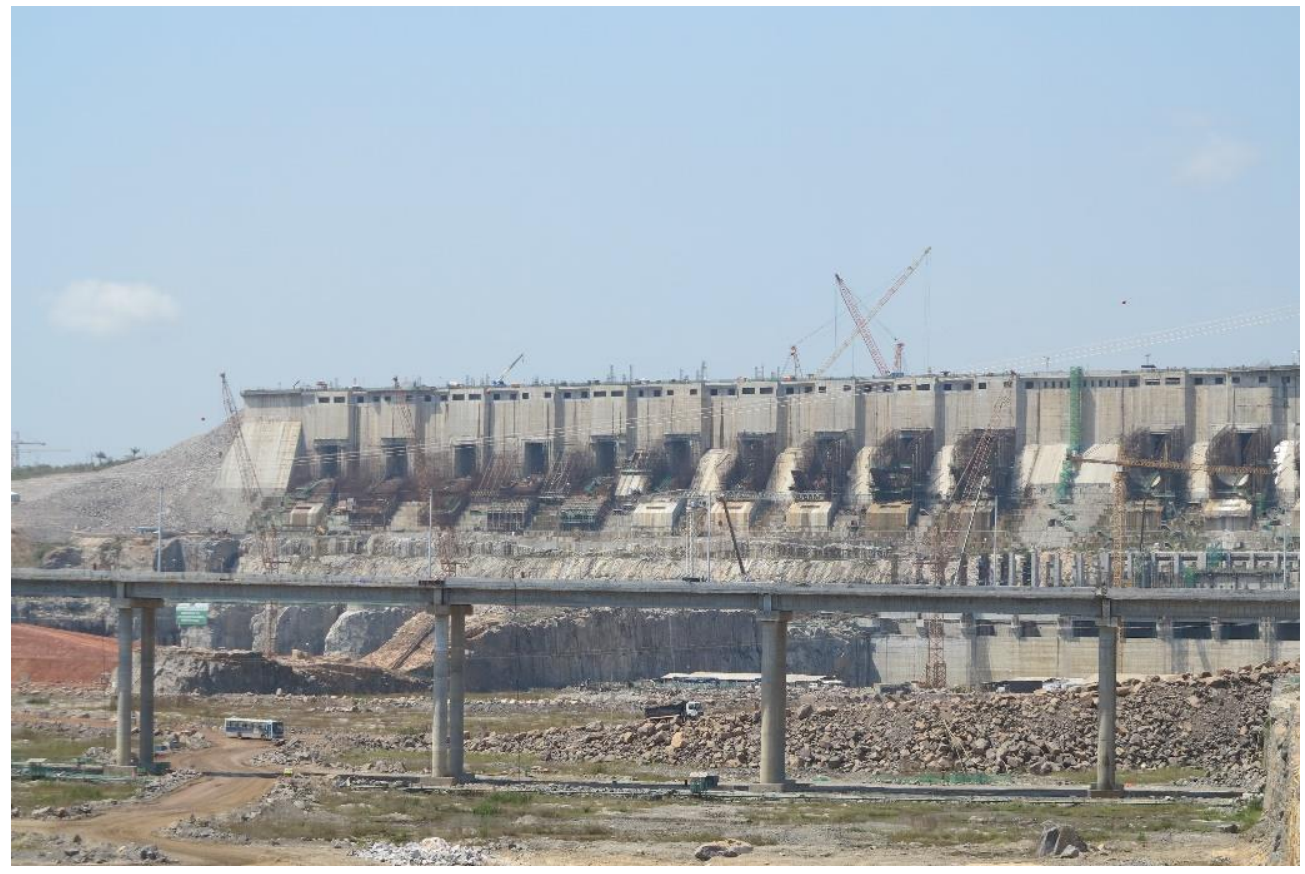

Figura 23 - Vista da UHE de Belo Monte

Fonte: Por Missifany Silveira, 2015.

Os dados a seguir evidenciam o cenário atual na cidade de Altamira no que diz respeito ao impacto causado pelo aumento de veículos na região, demonstrando um crescimento da frota veicular em aproximadamente 115\% entre os anos de 2010 a 2015 (Figura 24).

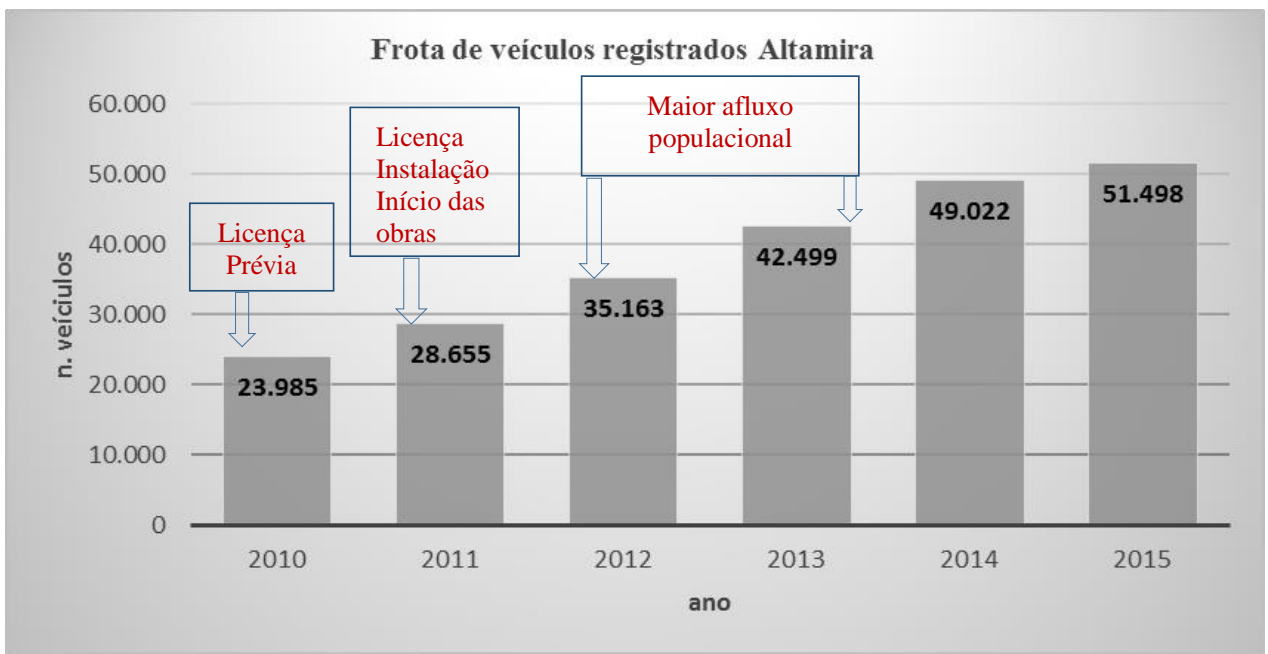

Figura 24 - Crescimento da frota veicular em Altamira, no período de 2010 a 2015 Fonte: Demutran, 2015. 
Tendo em vista o crescimento do número de acidentes notificados pelo Demutran no mesmo período, de 2010 a 2015, observa-se que se trata de tendência crescente, ou seja, a ocorrência de acidentes aumentou proporcionalmente ao número de veículos no período (Figura 25).

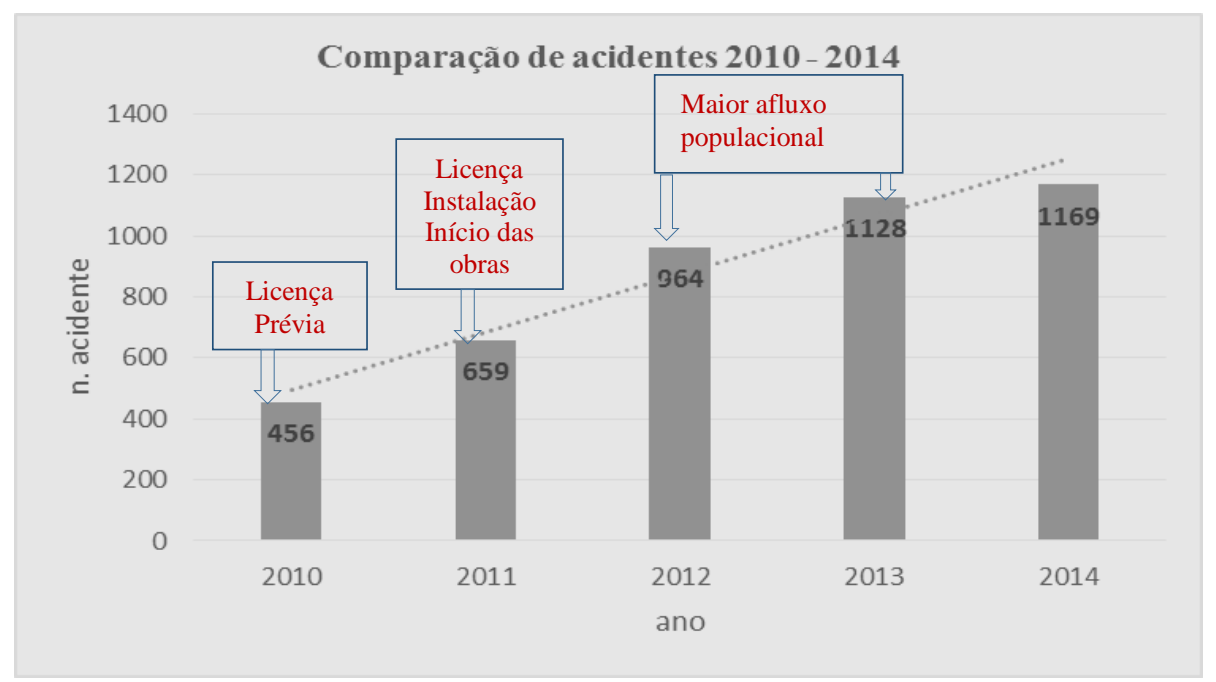

Figura 25 -Número de acidentes entre 2010 a 2015

Fonte: Demutran, 2015.

Em agosto de 2015, foram contabilizados 51.498 veículos emplacados na jurisdição de Altamira. Desses, as motocicletas representam $51,6 \%$ do total relativamente às outras categorias (Figura 26).

Cabe enfatizar que, de acordo com o Demutran, 30\% dos acidentes ocorridos não são registrados pelas vítimas. Outro dado alude ao registro de acidentes fatais, que assim não são considerados se a vítima foi encaminhada a um hospital ou pronto-socorro. Desse modo, somente são registrados pelo Demutran os casos de óbitos ocorridos no local do acidente. Demonstra-se, assim, a fragilidade dos dados relativos aos acidentes com vítimas fatais, tendo em vista que muitos dos óbitos por causas externas notificados pelas unidades de saúde não se enquadram nas estatísticas desse órgão.

Os dados verificados indicam um aumento anual do número de casos de acidentes e mortes provocados por veículos automotores, o qual não tem decrescido diante da redução dos trabalhadores na obra de Belo Monte. É possível afirmar, então, que Altamira permanece com uma população relativamente alta. Esse é um dos diversos motivos pelos quais os gestores municipais não concordam com a distribuição per capita dos recursos destinados para mitigar 
os impactos dos municípios mais afetados. Segundo os gestores locais, os recursos destinados as condicionantes deveriam ser melhor distribuídos entre os municípios mais afetados (Informação verbal ${ }^{18}$ ), como é o caso de Altamira.

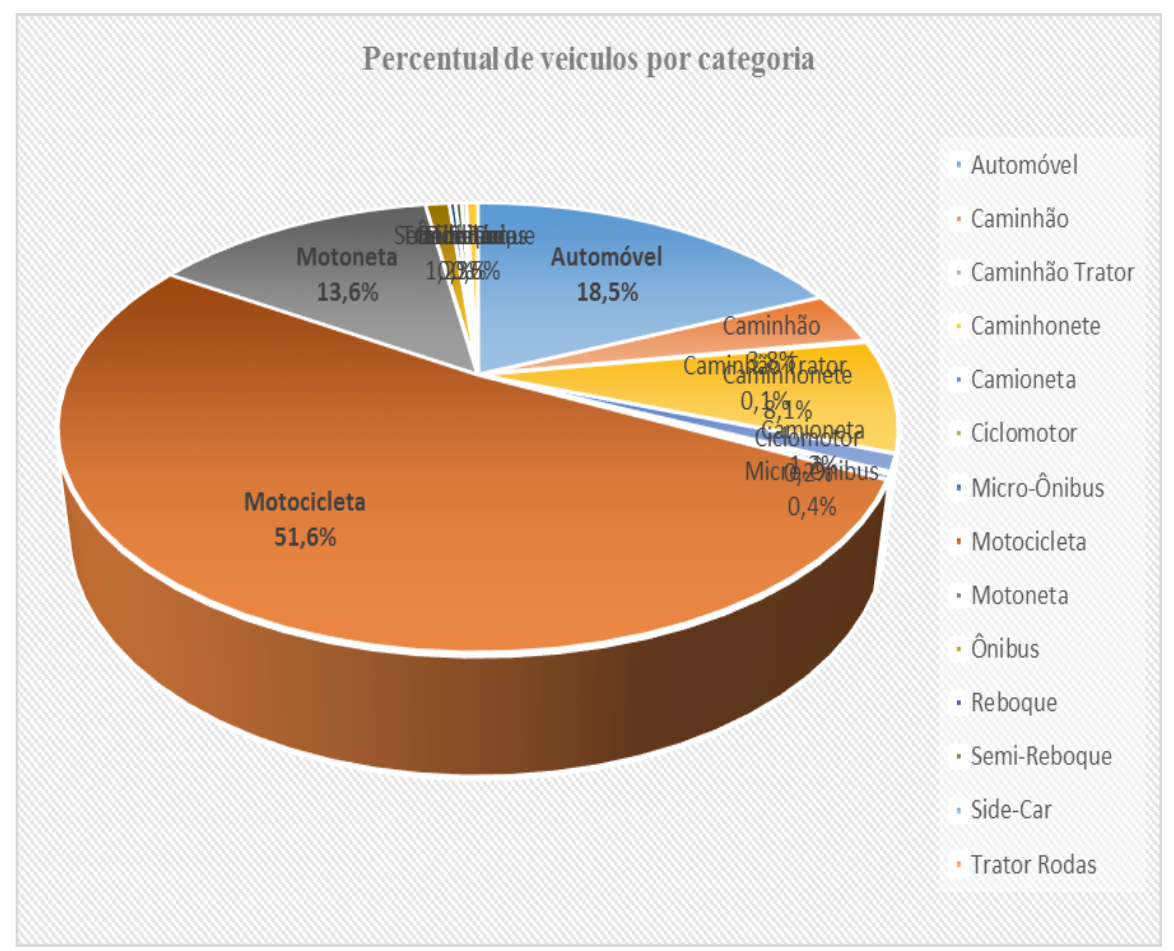

Figura 26 - Percentual de motocicletas em comparação aos demais veículos

Fonte: Demutran, 2015.

Além dos gestores, representantes dos movimentos sociais também relatam que o Município de Vitória do Xingu é o maior beneficiário da região, recebendo os royalties por ser o município onde está localizada a área da usina de Belo Monte. No entanto, possui uma população pequena, ou seja, "recebe mais incentivos e menos impacto, ficando o atendimento da maior parte da população da AID e AII para Altamira" (Informação verbal).

${ }^{18}$ Obtida durante a durante a Reunião do PRDS-X, em agosto de 2015. 


\subsubsection{Deslocamentos compulsórios: um fator de desestrutura social para as comunidades tradicionais rurais e urbanas}

Os impactos relacionados ao afluxo populacional de trabalhadores e outras pessoas desencadearam outros processos que contribuíram para conflitos e desestruturação social na região da construção da Usina de Belo Monte.

Um dos aspectos reveladores dos problemas identificados foram os deslocamentos compulsórios de pessoas que habitavam as áreas urbanas e rurais. Por conta do alagamento da extensão a ser ocupada pelo reservatório para formação da barragem, muitos dos habitantes dessas localidades foram compulsoriamente reassentados em outros locais. Esse fator estabeleceu uma nova dinâmica de vida para determinados grupos de populações tradicionais, como os ribeirinhos e pescadores, acarretando conflitos por terra e desagregação social. De acordo com recente relatório do Instituto Socioambiental (ISA) - Dossiê Belo Monte -, mais de oito mil famílias tiveram de ser reassentadas (ISA, 2015).

Uma das condicionantes da Licença de Instalação (LI), definida no Plano Básico Ambiental (PBA), era a retirada da população que vivia nos igarapés à beira do Rio Xingu, como parte da mitigação e prevenção dos impactos. Uma parcela dos residentes à beira do Rio Xingu foi reassentada em vilas nas adjacências da cidade mediante a retirada dos igarapés. De acordo com o gerente da Norte Energia, a "limpeza (retirada) dos igarapés deu lugar a urbanidade", deixando "pouco espaço à criminalidade", além de "contribuir para melhoria sanitária do local, diminuindo a carga de doenças" (Informação verbal).

Considerado pelo empreendedor um ponto "positivo", ocorreu o deslocamento (compulsório) da população dessa área nas vilas construídas pela Norte Energia, no âmbito do projeto chamado de Reassentamentos Urbanos Coletivos (RUCs). Esse projeto determinou que todos os residentes dessas localidades fossem reassentados nos RUCs, para dar lugar à urbanização da orla, com a construção de novas vias, pontes e parques, na cidade de Altamira (Figuras 27 e 28). 

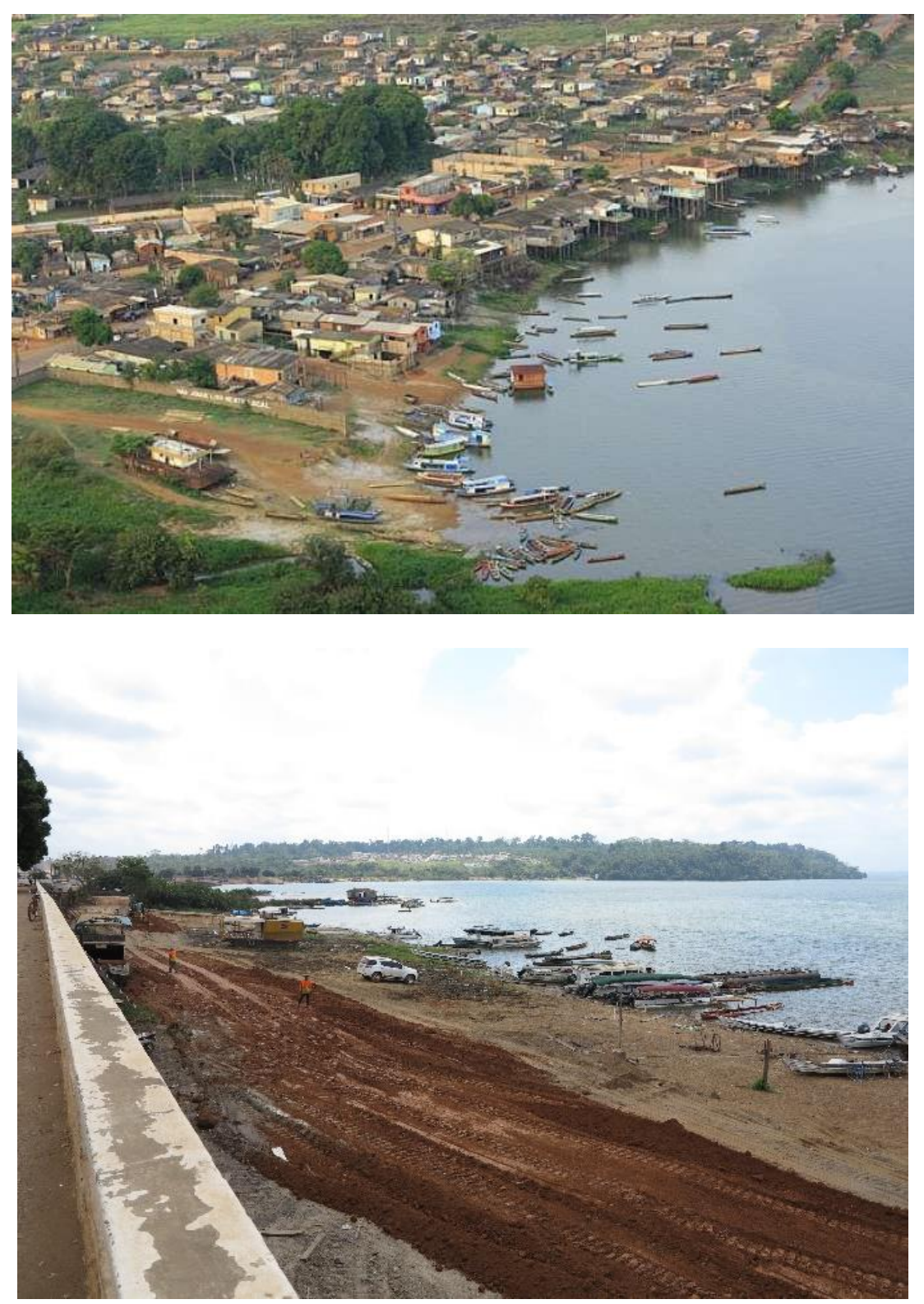

Figura 27 e 28 - Imagem antes e após o início da urbanização da orla à beira do Rio Xingu Fonte: Por http://educacaopolitica.com.br/2011/09/ e Missifany Silveira, 2015.

No entanto, a ausência de um diagnóstico adequado resultou na existência de falhas nas medidas mitigadoras e compensatórias para a população reassentada. O Dossiê Belo Monte aponta que os RUCs ainda apresentam infraestrutura precária, com insuficiência de prestação de serviços públicos como saneamento básico e abastecimento de água, além das dificuldades causadas pela separação de indivíduos das comunidades a que pertencem e com as quais tinham laços de afetivos e vínculos sociais (Figuras 29 e 30). Para os reassentados provenientes de áreas rurais, o problema se agrava pelo fato de terem sido deslocados para realidades e locais 
muito distintos, impossibilitando-os de ganhar seu sustento por se encontrarem distantes do rio e do lugar de trabalho (ISA, 2015).
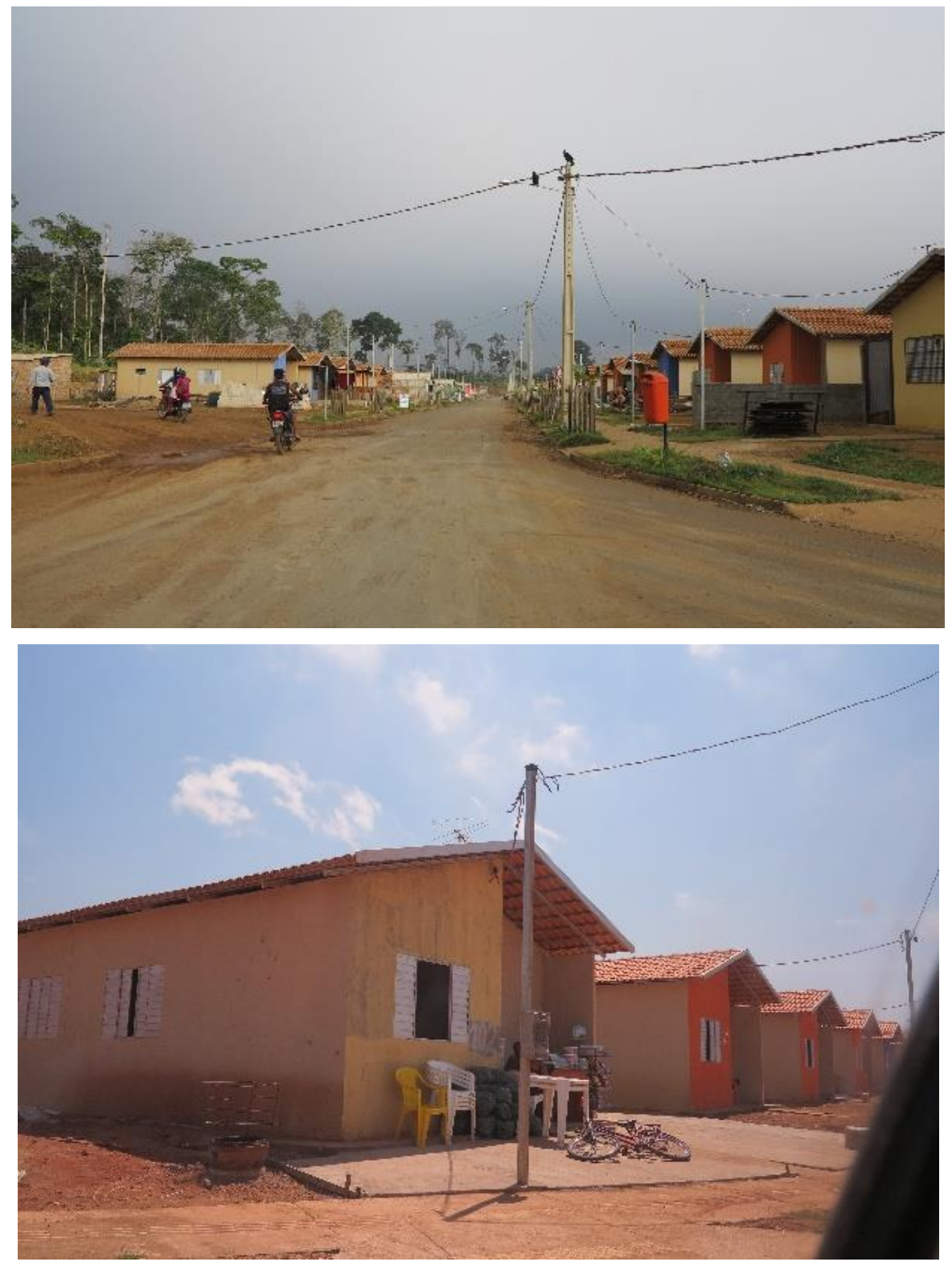

Figura 29 e 30 - Reassentamento Urbano Coletivo (RUC) no bairro Jatobá, em Altamira Fonte: Por Missifany Silveira,2015.

De acordo com relatos dos moradores, a restruturação da cidade em função das transformações que a obra impõe é uma realidade que não mudou para muitos deles.

Nas palavras da pescadora Maria do Socorro Pinheiro Nogueira, de Altamira:

Desde que a obra começou, o trânsito na cidade está um caos, com acidentes a toda hora, os hospitais estão mais lotados, a escola do meu neto não melhorou, minha pesca caiu mais de 30\%, a água continua não sendo potável, 
e o lixeiro só passa para pegar o lixo uma vez por semana, como eu posso acreditar que um plano de reassentamento vai construir uma casa melhor que a minha? (ISA, 2103).

Para as populações ribeirinhas que têm seus modos de vida transformados à medida que a obra avança, a situação se constitui predominantemente por inúmeros desequilíbrios locais.

Segundo o Ministério Público Federal (MPF), os grupos tradicionais foram negligenciados durante o licenciamento ambiental, sem direito à participação no processo decisório quanto ao reassentamento das populações na área do reservatório da hidrelétrica, sendo considerados, portanto, atores "invisíveis" ao processo.

O cotidiano do ribeirinho guarda uma dinâmica peculiar, num fluxo entre o rio e a cidade, no qual a dupla moradia tem um papel indispensável à manutenção do seu modo de vida. Deste modo, ficou evidente que, para garantir o modo de vida ribeirinho é necessário primeiro reconhecê-lo e, no mínimo: 1. a garantia de sua territorialidade no rio, que inclua seu ponto de pesca e sua moradia na ilha ou margem; 2. a garantia da pesca após as alterações que o desvio do curso do rio vai acarretar e; 3 . a garantia do acesso ao núcleo urbano, com moradia próxima ao rio" (BRASIL, 2015c).

O Relatório de Inspeção Interinstitucional: áreas ribeirinhas atingidas pelo processo de remoção compulsória da UHE Belo Monte, documento elaborado pelo MPF, apresenta uma dura crítica ao PBA, pelo descumprimento de suas premissas no que tange à participação de grupos tradicionais, como ribeirinhos, quilombolas e indígenas. Ressalta que essa população foi mantida à margem das informações sobre a perda de seu próprio território e sobre os impactos ao seu modo de vida. Para o MPF, em que pese a importância das hidrelétricas na matriz energética para o desenvolvimento econômico nacional, o Estado brasileiro deveria respeitar as peculiaridades da região, garantindo territorialidade aos ribeirinhos, fornecendo condições para a continuidade das suas atividades (BRASIL, 2015c).

\subsubsection{Povos indígenas: conflitos, desestruturação social das aldeias e reflexos para a saúde}

As Terras Indígenas (TIs) e as Unidades de Conservação (UCs) são áreas sob forte pressão na região amazônica, sobretudo mediante os conflitos desencadeados por madeiros ou 
grileiros de terra (Figura 31). A região onde se localiza a UHE de Belo Monte reproduz esse problema histórico

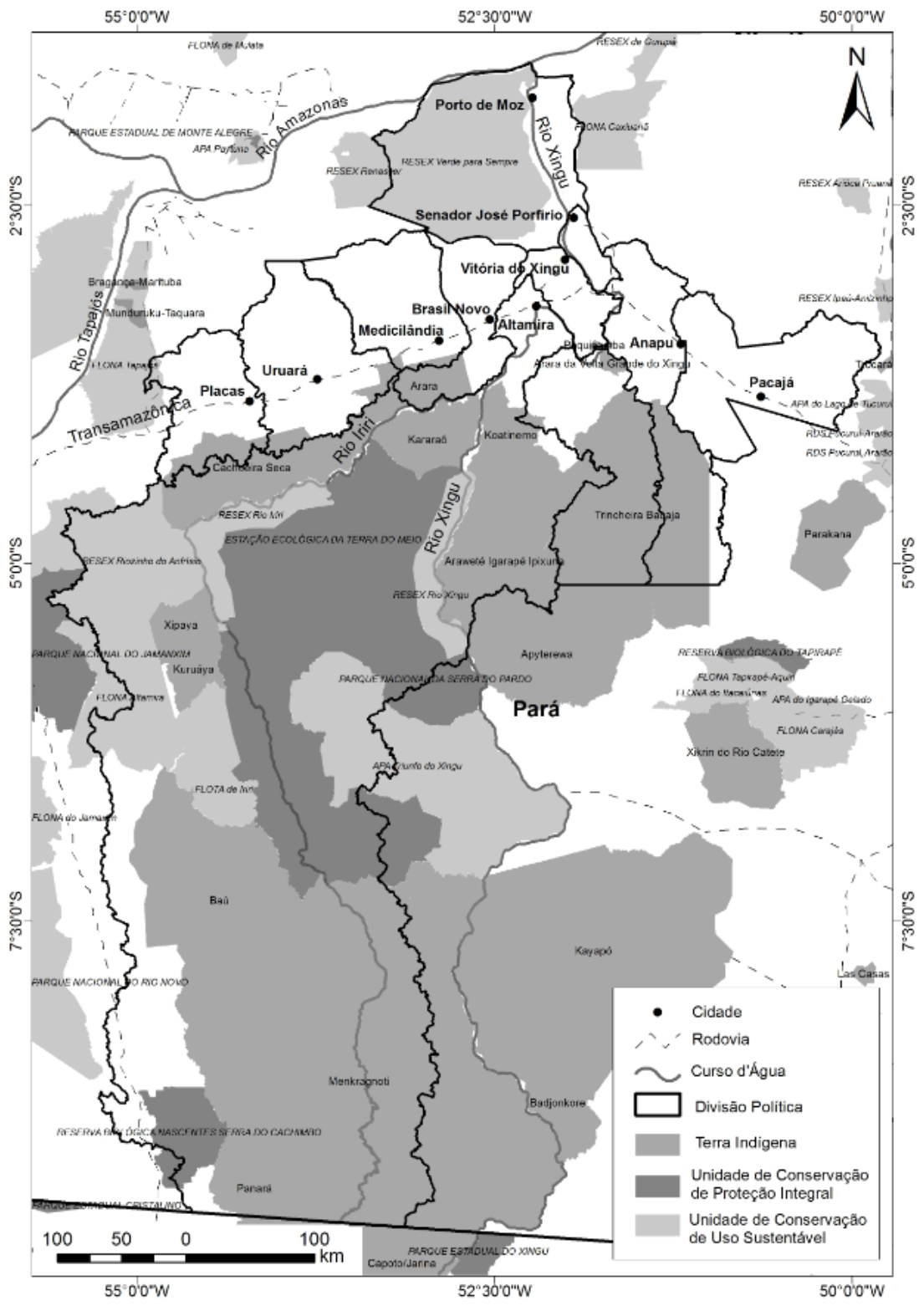

Figura 31 - Terras Indígenas e Unidades de Conservação na Área de Influência da UHE Belo Monte

Fonte: Elaborado por Missifany Silveira a partir de dados do IBGE; ANA; Funai, 2014.

Ao se avaliar a realidade indígena, é necessário considerar os grupos étnicos em pelo menos quatro situações sociais diferentes: indígenas isolados; indígenas aldeados; indígenas citadinos; indígenas não aldeados. Todos eles estão espalhados pelas margens do rio Xingu e tributários, sendo o município de Altamira o principal centro de referência para esses grupos.

De acordo com o Relatório de Impacto Ambiental (RIMA) apresentado pela Eletrobrás em 2009, o projeto Aproveitamento Hidrelétrico (AHE) de Belo Monte afetaria diretamente 
três Terras Indígenas (TIs) e, indiretamente, outras sete, localizadas na Bacia do Xingu, como se apresenta a seguir (Quadros 7 e 8). Vale destacar que toda a bacia do Rio Xingu congrega 28 etnias, em 29 TIs - doze delas situadas no Estado do Mato Grosso e dezesseis no Pará -, num total aproximado de vinte mil índios (BRASIL, 2014d).

Quadros 6 e 7- Terras Indígenas (Tis) e populações diretamente e indiretamente afetadas

\begin{tabular}{|l|l|c|}
\hline Terras Indígenas (TIs) & Impactos & População \\
\hline TI Paquiçamba & Diminuição da vazão do rio & 81 \\
\hline TI Arara da Volta Grande & Diminuição da vazão do rio & 107 \\
\hline $\begin{array}{l}\text { Aréa Indígena Juruna do } \\
\text { Km 17 }\end{array}$ & Aumento do tráfego na estrada & 38 \\
\hline Total & & $\mathbf{2 2 6}$ \\
\hline
\end{tabular}

Fonte: BRASIL/MME, 2009.

\begin{tabular}{|c|c|}
\hline Terras Indígenas (TIs) & População \\
\hline Trincheira do Bacajá & 673 pessoas \\
\hline Koatinemo & 144 pessoas \\
\hline Arara & 236 pessoas \\
\hline Kararaô & 39 pessoas \\
\hline Cachoeira Seca & 81 pessoas \\
\hline Araweté & 398 pessoas \\
\hline Apyterewa & 411 pessoas \\
\hline Total & $\mathbf{1 9 8 2}$ \\
\hline
\end{tabular}

Fonte: BRASIL, 2014d.

Considerado um dos empreendimentos mais estudados ao longo dos últimos anos no Brasil, Belo Monte é um projeto de relevância para a geração de energia no país. Contudo, é constantemente marcado por grandes polêmicas tendo em vista a sua complexidade socioambiental. Nesse âmbito, o componente indígena sempre se apresentou como uma das principais pautas das discussões em torno dos impactos socioambientais resultantes da construção da UHE, colocando esse imenso empreendimento sob a mira de organizações sociais e direitos humanos. 
O projeto denominado de Kararâ̂, abandonado por pressões de organismos internacionais, teve seu ponto alto no Encontro dos Povos Indígenas em 1989, quando a índia caiapó Tuíra enfrentou o presidente da Eletrobrás para exigir, junto com ambientalistas, a extinção do projeto da construção da hidrelétrica (mais tarde construída com o nome de Belo Monte) (Figura 32). Seu planejamento previa um reservatório muito maior que o atual, o que impactaria grande área à montante da barragem. No entanto, o "novo" projeto denominado Belo Monte foi construído conforme o modelo de hidrelétrica movida a fio d’água. Essa decisão acarretou mudanças na geopolítica dos impactos e seus contornos, já que a maior repercussão não se daria mais pela inundação de extensas áreas indígenas inundadas, mas sim pela seca do leito do rio Xingu à jusante, que banha as TIs e que poderá ter suas vazões reduzidas em determinados períodos do ano (OLIVEIRA; COHN, 2014).

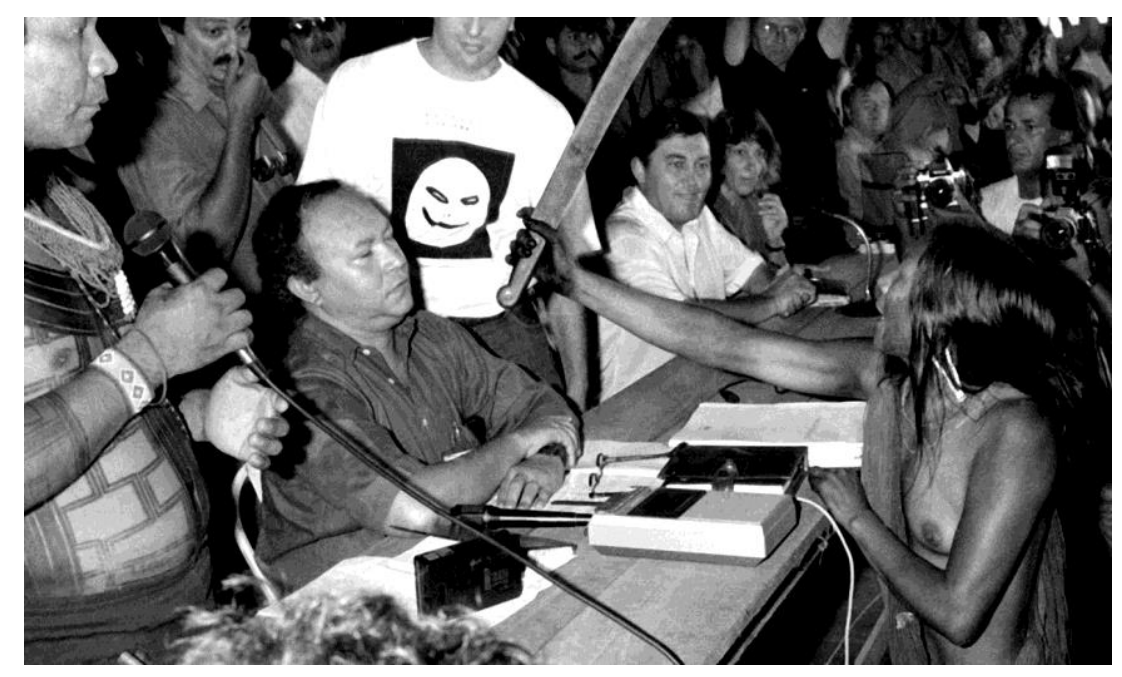

Figura 32 - A caiapó Tuíra aponta facão para o presidente da Eletronorte, Muniz Lopes, 1989.

Fonte: http://m.memorialdademocracia.com.br/card/povos-do-xingu-se-encontram-no-para

De acordo com a Funai “é indiscutível o esforço para a concepção de um projeto que evitasse as 'resistências socioambientais' previstas no projeto inicial" (BRASIL, 2015a). Contudo, a não ocorrência do alagamento previsto não significa ausência de impactos sobre os povos indígenas na região do médio Xingu. Trata-se de povos com uma relação complexa com o ambiente, decorrente de seu modo de vida dependente dos recursos naturais, cuja perturbação afeta de forma marcante sua estrutura social e cultural (BRASIL, 2015a).

Para os estudos de impacto ambiental, as áreas indígenas são consideradas regiões de impacto direto, sendo estudadas, entretanto, como áreas especiais. Desse modo, as 
condicionantes para o componente indígena foram consideradas separadamente no Plano Básico Ambiental (PBA).

A Fundação Nacional do Índio (Funai) é o órgão que estabelece e executa a política indigenista no Brasil. Assim sendo, é o responsável pelas áreas indígenas, assim como pela análise e acompanhamento do PBA do Componente Indígena (PBA-CI). Nesse caso, todas as medidas de mitigação e compensação dos impactos gerados da UHE de Belo Monte sobre essa população específica foram desenhadas pela Funai, em 31 condicionantes do Plano Básico Ambiental do Componente Indígena (PBA-CI). A elaboração do PBA-CI foi coordenada por antropólogos, indigenistas e por grupos de especialistas para dez eixos de atuação, tais como educação, saúde, gestão territorial, atividades produtivas, saneamento, dentre outros. Contudo, as populações indígenas da região não reconheceram o PBA, alegando não haverem sido consultadas sobre o plano de antemão.

Em 2011, o governo brasileiro recebeu da Comissão Interamericana de Direitos Humanos (CIDH) da Organização dos Estados Americanos (OEA) o pedido de paralisação do processo de licenciamento da Usina Hidrelétrica Belo Monte, no Rio Xingu, no Estado do Pará. A Comissão recomendava que o licenciamento da obra só poderia ser concedido mediante consulta pelo governo com as comunidades indígenas afetadas, de forma a adotar medidas mais abrangentes para proteger a vida e a integridade desses povos, prevenindo a disseminação de doenças (AGÊNCIA BRASIL, 2011).

Vale destacar que o Boletim Epidemiológico do Ministério da Saúde sobre indicadores de saúde relacionados à raça aponta que o risco de doenças e óbitos por tuberculose é maior entre os indígenas quando comparado às demais variáveis de raça/cor por conta da situação de extrema pobreza em que vive grande parte dessa população ${ }^{19}$ (BRASIL, 2015b). De acordo com o Boletim, a taxa de mortalidade mais elevada entre os indígenas chegou a 5,5/100 mil hab., em 2013. Constatou-se que uma das maiores dificuldades enfrentadas por esses povos é o acesso aos serviços de saúde, impedindo-os de obter diagnóstico precoce e tratamento oportuno. Ainda segundo o Boletim, "a vulnerabilidade social, possivelmente, justifica o maior risco de pessoas pretas, pardas e indígenas adoecerem ou morrerem por tuberculose, quando comparadas às pessoas amarelas e brancas” (BRASIL, 2015b).

\footnotetext{
${ }^{19}$ Boletim Epidemiológico. Secretaria de Vigilância em Saúde - Ministério da Saúde. Volume 46 No 10 - 2015. ISSN 2358-9450.
} 
No tocante à malária, o cenário não é diferente. A incidência parasitária anual (IPA) de malária é classificado como de alto ( $\geq 50$ casos/mil hab.), médio (10 a 49,9 casos/mil hab.) e baixo risco (<10 casos/mil hab.). Apesar de, em 2013, se haver registrado uma média IPA de 6,3 para os Estados da Amazônia Legal, a maior incidência de malária ocorreu na população indígena, com uma taxa de incidência de 63,7 casos para cada mil habitantes, único grupo classificado como de alto risco (Figura 33).

\begin{tabular}{|c|c|c|c|c|c|c|}
\hline UF & Amarela & Branca & Indigena & Parda & Preta & Total \\
\hline Acre & 0,9 & 17,5 & 16,5 & 54,9 & 33,6 & 43,5 \\
\hline Amazonas & 18,8 & 5,0 & 117,7 & 16,5 & 17,4 & 20,0 \\
\hline Amapá & 27,7 & 9,0 & 84,1 & 20,1 & 19,9 & 18,4 \\
\hline Maranháo & 0,1 & - & - & 0,1 & 0,1 & 0,1 \\
\hline Mato Grosso & 0,4 & 0,2 & 0,8 & 0,4 & 0,4 & 0,4 \\
\hline Pará & 2,9 & 1,1 & 65,5 & 3,4 & 3,1 & 3,2 \\
\hline Rondônia & 9,2 & 4,3 & 30 & 9,3 & 7,5 & 8,0 \\
\hline Roraima & 14,3 & 4,9 & 13,9 & 8,3 & 11,8 & 9,9 \\
\hline Tocantins & - & - & - & 0,0 & - & 0,0 \\
\hline Amazônia Legal & 4,6 & 2,1 & 63,7 & 6,4 & 4,4 & 6,3 \\
\hline
\end{tabular}

Figura 33 - Taxa de incidência parasitária anual (IPA), por mil hab., segundo a variável raça/cor nas Unidades da Federação e Amazônia Legal em 2013.

Fonte: Brasil, 2015b.

Alvo de muitas críticas, o convênio firmado entre a Norte Energia S/A e a Funai para a elaboração de um Plano Emergencial foi extinto em dezembro de 2012. Com o objetivo de instituir um montante de trinta mil reais por aldeia mensalmente a ser concedido na forma de uma lista de compras - a qual era revista pela própria Funai e executada pela Norte Energia S.A. -, o programa visava melhorar as condições dos povos indígenas. No entanto, acarretou consequências negativas, como o crescimento do trânsito de aldeados entre as aldeias e as áreas urbanas; aumento do consumo de produtos industrializados e do alcoolismo. Além do mais, surgiram conflitos entre as aldeias e também no interior delas, levando à abertura de novas comunidades e, por conseguinte, desencadeando desordens e desconfianças interétnicas (COHN, 2014).

Apesar de considerados desfavoráveis, os planos e programas do PBA-CI, condicionantes para o andamento do licenciamento ambiental do empreendimento, foram implementados, com responsabilidades compartilhadas entre a empresa Norte Energia e os 
órgãos do governo federal e estadual. Um dos objetivos desses instrumentos era a “reestruturação da Atenção à Saúde Indígena” (NORTE ENERGIA, 2015.

O Plano Operativo do PBA-CI, entregue pela Norte Energia, visava a reestruturação física do Distrito Sanitário Especial de Saúde Indígena (DSEI), com a construção de Unidades Básicas de Saúde e outras edificações. Além disso, o Programa de Infraestrutura previa projetos de abastecimento de água e saneamento, aquisição de equipamentos e insumos. No entanto, os projetos executivos para remessa das 39 Unidades Básicas de Saúde (UBS) só foram entregues no final de 2014, com previsão para início das obras em 2015 (BRASIL, 2015d).

Conforme dados da Fundação Getúlio Vargas (Indicadores de Belo Monte), a maior parte das condicionantes do PBA-CI ainda não foi cumprida. Requer-se, para o devido cumprimento, uma articulação maior entre a Secretaria Especial de Saúde Indígena (SESAI), o Ministério da Saúde, o Distrito Sanitário Especial de Saúde Indígena (DSEI) de Altamira, o Conselho Distrital de Saúde Indígena (CONDISI) e a Norte Energia (FGV, 2015).

A Nota Informativa da Funai, (Informação 233/2015CGLIC/DPDS/FUNAI/MJ), ressalta que, na própria avaliação da SESAI, "as ações de saúde vêm sendo prejudicadas pelos compromissos assumidos pelo empreendedor sem prévio planejamento com as instancias corretas, bem como pelo atraso nas ações de sua responsabilidade, que comprometem a efetividade das ações" (BRASIL, 2015a). No mesmo informativo, a Funai revela que o Componente Indígena não poderia ter sido considerado apenas pela legislação do licenciamento ambiental, mas teria de passar pelo crivo da legislação indigenista e da Constituição Federal. A explicação se encontra no fato de que, se houvessem sido elaboradas com apoio nesse aparato legal, as ações governamentais não teriam provocado grandes desordens sociais, como se verifica nas regiões afetadas diante das "migrações para as cidades, o desvirtuamento das propostas emergenciais, o 'mercado de troca' por apoio às causas pró e contra a usina" (BRASIL, 2015a), em situações que extrapolam a dimensão do processo de licenciamento ambiental.

Mesmo diante do "Plano Emergencial" e das ações do PBA-CI, os grupos indígenas paralisaram as obras da usina em diversas ocasiões. Solicitavam, sobretudo, maior transparência no concernente às informações sobre as ações definidas pelo PBA, questionando as oitivas que nunca foram realizadas. 
Contrariando todas as informações relatadas, a empresa Norte Energia defende que grande parte das ações do PBA-CI estão em fase de conclusão. Ainda restam, porém, as obras a serem executadas nas aldeias, as quais "não seguiram o mesmo ritmo daquelas realizadas em áreas urbanas e rurais, mas isso se deve ao respeito à cultura indígena e das exigências das lideranças e da própria Funai” (ELPAIS, 2015).

De acordo com a Norte Energia ${ }^{20}$, dois dos principais objetivos do PBA/CI - segurança territorial e fortalecimento étnico - estão sendo cumpridos integralmente. Afirma a empresa que já houve a implementação de 27 projetos dirigidos aos povos indígenas da área de influência da UHE de Belo Monta; informa também que, somados, os investimentos alcançam aproximadamente 252 milhões de reais (NORTE ENERGIA, 2015).

Além de ações em saúde e educação, o alto investimento nos projetos que fomentam atividades produtivas dessas comunidades já garantiu mais de 2 milhões de litros de combustível entre outubro de 2012 a setembro de 2015. Os povos indígenas também já receberam 594 motores para embarcações, 377 barcos e voadeiras, 43 veículos e 98 geradores de energia, além de roçadeiras, que garantem mais rapidez e segurança no processo de produção" (NORTE ENERGIA, 2015).

Em Audiência Pública convocada pelo Ministério Público Federal no Pará (MPF/PA), realizada em Altamira no dia 18 de agosto de 2015, para debater a saúde indígena no contexto dos impactos da usina hidrelétrica de Belo Monte, expôs-se que as condicionantes acordadas no PBA-CI não foram plenamente atendidas (BRASIL, 2015d). A audiência contou com a presença de diversas autoridades. Além do Ministério Público Federal (MPF), estiveram presentes os responsáveis pelo atendimento à saúde indígena, representados pela Secretaria Especial de Saúde do Índio (SESAI) do Ministério da Saúde, e pelos Distritos Sanitários Especiais Indígenas (DSEIs). Vale lembrar que a saúde indígena, desde 1999, é de responsabilidade do SUS, encontrando-se as ações de saúde desvinculadas das ações estratégicas indigenistas conduzidas pela Funai.

Nos depoimentos prestados na ocasião, relatou-se que as obras e ações previstas em 2010 como condições necessárias para a implantação da UHE de Belo Monte, bem como o cumprimento de todas as condicionantes, só haviam iniciado recentemente, depois de o empreendedor já haver solicitado a Licença de Operação (BRASIL, 2015d). Essa circunstância

20 Norte Energia. Hidrelétrica de Belo Monte. Disponível em: http://norteenergiasa.com.br/site/2015/ 10/16/investimentos-melhoram-vida-de-indigenas-no-xingu/. Acesso em: 18/10/2015. 
pode ter contribuído, em parte, para a ocorrência de conflitos e paralizações ao longo da construção das obras da usina.

Representantes do DSEI, órgão responsável na região por atender todos os povos indígenas atingidos pela UHE de Belo Monte, discorreram sobre as dificuldades para o atendimento dessa população, diante do descumprimento de compromissos firmados há mais de quatro anos no PBA. Em seu depoimento ${ }^{21}$, Lindomar Carneiro, Coordenador do Distrito Sanitário Especial Indígena (DSEI) de Altamira, afirma que:

As dificuldades que estamos enfrentando no atendimento da saúde estavam previstas no EIA. A gente apresentou a reestruturação das ações de saúde para que a gente pudesse atender o nosso compromisso com a saúde indígena. A gente sabe que muita coisa do PBA (Plano Básico Ambiental) que era para ter iniciado há mais de quatro anos e agora que está começando. Agora que está começando a construção das UBS (Unidades Básicas de Saúde), dos sistemas de abastecimento de água, agora que a gente está discutindo como vai ser o novo modelo de atenção (BRASIL, 2015d).

Representantes de diversas etnias também revelaram situações de saúde alarmantes, como a morte de crianças por desnutrição e diarreia, o aumento de doenças crônicas causadas pela substituição da alimentação tradicional por comida industrializada, além do crescimento dos casos de alcoolismo e depressão (BRASIL, 2015d). Para o MPF, com todo os "esforços" e o montante de recursos investidos para a realização de ações nas áreas indígenas, essa população ainda sofre com os impactos da hidrelétrica, visto que a implantação das condicionantes foi tardia e acarretou consequências desastrosas, como o descontrole, a desmobilização e a segregação das aldeias indígenas (BRASIL, 2015d).

Outro aspecto destacado diz respeito ao trecho de vazão reduzida (TVR) de cem quilômetros da Volta Grande do Xingu, que poderá alterar o ciclo natural de cheias e vazantes, impactando a navegação de barcos, bem como o ecossistema; estimam-se mudanças também na produção de espécies de peixes e, consequentemente, na principal atividade de subsistência desses povos, a pesca.

Conforme relatos durante a pesquisa de campo e de acordo com o exposto pelo ISA, o agravamento da situação da saúde indígena se confirma e requer atenção. Verifica-se, atualmente, o abandono das atividades agrícolas pelos indígenas, o que resulta numa alteração

\footnotetext{
${ }^{21}$ Audiência Pública realizada em Altamira. Disponível em: http://noticias.pgr.mpf.mp.br/noticias/noticias-dosite/copy_of_indios-e-minorias/mpf-pa-sem-cumprir-condicionantes-belo-monte-provoca-o-caos-na-saudeindigena-no-xingu/?searchterm=Belo\%20Monte. Acesso em: 02/09/2015d.
} 
dos hábitos alimentares, com a consequente mudança no perfil de saúde. É possível perceber desde já o aumento da ocorrência de obesidade, diabetes e desnutrição nas populações indígenas, especialmente nas crianças (ISA, 2015).

Como ressaltado no Dossiê Belo Monte, a Norte Energia, por meio do "Plano Emergencial", distribuía recursos, na forma de fornecimento de mercadorias, às aldeias indígenas. Essa prática levou ao consumo de produtos industrializados, causando a interrupção do processo de cultivo e a consequente insegurança alimentar (ISA, 2015).

No entanto, a empresa afirma que se tratava de "auxílio financeiro" - na ordem de trinta mil reais distribuídos mensalmente, por aldeia, como já destacado anteriormente -, parte do Plano Emergencial, assinado pela Funai e Norte Energia, para a execução de ações consideradas de urgência. Segundo a Norte Energia, tais "ações emergenciais" se destinaram ao "apoio, proteção e assistência" para as comunidades indígenas da área de influência de Belo Monte, e se materializaram na forma de "recurso mensal" para cada aldeia indígena, além de doações de veículos, motores fluviais, grupo gerador e kit fotovoltaico, entre outras benesses (ELPAIS, $2015)^{22}$.

A Funai, na tentativa de minimizar os problemas existentes, exigiu, na forma de Termo de Ajuste de Conduta (TAC), uma reavaliação, por parte do empreendedor, da matriz de impacto anteriormente apresentada, com todas as "obrigações e responsabilidades do empreendedor" e "prazos bem definidos", referentes ao componente indígena como condição para a Licença de Operação (LO) (ELPAIS, 2015). Cabe destacar que, recentemente, o Ministério Público Federal do Pará (MPF/PA) e a Justiça Federal de Altamira determinaram que a Funai e a empresa Norte Energia apresentassem e cumprissem um plano de reestruturação para que a Funai fosse capaz de atender às crescentes demandas dos povos indígenas afetados pela usina de Belo Monte.

Diante de um cenário conturbado e contraditório, verifica-se que os planos elaborados e implementados pelo poder público e pela empresa Norte Energia foram mal planejados. Não havia clareza nos critérios de atendimento a esses povos, os quais, além de sua especificidade, têm o direito originário de permanência nas TIs assegurado pela Constituição Federal.

\footnotetext{
22 Perguntas e respostas sobre a usina hidrelétrica de Belo Monte. Brasil. EL PAÍS Brasil, 21/10/2015. A empresa Norte Energia, responsável pela usina, responde às perguntas sobre as polêmicas ambientais e sociais da empresa. Disponível em: http://brasil.elpais.com/brasil/2015/10/19/politica/1445288959_623438.html. Acesso em: $15 / 12 / 2015$
} 


\subsection{DIAGNÓSTICO DA SITUAÇÃO DE SAÚDE NA ÁREA DE INFLUÊNCIA DA UHE DE BELO MONTE, NO CONTEXTO DAS PRINCIPAIS DOENÇAS RELACIONADAS À IMPLANTAÇÃO DE HIDRELÉTRICAS}

Os impactos ambientais causados pelas hidrelétricas, especialmente sobre os ecossistemas, com grandes áreas desmatadas, são alguns dos desequilíbrios que afetam a qualidade de vida das populações urbanas, rurais e de grupos tradicionais mais fragilizados, como os indígenas e outros agrupamentos étnicos. Estes se encontram vulneráveis às mudanças do ambiente físico e às dinâmicas econômicas e sociais impostas pelo empreendimento às localidades afetadas (GOUVEIA, 2013).

Em um cenário que abarca as mais diversas situações, o ambiente se torna propício para inúmeros impactos adversos, como o aumento da prevalência de determinadas doenças transmissíveis tanto por vetores, como a malária, gastroenterites, parasitoses intestinais, quanto sexualmente; a introdução de novas patologias; o comprometimento da segurança alimentar, assim como o surgimento de doenças psíquicas decorrentes do estresse social (GOUVEIA, 2103).

No caso da UHE de Belo Monte, dentre os municípios da sua área de Influência direta e indireta (AID e AII), Altamira recebeu o maior contingente populacional mediante o anúncio da construção da usina, pois ali se concentram as principais estruturas das dinâmicas locais. Portanto, a análise dos indicadores de saúde selecionados para a região permitiu uma configuração do perfil de saúde dos cinco municípios. Contudo, os dados apontam para o município de Altamira como aquele com a situação de saúde mais crítica em comparação aos demais.

A cidade vivencia uma mudança no perfil epidemiológico justamente por se apresentar como a localidade que estimulou as mudanças mais significativas e, em consequência, os maiores reflexos sobre a saúde da população local, com o aumento de novos casos de doenças e da sobrecarga nos serviços de saúde. Acompanhando a tendência nacional, Altamira e a região do entorno atualmente apresentam altos índices de agravos relacionados às doenças não transmissíveis, principalmente a morbimortalidade de causas externas, como apresentado adiante.

Para a realização do diagnóstico da situação de saúde na região, coletaram-se dados nas localidades da região afetada. Recorreu-se também às informações de diferentes instituições de 
saúde e de pesquisa, como a FGV e o ISA, que disponibilizaram documentos para subsidiar a pesquisa de campo em Altamira. Esses elementos se mostraram relevantes para a validação dos dados oficiais, apoiados pelos sistemas de informações do Datasus, como o Sistema de Informações sobre Agravos de Notificação (Sinan) ${ }^{23}$, o Sistema de Informações Hospitalares (SIH) e o Sistema de Informação de Mortalidade (SIM) (BRASIL, 2009b).

A seguir apresentam-se os resultados da análise dos agravos de morbimortalidade alusivos às principais doenças relacionadas à implantação de hidrelétricas - DST, Aids, hepatites, sífilis e as doenças não transmissíveis, de causas externas -, com o objetivo de traçar um perfil da região. Além destes, foram também analisados os dados sobre o processo de implementação das condicionantes de saúde, a qual visa garantir a suficiência de atendimento da população na área de influência da usina como parte do cumprimento das condicionantes estabelecidas na Licença de Instalação (LI) referente à construção de infraestrutura de saúde. Realizou-se a análise de tendências para verificar se houve mudanças no âmbito da saúde ao longo da série temporal, com o fim de identificar eventuais mudanças no perfil epidemiológico. Investigou-se também a parcela de influência da construção da hidrelétrica sobre os impactos identificados durante o período analisado.

É importante ressaltar que a seleção das causas externas neste estudo se justifica tanto por se tratar de um agravo de importância epidemiológica atualmente, como também pelo fato de ter sido uma das principais queixas da população local durante a pesquisa de campo, o que se confirmou pelas informações coletadas durante as entrevistas abertas com atores locais.

A análise realizada considerou as áreas de influência direta e indireta (AID e AII), na linha de tempo entre os períodos anteriores e posteriores ao início das obras da UHE de Belo Monte, assumindo como referencial o ano de 2011, quando da emissão da Licença de Instalação (LI) do empreendimento.

\footnotetext{
${ }^{23}$ A partir de 1998, regulamentou-se o uso do Sinan, que tornou obrigatória a alimentação regular da base de dados nacional pelos municípios, Estados e Distrito Federal e designou o Ministério da Saúde como gestor nacional do sistema. O Sinan é atualmente alimentado, principalmente, pela notificação e investigação de casos de doenças e agravos que constam da lista nacional de doenças de notificação compulsória (LDNC). É facultado aos Estados e municípios incluir outras questões de saúde pública que considerem importantes para a sua região (BRASIL, 2009b).
} 


\subsubsection{Situação de saúde no contexto das doenças sexualmente transmissíveis: HIV-Aids, hepatites e sífilis}

De acordo com o Centro de Testagem e Aconselhamento (CTA) de Altamira, houve um aumento na procura por exames relacionados às doenças sexualmente transmissíveis, o que pode levar à identificação de novos casos. Para o CTA, a maior procura tem relação direta com crescimento populacional, tendência decorrente da construção da usina, identificada a partir de 2011. A elevação do número de novos casos de HIV-AIDS notificados no CTA de Altamira foi significativa, passando de dez, em 2011, para trinta e sete, em 2014, conforme demonstra o gráfico a seguir. Considerando-se a soma dos cinco municípios da região da AID, chegou a cinquenta o número de novos casos em 2014 (Figura 34).



Figura 34 - Casos novos de AIDS notificados pelo CTA (Região da AID da usina de Belo Monte)

Fonte: SCTA/SMS-Altamira, 2015

Como os dados do CTA são repassados ao Centro de Vigilância Epidemiológica (CVE), que também faz parte da Secretaria Municipal de Saúde, para depois serem encaminhados à $10^{\mathrm{a}}$ Regional de Saúde, da Secretaria Estadual de Saúde do Pará, as informações são verificadas ao final do processo, podendo sofrer alterações. Para tanto, foram coletados os dados na $10^{\mathrm{a}}$ Regional para obter uma comparação entre a fonte de coleta com os dados finais. No entanto, somente se disponibilizaram informações relativas ao período posterior a 2009. Ao se realizar uma comparação, verifica-se que o total de notificações dos casos é significativamente menor 
que os dados fornecidos pelo CTA, apesar de manterem a tendência crescente a partir de 2010 (Figura 35).

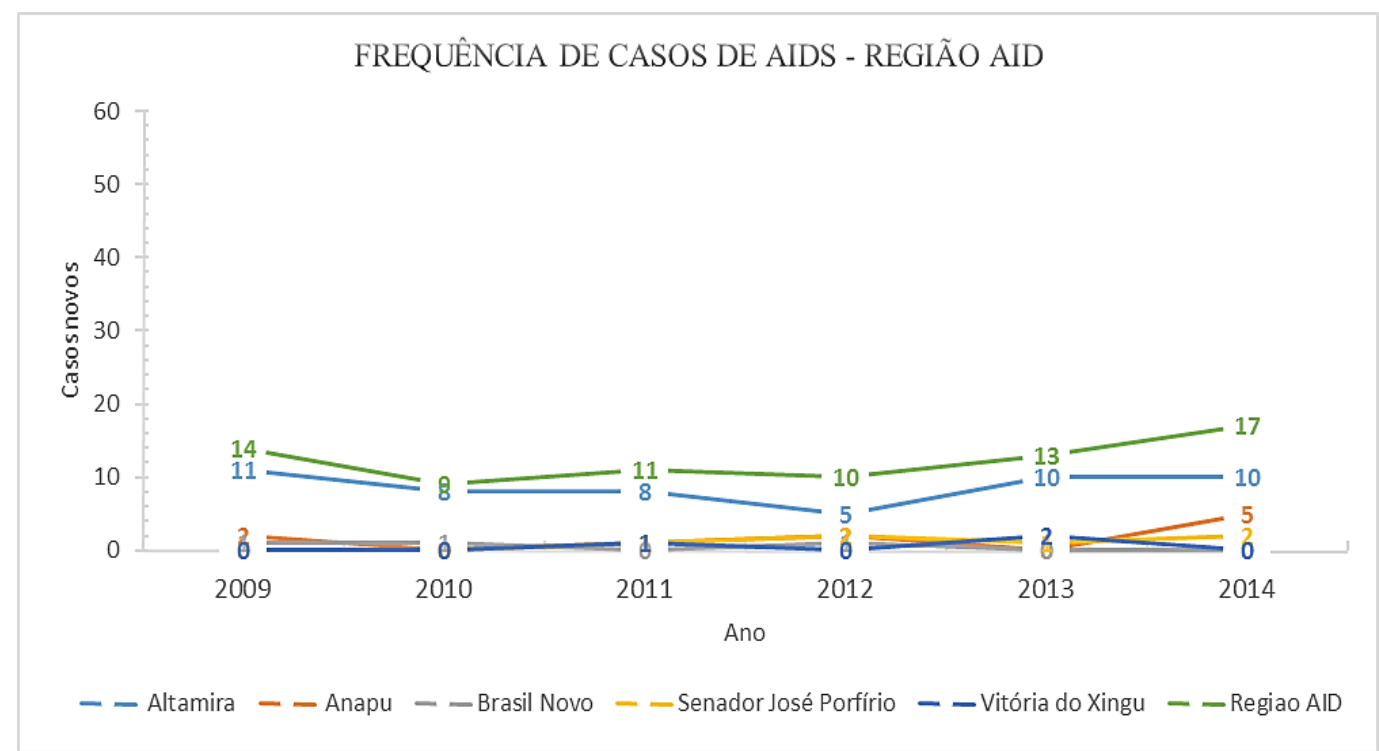

Figura 35 - Frequência de casos novos de Aids notificados pela SES, por município de residência e ano de diagnóstico (Região da AID da usina de Belo Monte)

Fonte: PARÁ/SES, 2015.

Na comparação dos dados da pesquisa de campo com os fornecidos pelo Ministério da Saúde (MS), observam-se diferenças menos significativas que as identificadas nos dados da $10^{\circ}$ regional em relação aos disponibilizados pelo CTA, como aponta a figura a seguir (Figura 36).

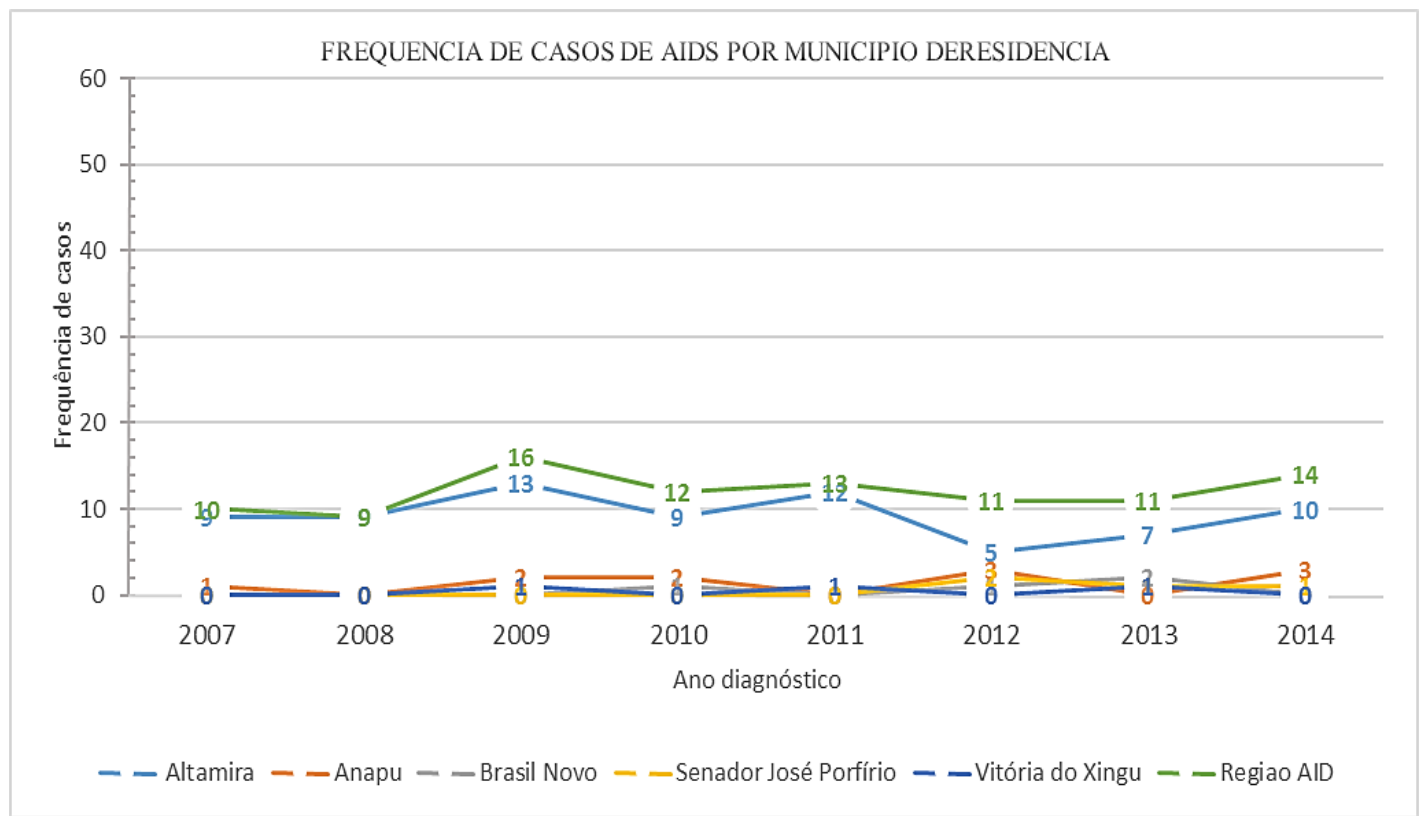

Figura 36 - Frequência de casos de Aids notificados pelo Datasus, por ano segundo município de residência e ano de diagnóstico (Região da AID da usina de Belo Monte)

Fonte: MS/Sinan, 2015. 
Essa discrepância demonstra a falta de relacionamento entre os bancos de dados nos sistemas de informação de saúde municipal e nos sistemas em esfera nacional, dificultando uma análise mais acurada dos dados. No entanto, cabe destacar que, de acordo com o Boletim Epidemiológico do Ministério da Saúde, existe um percentual de subnotificação de casos pelo Sinan, que gira em torno de $30 \%$ nos últimos anos. Para que seja possível corrigir essa subnotificação, o Datasus estabelece o relacionamento probabilístico entre os bancos de dados - Sinan, Siscel, Siclom e SIM (BRASIL, 2015b). Apesar das diferenças, todas as informações coletadas confirmam que Altamira possui de fato o maior número de casos registrados.

O CTA apontou um problema quanto ao acesso e à atenção à saúde para os pacientes mais graves de Aids. Como a principal "porta de entrada", o Hospital Municipal São Rafael atende todas as urgências e emergências da área. A maior parte dos pacientes que se dirigem a esse hospital não são recebidos por conta da deficiente infraestrutura para atendimento de casos de alta complexidade. Em determinadas situações, o paciente é direcionado ao Hospital Regional Público da Transamazônica de Altamira, que muitas vezes também não pode atender os casos graves de Aids devido ao comprometimento de sua capacidade de com outras especialidades.

No tocante ao aumento do número de casos de hepatites virais, estreitamente vinculado ao crescimento da população migrante na área, de acordo com relatos de profissionais da Norte Energia e do CTA, instituiu-se uma grande campanha para a realização de exames laboratoriais para a identificação de hepatites entre os trabalhadores da obra de Belo Monte no ano de 2013, em ação conjunta do Ministério da Saúde com o Consórcio Construtor Belo Monte (CCBM). Entretanto, desconhece-se a forma de organização dos fluxos de atendimento e os diagnósticos e se houve acompanhamento no tratamento dos casos positivos de vírus da hepatite. Os exames realizados não se encontram disponíveis no sistema de saúde pública, o que dificulta identificar com exatidão a real situação quanto à incidência da doença e aos tratamentos aplicados nos canteiros de obras. Tal circunstância se caracteriza como uma fragilidade na assistência à saúde do trabalhador e compromete o sistema como um todo, principalmente "por não saber se estes trabalhadores foram tratados ou voltaram aos seus domicílios contaminados e sem o devido tratamento" (Informação Verbal ${ }^{24}$ ).

\footnotetext{
${ }^{24}$ Coletada no CTA de Altamira em agosto de 2015.
} 
Ainda de acordo com os dados do CTA, a notificação dos casos positivos, resultantes dos exames realizados por demandas espontâneas, apresentou uma tendência crescente de casos novos de hepatite B e C a partir de 2013. Entretanto, como o CTA notifica diversas localidades do município de Altamira, torna-se difícil inferir se há uma relação direta com a UHE de Belo Monte. Assim se observou nos dados de 2015, aos quais foram agregados os resultados da investigação do CTA, com a notificação de casos positivos nas localidades de Castelo dos Sonhos e Cachoeira da Serra, áreas de garimpo localizadas a centenas de quilômetros de Altamira (Figura 37).

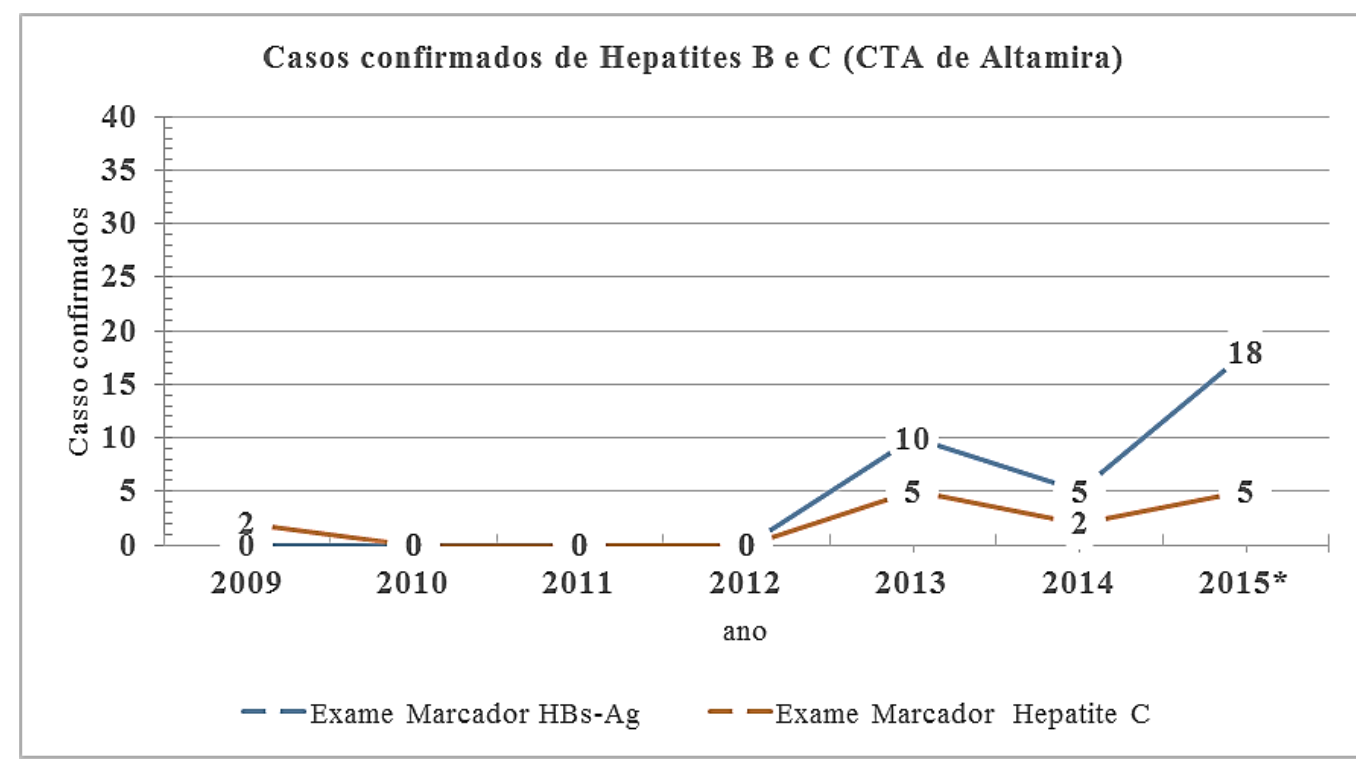

Figura 37 - Casos positivos de hepatites B e C confirmados pelo CTA de Altamira

Fonte: Sistema SCTA/SMS-Altamira, 2015

De acordo com os dados coletados no Centro de Vigilância Epidemiológica, e levandose em consideração que se trata do banco de dados oficial que agrega todos os dados notificados, observa-se uma tendência crescente a partir de 2010, sendo Altamira o município com maior número de casos (Figura 38). 


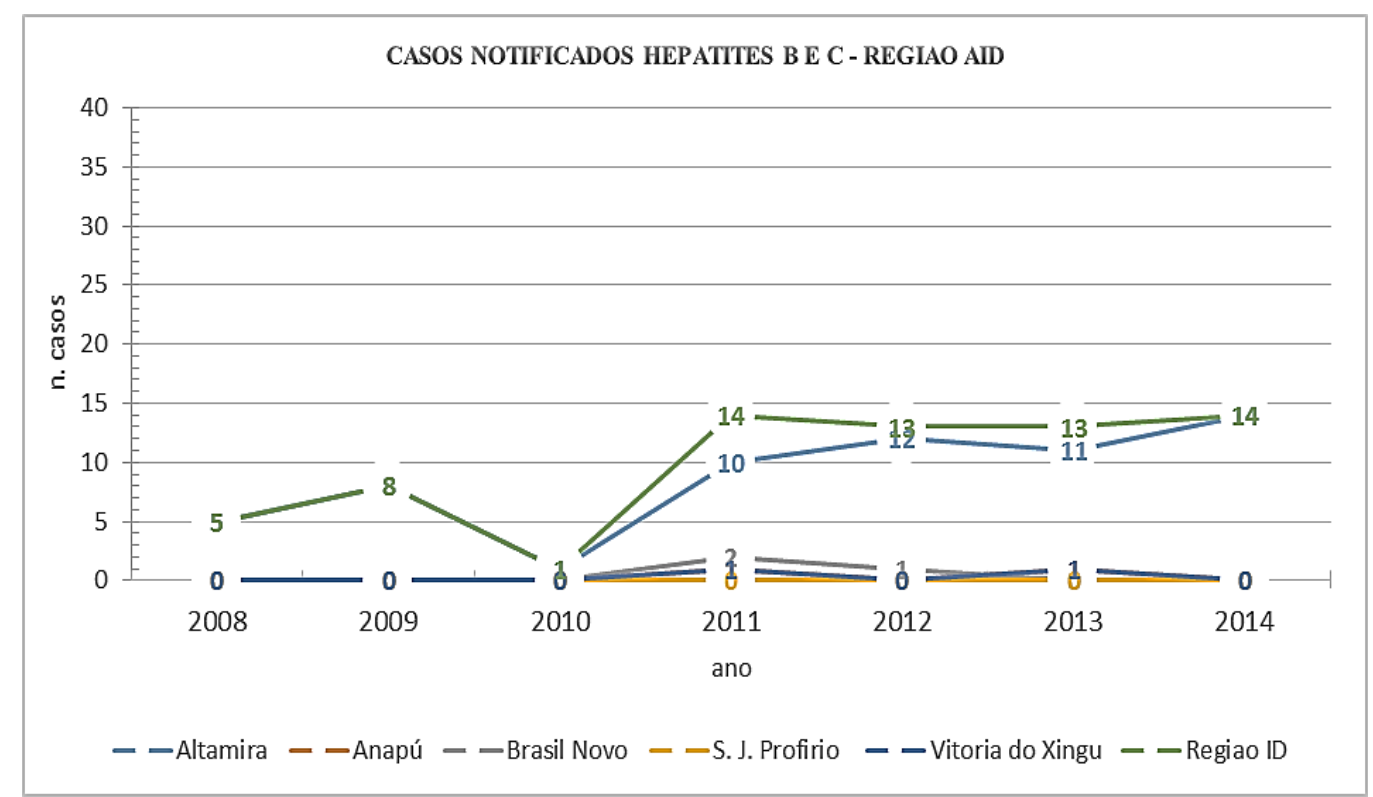

Figura 38 - Casos notificados de hepatites B e C pela SMS, para a Região de AID da UHE de Belo Monte

Fonte: PARÁ/SMS, 2015.

Destaca-se uma possível influência do aumento populacional sobre essa tendência crescente. No mais, identifica-se, além da maior procura para a realização de exames espontaneamente no CTA, a intensificação das notificações pelo CVE.

A respeito dos dados do Ministério da Saúde, a diferença se torna ainda mais acentuada. O aumento significativo no ano de 2013 quanto aos demais, contudo, pode corresponder às notificações ocorridas durante a campanha realizada pelo Ministério da Saúde em parceria com o Consórcio Construtor Belo Monte (CCBM) (Figura 39).

De acordo com o Boletim de Hepatites Virais, um dos mais graves problemas apontados é a existência de casos de hepatites virais subnotificados em âmbito nacional e mundial. Assim, o aprimoramento das informações no sentido de oferecer dados qualificados é um desafio constante para o Ministério da Saúde (BRASIL, 2015e). 


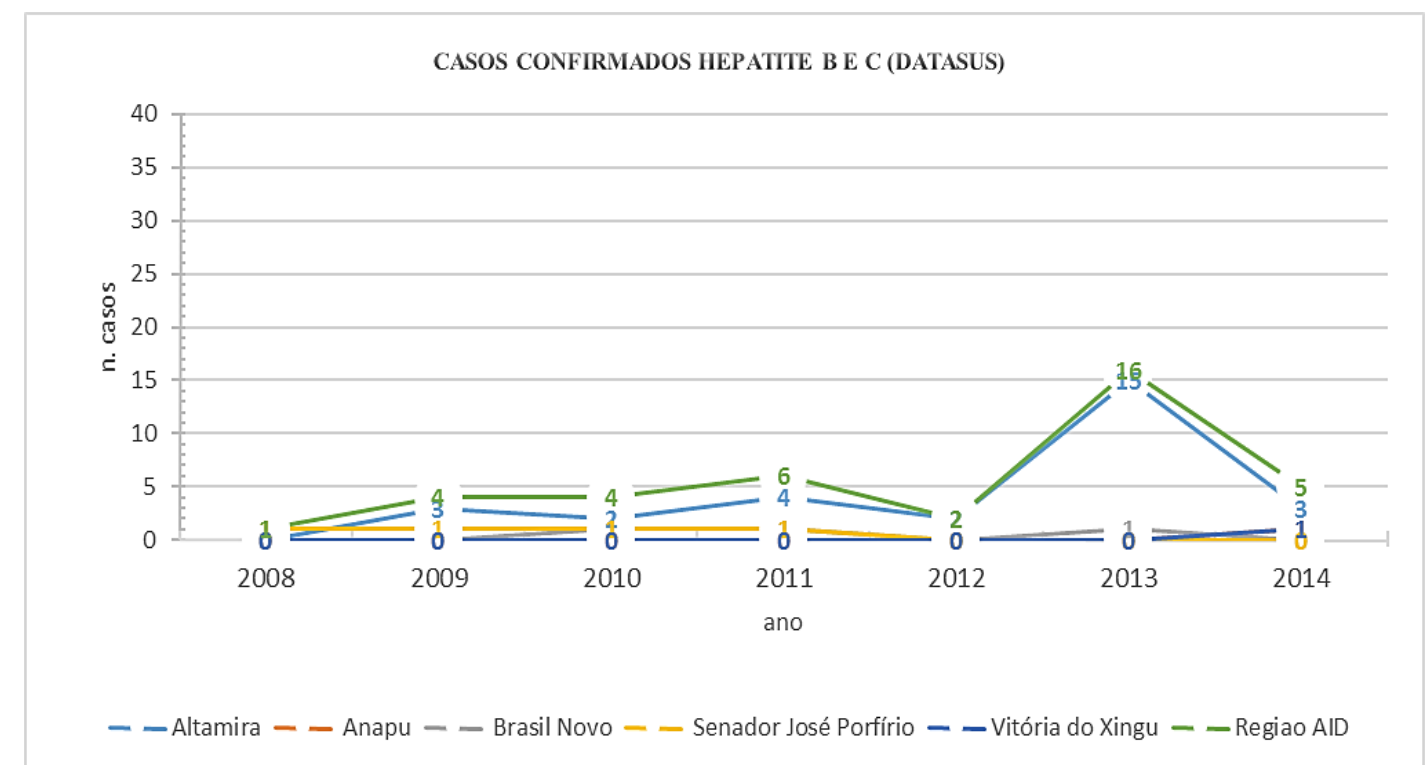

Figura 39 - Casos confirmados de hepatites B e C pelo Datasus, para a região AID da UHE de Belo Monte

Fonte: MS/Sinan, 2015.

Segundo o Boletim Epidemiológico Sífilis, em 2013, foi observado um aumento considerável na notificação de sífilis em gestantes em todas as regiões, que nos últimos anos deveu-se provavelmente ao fortalecimento dos serviços de pré-natal, por meio da "Rede Cegonha"25, o que propiciou o aumento na cobertura de testagem das gestantes e acompanhamento dos casos. No entanto, apesar da ampliação do diagnóstico, a maioria dos casos continua sendo detectada tardiamente (BRASIL, 2015f).

Nos últimos 10 anos, houve um progressivo aumento na taxa de incidência de sífilis congênita no Brasil, sendo que em 2004 a taxa era de 1,7 casos para cada 1.000 nascidos vivos e em 2013 subiu para 4,7. Com relação à incidência de sífilis congênita, a Região Nordeste apresentou a maior incidência de casos $(5,3)$, seguida da Sudeste $(5,1)$, Sul $(4,1)$, Norte $(3,5)$ e Centro-Oeste (3,3). Apesar do acesso ao pré-natal e o diagnóstico de sífilis durante a gravidez, a cadeia de transmissão vertical da sífilis não foi interrompida (BRASIL, 2015f.)

A sífilis em gestante e a sífilis congênita são agravos que apresentaram significativo crescimento a partir do ano de 2009 na região da Área de Influência Direta (AID) da usina de Belo Monte, com predominância para o município de Altamira. Para efeitos comparativos, os

\footnotetext{
${ }^{25}$ Em 2011, o Governo Federal lançou a "Rede Cegonha", estratégia que visa assegurar à mulher e à criança o direito à atenção humanizada durante o pré-natal, parto/nascimento, período pós-parto e atenção infantil em todos os serviços de saúde do Sistema Único de Saúde (SUS). Com a expansão do diagnóstico por meio de testes rápidos de HIV e sífilis e da "Rede Cegonha", observou-se elevação na taxa de detecção de sífilis em gestantes, decorrente da melhoria do diagnóstico e da vigilância epidemiológica (BRASIL, 2015f).
} 
gráficos a seguir apresentam a frequência por ano da notificação de casos de sífilis em gestante e sífilis congênita, de acordo com o município de residência, constante dos dois sistemas de informação: CVE de Altamira e Sinan. Observou-se uma tendência crescente do número de casos, principalmente entre os anos de 2010 a 2013, para a sífilis em gestante e sífilis congênita - quanto a esta última, verificou-se uma menor frequência, segundo as figuras a seguir.

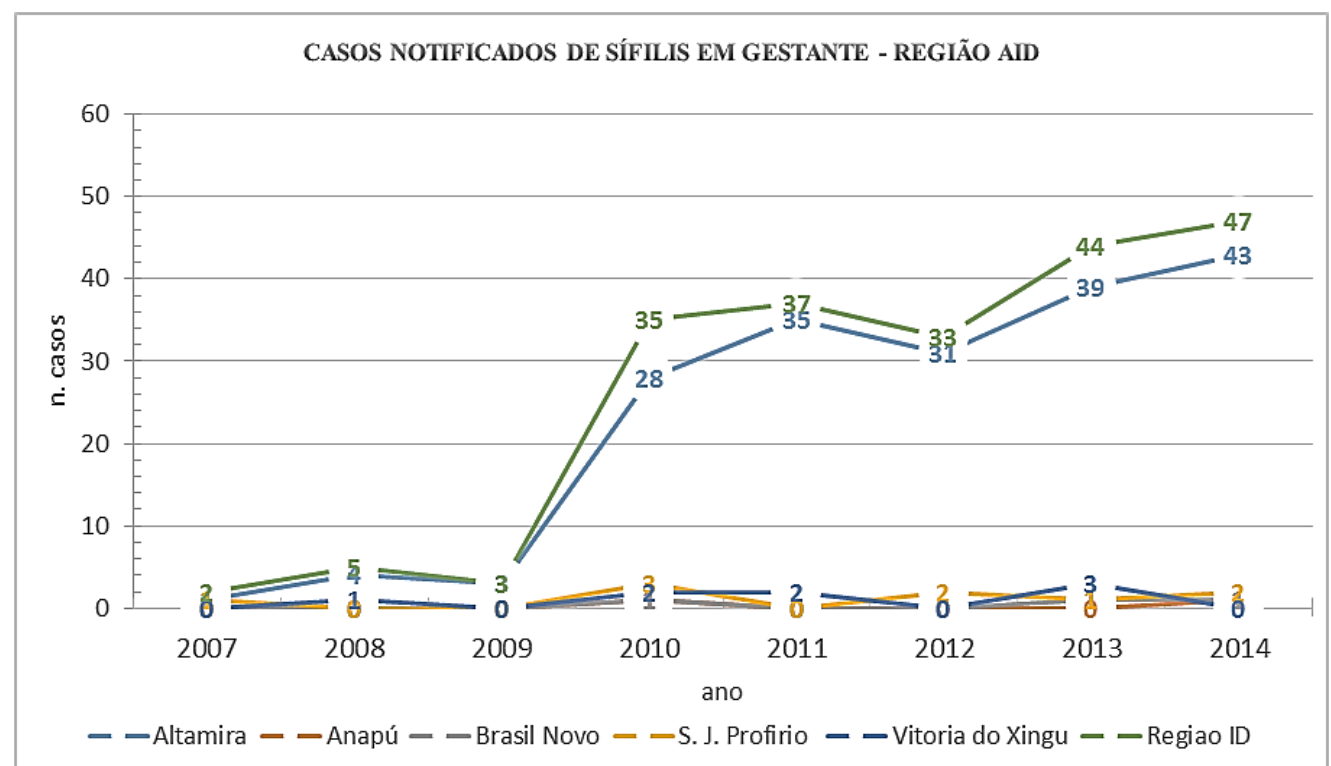

Figura 40 - Casos notificados de sífilis em gestante notificados pela SMS, por município de residência na região AID da UHE de Belo Monte Fonte: PARÁSMS, 2015.

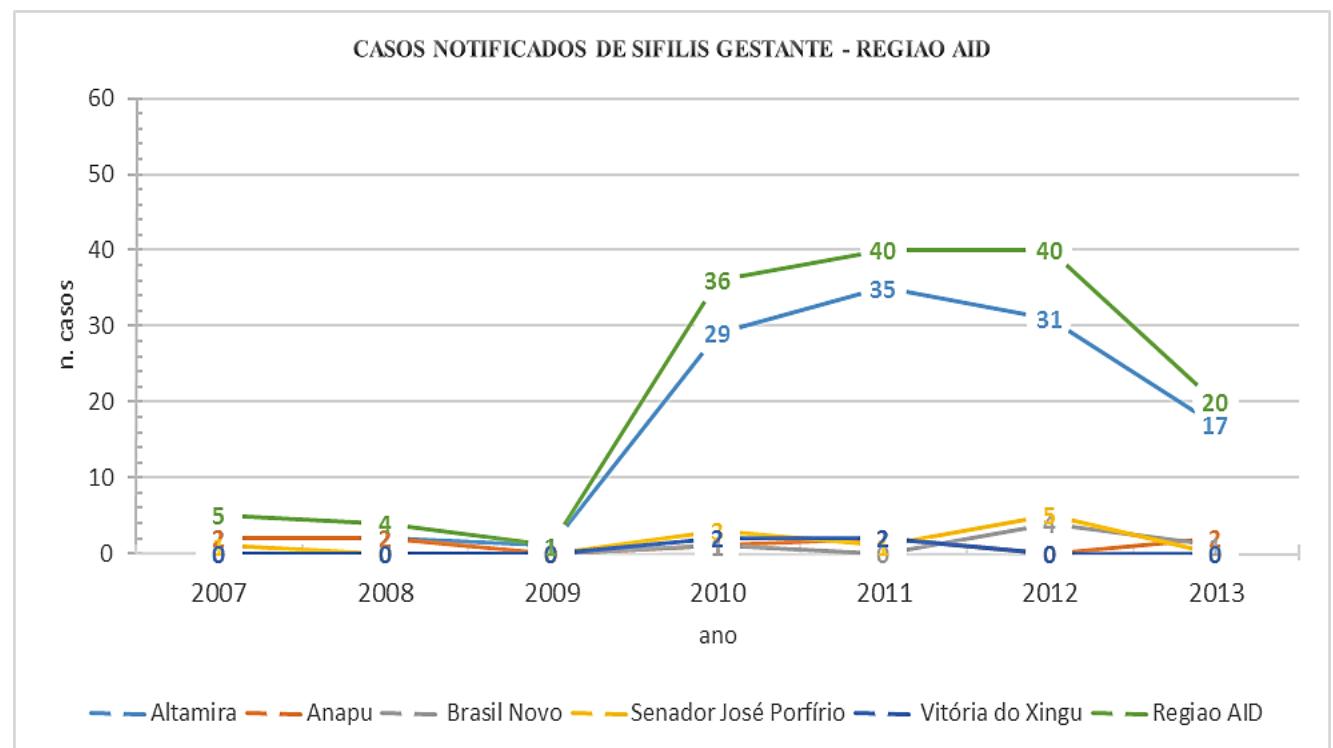

Figura 41 - Casos notificados de sífilis em gestante, notificados pelo Datasus, por município de residência, na região AID da UHE de Belo Monte.

Fonte: MS/Sinan, 2015. 


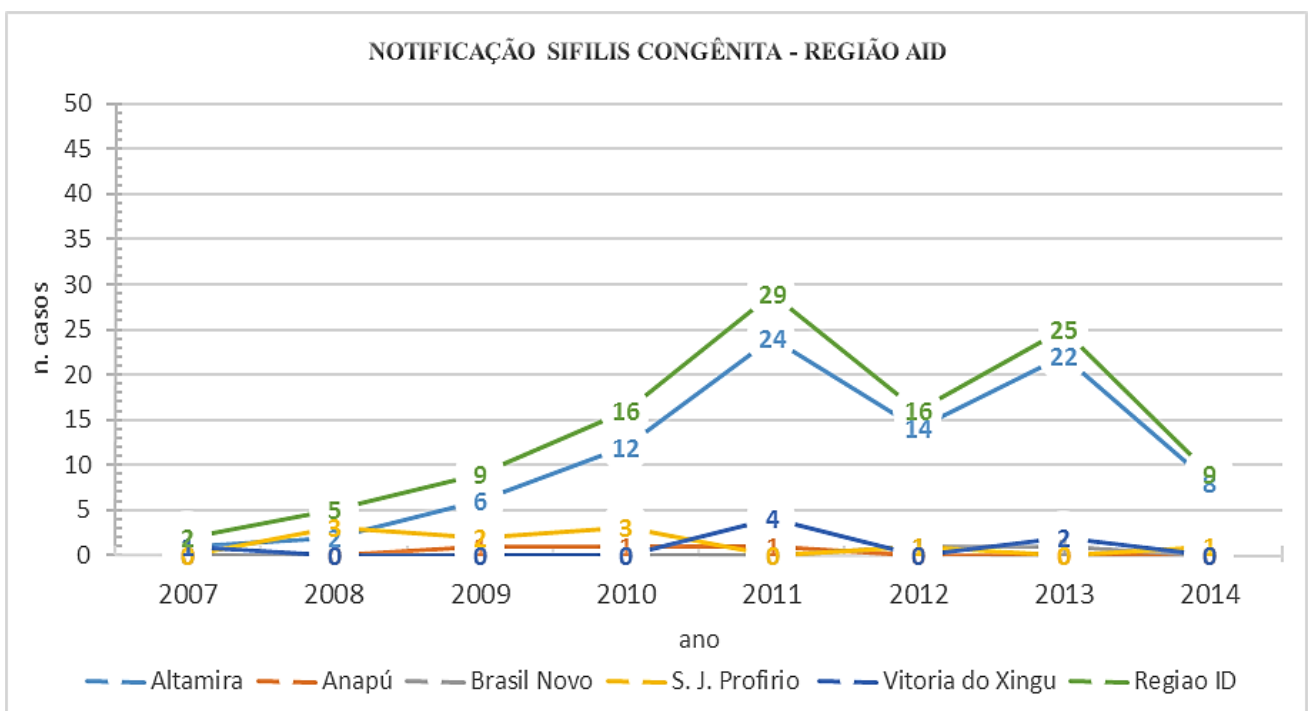

Figura 42 - Casos notificados de sífilis congênita, notificados pela SMS, por município de residência

Fonte: PARÁ/SMS, 2015.

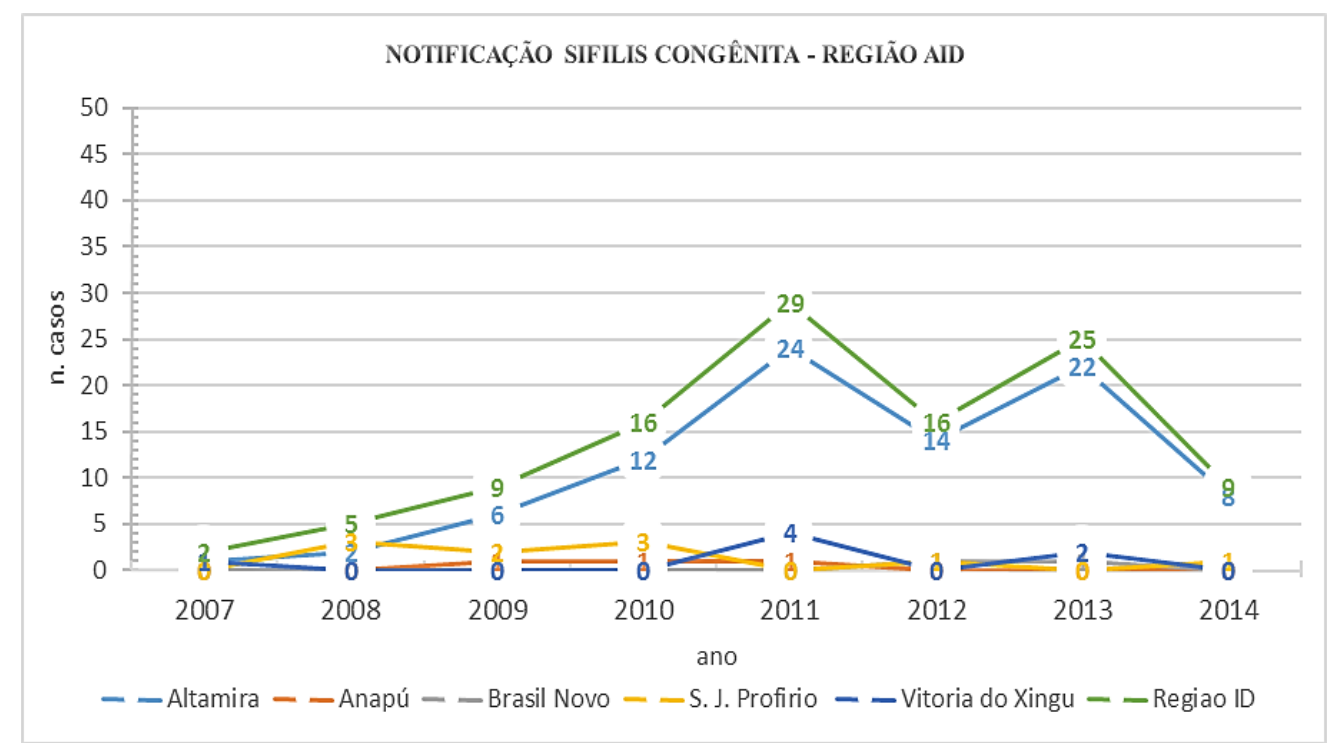

Figura 43 - Casos notificados de sífilis congênita, notificados pelo Datasus, por município de residência Fonte: MS/Sinan, 2015.

Cabe ressaltar que é possível evitar a ocorrência da sífilis congênita, desde que a mãe seja diagnosticada e adequadamente tratada durante o pré-natal. Se este, no entanto, não for realizado de forma correta e de qualidade, com o tratamento tardio ou inadequado da gestante e do parceiro, pode ocorrer a reinfecção. Oportuniza-se, assim, a continuidade das elevadas taxas da doença. Segundo o Ministério da Saúde, a notificação, a investigação de casos, o tratamento adequado e a implementação de medidas para a prevenção de novos casos de sífilis 
congênita contribuirão para a redução dos casos rumo à eliminação da doença. (BRASIL, 2015f).

Do que exposto até então, é possível afirmar que a totalidade dos dados apontou para a tendência de crescimento das doenças transmissíveis, como Aids, hepatite e sífilis, sobretudo a partir de 2011 e especialmente entre 2012 a 2014, para alguns casos. Esse aumento pode ter sofrido influência de diversos fatores. Um deles foi o incremento populacional para a região da UHE de Belo Monte, com a intensificação do fluxo migratório para Altamira a partir de 2009. Num contexto de maior necessidade de vigilância da saúde, ocorreu a ampliação das notificações e, por conseguinte, o aumento do número de casos registrados.

Diante dos dados apresentados, apesar do aumento do número ocorrências das doenças transmissíveis selecionadas neste estudo de caso, não é possível inferir a relação direta desse crescimento com a construção da usina de Belo Monte. No entanto, o intenso contingente de trabalhadores em busca de emprego nas obras de Belo Monte atingiu seu auge nos anos de 2012 a 2013. Nessa época, foram absorvidos mais de quarenta mil trabalhadores para a construção da maior obra do PAC, período historicamente marcado pelo aumento dos agravos à saúde da população local.

\subsubsection{A situação de saúde no contexto das doenças não transmissíveis: causas externas, uma epidemia em evidência}

De acordo com Departamento de Vigilância de Doenças e Agravos não Transmissíveis e Promoção da Saúde, as notificações de violência que compõem o banco de dados do sistema de Vigilância de Violências e Acidentes (Viva) são objeto de monitoramento contínuo pelas equipes das Secretarias Estaduais e Municipais de Saúde e pelo Ministério da Saúde (BRASIL, 2013b).

É importante ressaltar que as notificações de violência doméstica, sexual e as decorrentes de outros fatores apresentaram um acréscimo a partir de 2009, quando a notificação passou a ser registrada no Sinan. Dessa forma, verificou-se uma maior sensibilização por parte dos gestores e profissionais de saúde no sentido de comunicar agravos dessa natureza (BRASIL, 2013b). 
A fim de se compreender o estado de saúde das populações, é fundamental analisar os óbitos por causas específicas de modo a se aprofundarem os estudos epidemiológicos. Entretanto, no caso de dados sobre mortalidade, a confiabilidade sobre a informação a respeito das causas é um dos pontos mais importantes a se observar, haja vista que existe uma proporção grande de mortes por causas não definidas e de mortes sem assistência, principalmente nas regiões Norte e Nordeste (SANTO, 2008). Essa peculiaridade pode comprometer a qualidade dos dados analisados, especialmente quando se investigam as causas externas, como acidentes e violências.

A partir do que apontado pelos autores na revisão bibliográfica que embasou este estudo, os quais apontam os principais agravos relacionados às hidrelétricas, procedeu-se à seleção de dados que expressassem as principais doenças por grupo de causas, assumindo-se como principais as de transmissão vetorial, como malária, chagas, dengue, as demais patologias infecciosas como as gastroenterites, pneumonias, assim como as doenças sexualmente transmissíveis, como sífilis, aids e hepatites. A figura a seguir registra o número de óbitos relativos a esses agravos para efeito de comparação entre os anos de 2006 a 2014 (Figura 44). Considera-se que, em 2011, ocorreu o início das obras da UHE de Belo Monte e, consequentemente, o incremento da população, principalmente em Altamira.

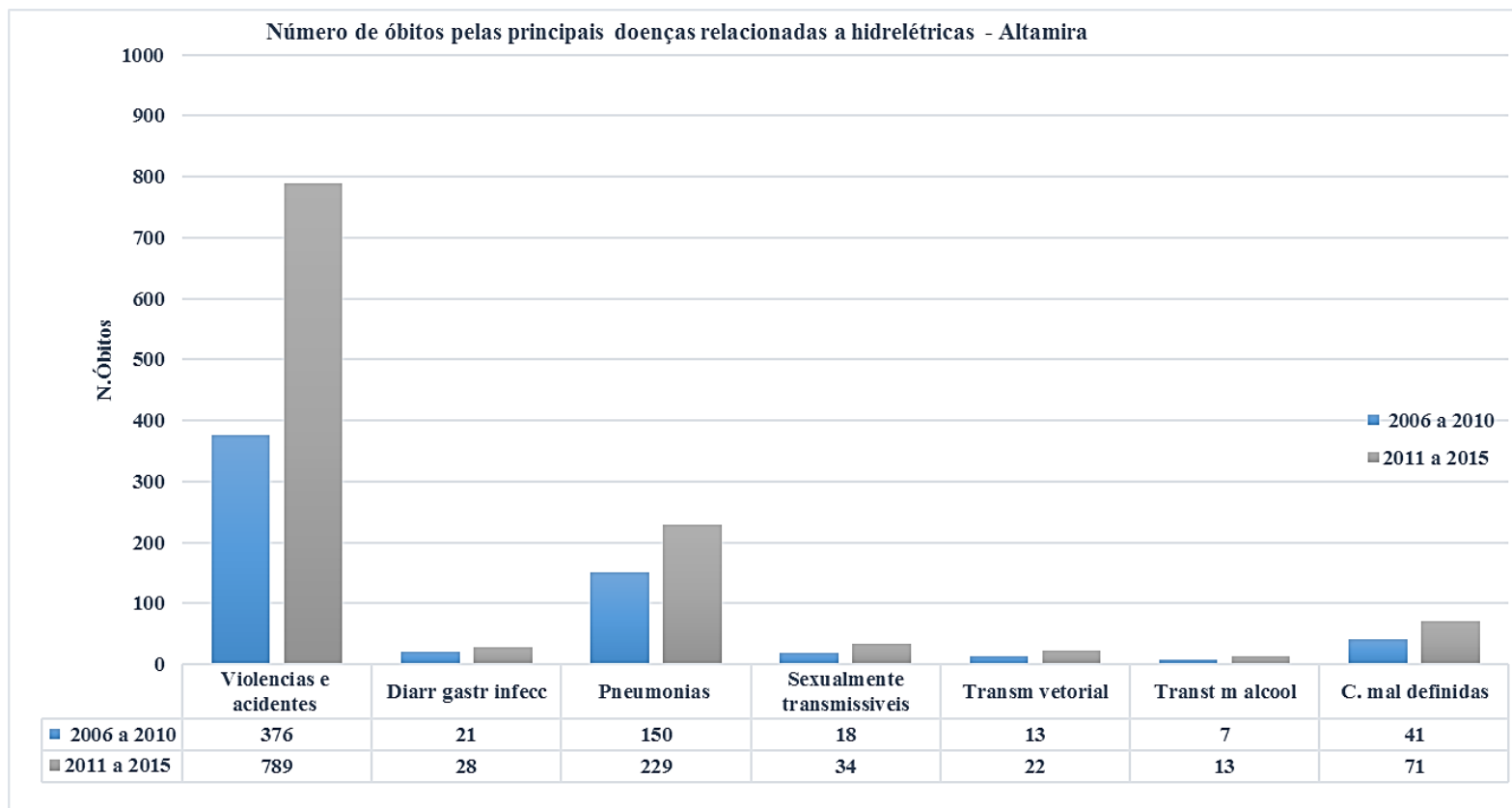

Figura 44 - Óbitos decorrentes das principais doenças relacionadas à implantação de hidrelétricas no município de Altamira no período de 2006 a 2015.

Fonte: PARÁ/SMS, 2015. 
A análise comparativa dos dados revelou que as causas externas, representadas aqui pelos acidentes e violências, foram as que mais afetaram a população de Altamira nos últimos anos, perdendo apenas para as doenças cardiovasculares e diabetes.

Verifica-se uma elevação significativa, no período estabelecido, do número de óbitos causados por doenças sexualmente transmissíveis (90\%), pneumonias (51\%), transmissão vetorial $(75 \%)$ e transtornos mentais $(85 \%)$, assim como por causas mal definidas $(73 \%)$. No entanto foram as causas externas, representadas pelas violências e acidentes, que, em números absolutos, apresentaram um crescimento de $110 \%$ de um período a outro (Figura 43). Os dados coletados no Centro de Vigilância Epidemiológica (CVE) da Secretaria Municipal de Altamira retratam essa tendência, já que o percentual de óbitos é bastante expressivo, sobretudo para os casos de acidentes e violências relacionados à série histórica de 2006 a 2104.

Observa-se, nesse período, a partir do início da construção da usina em 2011, a tendência crescente da mortalidade por acidentes de transito, chegando a um aumento de quase $100 \%$ no ano de 2014. Vale destacar que de 2012 e 2013 foi o período de maior concentração da população trabalhadora na região (Figura 45).

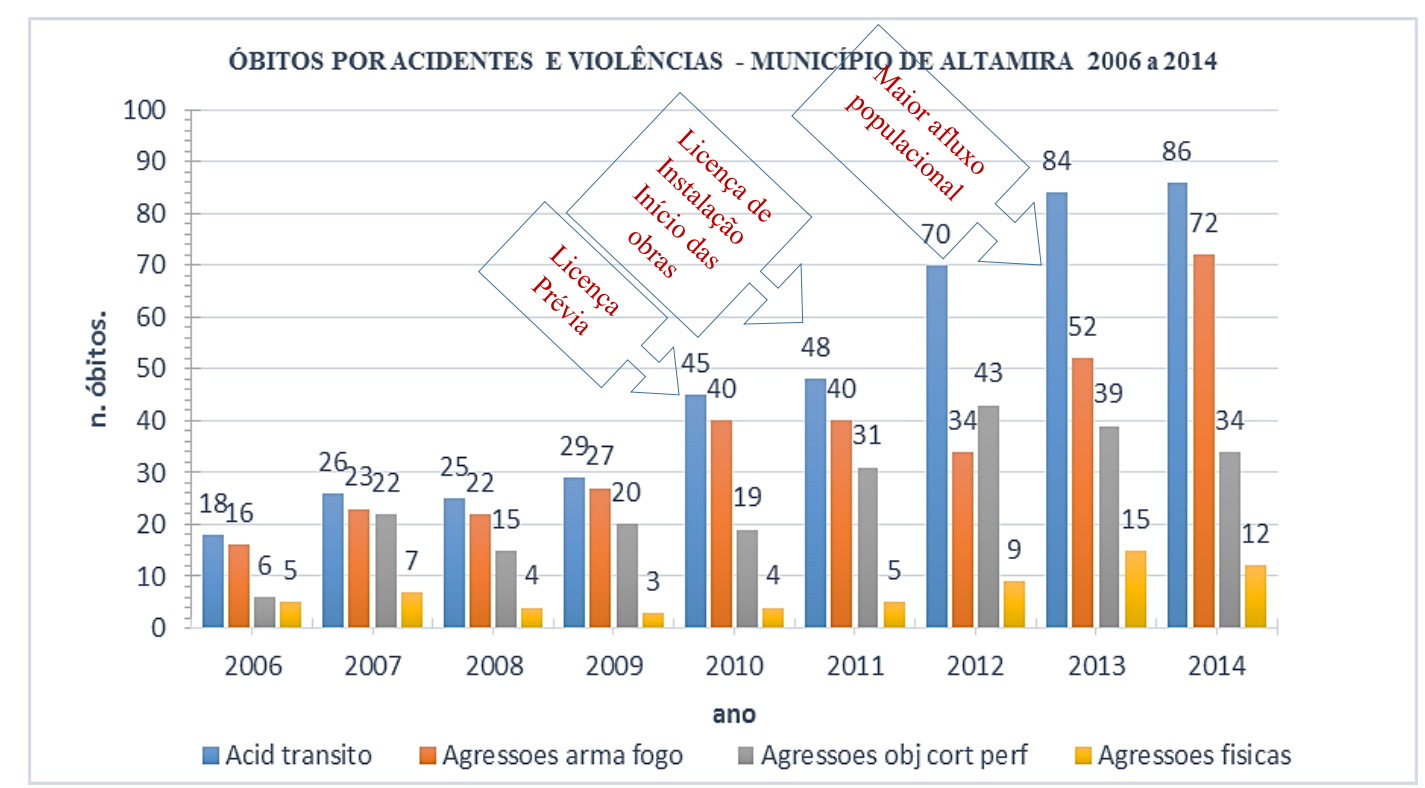

Figura 45 - Número de óbitos por acidentes e violências no município de Altamira no período de 2006 a 2014 Fonte: PARÁ/SMS, 2015

Os óbitos decorrentes de violências e acidentes, quando comparados a todas as demais causas - nos dois períodos, teve um aumento de $65 \%$, passando de $12,8 \%$, do total da 
mortalidade notificado no primeiro período, para $21,2 \%$ no intervalo subsequente, ou seja, de 2011 a 2015 (Figuras 46 e 47).
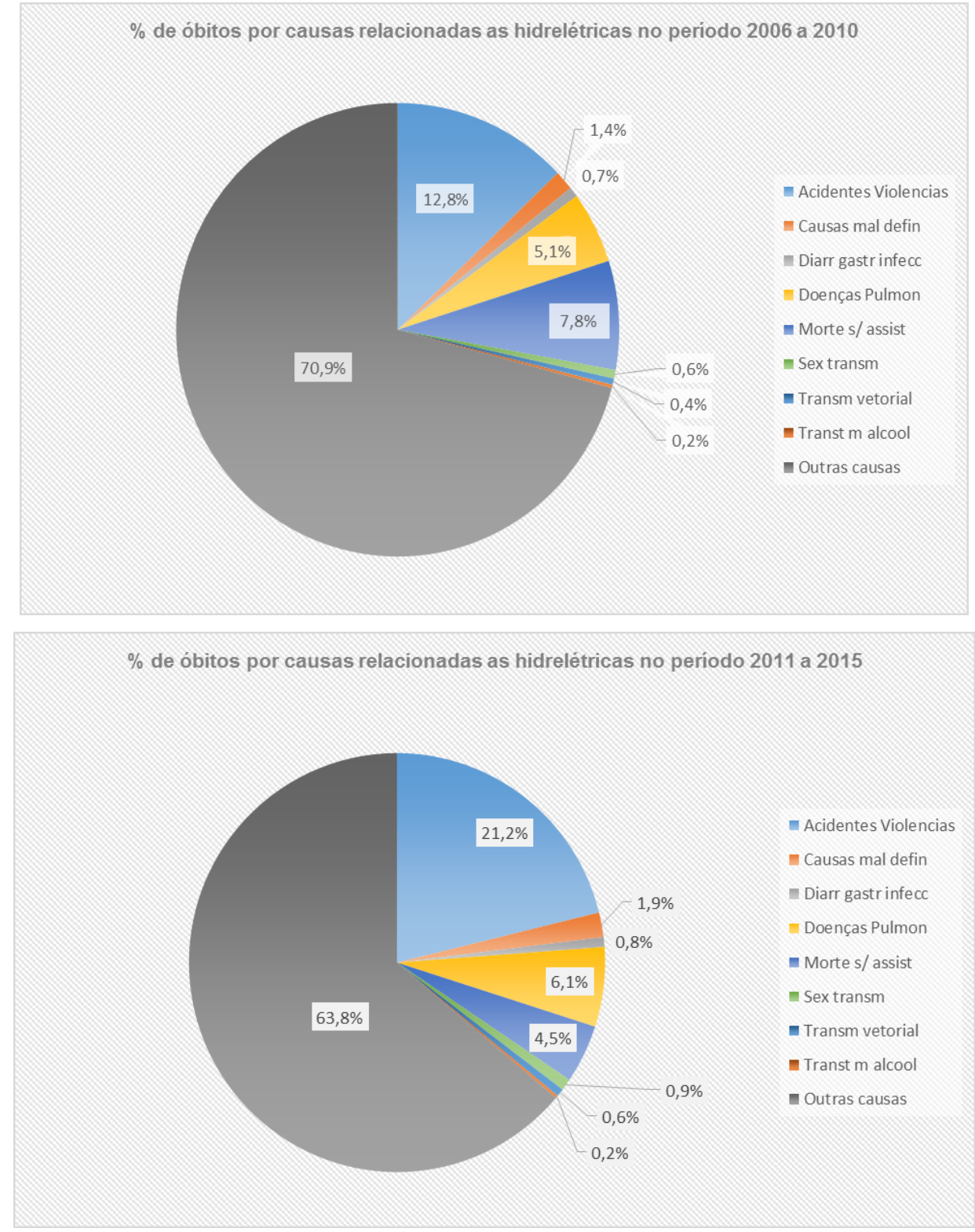

Figura 46 e 47 - Percentual de óbitos por grupos de causas relacionadas à implantação de hidrelétricas no município de Altamira, nos períodos de 2006 a 2010 e de 2011 a 2015 Fonte: PARÁ/SMS, 2015.

No concernente à morbidade hospitalar do Sistema Único de Saúde (SUS), analisaramse os dados de internação geral por município e ano de atendimento. O gráfico a seguir (Figura 48) registra o total de internações gerais por local de internação para os municípios da região de saúde do Xingu, que compreende a AID e AII da usina de Belo Monte. Verifica-se uma tendência de queda para Altamira, que, somados os períodos, participa com 53,3 \% das internações da região. 


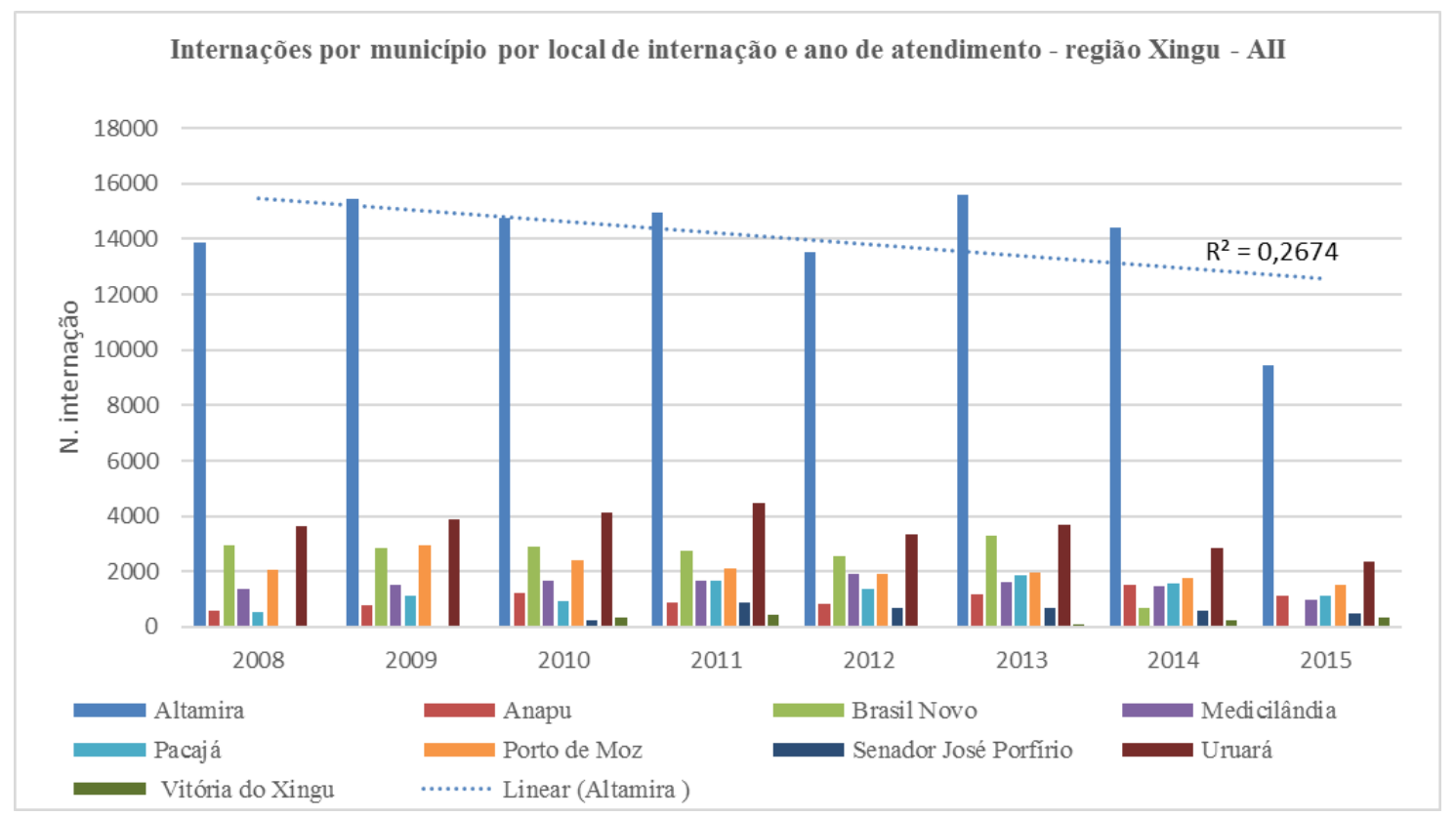

Figura 48 - Número de internações referentes a todas as causas para os municípios da AID e AII, entre 2008 e 2015

Fonte: MS/ SIH/SUS, 2016.

No tocante aos dados de Altamira, observa-se que as doenças do aparelho respiratório surgem como uma das principais causas de internação, com 19,8\% do total, seguida das doenças infecciosas e parasitárias, das patologias relacionadas ao parto e, por último, das consequências de causas externas. Estas últimas, no entanto, apresentaram uma tendência crescente quanto às demais, como registra a figura a seguir (Figura 49).

Ainda no que diz respeito a esse parâmetro, propôs-se analisar as internações por causas externas a fim de observar o comportamento na região da AID e AII. A figura adiante aponta para uma tendência crescente no município de Altamira e Uruará, com um aumento significativo nos anos de 2013 e 2014 (Figura 50). 


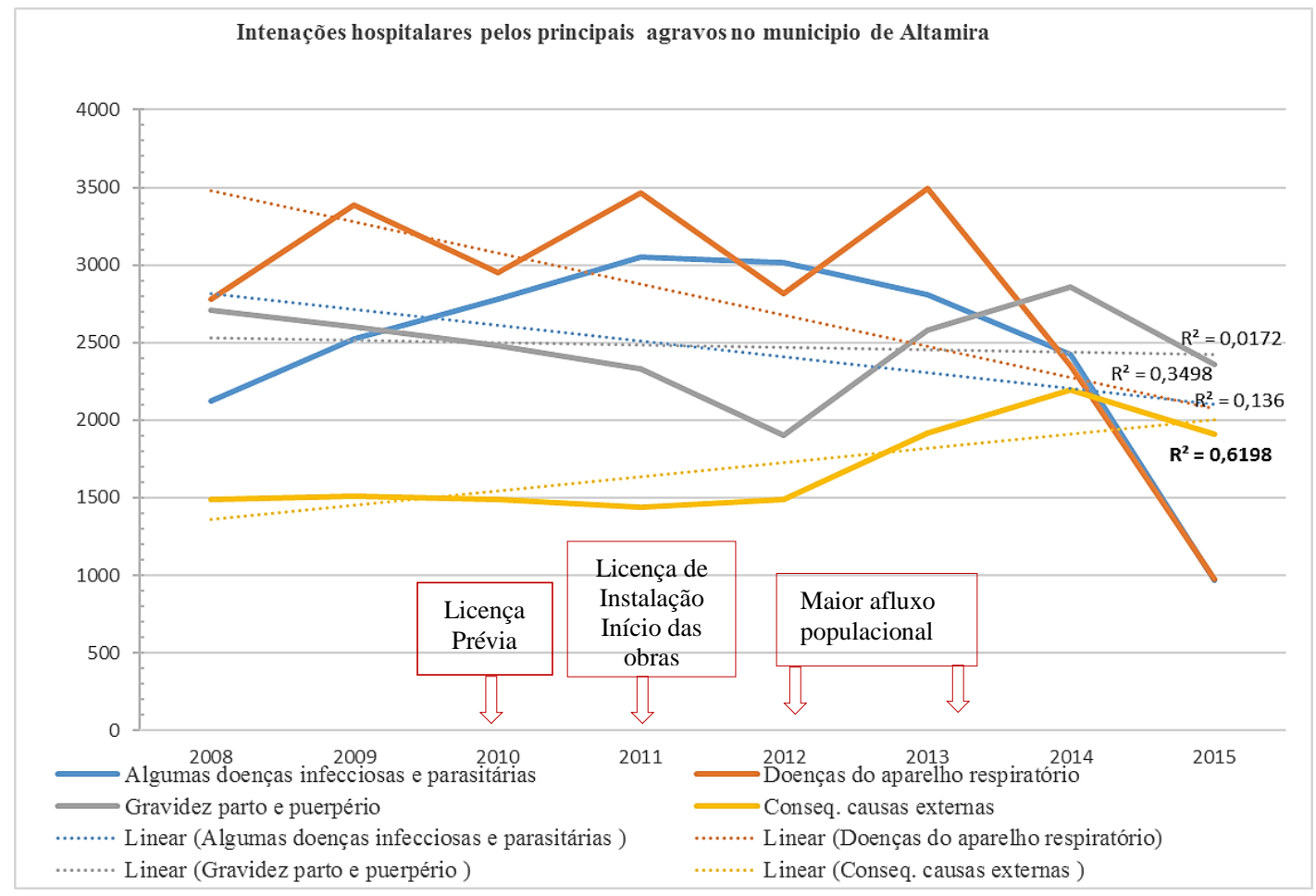

Figura 49 - Números de internações pelos principais agravos em Altamira

Fonte: MS/SIH/SUS, 2016.

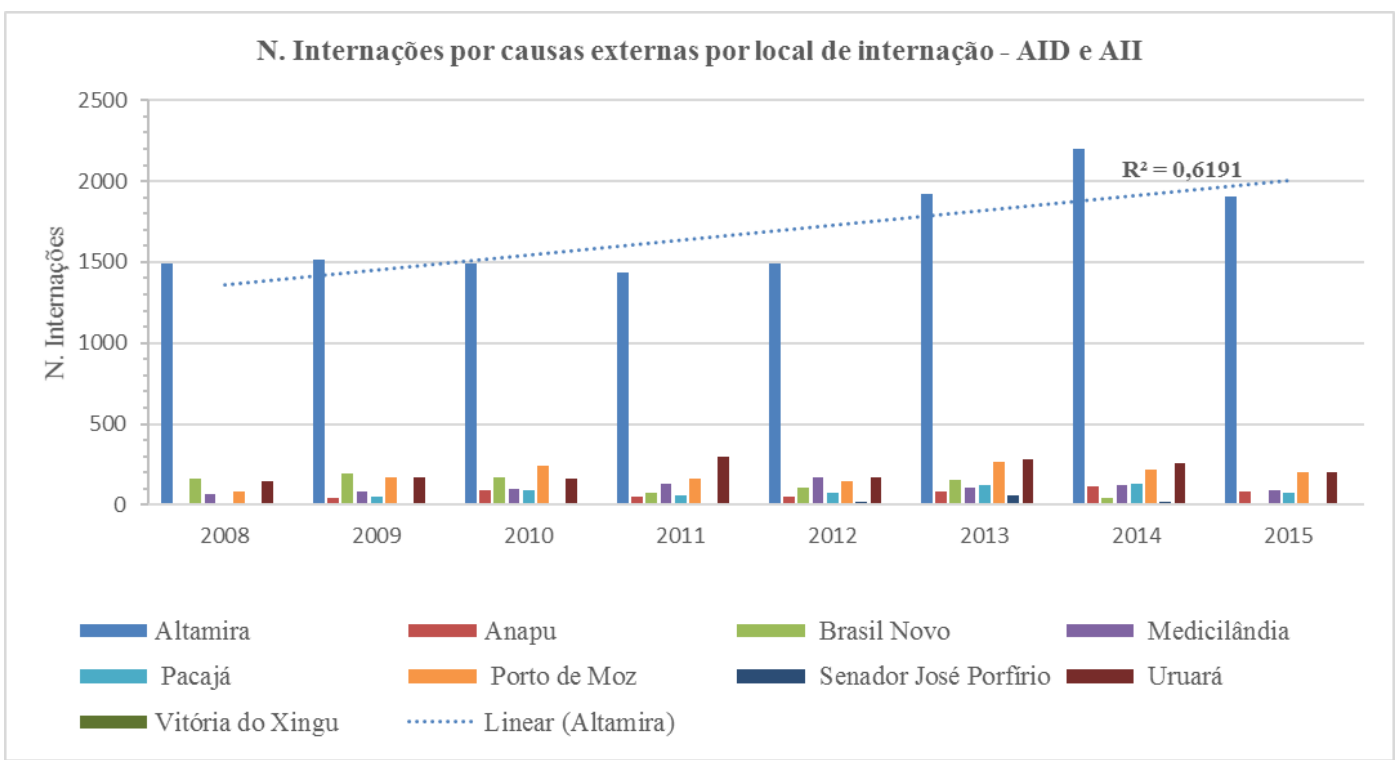

Figura 50 - Figura- Número de internações por causas externas, de acordo com o local de internação, nos municípios da AID e AII da usina de Belo Monte

Fonte: MS/SIH/SUS,2016.

A figura seguinte registra as taxas de mortalidade hospitalar por causas externas em Altamira, distribuídas por sexo. Quanto a esse critério, verifica-se a prevalência do sexo masculino, principalmente em 2010, seguindo tendência crescente até 2014. Apenas em 2012, 
ocorreu o destaque para o sexo feminino, com a taxa de 4,15 em cada 100 internações (Figura $51)$.

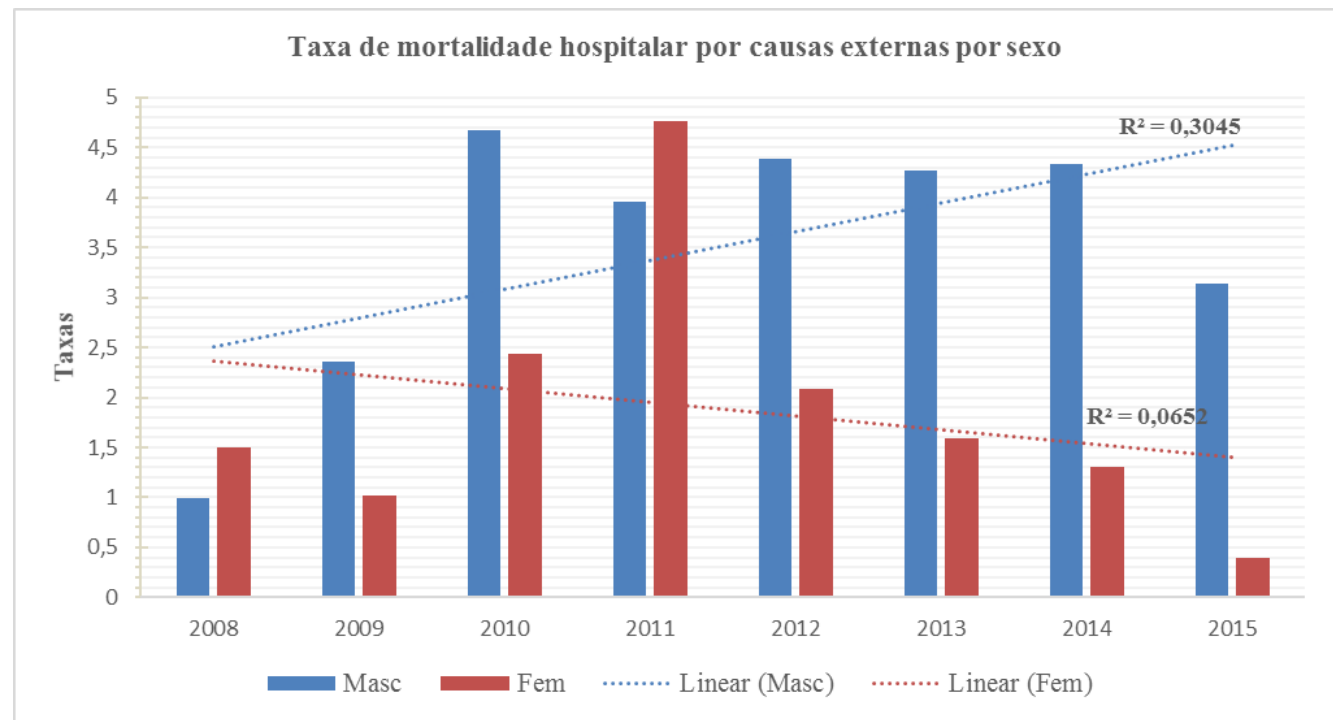

Figura 51 - Taxa de mortalidade hospitalar por causas externas de acordo com o sexo, no municipio de aAltamira

Fonte: MS/SIH/SUS, 2016.

As taxas de mortalidade hospitalar por causas externas na Região de Saúde do Xingu, que compreende os municípios da AID e AII, é a segunda maior, seguida da Região Metropolitana I (Belém, Ananindeua e Marituba), conforme aponta o Quadro 8.

Quadro 8 - Taxas de mortalidade por causas externas de acordo com a região de saúde do Pará.

\begin{tabular}{|l|r|r|r|r|r|r|r|r|r|}
\hline Região de Saúde & $\mathbf{2 0 0 8}$ & $\mathbf{2 0 0 9}$ & $\mathbf{2 0 1 0}$ & $\mathbf{2 0 1 1}$ & $\mathbf{2 0 1 2}$ & $\mathbf{2 0 1 3}$ & $\mathbf{2 0 1 4}$ & $\mathbf{2 0 1 5}$ & Total \\
\hline Araguaia & 1,57 & 1,1 & 1,91 & 1,26 & 1,67 & 1,53 & 1,49 & 2,56 & 1,63 \\
\hline Baixo Amazonas & 0,71 & 0,82 & 0,92 & 1,19 & 0,98 & 0,94 & 1,36 & 1,72 & 1,13 \\
\hline Carajás & 1,95 & 1,4 & 1,79 & 2,09 & 1,77 & 1,83 & 1,83 & 1,94 & 1,8 \\
\hline Lago de Tucuruí & 0,46 & 1,44 & 1,19 & 1,63 & 1,68 & 1,66 & 1,24 & 1,1 & 1,32 \\
\hline Metropolitana I & 1,5 & 1,82 & 2,1 & 2,48 & 2,54 & 2,82 & 2,9 & 2,52 & 2,35 \\
\hline Metropolitana II & & 0,12 & & - & - & & & - & 0,02 \\
\hline Metropolitana III & 0,05 & 0,09 & 0,07 & 0,07 & 0,09 & 0,06 & 0,18 & 0,73 & 0,17 \\
\hline Rio Caetés & 0,15 & 0,16 & 0,69 & 0,3 & 0,62 & 0,65 & 0,17 & 0,43 & 0,38 \\
\hline Tapajós & & 1,66 & 1,53 & 2,12 & 1,29 & 1,79 & 1,12 & 1,38 & 1,45 \\
\hline Tocantins & 0,16 & & 0,08 & 0,07 & 0,15 & 0,15 & 0,07 & & 0,09 \\
\hline Xingu & 0,76 & 1,58 & 2,04 & 2,32 & 2,55 & 1,97 & 2,57 & 2,13 & $\mathbf{2 , 0 1}$ \\
\hline Marajó I & - & 0,31 & 0,23 & - & - & - & - & 0,22 & 0,09 \\
\hline Marajó II & 0,71 & 0,73 & 0,67 & 0,15 & 0,74 & 0,55 & 0,25 & 0,71 & 0,53 \\
\hline Total & 1,05 & 1,25 & 1,52 & 1,69 & 1,71 & 1,76 & 1,83 & 1,91 & 1,6 \\
\hline
\end{tabular}

Fonte: MS/SIH/SUS, 2016. 
Entre os municípios da Região de Saúde do Xingu (AID e AII), Altamira é o mais impactado pela morbidade por causas externas; consequentemente, configura-se também como o que apresenta os maiores gastos com serviços hospitalares na região, como registra o quadro abaixo (Quadro 9). Observou-se, em 2009, um aumento de quase 50\% em relação a 2008, de acordo com a tendência de crescimento anual, com a maior alta ocorrendo em 2014.

Quadro 9-Custo dos serviços hospitalares por causas externas na Região de Saúde Xingu (em reais)

\begin{tabular}{|c|c|c|c|c|c|c|c|c|c|}
\hline $\begin{array}{c}\text { Municipios } \\
\text { AID e AII }\end{array}$ & 2008 & 2009 & 2010 & 2011 & 2012 & 2013 & 2014 & 2015 & Total \\
\hline Altamira & 799.160 & 1.190 .387 & 1.268 .861 & 1.346 .532 & 1.465 .545 & 1.771 .944 & 2.264 .162 & 1.999 .802 & 12.217.378 \\
\hline Anapu & 2.552 & 7.572 & 15.122 & 10.712 & 8.221 & 14.174 & 19.725 & 13.711 & 92.333 \\
\hline Brasil Novo & 59.774 & 73.803 & 69.512 & 35.166 & 57.986 & 80.680 & 21.145 & & 400.456 \\
\hline Medicilândia & 11.371 & 15.914 & 16.952 & 26.612 & 30.630 & 18.520 & 20.980 & 15.625 & 156.606 \\
\hline Pacajá & 2.806 & 9.340 & 14.661 & 10.557 & 12.911 & 22.059 & 25.613 & 14.511 & 113.133 \\
\hline $\begin{array}{c}\text { Porto de } \\
\text { Moz }\end{array}$ & 12.093 & 51.986 & 79.988 & 42.000 & 39.487 & 50.106 & 49.182 & 40.525 & 368.189 \\
\hline $\begin{array}{c}\text { Senador José } \\
\text { Porfírio } \\
\end{array}$ & & & 1.145 & 3.248 & 3.940 & 10.700 & 3.260 & 851 & 23.144 \\
\hline Uruará & 22.635 & 30.285 & 28.137 & 53.877 & 29.849 & 50.348 & 47.311 & 38.981 & 301.579 \\
\hline $\begin{array}{c}\text { Vitória do } \\
\text { Xingu }\end{array}$ & & & 170 & 2.603 & & 340 & 1.142 & 2.678 & 6.935 \\
\hline Total & 910.392 & 1.379 .289 & 1.494 .547 & 1.531 .307 & 1.648 .569 & 2.018 .872 & 2.452 .521 & 2.126 .685 & 13.679.751 \\
\hline
\end{tabular}

Fonte: MS/SIH/SUS, 2016.

Ainda no tocante aos gastos com internações por causas externas, chama a atenção o grande grupo relativo aos eventos cuja a intenção é indeterminada ${ }^{26}$. Do valor total gasto com serviços hospitalares apontados no quadro anterior, mais da metade foi aplicada para eventos dessa natureza.

Na comparação dos valores gastos por internação entre Altamira, o Estado do Pará e os municípios da AII de Belo Monte, relativamente a esse mesmo grupo de causas, verifica-se que Altamira, em 2011, alcançou a metade do montante dispendido pelo Estado do Pará com o mesmo evento, mantendo uma tendência crescente para os anos seguintes (Figura 52).

A crescente frequência de classificação de agravos decorrentes de eventos cuja intenção é indeterminada pode mascarar os dados, definindo as causas como acidentes ou violências.

\footnotetext{
${ }^{26}$ Os eventos cuja a intenção é indeterminada contempla eventos ou fatos sobre os quais a informação disponível não é suficiente para permitir que as autoridades médicas ou legais sejam capazes de distinguir entre acidente, lesão auto-infligida ou agressão (MS/DATASUS, 2015).
} 
Trata-se de circunstância que tende a prejudicar a análise do problema, colocando em xeque a qualidade do diagnóstico e expondo a fragilidade dos serviços de atendimento no município.

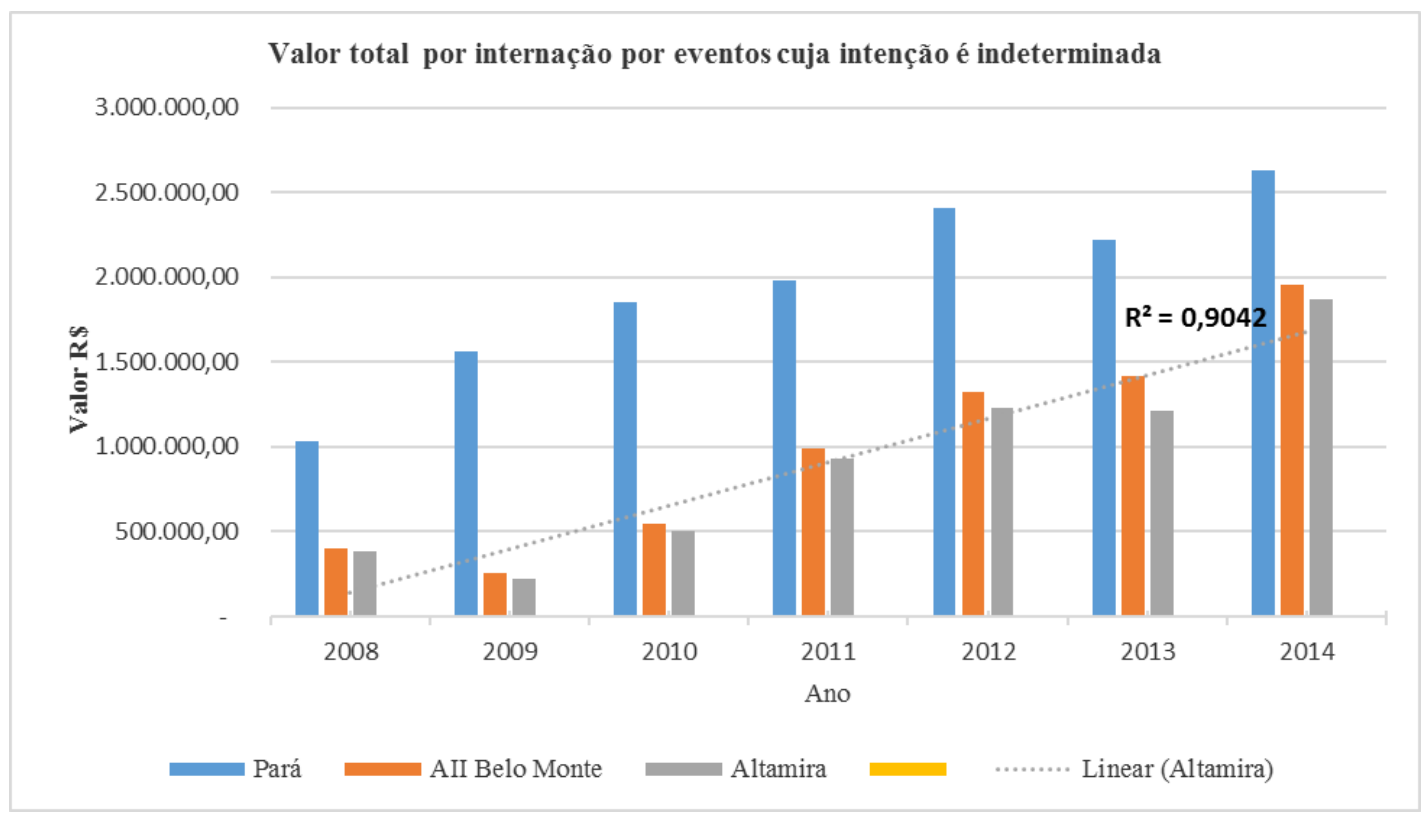

Figura 52 - Valores totais por internação em eventos de intenção indeterminada, para o Estado do Pará, Altamira e AII de Belo Monte FONTE: MS/SIH/SUS, 2015.

A análise dos dados da pesquisa de campo, apoiada pelas informações oficiais do Ministério da Saúde, permitiu observar tendência do número de casos novos notificados para as doenças sexualmente transmissíveis, bem como para a morbimortalidade por agravos não transmissíveis, como as causas externas, expressivamente maiores. No que se refere à totalidade de doenças e agravos analisados, durante os anos de 2008 a 2015, as causas externas de fato se mostraram as mais expressivas, revelando que essa tendência acompanhou o aumento populacional na região. De acordo com as informações coletadas para essa questão especificamente, o município de Altamira surge como o mais afetado, pelos motivos anteriormente mencionados. 


\subsubsection{O paradoxo entre a infraestrutura de saúde ofertada e o acesso aos serviços prestados na área: altos investimentos e resultados pouco expressivos}

As condicionantes de saúde da Licença de Instalação (LI) cuja concessão marcou o início das obras de Belo Monte possuíam como principais ações planejadas no PBA a construção e a instalação de equipamentos para atender a população dos municípios da Área de Influência Direta (AID) do empreendimento. O PBA, entregue ao Ibama em 2011, previa, no âmbito das medidas específicas para a saúde, a construção de seis hospitais e 28 Unidades Básicas de Saúde (UBS), com o fornecimento dos equipamentos necessários, para os cinco municípios da Área de Influência Direta (AID): Altamira (área urbana, rural e RUC), Vitória do Xingu, Senador José Porfírio, Brasil Novo e Anapu. Previa-se a conclusão dessas ações para o período anterior ao auge do afluxo populacional na região.

Em recente estudo realizado pela Fundação Getúlio Vargas (FGV), por meio do projeto Indicadores de Belo Monte ${ }^{27}$, a saúde foi um dos doze indicadores de monitoramento, dentre os vários temas selecionados. Esse controle faz parte da coleta de dados para a construção de um "painel de controle social", a fim de possibilitar à população local o acesso às informações pertinentes às condicionantes do Plano de Desenvolvimento Regional Sustentável do Xingu (PDRS-X). De acordo com esse estudo, até julho de 2105 foram construídos e equipados dois hospitais e 28 Unidade Básicas de Saúde (UBS), nos cinco municípios da AID da Usina de Belo Monte (Quadro 10). Apesar de se apontarem quatro hospitais como concluídos, dois deles ainda não foram repassados ao poder público local, por conta sobretudo da falta de recursos para seu custeio (FGV, 2015).

Antes da implementação das condicionantes do PBA, o município de Altamira, que se configura como polo regional, contava com dois hospitais - o São Rafael e o Hospital Regional de Altamira (Figuras 53 e 54). O primeiro foi construído na década de 1970 e hoje se encontra com sua capacidade de leitos esgotada e uma estrutura ultrapassada. No entanto, é o único disponível para o atendimento de urgências e emergências no município. A reforma prevista desse hospital seria de responsabilidade da Norte Energia, em contrapartida ao grande afluxo populacional na cidade causado pelas obras da usina de Belo Monte. Porém, segundo a

\footnotetext{
${ }^{27}$ O projeto Indicadores de Belo Monte foi realizado pela Fundação Getúlio Vargas (FGV), por meio do seu Centro de Estudos em Sustentabilidade (GVCes), com financiamento e supervisão da Câmara Técnica de Monitoramento das Condicionantes da UHE Belo Monte (CT-5) do Plano de Desenvolvimento Regional Sustentável do Xingu (PDRSX).
} 
Fundação Getúlio Vargas (FGV), esse acordo não faz parte das condicionantes do licenciamento ambiental, "tratando-se apenas de um Termo de Compromisso (TC) passível de ser revisto entre as partes", o que ainda não ocorreu (FGV, 2015).

Quadro 10 - Equipamentos ${ }^{28}$ de saúde e hospitais planejados e concluídos como condicionantes de saúde para a AID de Belo Monte

\begin{tabular}{|c|c|c|c|c|c|c|c|c|}
\hline \multicolumn{5}{|c|}{ EQUIPAMENTOS DE SAÚDE* } & \multicolumn{4}{|c|}{ HOSPITAIS } \\
\hline ANO & 2011 & 2012 & 2013 & 2014 & 2011 & 2012 & 2013 & 2014 \\
\hline ALTAMIRA & $2 / 5$ & $4 / 5$ & $5 / 8$ & $5 / 8$ & $0 / 1$ & $0 / 2$ & $0 / 2$ & $0 / 2$ \\
\hline ANAPU & $1 / 10$ & $8 / 10$ & $8 / 8$ & $8 / 8$ & $0 / 1$ & $0 / 1$ & $0 / 1$ & $0 / 1$ \\
\hline BRASIL NOVO & $0 / 8$ & $8 / 8$ & $8 / 8$ & $8 / 8$ & & & & \\
\hline SENADOR JOSE PORFIRIO & $1 / 7$ & $7 / 7$ & $7 / 7$ & $7 / 7$ & $1 / 1$ & $1 / 1$ & $1 / 1$ & $1 / 1$ \\
\hline VITORIA DO XINGU & $2 / 14$ & $7 / 7$ & $7 / 7$ & $7 / 7$ & $0 / 1$ & $0 / 2$ & $0 / 2$ & $1 / 2$ \\
\hline
\end{tabular}

Fonte: FGV, 2015.

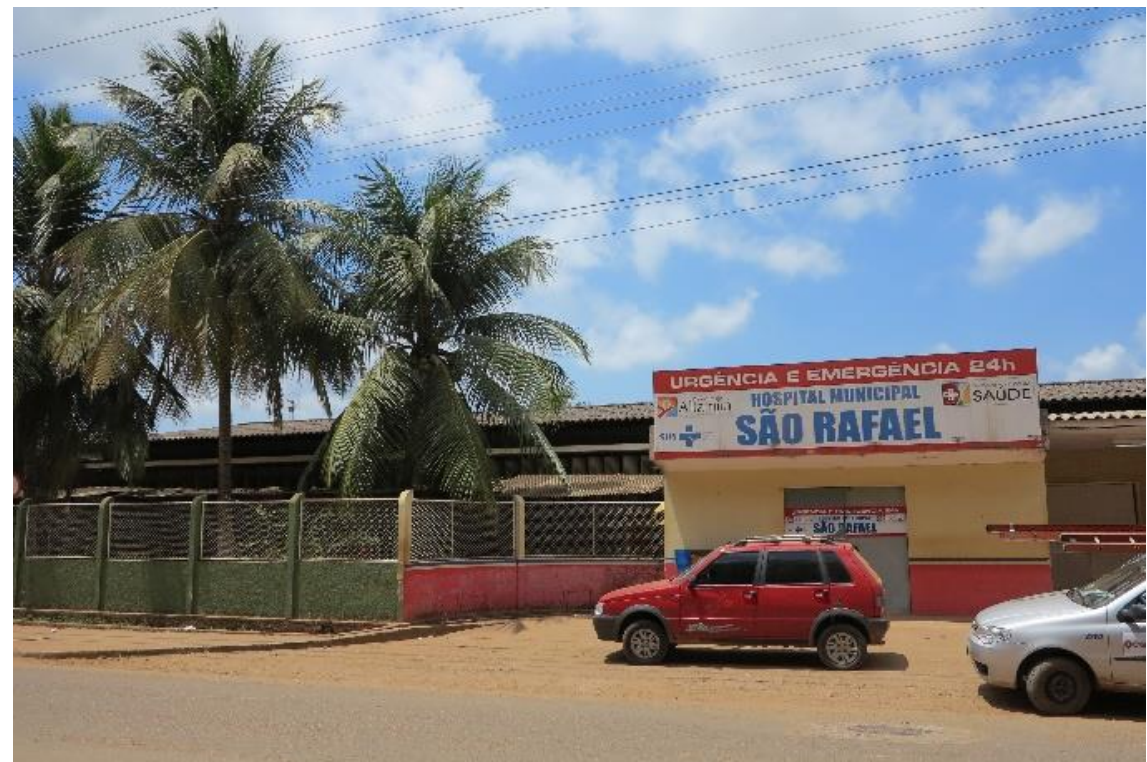

Figura 53 - Hospital Municipal São Rafael (Altamira, PA)

Fonte: por Missifany Silveira, 2015.

${ }^{28}$ Considera-se como "equipamentos de saúde": Unidade Básica de Saúde (UBS); Núcleo de Vigilância em Saúde (NUVS); Centro de Diagnóstico; Centro de Assistência Psicossocial (CAPS); Centro de Especialidade Odontológica (CEO); Centro de Testagem e Aconselhamento em DST/AIDS; Centro de Assistência Psicossocial, e Unidade de Saúde Móvel Ribeirinha. 


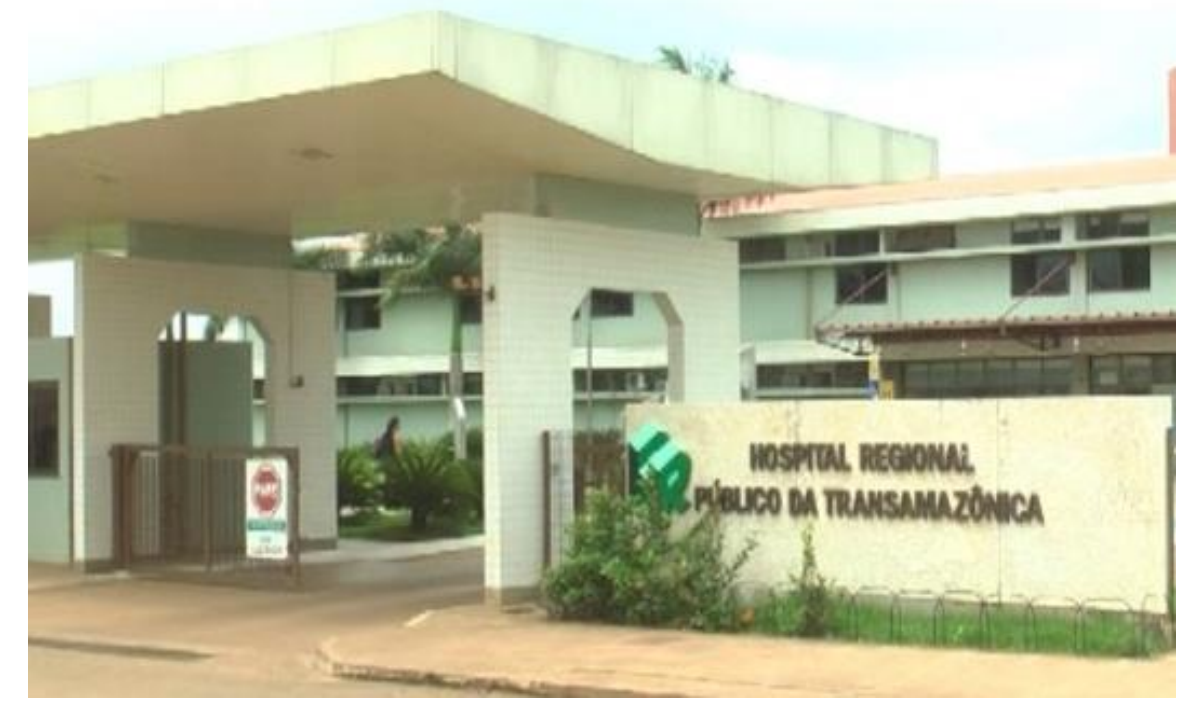

Figura 54 - Hospital Regional Público da Transamazônica de Altamira Fonte: por Missifany Silveira, 2015.

O Hospital Regional de Altamira foi construído em 2007 para atendimentos de média e alta complexidade. Porém, com a alta demanda de urgências e emergências no município e seu entorno, mediante o crescente número de traumas por acidentes automotivos, principalmente na faixa etária de adultos jovens, a Secretaria Estadual de Saúde do Pará (SESPA) criou a chamada "vaga zero" para esses casos específicos. Segundo o diretor técnico dessa casa de saúde, antes da construção da barragem, em 2011, o "acesso da população ao hospital era facilitado" (Informação verbal). No entanto, com a chegada do contingente populacional no município, a partir de 2011, e com o pico da obra em 2013, o acesso às vagas se apresenta cada vez mais difícil devido ao intenso fluxo de pacientes.

Há relatos de que o Consórcio Construtor Belo Monte (CCBM) recorre aos hospitais públicos para a internação de seus trabalhadores por falta de estrutura, na empresa, para tratamento dos casos mais graves, ou seja, aqueles caracterizados como de média e alta complexidade. Segundo a FGV, O hospital privado Santo Agostinho, que integrava a rede SUS, passou a atender exclusivamente os trabalhadores da empresa, por meio de convênio firmado com o CCBM. Esse aspecto demonstra a fragilidade na estrutura de saúde pública, com impacto ainda maior sobre os serviços públicos do município, já bastante comprometidos com a demanda local. 
A Norte Energia construiu um novo hospital no bairro Mutirão, conforme previa o PBA, com a finalidade de suprir a demanda da região. Todavia, apesar de pronto e equipado, ele ainda não se encontra em funcionamento por conta da falta de recursos do município, que é o gestor do estabelecimento (Figuras 55 e 56).

De acordo com a análise do estudo realizado pela FGV, um dos desafios depositados no poder público, na figura dos gestores dos estabelecimentos de saúde, é a indicação dos responsáveis pela operacionalização da infraestrutura construída e, por conseguinte, dos recursos orçamentários para o seu custeio. Esse estudo revela também que os municípios de Brasil Novo, Vitória do Xingu e Senador José Porfírio estão com sobrecarga no atendimento hospitalar. Os hospitais construídos pela Norte Energia em Brasil Novo e Altamira ainda não disponibilizam seus leitos para atendimento pelo SUS, e o hospital de Anapu, que passou por reformas, não dispõe de leitos suficientes, de acordo com a avaliação da Prefeitura.
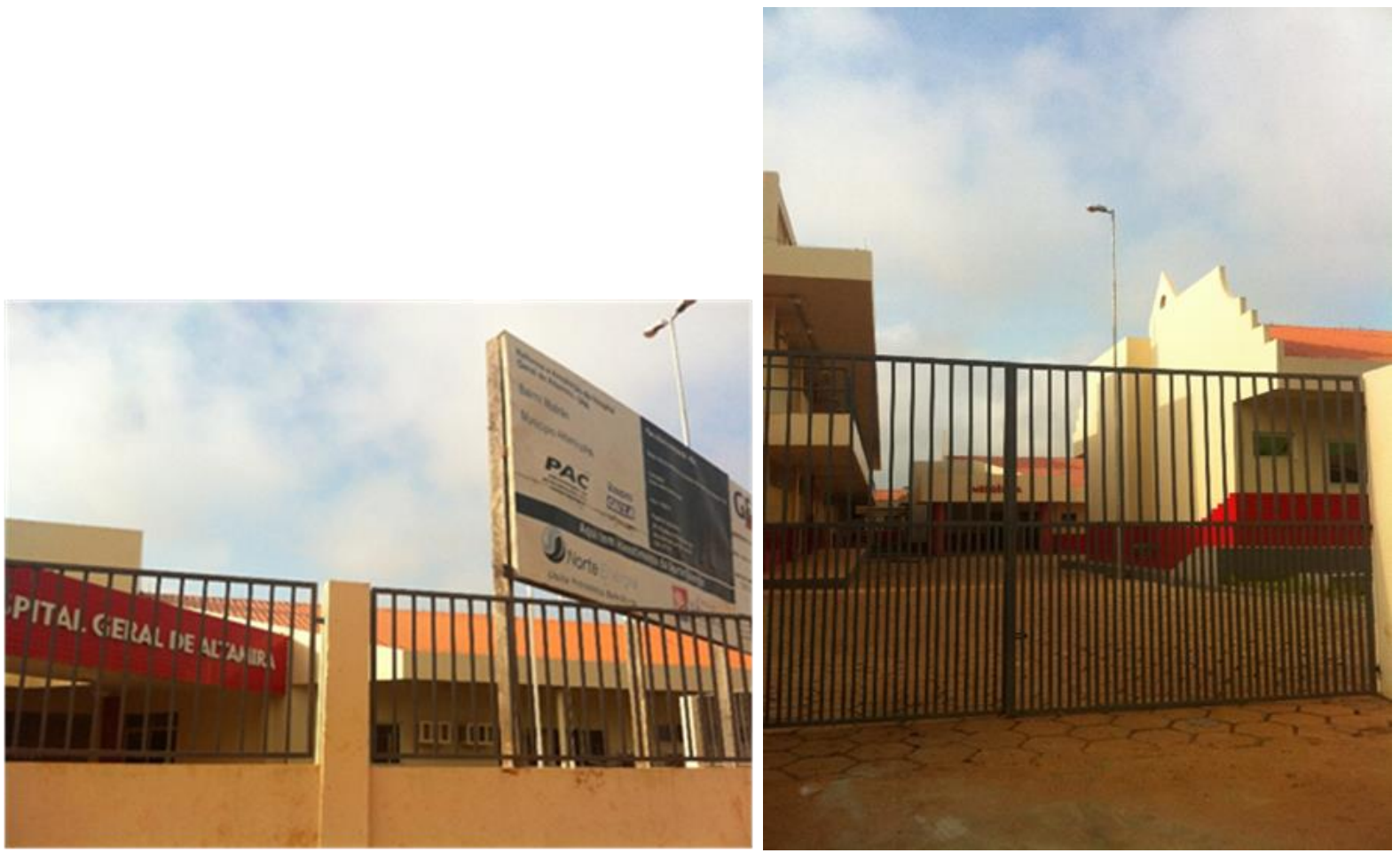

Figuras 55 e 56 - Novo Hospital Geral de Altamira, no Bairro Mutirão

Fonte: Por Missifany Silveira, 2015

Nesse sentido, o custeio desses hospitais é uma preocupação recorrente dos gestores, que estimam gastos muito superiores aos recursos disponíveis para outras despesas na área de 
saúde nos referidos municípios (FGV, 2015). Os repasses financeiros do Ministério da Saúde (MS), por meio de portarias para auxílio extraordinário aos municípios da AID, num reconhecimento a respeito dos fluxos migratórios, não foram suficientes para a gestão do sistema de saúde.

Quanto à reestruturação do setor saúde na região, com a implantação do empreendimento, a ex-Secretária de Saúde de Altamira, hoje representante do Movimento de Mulheres Trabalhadoras de Altamira, Campo e Cidade (MMTAC), Gracinda Magalhães, argumenta que não se consideraram os parâmetros essenciais para a reestruturação e mitigação dos impactos à saúde na região, em atendimento ao PBA.

No tocante à oferta de leitos, Gracinda Magalhães explica que o teto financeiro utilizado pela Programação Pactuada Integrada ${ }^{29}$ se fundamenta nos dados de 2010, enquanto o número de leitos permanece com base na população de 2009. Sendo assim, os leitos construídos nos novos hospitais permanecem fechados por falta de habilitação. "Hoje se tem uma estrutura de saúde dentro dos melhores parâmetros de qualidade do Pará, mas que está subutilizada porque os serviços não são habilitados pelo SUS" (Informação verbal). Ressalta ainda que os recursos provenientes do PDRS-X se mostraram de grande importância para a reestruturação dos Centros de Atendimento Psicossociais (CAPES), do Centro Especialidade em Odontologia (CEO) e das Unidades de Pronto Atendimento (UPAs). No entanto, esse plano "não foi capaz de suprir a falta de financiamento para o custeio dessas estruturas de saúde, que permanecem sem uso adequado" (Informação verbal). Dessa maneira, os recursos de financiamento permaneceram subestimados.

\footnotetext{
${ }^{29}$ Programação Pactuada e Integrada da Assistência em Saúde é um processo instituído no âmbito do Sistema Único de Saúde no qual, em consonância com o processo de planejamento, são definidas e quantificadas as ações de saúde para a população residente em cada território, bem como efetuados os pactos intergestores para a garantia de acesso da população aos serviços de saúde. Tem por objetivo organizar a rede de serviços, conferindo transparência aos fluxos estabelecidos, e definir, a partir de critérios e parâmetros pactuados, os limites financeiros destinados à assistência da população própria e das referências recebidas de outros municípios (BRASIL, 2006c).
} 


\subsection{OS PLANOS E PROGRAMAS NO ÂMBITO DO GOVERNO FEDERAL PARA O CUMPRIMENTO DE CONDICIONANTES E RITOS LEGAIS DO LICENCIAMENTO DA UHE DE BELO MONTE, COM FOCO NOS ASPECTOS DA SAÚDE}

A partir da implantação de grandes projetos de infraestrutura na região Amazônica, tornou-se prioridade do Governo Federal a elaboração de um planejamento para a região, visando a maximização dos benefícios gerados pelos empreendimentos e a mitigação de possíveis impactos negativos, especialmente de natureza social e ambiental nesses territórios. Desse modo, houve o estabelecimento de estratégias para se garantir que as ações entre as instituições federais, estaduais e municipais fossem implementadas no âmbito do projeto da usina de Belo Monte, com vistas à redução das desigualdades e promoção dos potenciais econômicos do território (BRASIL, 2010b).

O Plano de Desenvolvimento Regional Sustentável (PDRS-X), instituído pelo Decreto $\mathrm{n}^{\mathrm{o}}$. 7.340, de 21 de outubro de 2010, somou-se a outros planos de desenvolvimento regionais sustentáveis elaborados no país, em particular na Amazônia, como o Plano Amazônia Sustentável (PAS), que formulou um novo modelo de desenvolvimento para a Amazônia Legal (BRASIL, 2010b). No âmbito da saúde, além do PDRS-X, recebeu destaque, em esfera nacional, na área de influência da UHE de Belo Monte, o Programa Nacional para o Controle da Malária (PNCM), coordenado pelo Ministério da Saúde.

\subsubsection{Plano de Desenvolvimento Regional Sustentável do Xingu (PDRS-X): perspectivas para as ações socioambientais e de saúde na região da UHE de Belo Monte}

O Plano de Desenvolvimento Regional Sustentável do Xingu (PDRS-X), coordenado pela Casa Civil da Presidência da República, visou promover políticas públicas que resultassem na melhoria da qualidade de vida da população que habita a área de abrangência da usina de Belo Monte. Além dos nove municípios da Área de Influência Direta e Indireta (AID e AII) da UHE de Belo Monte, inclui-se o município de Gurupá, que, segundo censo do IBGE de 2010, possui 336.222 habitantes (Figura 57). Esse projeto compreende também as unidades de conservação e quinze Terras Indígenas, das quais dez já se encontram regularizadas, três declaradas e duas em estudo, as quais contribuem com a conservação dos recursos naturais e das áreas prioritárias. 


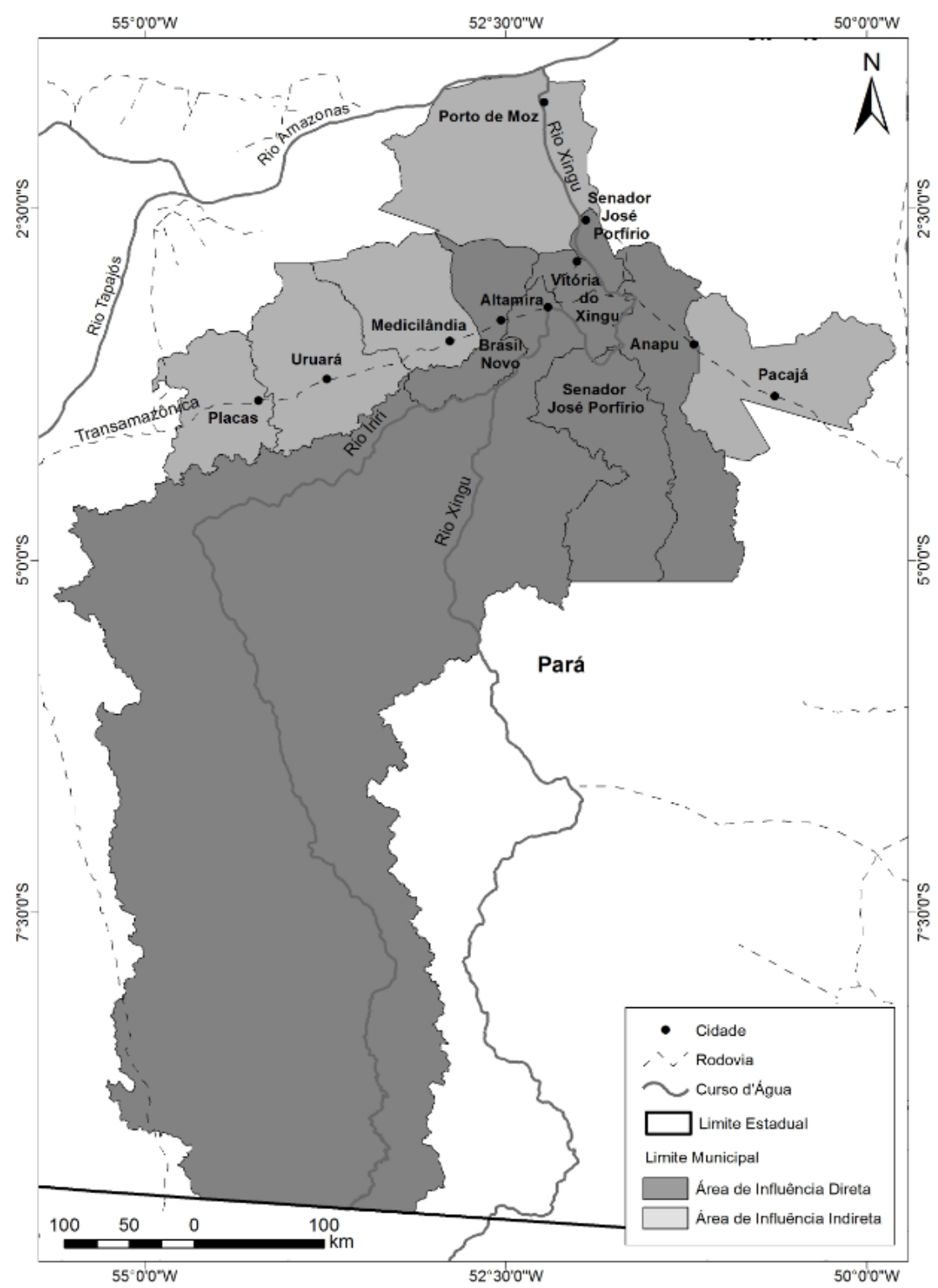

Figura 57 - Área de Influência Direta (AID) e Área de Influência Indireta (AII) da Usina de Belo Monte

Fonte: Elaborado por Missifany Silveira com base em dados do IBGE; ANA; OPEN STREET MAP, 2014.

O PDRS-X orienta programas, projetos e ações do governo federal, nos referidos municípios, por meio de um Comitê Gestor com a atribuição de monitorar sua execução e efetividade. O Comitê Gestor do PDRS-X foi criado para promover a articulação entre os instrumentos de planejamento governamentais e os órgãos públicos e, quando necessário, entre estes e as entidades sociais, conforme o Decreto $n^{\circ}$ 7.340/10 (BRASIL, 2010b). As diretrizes para viabilizar a implementação de políticas sociais públicas, voltadas ao atendimento das demandas da população, na perspectiva do desenvolvimento sustentável, bem como suas ações, foram distribuídas nos cinco eixos temáticos a seguir: 
I. Ordenamento Territorial, Regularização Fundiária e Gestão Ambiental;

II. Infraestrutura para o Desenvolvimento;

III. Fomento às Atividades Produtivas Sustentáveis;

IV. Inclusão Social e Cidadania; e

\section{Modelo de Gestão}

O desenvolvimento de programas e ações para a promoção da saúde e prevenção de doenças, realizados conforme as diretrizes do Sistema Único de Saúde (SUS), está contemplado no eixo IV de Inclusão Social e Cidadania.

As discussões sobre os aspectos relativos à saúde são realizadas no âmbito da Câmara Técnica de Saúde (CT Saúde), criada na esfera do Comitê Gestor para debater a respeito dos projetos de saúde, bem como para o acompanhamento da situação específica desse setor em função da implantação da UHE Belo Monte. A CT Saúde tem participação de entidades governamentais, em âmbito federal, estadual e municipal, e da sociedade civil, com o objetivo de discutir e deliberar sobre as ações de saúde a serem submetidas ao financiamento pelo PDRS$\mathrm{X}$. Dessa maneira, conferiu-se mais legitimidade às ações compensatórias junto ao empreendedor.

As formas de atuação e articulação do Ministério da Saúde (MS) com o Estado do Pará e os municípios da área de abrangência do Plano objetivaram estabelecer um conjunto de ações integradas, principalmente das áreas de Vigilância em Saúde Ambiental e Saúde do Trabalhador com aquelas de Atenção à Saúde, Promoção e demais esferas pertinentes.

Os recursos para a implantação desse plano resultam da contrapartida da empresa vencedora no processo licitatório. O valor estabelecido foi de quinhentos milhões de reais, a serem investidos ao longo de vinte anos na região de Belo Monte (BRASIL, 2010b). Vale ressaltar que o monitoramento da execução e da efetividade do PDRS-X foi instituído pela Portaria $n^{\circ} 1.003$, de 18 de maio de 2011, com a composição de representantes do governo, em suas três esferas de atuação, e a sociedade civil.

Segundo informações do Ministério do Planejamento, responsável por monitorar as obras do PAC, no período de 2011 a dezembro de 2014, já haviam sido liberados recursos para 147 projetos na região - municípios de Altamira, Anapu, Brasil Novo, Gurupá, Medicilândia, Pacajá, Placas, Senador José Porfírio, Uruará e Vitória do Xingu. Desse total, 22\% foram 
concluídas, $60 \%$ se encontravam em execução, e $18 \%$ em fase de contratação (BRASIL, 2014e).

Para os projetos na área da saúde, segundo a Norte Energia, houve o investimento, de 2011 até outubro de 2014, do montante de aproximadamente vinte milhões de reais, como aponta o quadro a seguir (NORTE ENERGIA, 20015) (Quadro 11). Se compararmos com os investimentos totais para a construção da obra, orçada em aproximadamente $\mathrm{R} \$ 33$ bilhões de reais, os gastos com o PDRS-X nesse período de quatro anos correspondem a aproximadamente 0,31\%, e se comparado somente os gastos com saúde no mesmo período corresponde a aproximadamente $0,06 \%$ do valor total gastos com a obra.

Quadro 11 - Recursos da Norte Energia para o PDRS--X, no período de 2011 a 2014 (Fundo Nacional de Saúde - FNS)

\begin{tabular}{|c|c|c|c|c|c|}
\hline \multicolumn{6}{|c|}{ Recursos da Norte Energia para projetos do PDRS-X (em R\$) } \\
\hline Câmaras Técnicas & 2011 & 2012 & 2013 & 2014 & TOTAL \\
\hline Comitê Gestor & & $3.889 .304,64$ & & & $3.889 .304,64$ \\
\hline $\begin{array}{c}\text { Ordenamento } \\
\text { Territorial, } \\
\text { Regularização Fundiária } \\
\text { e Gestão Ambiental }\end{array}$ & $1.985 .400,00$ & $3.352 .395,00$ & 7.191.058,06 & $437.500,00$ & $12.966 .353,06$ \\
\hline $\begin{array}{l}\text { Infraestrutura para o } \\
\text { Desenvolvimento } \\
\text { Sustentável }\end{array}$ & & $1.200 .000,00$ & $6.852 .550,00$ & $437.500,00$ & $8.490 .050,00$ \\
\hline $\begin{array}{l}\text { Fomento às Atividades } \\
\text { Produtivas Sustentáveis }\end{array}$ & $3.510 .625,12$ & $3.473 .560,53$ & $10.955 .139,82$ & $437.500,00$ & $18.376 .825,47$ \\
\hline Inclusão Social & $5.198 .930,00$ & $1.632 .669,76$ & $4.600 .119,28$ & $437.500,00$ & $11.869 .219,04$ \\
\hline Monitoramento & $90.000,00$ & & 4.929.600,00 & $437.500,00$ & $5.457 .100,00$ \\
\hline $\begin{array}{c}\text { Câmara Técnica dos } \\
\text { Povos Indígenas e } \\
\text { Comunidades } \\
\text { Tradicionais }\end{array}$ & $1.570 .000,00$ & 2.499.986,66 & $8.232 .412,53$ & $437.500,00$ & $12.739 .899,19$ \\
\hline Saúde & $1.472 .486,46$ & $12.520 .000,00$ & $5.044 .639,82$ & $437.500,00$ & $19.474 .626,28$ \\
\hline Educação & $3.024 .825,00$ & $1.867 .330,24$ & $3.267 .855,30$ & $437.500,00$ & $8.597 .510,54$ \\
\hline TOTAL & $16.852 .266,58$ & $30.435 .246,83$ & 51.073.374,81 & $3.500 .000,00$ & $101.860 .888,22$ \\
\hline
\end{tabular}

Fonte: SE/PDRS-XINGU, 2015.

Destaca-se que os valores repassados anualmente pelo Fundo Nacional de Saúde (FNS), responsável pelas transferências de recursos aos fundos estaduais e municipais de saúde, são superiores ao montante dispendido pela empresa para todas as ações de saúde, como registra o quadro adiante (Quadro 12). Os recursos do FNS contemplam o pagamento de vários 
programas, divididos em blocos: Assistência Farmacêutica; Atenção Básica; Gestão do SUS; Média e Alta Complexidade Ambulatorial e Hospitalar, e Vigilância em Saúde (FNS, 2015).

Quadro 12 - Repasses do Fundo Nacional de Saúde para os municípios da AID da Usina De Belo Monte

\begin{tabular}{|c|c|c|c|c|c|}
\hline \multicolumn{7}{|c|}{ Repasses do FNS para os municipios da AID de Belo Monte } \\
\hline Município/Ano & 2011 & 2012 & 2013 & 2014 & Total \\
\hline Altamira & $8.661 .113,53$ & $9.782 .551,46$ & $12.977 .364,41$ & $11.195 .671,46$ & $42.616 .700,86$ \\
\hline Anapu & $2.286 .785,28$ & $2.792 .154,78$ & $3.240 .851,43$ & $3.983 .298,67$ & $12.303 .090,16$ \\
\hline Brasil Novo & $2.290 .075,95$ & $3.314 .196,62$ & $3.656 .393,37$ & $4.954 .961,17$ & $14.215 .627,11$ \\
\hline Sen. J. Porfírio & $2.859 .291,15$ & $3.372 .851,78$ & $2.790 .432,63$ & $2.762 .956,38$ & $11.785 .531,94$ \\
\hline Vitóia Xingu & $1.725 .276,57$ & $1.921 .542,59$ & $3.578 .680,71$ & $2.611 .424,67$ & $9.836 .924,54$ \\
\hline Total & $\mathbf{1 7 . 8 2 2 . 5 4 2 , 4 8}$ & $\mathbf{2 1 . 1 8 3 . 2 9 7 , 2 3}$ & $\mathbf{2 6 . 2 4 3 . 7 2 2 , 5 5}$ & $\mathbf{2 5 . 5 0 8 . 3 1 2 , 3 5}$ & $\mathbf{9 0 . 7 5 7 . 8 7 4 , 6 1}$ \\
\hline
\end{tabular}

Fonte: FNS, 2015.

O quadro acima demonstra que os valores assegurados pelo poder público para os cinco municípios da AID são significativos quando comparados aos recursos aplicados pela empresa Norte Energia para compensar o aumento populacional na região e os impactos relacionados à construção da usina.

Vale destacar que, segundo o Ministério da Saúde, na AID da usina de Belo Monte, entre os anos 2011 a 2013, com base no que estimado pelo EIA-RIMA, verificou-se um incremento populacional de aproximadamente 74 mil pessoas, as quais foram atraídas para esses municípios (BRASIL, 2012). Esse crescimento acarretou um aumento no repasse extraordinário para as ações de Vigilância em Saúde para o Fundo Municipal de Saúde, por meio da portaria ministerial ${ }^{30}$ (Quadro 13). Apesar de considerado pequeno pelos gestores, esse incremento demonstra a importância dos mecanismos de participação social nos fóruns de discussão, nos quais se apontam as principais deficiências e necessidades locais.

Enquanto instrumento de descentralização das políticas públicas por meio do Planejamento Territorial Participativo, que viabiliza a relação entre Estado e sociedade civil, mediada pelo poder local, na busca de definição de ações estratégicas voltadas para o

\footnotetext{
${ }^{30}$ Portaria $\mathrm{n}^{\circ} 1.377$, de 3 de julho de 2012 - Define incentivo financeiro para compensação do acréscimo populacional resultante dos fluxos migratórios nos Municípios com impacto direto na implantação da Usina Hidrelétrica de Belo Monte. Disponível em: http://bvsms.saude.gov.br/bvs/ saudelegis/gm/ 2012/prt1377_03_07_2012.html. Acesso em: 15/12/014.
} 
desenvolvimento territorial, esse plano se mostrou importante para a região. Ele permitiu elencar questões importantes referentes aos impactos socioambientais e à saúde das populações na área de influência da UHE de Belo Monte.

Prioridade na elaboração de um planejamento para a região visando à maximização dos benefícios gerados pelos empreendimentos e a mitigação de possíveis impactos negativos, especialmente os de natureza social e ambiental (BRASIL, 2010b).

Quadro 13- Recursos da Vigilância em Saúde decorrentes do aumento populacional na Área de Influência Direta da Usina de Belo Monte

\begin{tabular}{|c|c|c|c|c|c|}
\hline Município & $\begin{array}{c}\text { População } \\
2010\end{array}$ & $\begin{array}{l}\text { População } \\
\text { atraída 2011- } \\
2012\end{array}$ & $\begin{array}{c}\text { Valor do } \\
\text { incentivo em } \\
2012(\mathbf{R} \$)\end{array}$ & $\begin{array}{l}\text { População } \\
\text { atraída } 2013\end{array}$ & $\begin{array}{c}\text { Valor do } \\
\text { incentivo em } \\
2013(\mathbf{R} \$)\end{array}$ \\
\hline Altamira & 99.075 & 15.537 & $148.001,59$ & 26.200 & $249.574,67$ \\
\hline Anapu & 20.543 & 2.627 & $18.793,46$ & 4.430 & $31.692,05$ \\
\hline Brasil Novo & 15.690 & 2.283 & $16.610,00$ & 3.850 & $28.010,73$ \\
\hline $\begin{array}{l}\text { Senador J. } \\
\text { Porfírio }\end{array}$ & 13.045 & 1.791 & $14.628,48$ & 3.020 & $24.666,67$ \\
\hline $\begin{array}{l}\text { Vitória do } \\
\text { Xingu }\end{array}$ & 13.431 & 21.645 & $124.154,34$ & 36.500 & $209.361,67$ \\
\hline TOTAL & 161.784 & 43.883 & $322.187,86$ & 74.000 & $543.305,78$ \\
\hline
\end{tabular}

Fonte: BRASIL, 2012.

Como relatado em reunião do PDRS-X por diversas entidades governamentais e não governamentais, esse plano resultou em impactos positivos para a região, já que estabeleceu condições favoráveis para alavancar os processos produtivos, a ampliação da demanda por bens e serviços e o aperfeiçoamento da infraestrutura. No tocante aos aspectos relativos à saúde, em que pesem as dificuldades já pontadas na região, a articulação entre o poder público e privado, juntamente com a participação dos movimentos sociais, mostrou-se estratégia de potencial eficiência, merecedora de um esforço continuo e sistemático.

No entanto, levando-se em consideração que, na AII da hidrelétrica de Belo Monte, foram previstas ações direcionadas à saúde em duas diferentes fontes de financiamento, ou seja, no PDRS-X e no PBA, as propostas sugeridas simultaneamente nos dois projetos causaram a sobreposição de ações nesse setor. Dificultou-se, assim, a otimização dos investimentos, causando atrasos nas análises para identificar os projetos que contemplavam os pontos comuns 
e para remanejar os recursos para medidas mais urgentes ou que não eram contempladas de forma equânime.

Os aspectos relacionados aos investimentos na região sempre estiveram presentes de forma marcante nas discussões da Câmara Técnica de Saúde como um ponto fora da curva. Uma das principais queixas dos gestores municipais dizia respeito à divisão de recursos entre os municípios, de acordo com a intensidade dos impactos, e sobre a responsabilidade desses gestores pelo gerenciamento e custeio do "legado" transmitido pelo empreendedor, como a construção de infraestrutura de saúde, de hospitais, postos de saúde, entre outros. Tendo em vista o montante repassado pelo FNS para a região da AID, como registrado anteriormente, torna-se evidente que os gastos com esses custos ultrapassam a capacidade de gestão dos municípios.

Outro ponto debatido pela CT Saúde aludiu à construção das redes de atenção à saúde, que não levou em consideração o princípio da equidade durante o planejamento. Assim, municípios que acusaram um menor contingente populacional receberam maior percentual de "royalties" com a obra, como foi o caso de Vitória do Xingu. Os participantes da CT reivindicaram, em reunião realizada em agosto de 2015, durante o balanço das ações de saúde, um empenho mais efetivo para o fortalecimento das redes de atenção, com ênfase na equidade e na regionalização, à luz do Decreto $n^{\circ} 7.508$, de 28 de junho de $2011^{31}$, segundo o qual Região de Saúde se configura como:

Espaço geográfico contínuo constituído por agrupamentos de Municípios limítrofes, delimitado a partir de identidades culturais, econômicas e sociais e de redes de comunicação e infraestrutura de transportes compartilhados, com a finalidade de integrar a organização, o planejamento e a execução de ações e serviços de saúde (BRASIL, 2011d).

\subsubsection{Programa Nacional de Controle da Malária (PNCM): impacto positivo para a saúde no contexto de uma política, programa e projeto}

A implementação do PNCM se iniciou em fevereiro de 2011, após a emissão da Licença de Instalação (LI) pelo Ibama. Contou com investimentos bastante significativos por parte do

\footnotetext{
${ }^{31}$ O Decreto $^{\circ}$ 7.508/2011 regulamenta a Lei no 8.080, de 19 de setembro de 1990, que dispõe sobre a organização do Sistema Único de Saúde (SUS), o planejamento da saúde, a assistência à saúde e a articulação interfederativa.
} 
empreendedor comparativamente com outras ações, sendo superiores aos que normalmente são aplicados em recursos públicos federais para a vigilância epidemiológica.

De acordo com a NESA, o aporte financeiro disponibilizado pela empresa para a elaboração do Plano de Ação para Controle da Malária (PACM) foi de trinta e seis milhões de reais a serem aplicados no período de seis anos. Utilizou-se esse montante principalmente para a contratação e capacitação de agentes de endemias; a instalação de estabelecimentos para diagnóstico e tratamento; a aquisição de veículos de apoio como lanchas e mosquiteiros; a realização de cursos, seminários, como também para a contratação de mão de obra nos seis municípios que integram o plano - os cinco municípios da AID e o município de Pacajá -, os quais registraram as maiores taxas de incidência da doença (NORTE ENERGIA, 2015).

Segundo o $10^{\circ}$ Centro Regional de Saúde, identificou-se o empenho no sentido do "fortalecimento da Atenção Primária com foco em outras doenças transmissíveis e, principalmente, em programas para a diminuição da carga de doenças não transmissíveis" (PARÁ/SES, 2015. Todavia, dentre os projetos instituídos, o que mais se destacou, com a apresentação de resultados satisfatórios, foi o Programa Nacional de Controle da Malária (PNCM).

Com o objetivo de verificar se as ações para o controle da malária se mostraram de fato eficientes, foram utilizados os dados do Sivep-Malária para a observação do comportamento da malária como indicador de impacto na saúde na região da UHE de Belo Monte, entre os anos de 2003 e 2014. Para tal, houve a seleção de três municípios da AID - Altamira, Anapu e Vitória do Xingu. O critério de escolha considerou o fato de Altamira ser o município mais impactado com o afluxo populacional e a proximidade de Anapu e Vitória do Xingu da usina, com a consequente concentração, nesses locais, dos canteiros de obras e alojamentos com o maior número de trabalhadores.

A seleção dos dados partiu das informações das unidades de saúde notificadoras, georreferenciadas pelo Sivep-Malária, separadas aqui em área urbana da rural (Figura 58). Com base nessas informações, elegeu-se o número de notificações totais e o montante de casos positivos confirmados no período para a área urbana dos três municípios. 


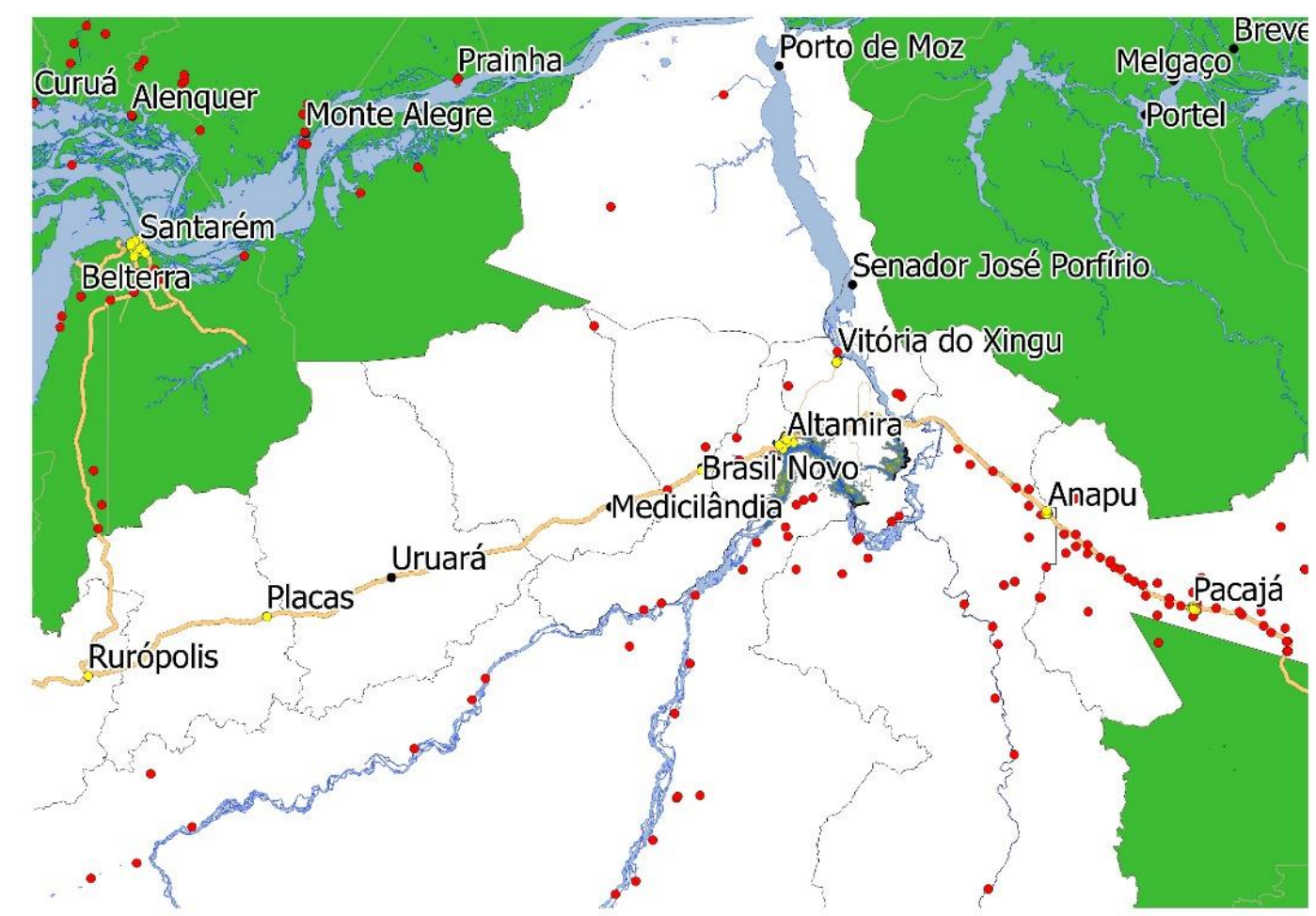

Figura 58 - Localização das unidades de saúde notificadoras da malária na região da área de influência de Belo Monte

Fonte: Elaborada por Missifany Silveira com base nos dados do Sivep-Malária, 2015.

Para a área urbana de Altamira, os períodos com mais ocorrências de notificações se concentraram entre os anos 2012 e 2014, destacadamente este último, a partir de quando se verificou, então, uma significativa queda nos dois últimos meses desse ano. Essa variação demonstrou que a vigilância para o agravo foi bastante ativa. Ressalta-se que se chegou a notificar cinco mil casos em abril de 2014, provavelmente tendo em vista o afluxo populacional intenso na região (Figura 59).

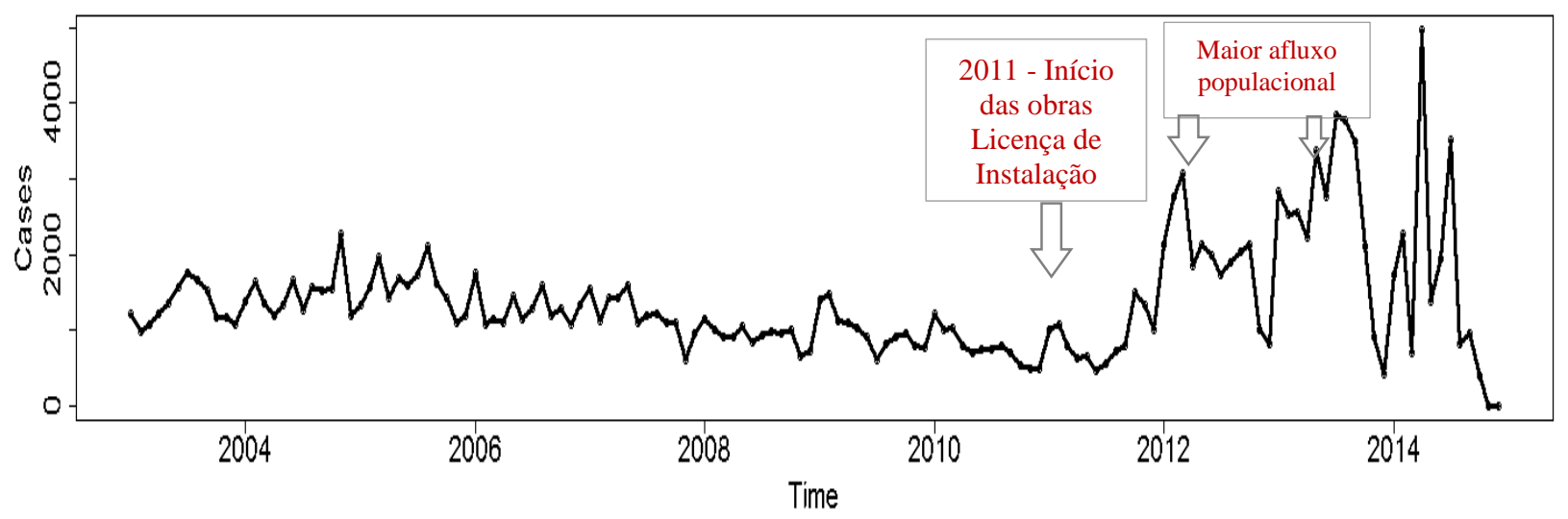

Figura 59 - Total de notificações na área urbana de Altamira no período de 2003 a 2014

Fonte: Elaborada por Missifany Silveira com base nos dados do Sivep-Malária, 2015. 
No que diz respeito ao total de casos positivos, constata-se uma tendência decrescente a partir de 2007, mantendo-se uma média constante até 2013. Neste ano em diante, verificouse forte queda desses índices, com menos de cem casos positivos, chegando-se, em dezembro de 2014, a nenhum caso confirmado (Figura 60).

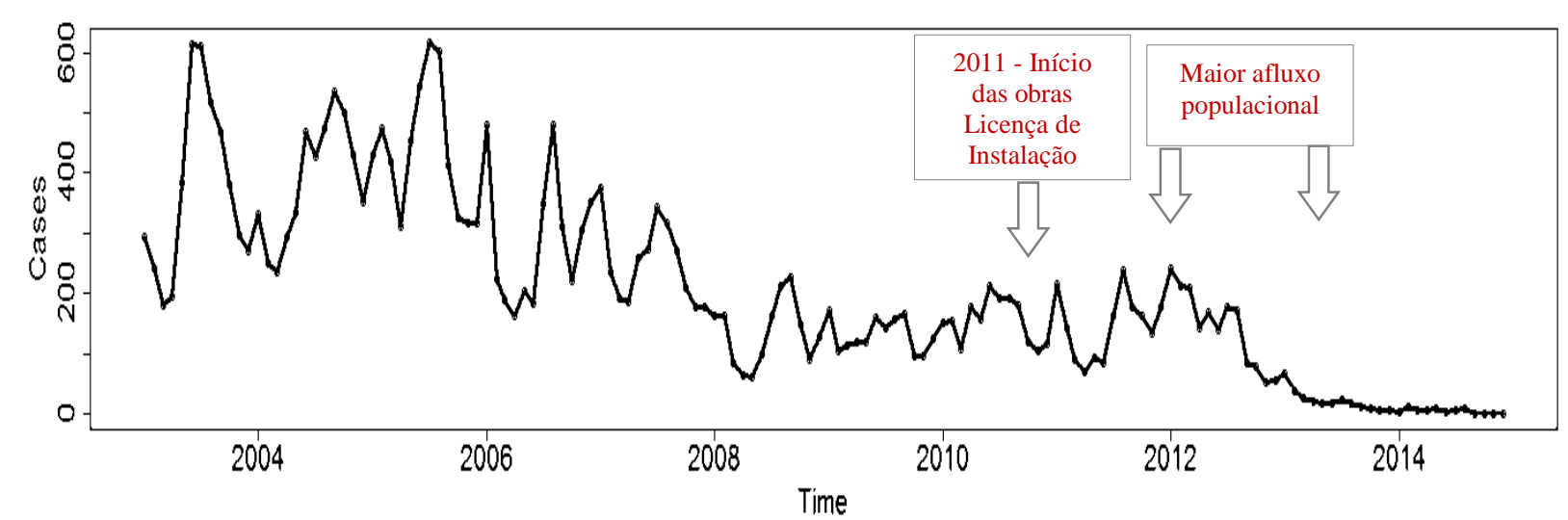

Figura 60 - Total de casos positivos na área urbana de Altamira no período de 2003 a 2014

Fonte: Elaborada por Missifany Silveira com base nos dados Sivep-Malária, 2015.

Os dados expostos acima expressam a queda no número de casos positivos de forma expressiva como um provável resultado da intensa campanha realizada pelo empreendedor em parceria com o Ministério da Saúde, mediante ações preventivas que contaram com investimentos financeiros para o incremento da estrutura de saúde e o aumento do número de agentes de saúde capacitados.

As próximas figuras (Figuras 61, 62 e 63) apresentam a serie temporal com os dados do Sivep-Malária, pelos quais se compara o total de casos positivos com o número de notificações em Altamira, Anapu e Vitória do Xingu. Deduz-se que o aumento das notificações coincide com o crescimento populacional. Infere-se também que houve uma detecção passiva dos pacientes pelos exames disponibilizados nas unidades de saúde. Além do mais, com o aumento no número de trabalhadores, as notificações se intensificaram, o que permitiu a detecção ativa das doenças pelos agentes de saúde da região. 


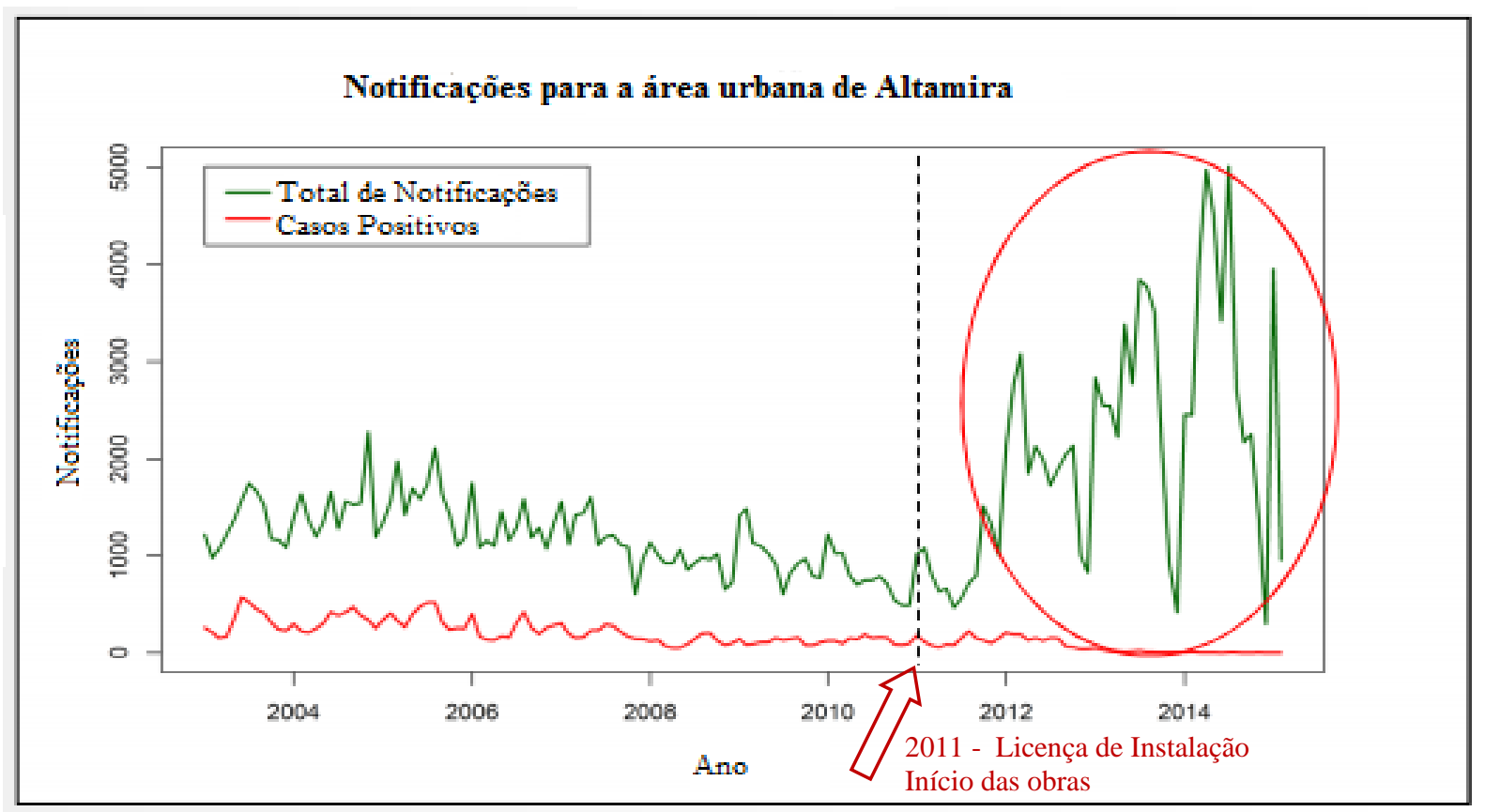

Figura 61 - Total de notificações comparado ao número de casos positivos na área urbana de Altamira, entre 2003 e 2014

Fonte: Elaborado por Missifany Silveira com base nos dados do Sivep-Malária, 2015.

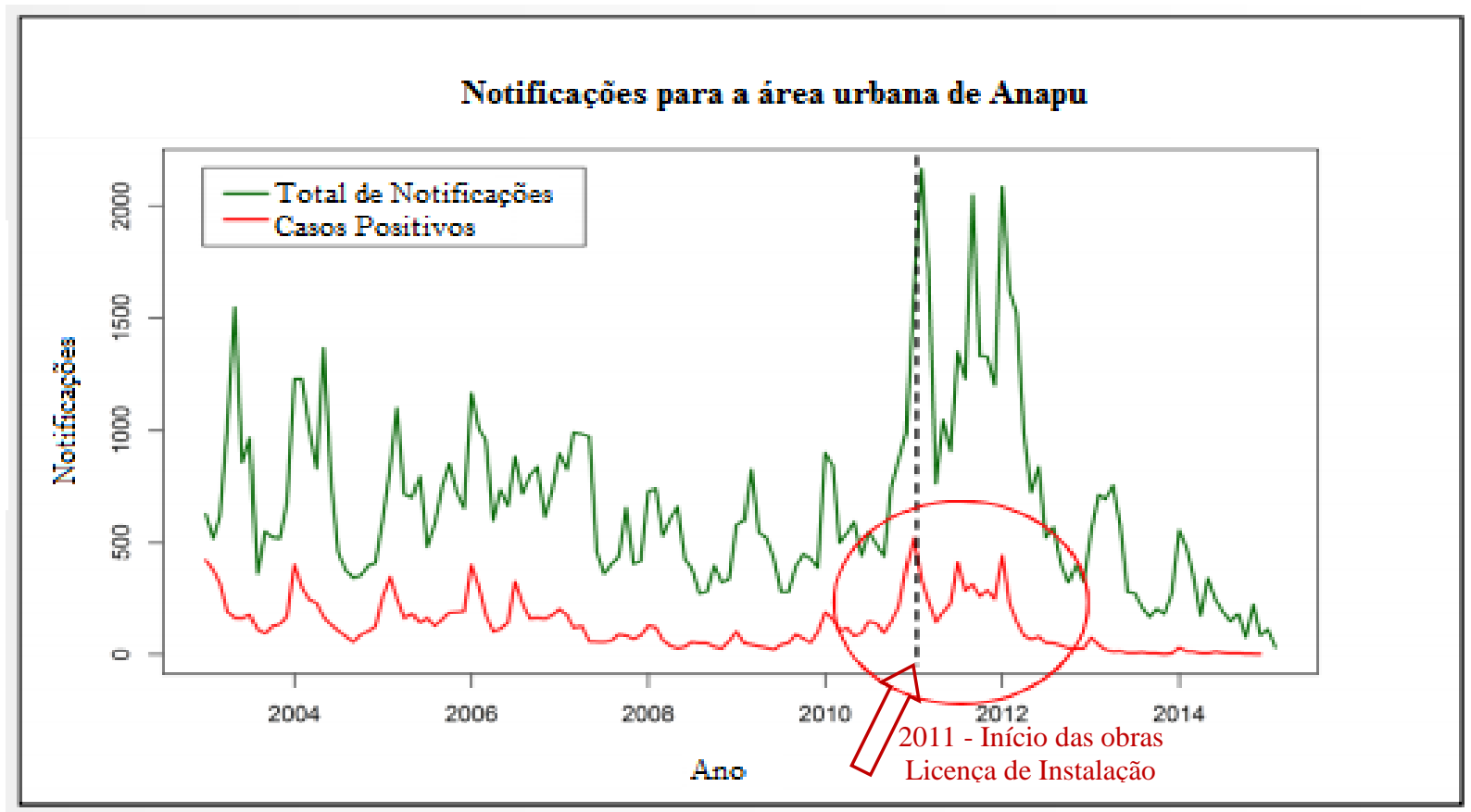

Figura 62 - Total de notificações comparado aos casos positivos na área urbana de Anapu, entre 2003 e 2014

Fonte: Elaborado por Missifany Silveira com base nos dados do Sivep-Malária, 2015. 


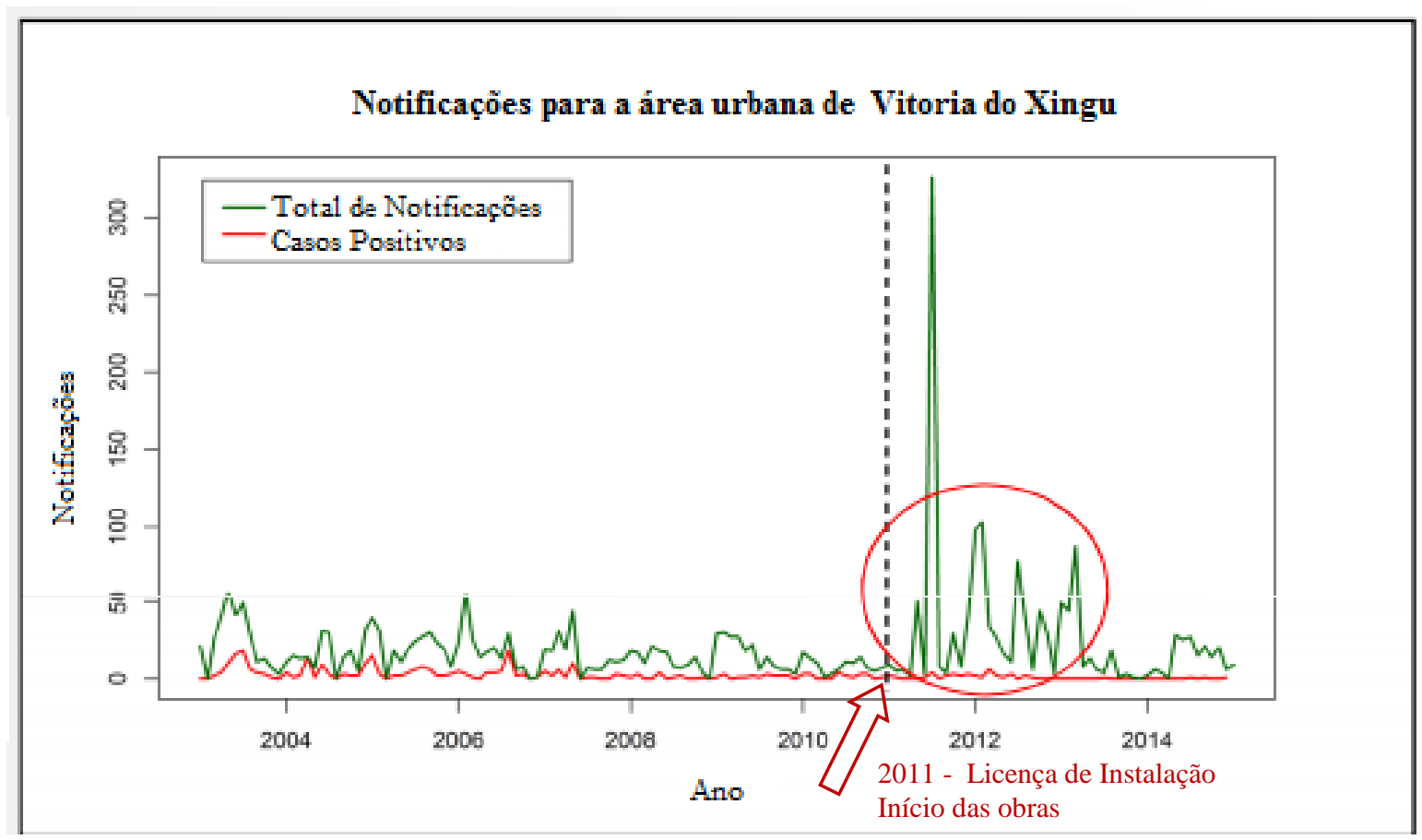

Figura 63 - Total de notificações comparado aos casos positivos de malária na área urbana de

Vitória do Xingu, entre 2003 e 2014

Fonte: Elaborado por Missifany Silveira com base nos dados do Sivep-Malária, 2015.

Os referidos dados corroboram as evidências encontradas na pesquisa de campo, segundo a qual a malária está sendo erradicada da região. De acordo com o $10^{\circ}$ Centro Regional de Saúde, os resultados alcançados com o Programa de Ações de Controle da Malária (PACM) demonstram a forte queda no registro de casos da doença nos municípios da região de Belo Monte. De acordo com o $10^{\circ} \mathrm{CRS}$, observou-se um aumento na detecção ativa mediante o contingente de trabalhadores que, no início das obras, em 2011, tiveram que se submeter a exames periódicos e admissionais do Consórcio Construtor Belo Monte (CCBM).

Em 2011, quando da implantação do PACM, foram registrados 10.838 casos da doença, número que, em 2014, caiu para 906, correspondendo a uma redução de 92\%. Se compararmos os primeiros semestres de 2011 e de 2015, a diminuição chega a 98\%. Para a Secretaria de Saúde Estadual (SES) do Pará, a região da área de influência de Belo Monte está em fase de eliminação da transmissão da malária.

O estudo de caso comprova que a malária tende a diminuir diante do fornecimento de condições suficientes para se manter uma vigilância permanente, com captação de recursos financeiros e humanos. Portanto, medidas integradas de controle do vetor em áreas endêmicas, 
associadas a uma gestão eficiente, são fundamentais para minimizar a sobrecarga da malária nessas regiões de construção dos grandes reservatórios.

O PNCM nas áreas de risco e endêmicas de malária é considerado por todos os segmentos da sociedade civil e pelos gestores locais como um bom exemplo de articulação institucional. Para eles, esse modelo poderia ser adaptado para reduzir outros agravos, visando a diminuição da carga de doenças na região e, consequentemente, da sobrecarga dos serviços de saúde, a exemplo do que ocorre relativamente às causas externas, que impactam fortemente o sistema de saúde e representam um prejuízo para a qualidade de vida das populações locais.

\subsection{CONSIDERAÇÕES: ASSIMETRIAS E AVANÇOS NA EFETIVIDADE DAS AÇÕES COMPENSATÓRIAS NO CONTEXTO DOS PLANOS E PROGRAMAS NA REGIÃO DA UHE DE BELO MONTE}

As ações compensatórias propostas no Plano Básico Ambiental (PBA) e no Plano de Desenvolvimento Regional Sustentável do Xingu (PDRS-X), observadas durante a pesquisa de campo e apoiadas por dados provenientes de diferentes fontes, demonstraram que muitos dos impactos previstos anteriormente ainda não foram mitigados. É o caso do saneamento, dos deslocamentos compulsórios no meio rural, do custeio e gestão da infraestrutura de saúde, além de novos problemas que surgiram no decorrer da obra da usina e que ainda persistem na região.

Considerado pela empresa Norte Energia um impacto positivo para a área, o saneamento básico construído para atender uma das condicionantes da usina depende de uma definição de gestão municipal ou compartilhada com o empreendedor, imprescindível para a operação dos sistemas implantados. No entanto, a falta de ligações domiciliares passou a ser um problema a ser gerenciado junto à população, numa ação conjunta do poder público e da empresa no sentido de convencer o usuário dos benefícios a assumirem parte do custo.

A forma como ocorrem os deslocamentos compulsórios no meio rural representa um risco à manutenção das atividades de subsistência e dos modos de vida, principalmente no tocante às populações tradicionais, como os ribeirinhos. A desestruturação social se tornou fator preponderante para a exacerbação de conflitos e a deterioração da sociedade, acarretando problemas psicossociais, com o aumento do uso de álcool e drogas e, por conseguinte, da violência. 
No que se refere à mobilidade urbana, a cidade de Altamira foi o município mais afetado, como demonstrado pelos dados. O crescimento populacional desproporcional nesse município produziu reflexos diretos na morbimortalidade, decorrente sobretudo dos acidentes ocasionados pelo incremento na frota de veículos, que, nos últimos anos, apresentou um exponencial. Trata-se de fenômeno diretamente relacionado à construção da usina; requer políticas intersetoriais mais eficientes para conter o avanço dos óbitos causados por acidentes, os quais implicam consequências onerosas para o serviço público de saúde, que já se encontra defasado.

Na análise da situação de saúde, a pesquisa apontou para o aumento de novos casos, associados às doenças transmissíveis como HIV-Aids, hepatites, sífilis congênita e sífilis em gestante, em comparação aos anos anteriores à construção da usina. Vale destacar que os dados coletados nos estabelecimentos de saúde local apresentaram diferenças significativas relativamente às informações de âmbito nacional. Sobre esse aspecto, é imperativo que os sistemas sejam aperfeiçoados, de forma que os dados passem por validação constante nas localidades, uma vez que as dinâmicas de território impostas por uma obra dessa magnitude conduzem a discrepâncias, num comprometimento dos resultados finais.

No entanto, foram os dados de morbimortalidade para as doenças não transmissíveis, decorrentes de causas externas, que mais chamaram atenção. Agravados pela dificuldade de atendimento médico hospitalar, esse grupo de causas pode ser um dos grandes problemas a ser enfrentado pelo setor público de saúde, visto que a infraestrutura construída para receber o aumento do fluxo esperado na região ainda não funciona adequadamente, por conta da falta de recursos humanos e financeiros, como exposto. O crescimento populacional na região, agravado pela deficiência do acesso à saúde, pode potencializar os processos de transmissão de doenças e aumentar as taxas de morbimortalidade.

Constatou-se, assim, que a saúde é um dos grandes entraves, tendo em vista que a responsabilidade do custeio para a manutenção da infraestrutura construída pela empresa Norte Energia deve ser o principal problema enfrentado pelos gestores da região. Esse fator demonstra que houve um descompasso no planejamento: o apoio oferecido pela empresa não se mostrou adequado à capacidade de gestão local. A infraestrutura de saúde foi de fato construída dentro dos padrões estabelecidos, mas não se sabe como serão alocados recursos necessários para uma gestão eficiente desse "legado". Para que se encontre a devida solução a esse problema, são necessárias articulações institucionais e a participação do controle social. 
Um dos aspectos mais positivos para a região, no âmbito da saúde, foi o Programa Nacional de Controle da Malária (PNCM), como cumprimento de condicionante e rito legal. Esse plano alcançou resultados bastante expressivos, conseguindo reduzir os casos de malária nos municípios da área de influência da usina a praticamente zero no ano de 2014, como já destacado anteriormente. Como principais fatores para sua eficácia identificamos a realização das ações preventivas e a "interface entre o sistema privado e público de saúde" (PARÁ/SES, 2015 pela empresa Norte Energia para a implementação do Plano de Controle da Malária (PACM).

O PACM atuou de forma preponderante para a diminuição do número de casos de malária, na região, diferentemente do que ocorre com os outros agravos, que não se beneficiaram das mesmas estratégias de ação. No entanto, a malária como único indicador para avaliar a situação de saúde da população afetada pelas transformações ocorridas no território parece insuficiente.

A intervenção sobre as demais doenças, como os impactos decorrentes de causas externas - os quais têm crescido na região -, não recebeu a mesma atenção que as medidas preventivas da malária durante o planejamento das ações de saúde. Não se pode esquecer que muitos outros impactos à saúde ocorrem na região, sendo igualmente importantes do ponto de vista da vigilância epidemiológica e ambiental. Nas palavras do enfermeiro Oswaldo Correia,

Para se obter sucesso para que outros agravos, a exemplo das causas externas que vem aumentando, alcancem os mesmos resultados que teve com o plano da Malária, é necessário haver interesse dos gestores municipal e estadual, na busca de investimentos. Deve haver aumento no número de técnicos especializados e a realização de capacitação para estruturação das áreas para sua operacionalização (PARÁ/SES, 2015).

Nesse sentido, os dados apontados neste estudo de caso corroboram a hipótese de que, a partir de investimentos financeiros e ações intersetoriais envolvendo tanto o setor responsável pelo licenciamento como o setor saúde, e em consonância com os atores locais, é possível se alcançarem melhores resultados na saúde, a exemplo do que ocorreu quanto à malária. Nesse sentido, conforme depoimento de Gracinda Melo,

O PACM provou que se houver investimento, comprometimento técnico e formação de profissionais de saúde a gente consegue erradicar a malária na Amazônia. O PACM deu certo porque foi um planejamento com antecedência. O PACM foi uma das coisas positivas! Para os outros agravos deveriam 
também ter tido mais investimentos, comprometimento e parâmetros técnicos, o que não houve! "(GRACINDA MELO ${ }^{32}$ ).

Há de se destacar que, além do PACM, o PDRS-X também instituiu ações concretas para a região do Xingu no âmbito das questões socioambientais e de saúde. No entanto, ele também não se mostrou suficiente para abarcar a magnitude dos problemas numa região carente de recursos estruturantes e com baixos indicadores de saúde.

Este estudo demonstrou ainda que, para se obter a efetividade das ações compensatórias, é necessária a continuidade das propostas elencadas no PBA e no PDRS-X para os próximos anos, visando a realização das ações estruturantes previstas, mas ainda não concretizadas. A participação da sociedade civil se configurou como mecanismo importante no PDRS-X. Prevêse a sua continuidade para o acompanhamento das ações propostas, no sentido de manter um ambiente de participação e governança para o fortalecimento das parcerias entre as diversas esferas institucionais, de modo a se alcançar a redução dos impasses e conflitos na região.

No referente à questão indígena, uma das mais emblemáticas e marcantes do ponto de vista socioambiental, responsável por inúmeras paralisações e conflitos durante a construção da usina, a demanda é ainda latente. Para tanto, mostra-se fundamental que se encontrem alternativas, como a implementação de um plano de proteção à saúde, para a reestruturação do atendimento a esses povos, com responsabilidades compartilhadas entre o Estado e o empreendedor, pois as ações compensatórias, planejadas para mitigar os impactos, não obtiveram sucesso.

Quanto a esse aspecto, observam-se muitas críticas por parte da Funai sobre a maneira como os impactos foram mensurados, avaliados e mitigados. Para a instituição, cada matriz de impacto do processo de licenciamento ambiental deveria ser construída com seu público correspondente, com metodologias participativas, levando-se em consideração suas particularidades, sem replicar a mesma matriz de impacto a todos os povos ou comunidades. Ressalta-se que as populações tradicionais, como os povos indígenas, ribeirinhos, quilombolas, são diferentes de outras comunidades e, portanto, deveriam ser tratados de maneira diferenciada (BRASIL, 2015).

\footnotetext{
${ }^{32}$ Entrevista concedida em 28/09/2015, na cidade de Altamira/PA.
} 
Diante da análise realizada neste estudo, a fim de que não se repitam os mesmos problemas identificados em Belo Monte nas obras das próximas usinas planejadas para a região amazônica, a exemplo do Complexo do Rio Tapajós, o planejamento de ações antecipatórias deve estar em consonância com os diferentes setores e com as comunidades locais envolvidas no processo. Dessa forma, acredita-se ser possível evitar os conflitos e paralisações observados em Belo Monte, cessando-se também as perdas econômicas no setor público e privado.

A UHE de Belo Monte passou por inúmeros entraves, conflitos e debates, com o envolvimento de diversos setores, organizações da sociedade civil, populações tradicionais, pesquisadores, órgãos de controle, dentre outros. Diante desse cenário controverso e marcado por turbulências, as condicionantes exigidas - primeiramente pelo órgão ambiental, e posteriormente pelas pressões dos diversos atores envolvidos no território - foram se concretizando de forma a se erguer a terceira maior usina hidrelétrica do mundo. O volume de recursos dispensados pelo empreendedor para mitigar os impactos socioambientais ocasionados pela sua construção e futura operação se mostrou bastante expressivo.

No entanto, apesar das obras de infraestrutura de saúde, dos inúmeros acordos, dos planos emergenciais para os povos indígenas, da realocação das populações urbanas e rurais tradicionais para os Reassentamentos Urbanos Coletivos (RUCs), entre outras "benesses" oferecidas pela empresa, essas condicionantes ainda geram controvérsias, apontando para a premência de se buscarem as devidas soluções. Para tanto, um aspecto desafiador para romper com os entraves que o empreendimento impõe no território diz respeito aos arranjos institucionais. Nesse sentido, é fundamental que haja uma articulação entre as ações governamentais e as políticas públicas, não se subestimando a presença de estruturas de participação e controle social. 


\section{CAPÍTULO 5 - ASPECTOS RELEVANTES NO CONTEXTO DA AVALIAÇÃO DE IMPACTOS DE PROJETOS HIDRELÉTRICOS}

\subsection{DELIMITAÇÃO DOS IMPACTOS NO TERRITÓRIO}

No Brasil, embora a legislação ambiental seja considerada como uma das mais avançadas do mundo, as avaliações de impacto ambiental de grandes empreendimentos, a exemplo das hidrelétricas, ainda são reducionistas, compartimentalizadas e alheias ao âmbito social (MAYNARI, 2007).

As avaliações de impacto ambiental são reducionistas em sua abordagem ao dividir e subdividir os vários componentes biofísicos. Estes componentes são medidos e avaliados independentemente uns dos outros e frequentemente contemplados separadamente do contexto social [...] Esta compartimentação é contrária à visão das comunidades locais indígenas e de ribeirinhos, no caso da Amazônia, em que todas as dimensões, social, cultural, espiritual e econômica do meio ambiente têm igual importância (MANYARI, 2007).

Nessa perspectiva, o território pode ser compreendido como recurso metodológico para a análise dos impactos socioambientais, de forma a se evidenciarem as escalas global/nacional ou local das questões abordadas com a finalidade de se compreenderem as relações de poder e suas formas de organização nessas diferentes escalas de atuação.

O território é uma categoria de análise que permite uma percepção mais clara das muitas dimensões de uma situação ou conflito, facilitando o reconhecimento dos agentes sociais e instituições envolvidas [...] onde os atores sociais delimitam suas esferas de atuação e influência, onde as relações sociais e formas de poder são construídas [...] ressaltadas as desigualdades existentes tanto entre as regiões quanto entre os grupos sociais (PAZ, 2006).

Para os estudos de impacto ambiental (EIAs), não se exige a explicitação de critérios que justifiquem a abrangência espacial. Assim, certos impactos permanecem imprecisos, ocultos. Um exemplo é o que ocorre em áreas que normalmente transcendem às do reservatório, no caso das hidrelétricas: para essas localidades, os impactos só serão perceptíveis décadas depois do barramento, como o que aconteceu no caso de Tucuruí. Nesse sentido, a espacialização dos impactos nos estudos ambientais deveria considerar as questões mais abrangentes do território, segundo as escalas pertinentes e a temporalização das transformações intrínsecas ao projeto, e não apenas enfatizar a caracterização de recursos ambientais em sua situação atual (MANYARI, 2007). 
Manyari (2007) ressalta a negligência quanto à dimensão espacial e temporal no EIA quando se trata das transformações introduzidas nos sistemas ambientais, fator que o caracteriza como um instrumento compartimentalizado. No entanto, é fundamental, para os estudos na área de hidrelétricas, a espacialização dos impactos, pois, por conta de sua implantação, ocorre uma segmentação do sítio hidroenergético, dividido em: (i) o lago artificial do reservatório e a região de entorno e os trechos (ii) a montante e a (iii) jusante. Portanto, no âmbito de uma avaliação dos impactos causados pela construção de hidrelétricas, a análise espaço-temporal é essencial para se compreender o objeto de investigação, delimitando-se os períodos e as escalas geográficas no território.

Todavia, há a necessidade de uma base de referência para a identificação e previsão de impactos quando se realizam os estudos ambientais, situando-se a incidência temporal (curto, médio e longo prazo), com a distinção dos impactos resultantes da construção ou da operação em si, no caso da implantação de uma usina hidrelétrica. Nesse sentido, o território como local onde se aplicam as políticas públicas deve ser reconhecido pelo seu conteúdo ambiental, social e político (PEITER et al, 2006). Assim, a delimitação dos impactos permite que as diferentes populações que habitam os locais próximos ao empreendimento sejam menos afetadas por ele

A UHE de Belo Monte está sendo erguida em território que apresenta contradições diversas que alimentam os inúmeros conflitos na região. Considerado um dos pontos críticos durante seu licenciamento, o trecho do rio à jusante da barragem, na Volta Grande do Xingu, tornou-se alvo de diversas críticas por estudiosos, ambientalistas e lideranças indígenas e ribeirinhos diante da estimativa de vazão reduzida nos períodos de seca pelo enchimento da barragem (Figuras 64 e 65).

Trata-se de tema controverso que requer transparência nos debates a respeito. Mesmo antes da construção da barragem, já se configurava um cenário de divergências, com poucas discussões e avaliações no sentido de encontrar resoluções para os problemas apresentados. Apesar de "tecnicamente viável", as inúmeras críticas apontam que o trecho de vazão reduzida (TVR) pode afetar o modo de vida das populações tradicionais que vivem às margens do Rio Xingu. 

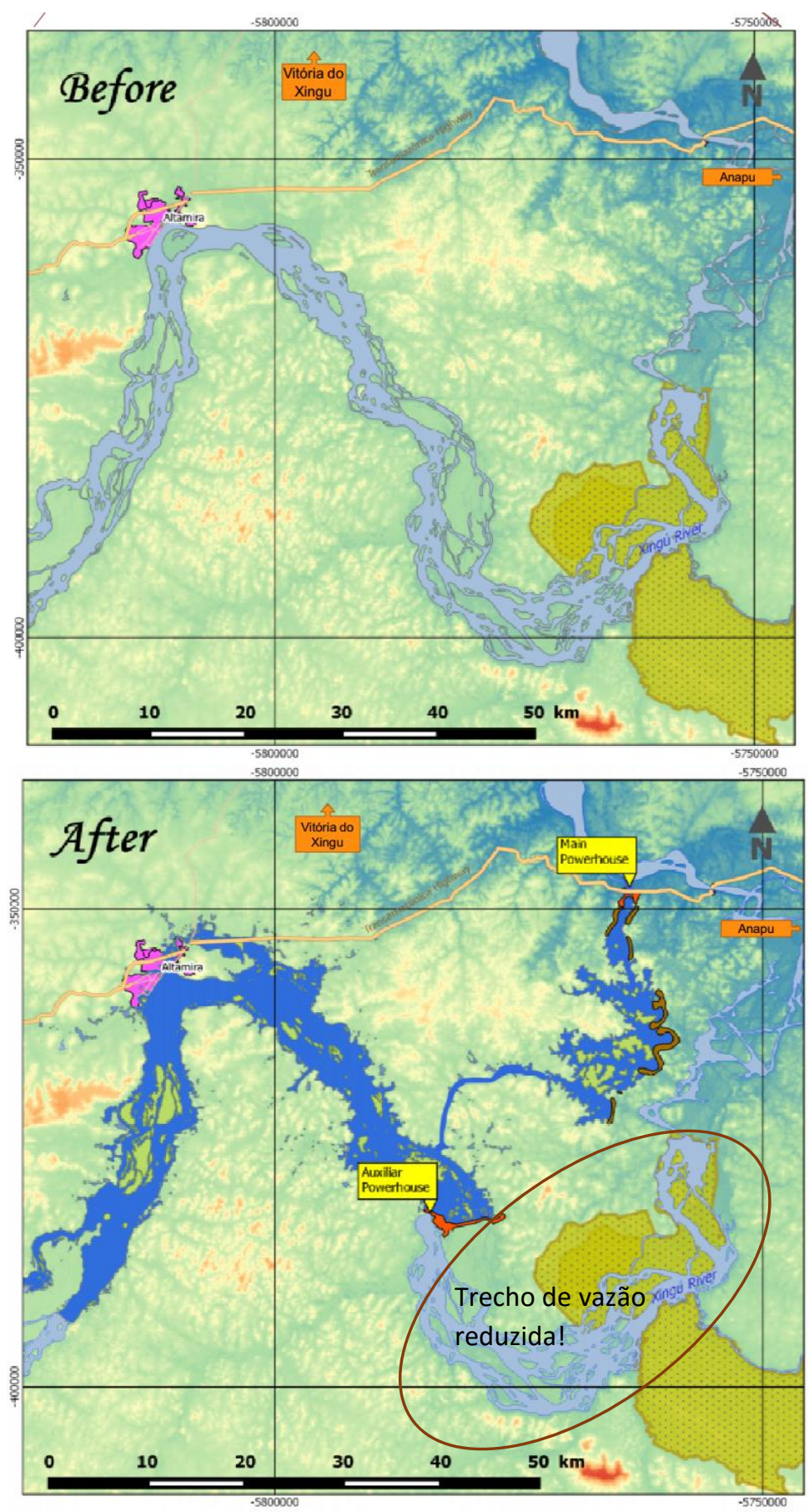

Figuras 64 e 65 - Cenário para o Rio Xingu antes e depois do enchimento do Reservatório Fonte: Elaborado Por Missifany Silveira com base em OPEN STREET MAP, 2014; IBGE, 2010; SRTM, 2000.

A Agência Nacional de Águas (ANA), por meio da Resolução n 48/2011 $1^{33}$, estabeleceu inicialmente que o enchimento do reservatório deveria ocorrer entre os meses de janeiro e

${ }^{33}$ DOU de 2 de março de 2011. Seção 1, fl. 76. Resolução n 48, de 28 de fevereiro de 2011. 
junho, de forma a se respeitarem as vazões mínimas de água do Rio Xingu. Objetivava, assim, manter um volume mínimo para que a população não fosse afetada pela falta de água nesse trecho. Contudo, uma nova norma ${ }^{34}$ foi emitida em 2104, flexibilizando o período anteriormente determinado. A Resolução no 2.046/2014 estabeleceu apenas que a empresa teria de respeitar as vazões mínimas do Rio Xingu. No mais, permitiu que o enchimento do lago ocorresse em qualquer mês do ano, desde que garantisse a "preservação dos usos múltiplos dos recursos hídricos, inclusive a manutenção de condições adequadas ao transporte aquaviário" (ANA, 2014).

Em março de 2014, por meio de uma ação civil pública, requereu-se a anulação da Licença Prévia (LP) para as obras de Belo Monte sob a alegação de que o diagnóstico do EIARIMA não apresentava consenso sobre a viabilidade socioambiental do Trecho de Vazão Reduzida (TVR) e sobre a redução ou mitigação dos danos.

No diagnóstico realizado pelo EIA/RIMA, destacou que quanto à viabilidade socioambiental do Trecho de Vazão Reduzida (TVR), não há consenso entre o órgão licenciador e técnicos que elaboraram o EIA/RIMA acerca da redução ou mitigação dos danos, a exemplo do Parecer Técnico no 114/2009 do lbama, o qual explicita a incerteza acerca da área a ser impactada, demandando a complementação de estudos (BRASIL, 2014f).

Essa é umas das evidências de que a avaliação de impacto ambiental deixa lacunas passíveis de questionamento, demonstrando a ausência de critérios mais específicos de consideração dos impactos cumulativos e dos efeitos sinérgicos na região, que submetem a população local, principalmente as mais vulneráveis, a situações de desequilíbrios ou conflitos que poderiam ser evitados com uma avaliação e planejamento adequados. As circunstâncias adversas também acarretam prejuízos ao poder público - que, no caso da hidrelétrica de Belo Monte, é o proponente do projeto -, considerando-se que houve inúmeras paralizações e gastos pela ausência de planejamento eficiente que contemplasse uma avaliação mais abrangente em torno dos impactos sociais, tendo em vista os altos investimentos nos programas de mitigação.

A concepção dos estudos de impacto ambiental se caracteriza como o momento de discussão a respeito de quais localidades se mostram mais adequadas ao empreendimento e, teoricamente, em quais delas haveria um menor impacto no ambiente e nas comunidades afetadas. No entanto, quando se observam os estudos ambientais realizados por consultorias,

\footnotetext{
34 Agência Nacional de Águas (ANA). Resolução n. 2046, de 19 de dezembro de 2014. Disponível em: http://arquivos.ana.gov.br/resolucoes/2014/2046-2014.pdf. Acesso em: 20/12/2015
} 
via de regra contratadas pelo empreendedor, a seleção dos locais se orienta predominantemente pela viabilidade econômica, de modo que a "área de influência" do empreendimento se configurada por limites de linhas imaginárias, como se dessa maneira fosse possível limitar todos os impactos previstos. Quando da apresentação do diagnóstico da área de impacto e da escolha da localidade que "melhor" corresponde à realidade, sujeito a consultas públicas, é comum que tais parâmetros já se encontrem predefinidos pelos detentores do projeto.

É inquestionável a importância do diagnóstico ambiental da Área de Influência Direta (AID) e Indireta (AII) como elemento fundamental para o processo de licenciamento, com vistas à obtenção das licenças ambientais. Contudo, a questão de fundo são os parâmetros de escolha das áreas para a implantação de determinados empreendimentos que não consideram o território onde as pessoas vivem, trabalham e estabelecem relações, aspecto que se estende para além dos critérios estabelecidos por uma AID ou AII.

Os parâmetros para a definição das áreas de influência não levam em conta os impactos cumulativos da obra, que geralmente abrangem áreas onde se localizam grupos indígenas e populações tradicionais, e que, portanto, permanecem fora do escopo de "influencia" ou de áreas diretamente afetadas. Sendo assim, os processos de licenciamento ignoram as populações que se encontram "fora” desse limite. É justamente nesses locais, porém, que se encontram povos que dependem do ambiente para sua subsistência. O caso de Belo Monte expôs esse problema quando o EIA considerou que das nove terras indígenas afetadas pelo projeto, apenas duas estariam dentro da AID, com as outras sete classificadas como situadas na AII (ACSELRAD; MELLO, 2009). Após quase seis anos da apresentação do EIA/Rima, os conflitos com as populações tradicionais ainda persistem na região.

Para Andrade (2011), durante a avaliação dos impactos ambientais, a escolha das alternativas locacionais para a construção dos aproveitamentos hidrelétricos deveria se embasar em critérios técnicos e indicadores de sustentabilidade, a fim de se avaliarem os aspectos sociais e ambientais na mesma escala de importância dos fatores econômicos.

No caso de Belo Monte, a cidade de Altamira é a que mais tem sofrido com os impactos do empreendimento. As regras atuais que disciplinam a cobrança de royalties criam nichos de riqueza aparente, revelando o quão incoerente são os critérios de distribuição para as áreas de influência do projeto. Como exemplo pode-se citar Vitória do Xingu, que recebe valores de recursos superiores aos demais quando se considera seu número de habitantes, bastante inferior ao estimado para Altamira, que recebeu o maior contingente de trabalhadores da obra e a 
maioria dos migrantes em busca de trabalho e renda. Esse é um dos problemas que têm desestabilizado a infraestrutura local, principalmente nos setores de saúde pública, como exposto no capítulo anterior.

Assim, quando se discute avaliação de impactos, a população não pode ser vista apenas como uma externalidade pelo empreendedor, mas deve ser tratada de forma integrada às dinâmicas locais que sofreram transformações de ordem ambiental, social e econômica por imposição do empreendimento. Essas mesmas populações, com especificidades tão diversas, podem contribuir para o incremento do desenvolvimento da região se forem consideradas na sua condição de atores visíveis do debate.

Para muitos críticos dos empreendimentos dessa natureza, a implantação de grandes projetos de infraestrutura na região da Amazônia brasileira, a exemplo das hidrelétricas, continua a adotar o paradigma de acordo com o qual as populações seriam coadjuvantes no processo de implementação dessas obras, e, portanto, permaneceriam excluídas da tomada de decisão, contrariando a percepção de que esses povos são, na verdade, importantes atores do processo.

Nesse sentido, na avaliação dos impactos dos projetos de desenvolvimentos, a espacialização e a temporalidade são fundamentais para mensurar os impactos cumulativos e sinérgicos que acontecem no território. Dessa maneira, delimitam-se não somente os aspectos biofísicos, mas, principalmente, aqueles que causam impactos sociais. Intenta-se, assim, evitar a repetição de modelos adotados há décadas, que ignoram as mazelas impostas pelo empreendimento, no que costumamos chamar de externalidades.

\subsection{PARTICIPAÇÃO SOCIAL COMO VALOR ESSENCIAL À SUSTENTABILIDADE DOS PROJETOS}

A institucionalização de procedimentos relativos à participação das populações afetadas com a implantação de grandes empreendimentos é marcada por audiências públicas, realizadas pelos órgãos responsáveis no exercício da administração pública. No caso da avaliação de impacto ambiental, esse tipo de audiência se constitui como uma das etapas previstas, caracterizando-se como o principal canal de participação das comunidades nas decisões em esfera local (BRASIL, 2008c). 
A criação de fóruns ou comitês de negociação são instrumentos importantes principalmente porque possibilitam a redução de conflitos e a diminuição das interferências no modo de vida dos diversos grupos sociais locais durante a implantação das hidrelétricas. Todavia, tanto as audiências públicas quanto os fóruns de negociação e comitês de cogestão são instâncias que, apesar de influenciarem o processo, não determinam a tomada de decisão, pois possuem caráter apenas consultivo. De acordo com Bessa et al (2011), para ocorrer de fato o fortalecimento da governança e, com ela, a possibilidade de se estabelecer um processo político mais abrangente, com eficiência e transparência nas decisões públicas, é necessária a inclusão de uma ampla gama de atores sociais no processo.

Segundo Gomide (2015), a origem dos conflitos ocasionados pelos impactos socioambientais se apresenta justamente na ausência de consultas antecipadas aos grupos sociais e à sociedade como um todo, afetada pelas obras. Esse fator acarreta, dentre muitos outros obstáculos, o atraso nas obras pela ocorrência de paralizações e judicializações, que acabam por emperrar o ritmo da execução dos investimentos em infraestrutura (GOMIDE, 2015).

O Movimento dos Atingidos por Barragem (MAB) sustenta que os resultados das audiências públicas não se mostram eficientes para atender os anseios da população. Sem a concessão do devido espaço para expressarem suas opiniões ou contestar os argumentos dos interessados, os habitantes dessas localidades se sentem manipulados pelo empreendedor ou pelos grupos de interesses particulares (MAB, 2011). Para Santos (2015), "as audiências públicas ainda são realizadas de forma verticalizada", as populações atingidas pelas barragens não são prioridades por parte do empreendedor, além da ausência de consultas às populações indígenas e tradicionais (SANTOS, 2015).

Conforme exposto, o modelo de participação adotado na AIA no Brasil não é suficiente para refletir os impactos reais sobre determinada população. Nessa perspectiva, a saúde, como conceito unificador dos principais problemas identificados, deveria ser objeto sistemático de avaliação e participação social. Assim, é importante enfatizar que a AIS, como estratégia pensada no país, conectada aos processos de licenciamento ou a outras formas de avaliação, como a Avaliação Ambiental Estratégica (AAE), poderia ser aplicada com o objetivo de inserir, no escopo das políticas, planos e projetos, o processo participativo das populações envolvidas.

No entanto, apenas a AIA se consolidou como instrumento de avaliação normativo. Desse modo, os interesses, sejam eles governamentais ou empresariais, acabaram por reduzir a 
importância dos instrumentos da política ambiental, materializados nos EIAs/RIMAs, por meio das audiências públicas, transformando-se, por conseguinte, em etapas burocráticas, cujo resultado objetivo único se restringe à aprovação dos respectivos projetos, mediante as licenças ambientais (SABBAG, 2006). Para que os instrumentos de avaliação de impactos considerem no seu escopo os aspectos sociais e de saúde, indica-se a criação de instrumentos jurídicos ou legislação específica para sua aplicação sistemática no interior de uma política, plano ou projeto de desenvolvimento (Figura 66).

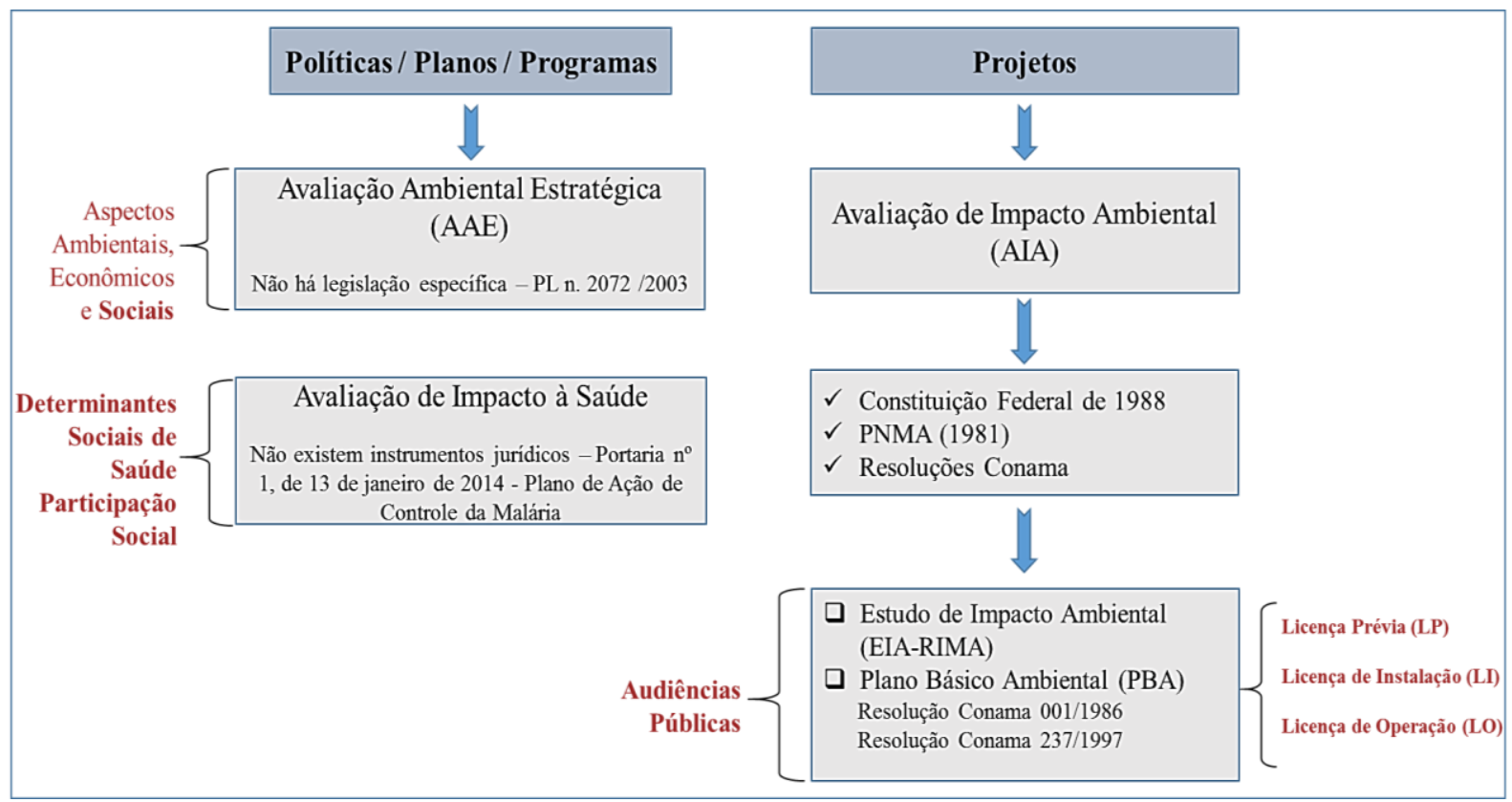

Figura 66 - Instrumentos de avaliação de impacto no contexto das Políticas, Planos e Projetos no Brasil Fonte: Elaborada por Missifany Silveira, 2015.

Desde a década de 1980, reconhecidos estudiosos na área de hidroeletricidade no Brasil têm se mostrado preocupados diante dos prováveis impactos gerados pelos grandes projetos hidrelétricos e sua correlação com os povos atingidos nos seus espaços territoriais. Segundo Rosa et al (1988), a partir das consequências das "intervenções vindas de cima" pelas agências governamentais, configuram-se os impactos. $\mathrm{Na}$ medida em que a população "reage" ao "estímulo" dessas intervenções, surgem os conflitos nessas comunidades. Esses autores recomendavam, há décadas, que as tomadas de decisões em projetos dessa magnitude deveriam ocorrer junto à sociedade, de forma a se avaliarem os impactos e estabelecer o devido gerenciamento dos diferentes conflitos. Sustentam também que a omissão dos problemas ambientais e socioeconômicos exige a elaboração, no futuro, de avaliações para mitigar e 
diminuir a amplitude dos riscos e impactos gerados por essas obras, incluindo os aspectos de saúde. (ROSA et al, 1988).

A partir desse debate, como também diante das críticas ao modelo de desenvolvimento vigente, segundo o qual são instituídos os projetos de desenvolvimento em áreas de grande biodiversidade e com recursos ambientais abundantes, assinala-se a importância da participação dos atores sociais que habitam as áreas afetadas para que possam ter voz ativa diante de qualquer intervenção no seu território.

Nessa perspectiva, o esquema a seguir (Figura 67) ilustra um modelo conceitual que ressalta a importância de se assegurar a participação social durante a tomada de decisão. Nesse momento específico, verifica-se a eminência de impactos gerados por um grande empreendimento hidrelétrico - geralmente originado por uma intervenção política. Infere-se, no esquema adiante, a importância de se considerar as populações atingidas como partícipes do processo de avaliação de impactos, assim como preconiza a Avaliação de Impacto Ambiental e Avaliação de Impacto à Saúde (AIS).

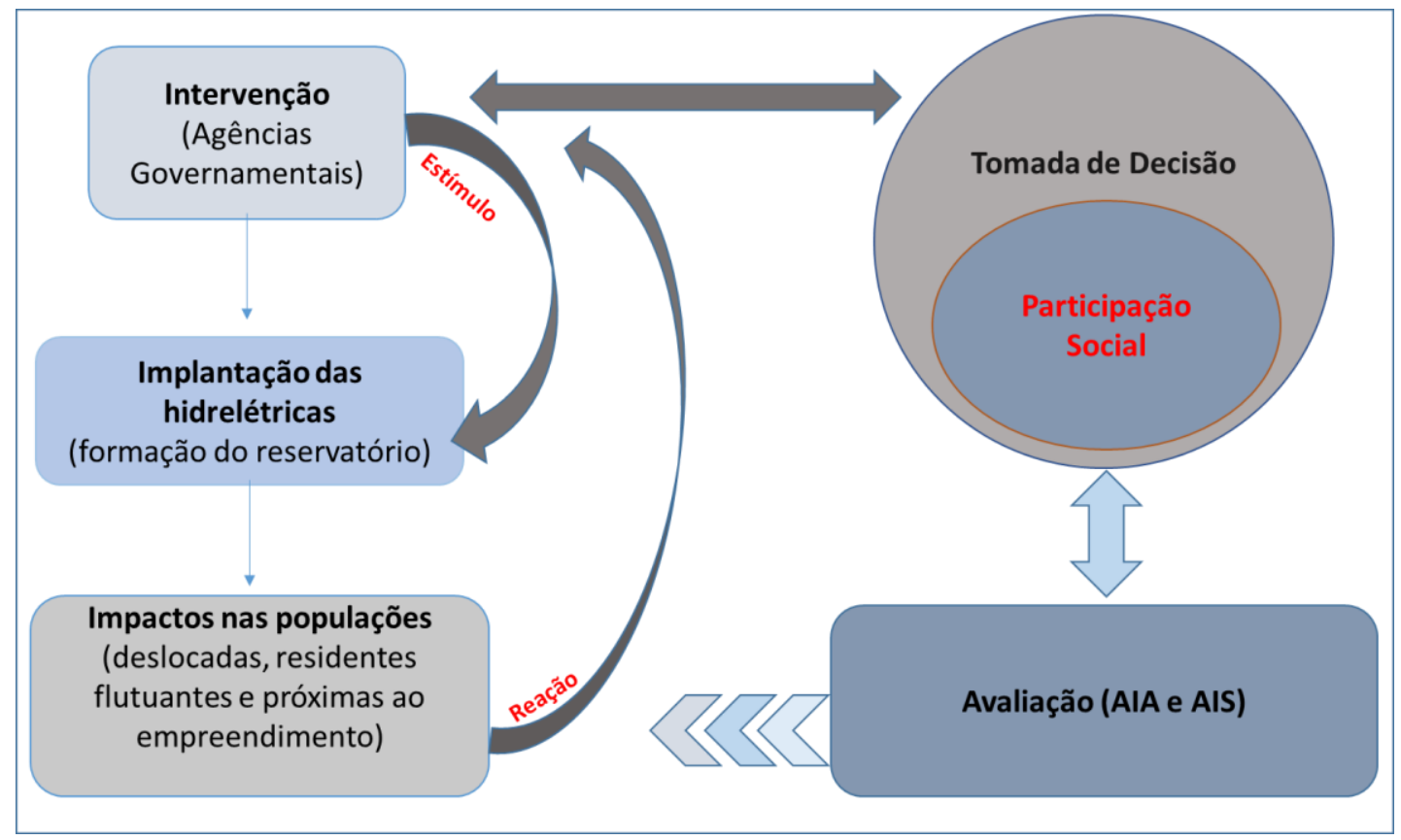

Figura 67 - Modelo de participação social na tomada de decisão e gerenciamento de conflitos em projetos hidrelétricos

Fonte: Elaborada por Missifany Silveira com base em Rosa et al, 1988.

Há de se destacar que houve mudanças significativas no cenário atual do setor elétrico brasileiro em face das questões decorrentes dos impactos sociais causados pela implantação das 
hidrelétricas. Porém se reconhece que tais alterações não foram suficientes, levando-se em conta os desafios enfrentados pelas comunidades afetadas. Vale ressaltar também que os trabalhos de elaboração dos estudos ambientais e seus respectivos relatórios (EIA-RIMAs) são realizados por equipes multidisciplinares. De modo geral, a análise que ocorre após a definição do projeto se mostra pouco satisfatória no sentido da inclusão de determinados aspectos relevantes, como os riscos ou impactos na saúde, contribuindo, assim, para a exclusão dos elementos sociais. Quando ocorre a inclusão destes últimos de maneira subjetiva e pouco relevante, observa-se a valorização sobretudo dos aspectos biofísicos.

Outro ponto de destaque se refere aos fóruns de negociação direta com a população. Segundo Bessa et al (2011), no âmbito dos empreendimentos hidrelétricos no Brasil, esses fóruns comumente atribuem governança aos grupos envolvidos, com reais possibilidades de fortalecimento local e de constituição de processos de descentralização, assim como a valorização dos movimentos sociais, essenciais para o empoderamento dos atores envolvidos (BESSA et al, 2011). No entanto, ainda é uma tarefa complexa e requer o envolvimento de diversos setores, como observado durante a implementação do Plano Básico Ambiental (PBA) da UHE de Belo Monte. Esse processo adquiriu contornos mais significativos diante da posição dos movimentos sociais, que apontaram e enfrentaram os desafios decorrentes dos impactos causados pelo empreendimento, beneficiando-se também da mediação dos conflitos socioambientais. Ao contrário desse fórum, as audiências públicas, coordenadas pelo órgão ambiental, se mostraram mecanismos frágeis de discussão frente a falta de espaço para questionamentos de interesse social pelos principais grupos tradicionais afetados pela usina, como os povos indígenas.

Nesse cenário, o PDRS-X, apresentado pelo poder público em esfera federal e estadual, surgiu como mecanismo de resolução de conflitos, com a finalidade de apontar soluções para a mitigação dos impactos sobre a população na área de influência da usina, por representantes de diferentes segmentos vinculados às Câmaras Técnicas. Mesmo com a plausibilidade de iniciativas dessa natureza, observa-se a persistência de descompassos nas diferentes etapas de tomada de decisão com envolvimento da participação social, como exposto no capítulo anterior.

O Relatório da Comissão Mundial de Barragens (CMB), elaborado na virada do milênio, apresentava novas proposições para que a tomada de decisões relativamente ao planejamento de barragens tivesse como base cinco valores essenciais: equidade, sustentabilidade, eficiência, processo decisório participativo e responsabilidade (WCD, 2000). 
À época, o Relatório já apontava que a construção de barragens é "uma das questões mais controvertidas na área do desenvolvimento sustentável" (WCD, 2000). Decorridos mais de quinze anos do lançamento desse relatório, ainda hoje essa se configura como questão ambígua, na qual persistem os mesmos problemas.

Os partidários das barragens apontam para as necessidades de desenvolvimento social e econômico que as barragens visam satisfazer, como a irrigação, a geração de eletricidade, o controle de inundações e o fornecimento de água potável. Os oponentes ressaltam os impactos adversos das represas, como o aumento do endividamento, o estouro dos orçamentos, o deslocamento e o empobrecimento de populações, a destruição de ecossistemas e recursos pesqueiros importantes e a divisão desigual dos custos e dos benefícios (WCD, 2000).

A Usina Hidrelétrica de Belo Monte foi financiada pelo Banco Nacional de Desenvolvimento Social (BNDES), considerado um dos maiores bancos públicos de desenvolvimento do mundo. No entanto, o BNDES não é signatário dos Princípios do Equador $^{35}$, que asseguram critérios mínimos para a concessão de crédito pelos maiores bancos financiadores para garantir a sustentabilidade de projetos de maneira socialmente responsável.

Apesar de o BNDES contar com uma política social e ambiental, caracteriza-se como incipiente, no âmbito dos projetos por ele financiados, o tratamento das questões alusivas aos impactos negativos na esfera dos direitos humanos, além da ausência de canais de diálogo com as comunidades que sofrem diretamente as consequências prejudiciais desses empreendimentos. Conforme documento publicado pela Conectas Direitos Humanos (2014), os maiores problemas constatados pelos órgãos de controle - Ministério Público e o Tribunal de Contas da União - recai sobre a falta de políticas direcionadas aos direitos humanos no contexto de implantação dos grandes empreendimentos, especialmente sobre os grupos sociais e comunidades vulneráveis (CONECTAS, 2014).

O documento também indica lacunas legais e regulatórias do ordenamento jurídico brasileiro no tocante, por exemplo, ao acesso de informações pela sociedade sobre o uso dos recursos públicos pelo BNDES em projetos dessa monta. Ressalta que, apesar da sua inegável

\footnotetext{
${ }^{35}$ Em 2002, o International Financial Corporation (IFC), braço do Banco Mundial para financiamento do setor privado, iniciou a articulação internacional para o lançamento, dos Princípios do Equador, pelos quais instituições financeiras signatárias devem realizar avaliação socioambiental dos projetos financiados a partir de US\$10 milhões. No Brasil o Banco do Brasil, Itaú e Bradesco, são signatários dos Princípios do Equador, e O BNDES optou por não os assinar (REPÓRTER BRASIL, 2011).
} 
importância para o desenvolvimento social e econômico brasileiro, "é fundamental trazer à discussão o papel e a responsabilidade do BNDES na prevenção desses impactos e sua reparação" (CONECTAS, 2014). Para tanto, propõe que, com vistas ao fortalecimento do quadro normativo que rege a sua atuação, o BNDES se paute em três dimensões: i) transparência e acesso à informação, ii) participação das pessoas diretamente afetadas pelos projetos nas fases de planejamento e execução, e iii) efetividade das diretrizes e políticas socioambientais e de respeito aos direitos humanos (CONECTAS, 2014). Argumenta ainda que, segundo a Declaração da ONU sobre o Direito ao Desenvolvimento (1986), em seu artigo $2^{\circ}$, "A pessoa humana é o sujeito central do desenvolvimento e deve ser ativa participante e beneficiária do direito ao desenvolvimento" (CONECTAS, 2014).

De acordo com Bessa et al. (2011), os grupos sociais impactados por um empreendimento hidrelétrico são os principais atores da engrenagem, uma vez que cedem seus territórios e locais de moradia para esses grandes projetos, considerados como estruturantes do desenvolvimento regional e nacional.

Para o reconhecimento dos direitos à mitigação dos impactos e os deveres adquiridos pelo benefício do desenvolvimento, as negociações devem ocorrer em conjunto com as populações afetadas pelo empreendimento em um contexto de acordo mútuo e fundamentos jurídicos. Para tanto, é preciso cumprir todos os compromissos assumidos, desde o planejamento até a operação do empreendimento, por todos os envolvidos, quais sejam, os governos, o empreendedor e a sociedade civil, por intermédio dos conselhos especializados e movimentos sociais. Dessa forma é possível conferir legitimidade ao processo, que se desenvolve, então, num contexto de reconhecimento dos direitos e dos riscos existentes, salvaguardando os devidos benefícios às populações afetadas, como propôs o Relatório da Comissão Mundial de Barragens (WCD, 2000).

\subsection{CAPACIDADE POLÍTICA E INSTITUCIONAL LOCAL}

Para a compreensão das dinâmicas que se estabelecem no território a partir da implantação de projetos de desenvolvimento, é importante a utilização de uma base teórica segundo a qual os recursos naturais e sua utilização pelos atores sociais são compreendidos 
numa esfera de gestão, nas várias perspectivas adotadas numa esfera temporal - passado, presente e futuro - e numa escala espacial - local, regional, nacional e global (Figura 68).

Na concepção de Mitchell (1979), as três abordagens que envolvem a gestão dos recursos naturais - ecológica, etnológica (cultural e social) e econômica - revelam perspectivas importantes e necessárias para a realização de uma análise abrangente dos problemas, a qual engloba diferentes óticas, como a biofísica, econômica, social, política, jurídica, institucional e tecnológica. Esse pode ser o ponto de partida para se avaliarem as adequações necessárias à tomada de decisões no contexto de uma política, plano ou projeto. Para a implantação de uma hidrelétrica, por exemplo, trata-se de passo fundamental para a identificação de problemas e a definição de estratégias nos âmbitos envolvidos no reconhecimento das especificidades dos recursos naturais, seu uso e os conflitos que se inserem nos territórios, quando consideradas as escalas temporal e espacial.

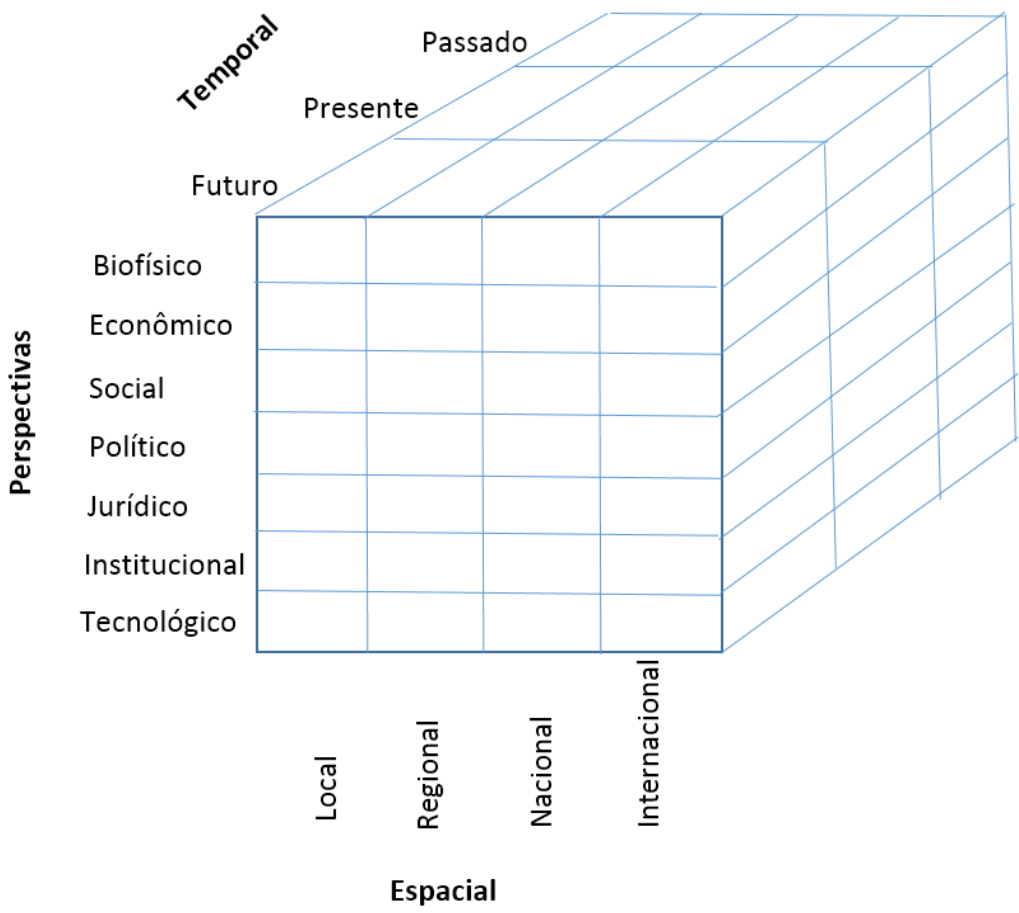

Figura 68 - Representação dos vários aspectos envolvidos na tomada de decisões, em escala espacial e temporal, para a gestão de recursos naturais Fonte: MITCHELL 1979.

A implantação de projetos de desenvolvimento, como as grandes hidrelétricas, requer a consideração das diferentes dimensões, de forma a garantir melhores arranjos institucionais e uma capacidade de resposta adequada à tomada de decisão. Destaca-se também a importância 
da proposição de estratégias políticas com vistas à resolução dos problemas, a partir de soluções claras e eficazes. De modo geral, o processo de análise dos grandes projetos se mostra limitado no tocante às inúmeras perspectivas que compõem o contexto socioambiental. Questões fundamentais, como a participação efetiva das populações afetadas pelos empreendimentos, recebem tratamento excludente e alheio ao processo de decisão.

Mitchell (1979) sugere quatro etapas essenciais para a formulação de políticas: i) identificação do problema significativo, para o qual não existe qualquer política - ou as que existem são insuficientes; ii) formulação de uma política que objetive resolver o problema; iii) implementação da política; iv) acompanhamento dos seus efeitos.

As etapas para a evolução de uma política são complexas e requerem o empenho e a influência daqueles que tomam as decisões e seus assessores técnicos. No entanto, para ser eficaz, a hierarquia administrativa depende da articulação ou do entrelaçamento das diferentes esferas de poder - local, regional ou nacional -, e não apenas as habilidades de cada um.

Tendo em vista a matriz a seguir, baseada em Mitchell (1979), em uma escala hierárquica de decisão política, é comum identificar como muitas vezes os responsáveis pela decisão se situam em uma das extremidades da escala, ou seja, no patamar mais alto. No extremo oposto, localizam-se os atores interessados em entender o problema a ser enfrentado pelos tomadores de decisão, os quais, apesar de participarem frequentemente, influenciam em menor grau a implantação de uma política. Existem também aqueles não envolvidos diretamente, mas que apresentam participação ocasional, apesar da sua grande importância para o processo de identificação dos problemas (Figura 69).

Contudo, a identificação dos problemas é apenas o primeiro passo para a implementação e avaliação de determinada política. O modelo hierárquico pelo qual o poder de decisão é influenciado pelos decisores no alto da escala, num processo que ocorre de forma vertical, de cima para baixo, precisa ser revisto a fim de abrir espaço para participação de outros atores não menos importantes. Essa mudança levaria à propositura de modelos políticos institucionais em que os objetivos de um plano, programa ou projeto se adequassem à natureza dos problemas identificados e suas respectivas soluções.

Castro (2003) sustenta que, por ser a política um campo de disputas de interesses do qual emergem as noções de controle e poder no território, os conflitos aparecem, necessitandose, portanto, das instituições de poder - políticas, econômicas e sociais - para controlá-los. De 
acordo com essa argumentação, são as instituições que "constituem os meios de socialização e que asseguram a transmissão de normas e valores sociais" (CASTRO, 2003). Elas definem as regras numa sociedade, desempenhando funções basilares no território, na organização da política local e no estabelecimento de padrões significativos de fenômenos sociais no espaço (CASTRO, 2003).

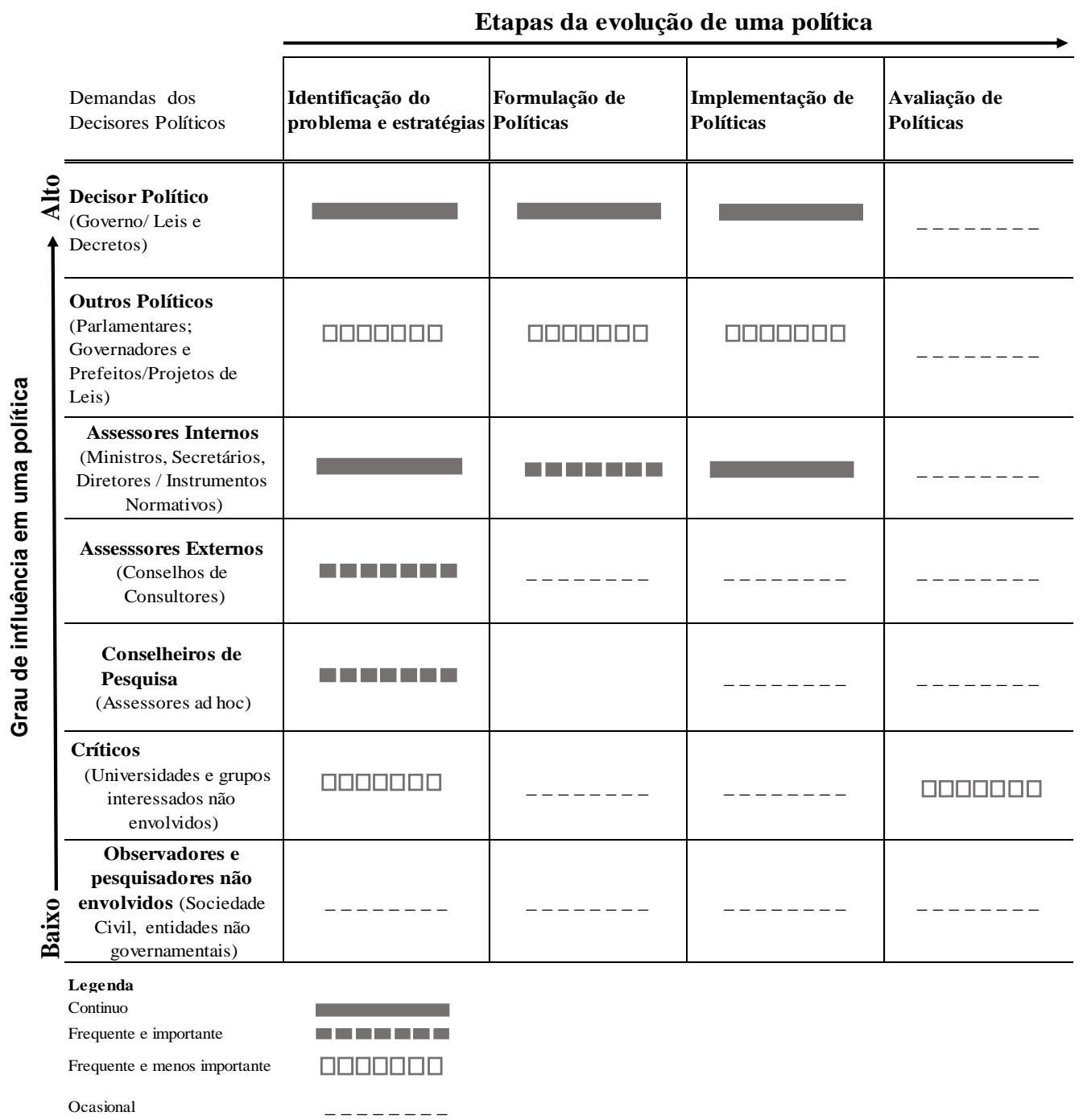

Figura 69 - Etapas da evolução de uma política e o grau de influência dos atores envolvidos Fonte: Adaptado de Mitchell, 1979.

Para Bursztyn e Bursztyn (2012), quando se trata de políticas públicas, estas "estão associadas aos processos de decisão referentes aos governos e voltados aos interesses coletivos, onde suas ações são regulares, institucionalizadas e visam objetivos e fins determinados". Os autores destacam que uma das questões críticas da ciência política, particularmente no contexto ambientalista, é que nem sempre o interesse de todos corresponde ao propósito público. Nesse 
sentido, quando entram em jogo divergências entre as intenções de determinados grupos e o interesse público, surgem os conflitos de território.

No entanto, as políticas públicas ambientais não podem se dissociar das medidas relativas à proteção social. Dentre estas, as políticas de saúde configuram como fundamentais para assegurar o equilíbrio social e a proteção ambiental, já que as relações entre a sociedade e meio ambiente envolvem o comprometimento das condições de vida. Porém, sabe-se que a integração entre as políticas públicas - social, econômica, educacional, regional, energética continua a ser um ponto crucial.

No Brasil, a saúde é parte integrante das ações sociais como elemento central da estratégia da seguridade social, compondo o sistema de proteção social. Na condição de elemento essencial para as transformações econômicas, sociais e políticas, que conduz à melhoria da qualidade de vida, apresenta influência direta sobre o desenvolvimento do país. O setor saúde, consolidado como um dos principais focos das políticas públicas, possui um aparato técnico e profissional para a oferta de bens e serviços. Além do mais, elabora medidas transversais para atender as populações em situações de desigualdade, as quais, portanto, requerem a aplicação de recursos humanos e financeiros (CASTRO, 2013)

Conforme já observado, os empreendimentos hidrelétricos incorporam um custo social que se distribui pelas diferentes esferas de gestão, sejam elas públicas ou privadas, afetando diretamente as populações mais vulneráveis da região onde implantadas. A situação pode se tornar ainda mais grave diante dos elevados índices de pobreza expressos na ineficiência e escassez dos serviços de saúde, saneamento e habitação. Nesse aspecto, para que os problemas e conflitos socioambientais sejam avaliados e solucionados, no âmbito dos projetos de desenvolvimento, é premente que as instituições envolvidas elaborem arranjos políticos institucionais mais eficazes. Objetiva-se, assim, a sustentabilidade e o planejamento adequado das ações no território, promovendo melhores condições de vida, ambientais e de saúde para a população.

Vale destacar que a promoção da saúde e da qualidade de vida dos habitantes dos territórios onde são implantados os projetos de desenvolvimento não é responsabilidade de apenas um único setor, mas, sim, conjunta, devendo ser compartilhadas pelos diversos setores envolvidos e firmadas por meio de ações intersetoriais e interdisciplinares, com apoio em políticas públicas eficazes. Com o objetivo de reconhecer, delimitar e propor ações que reduzam diversos problemas sociais no âmbito da saúde e da proteção social - aumento da 
carga de doenças, falta de acesso ao saneamento e mobilidade urbana -, se faz necessário que as políticas públicas sejam indutoras de soluções efetivas, assumindo como base os valores éticos, ecológicos e econômicos, inter-relacionados e interdependentes, como determinantes estruturais para a manutenção do valor humano (Figura 70).

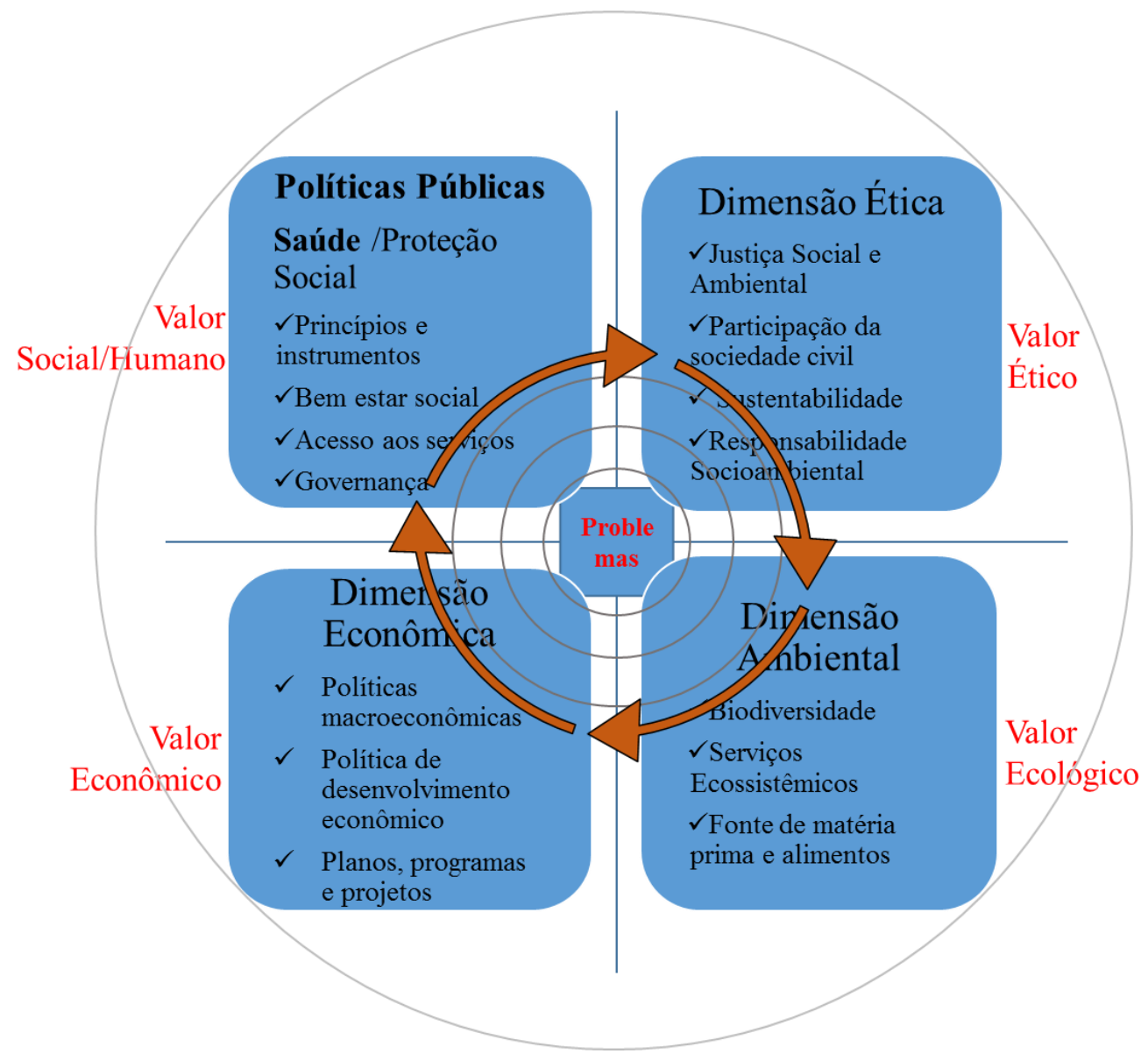

Figura 70 - Determinantes estruturais no âmbito das políticas públicas sustentáveis Fonte: Elaborada por Missifany Silveira, 2015.

Uma das formas de garantia da integração das iniciativas para a resolução de conflitos e outras externalidades impostas pela implantação das hidrelétricas, assim como por outros projetos de infraestrutura e desenvolvimento, perpassa a promoção de espaços de articulação permanentes, com a participação de atores políticos e sociais na coordenação das políticas públicas para a construção de territórios mais saudáveis. Assim sendo, a capacidade institucional e política local deve estar em sinergia com as esferas governamentais - federal, estadual e municipal -, as instituições e o capital humano, para a plena capacidade de gestão das demandas sociais. 


\section{CONSIDERAÇÕES FINAIS}

Identificar os impactos socioambientais e à saúde ocasionados pela implantação de grandes projetos de desenvolvimentos, como é o caso das hidrelétricas na região amazônica, é complexo e se impõe como um grande desafio. As considerações desenvolvidas neste estudo reafirmaram a complexidade e a urgência de se discutir e propor, no âmbito de uma abordagem intersetorial, uma relação estreita entre as áreas da saúde, do meio ambiente e do desenvolvimento, com vistas a se possibilitar a elaboração de um modelo de desenvolvimento que incorpore as questões alusivas à sustentabilidade ecológica e social.

A discussão sobre o planejamento de empreendimentos hidrelétricos na região Amazônica traz à tona a necessidade de uma nova ótica sobre as questões socioambientais decorrentes das modificações do território diante da construção das hidrelétricas. Apesar de se configurarem como a "nova fronteira" para a geração de energia elétrica no país, os princípios éticos fundamentais para que a comunidades locais vivam de maneira mais justa ambiental e socialmente não podem ser negligenciados. É imprescindível e urgente um novo enfoque que abranja as necessidades das populações, mediante um processo participativo que reconheça os direitos e avalie os riscos do empreendimento nas diferentes fases de planejamento e implementação. Somente assim não se repetirão os mesmos conflitos nas próximas hidrelétricas previstas para a região.

Pensar o território como área delimitada e estanque não se apresenta como suficiente para a devida compreensão dos processos que nele ocorrem de forma entrelaçada. Mostra-se essencial reconhecer os atores sociais locais e legitimá-los a participar das estratégias de ação adequadas às suas necessidades. Há de se considerar a dimensão espacial e temporal dos impactos de maneira a incorporar a dinâmica dos processos sociais, econômicos, políticos e ambientais. Permite-se, desse modo, que os acordos entre as partes, os compromissos e responsabilidade assumidos sejam cumpridos efetivamente, visando a redução dos impactos socioambientais e seus reflexos profundos na qualidade de vida das diferentes populações que habitam as áreas afetadas. O diagnóstico sobre as condições de vida e a situação de saúde não deveria ser tratado como conteúdo desarticulado do território de análise, e sim "estar relacionado ao trinômio estratégico: informação-decisão-ação" (GONDIM et al, 2008). Consequentemente, possibilita-se a contribuição participativa na tomada de decisões, com a 
adequada identificação de estratégias de ação nas diferentes dimensões das necessidades sociais.

A UHE de Belo Monte é abalizada, tanto por determinados setores da gestão ambiental pública e privada quanto pela empresa Norte Energia, como o processo de licenciamento ambiental mais completo e pesquisado de todos os tempos no Brasil. No entanto, quando se observam os resultados das ações de mitigação e compensação dos impactos implementadas pelo empreendedor e pelo poder público, essa característica não se traduz em melhores condições socioambientais ou de qualidade de vida na região, pelo menos por enquanto.

Palco de inúmeros conflitos e paralizações, a UHE de Belo Monte, a obra mais onerosa do PAC, negligenciou aspectos fundamentais decorrentes da sua implementação como a ausência de diálogos mais contundentes com as comunidades tradicionais, particularmente as indígenas, caracterizando as oitivas com esses povos como mera formalidade. Em um contexto de evidente descompasso entre o plano de ação para a mitigação e compensação dos impactos, as soluções dos problemas socioambientais se mostraram insuficientes, originando novos conflitos e gastos bastante superiores ao previstos originalmente. Portanto, para que os próximos projetos não enfrentem as mesmas mazelas reveladas, torna-se prioritário que se estabeleça maior efetividade no tocante às diretrizes e políticas socioambientais, além da elaboração de mecanismos mais transparentes de participação das populações afetadas, respeitando seus direitos de beneficiário ao desenvolvimento. Assim sendo, devem ser consideradas as especificidades culturais e os direitos históricos e constitucionais desses povos, assim como o que determinado pelas convenções internacionais.

A nova proposta de uma agenda global sobre os Objetivos de Desenvolvimento Sustentável (ODS) a ser implementada até 2030 abarca, entre seus dezessete objetivos, aspectos como saúde, água e saneamento; energia; padrões de produção e consumo; clima; uso da terra e biodiversidade, os quais se relacionam diretamente com o tripé desenvolvimento, ambiente e sociedade. Considerando tal proposta, não se há como assumir um planejamento e a construção de novos empreendimentos sem discutir a importância dessa integração no contexto do desenvolvimento sustentável. Nesse sentido, porém, o papel do setor saúde, nos processos de licenciamento ambiental de empreendimentos, ainda se mostra incipiente.

O estudo de caso realizado nesta pesquisa demonstrou que os recursos aplicados não solucionaram os conflitos nas áreas de influência do empreendimento, evidenciando uma gestão pouco eficiente no sentido de gerenciá-los. Uma alternativa para superar a questão seria o 
desenvolvimento de um trabalho voltado para os cenários ambientais e sociais observados na região. Desse modo, ao se anteciparem os principais efeitos decorrentes da implantação da hidrelétrica, as ações mitigatórias e compensatórias não se apresentariam mais as únicas soluções disponíveis, considerando-se que tais medidas, no caso de Belo Monte, foram implementadas ao longo da sua construção e não no período anterior ao seu planejamento.

Considerado como indicador que se expressa sobre as populações de forma direta e indireta durante a implantação projetos de infraestrutura no país, a saúde se qualifica como objeto importante de análise, com o objetivo primordial de assegurar ações permanentes para a redução da carga de doenças e medidas eficientes de prevenção e promoção à saúde na região. No entanto, este estudo apontou que tais aspectos ainda são tratados como externalidades durante sua a implantação.

Avaliar impactos à saúde é uma tarefa multifacetada e requer estudos aprofundados, com o desenvolvimento de metodologias capazes de correlacioná-los. A partir da análise do diagnóstico do quadro da saúde na região afetada, não se pôde inferir que o aumento das doenças transmissíveis sofreu influência direta da implantação da usina. No entanto, entendese que o aumento da população atraída para a região afetou as taxas de morbimortalidade das doenças não transmissíveis, principalmente as de causas externas, como os acidentes e violências. As eventuais distorções verificadas nos dados secundários obtidos nos bancos de dados públicos de saúde para as doenças transmissíveis, pode ter sido tanto pelo fato do aumento no número de notificações como pela falta de correções no sistema de informações. No entanto, existe grande potencial exploratório da situação da saúde na região da UHE de Belo Monte e que deve ser considerado em futuros estudos.

Proposta pela OMS e difundida em diversos países, a AIS constitui uma metodologia eficaz para apontar os impactos positivos e negativos de uma intervenção no território, seja ela proveniente de política, plano, programa ou projeto. Não se sobrepondo às outras avaliações, a AIS permite que a variável saúde seja avaliada durante as diferentes intervenções, oferecendo uma nova perspectiva de avaliação que antes não era levada em conta pelos tomadores de decisão. Em que pese a iniciativa do Ministério da Saúde, por intermédio do campo da saúde ambiental - o qual tem participação pontual nesses processos -, a proposta de uma nova metodologia de análise como a Avaliação de Impacto à Saúde (AIS) se apresenta de maneira tímida diante da importância da conexão dos projetos de desenvolvimento com as políticas públicas de saúde e meio ambiente. Para tanto, a fim de que esse método avance no âmbito das 
políticas públicas no Brasil, mostra-se necessário ainda, além de um trabalho metodológicocientifico, com o apoio das instituições de pesquisa, o respaldo político para que a iniciativa do Ministério da Saúde seja implementada no Brasil sistematicamente.

O setor saúde teve destaque no planejamento das medidas mitigatórias e compensatórias com a implantação do Plano Básico Ambiental (PBA) da UHE de Belo Monte, no âmbito do Plano de Desenvolvimento Regional Sustentável do Xingu (PDRS-X) e no Programa Nacional de Controle da Malária (PNCM). Contudo, o único indicador de saúde considerado nas avaliações sistemáticas se concentra sobre a malária. Sem dúvida o PNCM é um dos programas mais estruturados no âmbito do licenciamento ambiental, em que pese ser um pré-requisito à obtenção de licenças para o pleno funcionamento do empreendimento no território. O mesmo não ocorreu relativamente a outras doenças ou agravos de saúde, como elucidado no estudo de caso. Esse fator comprova a hipótese de que programas eficientes, somados a recursos financeiros e capacidade técnica, conduzem a resultados positivos sobre a situação de saúde quando da construção de grandes empreendimentos, como as hidrelétricas. Cabe destacar, no entanto que, embora o setor saúde esteja compreendido nas políticas ambientais, por meio do cumprimento do Plano de Ação para o Controle da Malária (PACM), ainda não existem instrumentos jurídicos satisfatórios que estabeleçam a obrigatoriedade para o cumprimento de outras ações de saúde durante a implantação de projetos dessa dimensão.

A construção de hidrelétricas, via de regra, induz migrações, desmatamentos e conflitos fundiários. A fim de se reduzirem os problemas nos territórios afetados, o Estado, principalmente quando figura como detentor do projeto, precisa agir antecipadamente, por meio de medidas políticas mais eficazes. Para tanto, essas ações preventivas devem considerar a ética como princípio, sobretudo quando os impactos da geração de energia se concentram sobre determinadas regiões e suas populações específicas. Trata-se de aspecto que adquire maior importância à medida que as políticas econômicas e ambientais não se dissociem das políticas de proteção social. Desse modo, é possível assegurar o equilíbrio das relações entre a sociedade e o meio ambiente, resguardando os direitos e deveres. Outro ponto importante é que não se considere apenas o interesse predominante das grandes construtoras, que parece se contrapor às necessidades futuras da região. A partir de então, se poderá alcançar a devida sustentabilidade das ações de (re)estruturação do território, com a promoção de melhores condições e qualidade de vida na região. 
Os projetos de desenvolvimento, a exemplo das hidrelétricas, possuem um grande potencial no sentido de contribuírem e apoiarem a sustentabilidade social e ambiental das comunidades residentes nos territórios em que implantados. Criam, assim, oportunidades para alavancar a cadeia produtiva local por meio das receitas originadas dos royalties, além de incrementarem a infraestrutura de saúde, saneamento, abastecimento de água, gestão de resíduos, dentre outros serviços sociais. No entanto, para que isso aconteça é necessária uma articulação política institucional para a construção de agendas que orientem o desenvolvimento sustentável, com a elaboração de ações articuladas entre os atores políticos das três esferas de poder público, assim como o setor privado e a sociedade civil organizada, para a construção de diálogos.

Assim, um trabalho em conjunto realizado pelas diferentes esferas de atuação envolvidas na instauração desses grandes projetos evitaria de forma mais eficaz e assertiva os recorrentes conflitos socioambientais e de direitos humanos, os quais atualmente são contornados pelas ações mitigatórias e compensatórias apresentadas pelas empresas construtoras. Nesse sentido, a permanência do modelo de Avaliação de Impacto Ambiental (AIA), no qual as licenças ambientais possuem apenas um papel meramente cartorial, revelase insuficiente para abarcar questões mais abrangentes do ponto de vista da sustentabilidade socioambiental.

A elaboração de um novo modelo econômico e tecnológico, com bases ecológica e socialmente mais justas e sustentáveis para o desenvolvimento social e econômico do País, é expectativa demonstrada por muitos. Entretanto, entre o desejo e a vontade política ainda há um longo caminho. Resta a pergunta: já não é hora de propormos medidas políticas para o fortalecimento de novas opções tecnológicas com vistas à geração de energia limpa que não sejam provenientes apenas das grandes usinas hidrelétricas (UHEs), deixando para trás esse "símbolo de modernidade" e de alto custo ambiental e social? Em inúmeros países, e mesmo no Brasil, novas tecnologias de energia limpa como a eólica, solar, biomassa se destacam como alternativas a esse padrão mais tradicional. Contudo, para se tornarem viáveis, é fundamental o redirecionamento da política energética no sentido de se estabelecer uma mudança do paradigma no país. Além disso, os bancos financiadores, a exemplo do BNDES, deveriam conceder maiores incentivos para impulsionar a elaboração de tais iniciativas no âmbito de diversos setores da sociedade e da economia, na expectativa de se contribuir ao desenvolvimento verdadeiramente sustentável. Apesar de o BNDES não ser signatário dos 
Princípios do Equador que trata dos riscos sociais e ambientais no financiamento de projetos de desenvolvimento, seu escopo da oferta de financiamento deveria ultrapassar a lógica do custo benefício, e incorporar também os custos sociais nos projetos financiados por esta instituição pública.

No entanto, é importante enfatizar, por fim, que esse aspecto se caracteriza como um novo objeto de estudo a ser explorado, o que não impede, porém, que ocorra uma reflexão pela sociedade, especialistas, acadêmicos e toda a comunidade científica a respeito da sua real viabilidade como alternativa ao modelo dominante. 


\section{REFERÊNCIAS BIBLIOGRÁFICAS}

ABRAHAMS D.; BROEDER, L.; DOYLE, C.; FEHR, R.; HAIGH, F.; MEKEL, O.; METCALFE, O.; PENNINGTON, A.; SCOTT-SAMUEL, A. Policy Health Impact Assessment for the European Union: Final Project Repost. Aug/2004. Disponível em: http://www.ihia.org.uk/ephia/reports/finalprojectreport.pdg. Acesso em: 04/04/2012.

AB'SABER, A.N. e MULLER-PLANTENBERG, C. (Orgs.). Previsão de Impactos: o Estudo de Impacto Ambiental no Leste, Oeste e Sul. Experiências no Brasil, na Rússia e na Alemanha. $2^{a}$ ed. São Paulo: Editora Universidade de São Paulo, 2006.

ACSELRAD H., MELLO C.C.A.; BEZERRA, G.N. O que é justiça ambiental. Rio de Janeiro: Garamond, 2009.

ACSELRAD H., MELlO C. Elementos para análise do RIMA de Belo Monte à luz das conclusões e recomendações do projeto Avaliação de Equidade Ambiental. In: MAGALHÃES, S. M. S. B.; HERNANDEZ F. M. (Org.). Painel de Especialistas: Análise Crítica do Estudo de Impacto Ambiental do Aproveitamento Hidrelétrico de Belo Monte. Belém, 2009. https://www.socioambiental.org/banco_imagens/pdfs/Belo_Monte_Painel_especialistas_EIA. pdf\%20\%20 Acesso em: 02/03/2014.

AGÊNCIA BRASIL. Empresa Brasil de Comunicação. Disponível em: http://memoria.ebc.com.br/agenciabrasil/noticia/2011-04-05/procurador-defende-paralisacaoimediata-de-belo-monte-para-evitar-danos-imagem-do-brasil-no-exterior. Acesso em:10/12/2011.

AGÊNCIA Fiocruz de Notícias. Ensp/Fiocruz inicia projeto que integra saúde, ambiente e educação em Rondônia. Projeto da pesquisadora da Escola Nacional de Saúde Pública (Ensp/Fiocruz) Sandra Hacon, junto com o vice-coordenador, Salvatore Siciliano. Disponível em: http://www.fiocruz.br/ccs/. Acesso em: 12/12/2013.

AGUIAR, C. D. Sobreposições entre Políticas Públicas: obras do PAC e unidades de conservação no corredor de biodiversidade da Serra do Mar. Dissertação (Mestrado). Centro de Desenvolvimento Sustentável. Universidade de Brasília, Brasília, 2011.

ALMEIDA F. O bom negócio da sustentabilidade. Rio de Janeiro: Nova Fronteira; 2002.

ALMEIDA, M. G. A propósito do trato do invisível, do intangível e do discurso na geografia cultural. Revista da ANPEGE, v. 9, n. 11, p. 41-50, 2013.

ANA. Agência Nacional de Águas. Cadernos de Recursos Aproveitamento do Potencial Hidráulico para a Geração de Energia. Brasília: Superintendência de Usos Múltiplos, 2005.

Diário Oficial da União de 2 de março de 2011. Seção 1, fl. 76. Resolução n 48, de 28 de fevereiro de 2011.

Resolução n. 2046, de 19 de dezembro de 2014. Disponível em: http://arquivos.ana.gov.br/resolucoes/2014/2046-2014.pdf. Acesso em: 20/12/2015. 
ANDRADE, A. O desafio do licenciamento ambiental de usinas hidrelétricas no Brasil. Revista Brasileira de Energia, vol. 17, n. 2, p.177-190, 2011.

ANEEL. Agência Nacional Energia Elétrica. Capacidade de geração do Brasil. Disponível em: http://www.aneel.gov.br/aplicacoes/capacidadebrasil/capacidadebrasil.cfm. Acesso em: 10/02/2014.

Agentes de geração. Disponível em: http://www.aneel.gov.br/aplicacoes/Agente Geracao/agentegeracao.cfm. Acesso em: 03/5/2015.

ARAÚJO, T.B. A Experiência de Planejamento Regional no Brasil. In: Reestruturação do Espaço Urbano e Regional no Brasil. Ed. Hucitec, São Paulo, 1993.

ARAÚJO, M. A. T.; BELO, P.S. Grandes projetos minerários e comunidades tradicionais na Amazônia: impactos e perspectivas. Revista de Políticas Públicas, v. 13, n. 2, 2009.

ASSIS, W. F. T.; ZHOURI, A. Representar territórios e des-figurar conflitos ambientais: o discurso do desenvolvimento sustentável na publicidade brasileira. Novos Cadernos, v. 14, n. 2 , p. 117-140, dez/2011.

ATLAS DO DESENVOLVIMENTO HUMANO NO BRASIL. Disponível em: http://www.atlasbrasil.org.br/2013/pt/home/ Acesso em: 15/12/2015.

AUGUSTO L.G.S. Saúde e ambiente. In: BRASIL. Ministério da Saúde. Saúde no Brasil: contribuições para a Agenda de Prioridades de Pesquisa. Brasília: Ministério da Saúde, 2004.

BACIGALUPE, A.; ESNAOLA, S.; CALDERÓN, C.; ZUAZAGOITIA, J.; ALDASORO, E. La evaluacion del impacto sobre la salud: una herramienta para incorporar la salud en las intervenciones no sanitarias. Gaceta Saniaria, n.23(1), Ed. Impresa, Barcelona, 2009.

BAINES, S.G. Terras Indígenas e projetos de desenvolvimento. A responsabilidade profissional ética: laudos e perícias antropológicos. Povos Indígenas no Brasil. 13-05-2003. Disponível em: http://pib.socioambiental.org/en/noticias?id=7980 Acesso em: 24/03/2013.

BALBY, C.N. Avaliação de Impactos a Saúde: Desenvolvimento Internacional e Perspectivas no Brasil. 2012. 158 f. Dissertação (Mestrado em Saúde Pública - Concentração em Saúde ambiental) - Faculdade de Saúde Pública, Universidade de São Paulo, São Paulo, 2012.

BARBOSA, E. M.; BARATA, M.M.L.; HACON, S.S. A saúde no licenciamento ambiental: uma proposta metodológica para a avaliação dos impactos da indústria de petróleo e gás. Ciência \& Saúde Coletiva, vol.17, n.2, Rio de Janeiro, 2012.

BARCELLOS, C.; MONKEN, M. Instrumentos para o Diagnóstico Sócio-Sanitário no Programa Saúde da Família. In: FONSECA, A.F.; CORBO, A. (Orgs.). O território e o processo saúdedoença. Rio de Janeiro: EPSJV/Fiocruz, 2008.

BARCELLOS C, RAMALHO W. Situação atual do geoprocessamento e da análise de dados espaciais em saúde no Brasil. Revista IP - Informática Pública, 2002.

BECKER, B. K. Gestão do território e territorialidade na Amazônia: a CVRD e os garimpos na província mineral de Carajás. In: BECKER, B. K.; MIRANDA, M.; MACHADO, L. Fronteira 
Amazônica. Questões sobre a gestão do território. Brasília: Editora Universidade de BrasíliaUnB/Rio de Janeiro: Ed. UFRJ, 1990.

. A urbe amazônida: a floresta e a cidade. Rio de Janeiro: Garamond, 2013.

BERMANN, C. Entrevista. A energia hidrelétrica não é limpa, nem barata. In: Viomundo. Publicada em 03 de junho de 2010. Disponível em: http://www.viomundo. com.br/entrevistas/bermann-a-energia-hidreletrica-nao-e-limpa-nem-barata.html. Acesso em: $10 / 04 / 2014$.

BESSA, N.G.F.; PEREIRA, A.G.; ZITZKE, V.A. Foro de Negociação e Comitês de Co-gestão em empreendimentos hidrelétricos no Brasil. Sustentabilidade em Debate, vol. 2, n. 2. 2011.

BEZZI, M. L. Uma (Re)visão Historiográfica - da Gênese aos Novos Paradigmas. Ed. UFSM. Santa Maria, 2004.

BHATIA, R.; WERNHAM, A. Integrating human health into environmental impact assessment: an unrealized opportunity for environmental health and justice. Review, 14(4), p. 1159-1175, 2009.

BRASIL. Câmara Interministerial de Segurança Alimentar e Nutricional (CAISAN). Plano Nacional de Segurança Alimentar e Nutricional: 2012/2015. Brasília, 2011e.

. Casa Civil da Presidência da República. Plano de Desenvolvimento Regional Sustentável do Xingu. Decreto N. 7.340, de 21 de outubro de 2010. Diário Oficial da União. Brasília, DF, 22.10.2010. 2010b.

. Casa Civil da Presidência da República. Decreto no 7.508, de 28 de Junho de 2011. Diário Oficial da União. Brasília, DF, 29.06.2011, 2011d.

CGAVAM/SVS/MS. I Oficina de Trabalho sobre Avaliação de Empreendimentos pelo Sistema Único de Saúde - SUS. Brasília, 6 a 8 de julho de 2005 (Arquivo CGVAM).

Comitê Interministerial Sobre Mudança do Clima. Plano Nacional Sobre Mudança do Clima - PNMC. Brasília, 2008a.

Coordenação Geral de Vigilância Ambiental em Saúde (CGVAM). Memorando $n^{o}$ 727/CGVAM/SVS/MS de 15/12/2004. Brasília, 2004.

Eletrobrás. Sistema de Informações do Potencial Hidrelétrico Brasileiro - SIPOT. Fevereiro de 2012a. Disponível em: http://www.eletrobras.com/elb/data/Pages/ LUMIS21D128D3PTBRIE.htm. Acesso em:17/09/2014.

Ministério da Justiça. Fundação Nacional do Índio. Diretoria de Promoção ao Desenvolvimento Sustentável. Coordenação-Geral de Licenciamento Ambiental. Informação $n^{o}$ 223/2015/CGLIC /DPDS/FUANAI- MJ. Brasília, 23 de setembro de 2015a.

Ministério da Saúde. A experiência brasileira em sistemas de informação em saúde. Organização Pan-Americana da Saúde. Fundação Oswaldo Cruz. Brasília: Editora do Ministério da Saúde, 2009b 
Ministério da Saúde. Secretaria de Vigilância em Saúde. Boletim Eletrônico Epidemiológico, ano 10, $\mathrm{n}^{\circ}$ 6, dezembro 2010a. Disponível em: http://portal.saude.gov.br/portal/arquivos/pdf/boletim_epi_n5__17dez2010_.pdf. Acesso em:21/03/2012.

. Ministério da Saúde. Secretaria de Vigilância em Saúde. Boletim Eletrônico Epidemiológico, Volume 44, $\mathrm{n}^{\circ}$ 1, 2013a. Disponível em: http://bvsms.saude.gov.br/bvs/periodicos/boletim_epidemiologico_numero_1_2013.pdf Acesso em: 10/02/2014.

Ministério da Saúde. Secretaria de Vigilância em Saúde Boletim Eletrônico Epidemiológico, Volume 46, $\mathrm{n}^{\circ} \quad 10, \quad 2015 \mathrm{~b} . \quad$ Disponível em: http://portalsaude.saude.gov.br/images/pdf/2015/abril/22/Boletim-raca-cor-09-04-15-v2.pdf Acesso em: 21/12/2015.

. Ministério da Saúde. Secretaria de Vigilância em Saúde. Departamento de DST, Aids e Hepatites Virais Boletim Eletrônico Epidemiológico- Hepatites Virais, Ano IV- no 1, 2015e. Disponível:http://www.aids.gov.br/sites/default/files/anexos/publicacao/2015/58210/_p_bolet im_hepatites_final_web_pdf_p_16377.pdf. Acesso em: 22/12/2015.

Ministério da Saúde. Secretaria de Vigilância em Saúde. Departamento de DST, Aids e Hepatites Virais Boletim Eletrônico Epidemiológico de Sífilis, Ano IV- no 1, $2015 \mathrm{f}$. Disponível em: http://www.aids.gov.br/sites/default/files/anexos/publicacao/2015/57978/_p_boletim_sifilis_2 015_fechado_pdf_p_18327.pdf Acesso em 22/12/2015.

Ministério da Saúde. Conselho Nacional de Saúde. Moção $n^{o} .001$ de 18 de janeiro de 2007 do Conselho Nacional de Saúde. Plenário do Conselho Nacional de Saúde, em sua Centésima Sexagésima Nona Reunião Ordinária. Brasília, 2007c. Disponível em: http://conselho.saude.gov.br/mocao/mocoes_07.htm. Acesso em: 12/02/2008.

Ministério da Saúde. Conselho Nacional de Saúde. Subsídios para construção da Política Nacional de Saúde Ambiental. Brasília, 2007b.

Ministério da Saúde. Instrução Normativa n 01. Diário Oficial da União. Brasília, DF, 08/03/2005, n. 45, Seção 1, p. 45.

Ministério da Saúde. Portaria $N^{o} 1$, de 13 de janeiro de 2014. Secretaria de Vigilância em Saúde. Brasília, 2014a.

Ministério da Saúde. Secretaria de Vigilância em Saúde. Departamento de Vigilância em Saúde Ambiental e Saúde do Trabalhador. Avaliação de Impacto à Saúde - AIS: metodologia adaptada para aplicação no Brasil. 68 p Brasília, 2014c.

Ministério da Saúde. Secretaria de Atenção à Saúde. Departamento de Atenção Básica. Saúde da família no Brasil: uma análise de indicadores selecionados: 1998-2004. Brasília, 2006b. 
Ministério da Saúde. Secretaria de Atenção à Saúde. Departamento de Regulação, Avaliação e Controle de Sistemas. Diretrizes para a programação pactuada e integrada da assistência à saúde. 148 p. (Série B. Textos Básicos de Saúde). Brasília, 2006c.

Ministério da Saúde. Secretaria de Vigilância em Saúde. Departamento de Análise de Situação de Saúde. Saúde Brasil 2008: 20 anos de Sistema Único de Saúde (SUS) no Brasil. Brasília, 2009a.

Ministério da Saúde. Secretaria de Vigilância em Saúde. Departamento de Vigilância de Doenças e Agravos não Transmissíveis e Promoção da Saúde. Viva: Vigilância de violências e acidentes, 2009, 2010 e 2011. Brasília: Ministério da Saúde, 2013b.

Ministério da Saúde. Secretaria de Vigilância em Saúde. Departamento de Vigilância em Saúde Ambiental e Saúde do Trabalhador. Saúde ambiental: guia básico para construção de indicadores. Brasília, 2011a.

Ministério da Saúde. Secretaria de Vigilância em Saúde. Situação Epidemiológica da Malária no Brasil. 2008b. Disponível em: http://portal.saude.gov.br/portal/ arquivos/pdf/folder_malaria_2008_final.pdf. Acesso em: 02/02/2013.

Ministério da Saúde. Seminário sobre saúde ambiental e saúde do trabalhador e suas interfaces com o Programa de Aceleração do Crescimento (PAC). Brasília, 2007d.

. Ministério da Saúde. SVS. Portaria No 47, de 29 de dezembro de 2006. Diário Oficial da União. Brasília, DF, 04-01-2007.

Ministério de Minas e Energia. Relatório de Impacto Ambiental AHE Belo Monte. 2009. Disponível em: http://norteenergiasa.com.br/site/wp-content/uploads/2011 /04/NE. Rima_.pdf. Acesso em: 10/10/2014d.

Ministério de Minas e Energia. Manual de Inventário Hidroelétrico de Bacias Hidrográficas. Ministério de Minas e Energia. CEPEL. Rio de Janeiro, 2007a.

Ministério de Minas e Energia. Plano Decenal de Expansão de Energia 2021. Empresa de Pesquisa Energética. Brasília: MME/EPE, 2012b.

. Ministério de Minas e Energia. Plano Decenal de Expansão de Energia 2023. Empresa de Pesquisa Energética. Brasília: MME/EPE, 2014b.

Ministério do Meio Ambiente. Avaliação Ambiental Estratégica. Brasília, 2002.

Ministério do Meio Ambiente. Ministério do Meio Ambiente. Consultoria Jurídica. Legislação Ambiental Básica. Consultoria Jurídica. UNESCO. 350 p. Brasília, 2008c.

Ministério do Meio Ambiente, Secretaria de Recursos Hídricos. Caderno setorial de recursos hídricos: geração de energia hidrelétrica. Brasília: MMA, 2006a. Disponível em: http://www.mma.gov.br/estruturas/161/_publicacao/161_publicacao23022011031204.pdf. Acesso em: 15/03/2014.

Ministério do Meio Ambiente, Gabinete da Ministra. Portaria Interministerial $\mathrm{n}^{\mathrm{o}}$ 419, de 26 de outubro de 2011. Diário Oficial da União. Brasília, DF, 28.10.2011, 2011 c. 
Ministério do Planejamento. PAC. Notícias. Comitê Gestor do PDRS do Xingu define projetos que receberão $R \$ 50$ milhões na região de Altamira. Disponível em: www.pac.gov.br/noticias/f3f62661. 2014e

. Ministério do Planejamento, Orçamento e Gestão. Programa de Aceleração do Crescimento (PAC). Disponível em: http://www.planejamento.gov.br/noticia.asp? $p=$ not $\& \operatorname{cod}=2194 \& \mathrm{cat}=264 \& \mathrm{sec}=29$. Acesso em: $17 / 07 / 2011$.

Ministério Público Federal. Relatório de Inspeção Interinstitucional: áreas ribeirinhas atingidas pelo processo de remoção compulsória da UHE Belo Monte. Altamira/PA, 2015c. Disponível em: http://www.prpa.mpf.mp.br/news/2015/mpf-divulga-relatorio-sobreremocao-de-ribeirinhos-pela-hidreletrica-de-belo-monte. Acesso em: 27/12/2015.

Ministério Público Federal. Audiência Pública realizada em Altamira. Altamira/PA, 2015d. Disponível em: http://noticias.pgr.mpf.mp.br/noticias/noticias-do-site/copy_of_indiose-minorias/mpf-pa-sem-cumprir-condicionantes-belo-monte-provoca-o-caos-na-saudeindigena-no-xingu/? searchterm=Belo\%20Monte. Acesso em: 02/09/2015.

Palácio do Planalto. Lei $n^{o} 11.445$, de 5 de janeiro de 2007, que estabelece as diretrizes nacionais para o saneamento básico e para a política federal de saneamento básico no Brasil. Disponível em: http://www.planalto.gov.br/ ccivil_03/_ato20072010/2007/lei/111445.htm. Acesso em: 25/04/2014, $2007 \mathrm{f}$.

. Portaria $n^{\circ} 1.377$, de 3 de julho de 2012. Ministério da Saúde. Gabinete do Ministro. Disponível em: http://bvsms.saude.gov.br/bvs/saudelegis/gm/2012/ prt1377_03_07_2012.html. Acesso em: 20/11/2014c.

Portaria Interministerial $n^{\circ} 822$, de 30 de abril de 2008. Diário Oficial da União. Brasília, DF, 02/05/2008.

. Tribunal de Contas da União. Cartilha de licenciamento ambiental - em colaboração do Instituto Brasileiro do Meio Ambiente e dos Recursos Naturais Renováveis (Ibama). $2^{\text {a ed. }}$ Brasília, 2007e

. Tribunal Regional Federal. TRF-1. AC: 259997520104013900 PA 002599975.2010.4.01.3900. Relator: Desembargador Federal Souza Prudente. Data de julgamento: 26/03/2014, Quinta Turma. E-DJF1, p.360, Brasília, 22/04/2014f.

BREILH, J. Pilhagens, Ecossistemas e Saúde. In: MIRANDA, A.C; BARCELLOS, C., MOREIRA, J.C et al (Org.). Território, ambiente e saúde. Rio de Janeiro: Editora Fiocruz, 2008 .

BRITTO, F. G. A. Análise Crítica do Licenciamento Ambiental de UHEs na Amazônia Brasileira. 2014. 266f. Tese (Doutorado em Engenharia Civil) - Programa de Pós-graduação em Engenharia Civil - COPPE, Universidade Federal do Rio de Janeiro, Rio de Janeiro, 2014.

BULCÃO, J. A. S. Proposta de um Modelo para Avaliação do Impacto dos Empreendimentos Hidroelétricos sobre as Doenças Transmitidas por Vetores com Especial Referência à Malária. 1994. Dissertação (Mestrado em Medicina Tropical) - Fundação Oswaldo Cruz, Rio de Janeiro, 1994. 
Principais Impactos Sobre a Saúde da População Afetada por Projetos Hidrelétricos no Brasil. In: VI CONGRESSO BRASILEIRO DE ENERGIA/SEMINÁRIO LATINOAMERICANO DE ENERGIA. Rio de Janeiro, Out/1993.

BURSZTYN, M; BURSZTYN, M.A. Fundamentos de políticas e gestão ambiental: os caminhos do desenvolvimento sustentável. Gramond. Rio de Janeiro.2012.

BUSS, P. MACHADO; J. M. H. GALlO. E.; MAGALHÃES, D. P.; SETTI, A. F. F.; FRANCO NETTO, F. A.; D. F. BUSS. Governança em saúde e ambiente para o desenvolvimento sustentável. Ciência \& Saúde Coletiva, 17(6), p.1479-1491, 2012.

CARNEIRO E. J. Política ambiental e a ideologia do desenvolvimento sustentável. In: ZHOURI, A; LASCHEFSKI, K; PEREIRA, D.B. A insustentável leveza da política ambiental: desenvolvimento e conflitos socioambientais. Belo Horizonte: Autêntica, 2005.

CASTRO, E. Expansão da fronteira, megaprojetos de infraestrutura e integração sulamericana. Cad. CRH, Salvador, v. 25, n. 64, p. 2012. Disponível em: http://www.scielo.br/scielo.php?script=sci_arttext\&pid=S0103-

49792012000100004\&lng=en\&nrm=iso Acesso em: 21/08/2015.

CASTRO, I. E. Instituições e território. Geosul, v.18, n.36, p 7-28, 2003.

CASTRO. J. A. Saúde e desenvolvimento no Brasil. In: COHN A. (org.) Saúde, cidadania e desenvolvimento. Centro Internacional Celso Furtado. 1ª Ed. 240 p. Rio de Janeiro, 2013.

CAVEDON F.S.; VIEIRA R.S. A política jurídica e o direito socioambiental: uma contribuição para a decidibilidade dos conflitos jurídico-ambientais. Revista NEJ - Eletrônica, p. 60-78. Edição Especial, 2011. Disponível em: www.univali.br/periodicos. Acesso em: 8/12/2012.

CBDES. Conselho Empresarial Brasileiro para o Desenvolvimento Sustentável. Estudo sobre adaptação e vulnerabilidade à mudança climática: o caso do setor elétrico brasileiro. Disponível em: http://cebds.org/wp-content/uploads/2014/02/Estudo-sobre-Adapta\%C3\% A7\%C3\%A3oe-Vulnerabilidade-\%C3\%A0-Mudan\%C3\%A7a-do-Clima-o-caso-do-setor-el\%C3 \%A9tricobrasileiro_BxResolucao.pdf. Acesso em: 10/04/2014.

CDSS. Redução das desigualdades no período de uma geração. Igualdade na saúde através da ação sobre os seus determinantes sociais. Relatório Final da Comissão para os Determinantes Sociais da Saúde. Portugal: Organização Mundial da Saúde, 2010.

CHRISTOFOLETTI, A. As perspectivas dos estudos geográficos. In: Perspectivas da geografia. São Paulo: Difel, 1982

CIDADE, L.C.F. Visões de mundo, visões da natureza e a formação de paradigmas geográficos. Terra Livre, $N^{\circ} 17$ - Paradigmas da Geografia, parte II, p.99-118. Associação dos Geógrafos Brasileiros - AGB. São Paulo, 2001.

COBRAPE. Relatório de análise dos estudos de impacto ambiental (EIA) e do relatório de impacto ambiental (RIMA) dos Aproveitamentos Hidrelétricos de Santo Antônio e Jirau, no Rio Madeira. Porto Velho: Cobrape - Cia. Brasileira de Projetos e Empreendimentos/Ministério Público do Estado de Rondônia, 2006. 
COHN, C. A produção de um dossiê sobre um processo em curso. In: OLIVEIRA, J. P.; COHN, C. (Orgs.). Belo Monte e a questão indígena. Brasília: ABA, 2014.

CONECTAS DIREITOS HUMANOS. Desenvolvimento para as pessoas? O financiamento do BNDES e os Direitos Humanos. $1^{\text {a }}$ edição. São Paulo, 2014. Disponível em: http://www.conectas.org/arquivos/editor/files/Conectas_BNDES\%20e\%20Direitos\%Humano s_Miolo_Final_COMPRIMIDO.pdf. Acesso em: 10/11/2015.

CORDANI U.G., MARCOVITCH J.E., SALATI E. Avaliação das ações brasileiras após a Rio-92. Estud. av. [Internet]. 1997. 11(29):399408. Disponível em: http://www.scielo.br/scielo.php?script=sci_arttext\&pid+S0103-40141997000100019 \&Ing= en\& nrm+iso. Acesso em: 02/08/2012.

CORVALÁN C.F; KJELLSTRÖM T.; SMITH K.R. Health, Environment and Sustainable Development. Identifying Links and Indicators to Promote Action. Epidemiology Resources Inc., vol. 10, n. 5, 1999.

COSTA, W.M. O Estado e as Políticas Territoriais no Brasil. São Paulo: Contexto, 2000.

COSTA GF. Geoprocessamento: uso e aplicação na saúde pública e na saúde ambiental. In: RIBEIRO, H. Olhares geográficos: meio ambiente e saúde. São Paulo: Senac; 2005.

DAMASCENO, E.S.; SANTANA JÚNIOR, H.A.A. Rede Brasileira de Justiça Ambiental (RBJA): expressão e forma do movimento social contemporâneo. In: V Jornada Internacional de Políticas Públicas. São Luís, 2011. Disponível em: http://www.joinpp.ufma.br/ jornadas/joinpp2011/CdVjornada/vjornada.html. Acesso em: 12/12/2012.

D`ARAÚJO, R.P. O setor elétrico brasileiro - uma aventura mercantil. 300p. Brasília: Confea, 2009.

ELPAIS Brasil. A empresa Norte Energia, responsável pela usina, responde às perguntas sobre as polêmicas ambientais e sociais da empresa. Brasil, 21/10/2015. Disponível em: http://brasil.elpais.com/brasil/2015/10/19/politica/ 1445288959_623438.html. Acesso em: $15 / 12 / 2015$.

ESCADA, M. I. S.; MAURANO, L. E.; SILVA, J. H. G. Dinâmica do desmatamento na área de influência das usinas hidroelétricas do complexo do Rio Madeira, RO. In: XVI SIMPÓSIO BRASILEIRO DE SENSORIAMENTO REMOTO. Anais. Foz do Iguaçu/PR, 2013.

FEARNSIDE, P.M. O Novo EIA-RIMA da Hidrelétrica de Belo Monte: Justificativas Goela Abaixo. In: MAGALHÃES, S. M. S. B.; HERNANDEZ F. M. (Orgs.). Análise Crítica do Estudo de Impacto Ambiental do Aproveitamento Hidrelétrico de Belo Monte (Painel de Especialistas). Belém, 2009.

FEARNSIDE, P. M. Hidrelétricas na Amazônia: impactos ambientais e sociais na tomada de decisões sobre grandes obras. Manaus: Editora do INPA, 2015.

FERRETE, J. A; LEMOS, J. C.; LIMA S.C. Lagos artificiais e os fatores condicionantes e determinantes no processo saúde-doença. Caminhos de Geografia, vol. 5(13), p. 187-200, 2004. 
FINKELMAN J. Considerações sobre conceitualização e operacionalização da saúde ambiental. Ciência \& Ambiente. Santa Maria: Universidade Federal de Santa Maria (UFSA), 2002.

FLEURY, L.C. Conflito ambiental e cosmopolíticas na Amazônia brasileira: a construção da Usina Hidrelétrica de Belo Monte em perspectiva. 2013. 320f. Tese (Doutorado em Sociologia) - Instituto de Filosofia e Ciências Humanas, Programa de Pós-Graduação em Sociologia, Universidade Federal do Rio Grande do Sul, Porto Alegre, 2013.

FGV. Fundação Getúlio Vargas. Centro de Estudos em Sustentabilidade (GVces). Indicadores de Belo Monte. Câmara Técnica de Monitoramento das Condicionantes - PDRSX. Resumo dos resultados de junho de 2014 a julho de 2015.

GANEM, R.S.; JURAS, I.A.G.M.; VIANA, M. B.; MERCADANTE, M.; ARAÚJO, S. M. V. G.; BRASILEIRO, V. M. M. Avaliação Ambiental Estratégica. Consultoria Legislativa. Câmara dos Deputados. Brasília, 2014.

GOMIDE, A. A. Condicionantes institucionais à execução de projetos de investimentos em infraestrutura: uma nota de pesquisa. Boletim de Análise Político-Institucional, n. 7, jan.-jun., Instituto de Pesquisa Econômica Aplicada (IPEA), Brasília, 2015.

GONDIM, G. M. M.; MONKEN, M.; ROJAS, L. I.; BARCELLOS, C.; PEITER, P.; NAVARRO, M.; GRACIE, R. O Território da Saúde: A organização do sistema de saúde e a territorialização In: MIRANDA, A.C.; BARCELLOS, C.; MOREIRA, J.C.; MONKEN, M. (Orgs.). Território, ambiente e saúde. Rio de Janeiro: Editora Fiocruz, 2008.

GOUVEIA, N. Saúde e desenvolvimento: as questões dos grandes empreendimentos. Revista Pagina 22. Centro de Estudos em Sustentabilidade da FGV (Gvces). Texto de 9 de abril de 2013. Disponível em: http://www.pagina22.com.br/2013/04/09/saude-e-desenvolvimento-asquestoes-dos-grandes-empreendimentos/. Acesso em: 10/07/2104.

GULIS, G.; MEKEL, O.; ÁDAM, B.; CORI, L. Assessment of Population Health Risks of Policies. Springer. New York, 2014.

HACON, S. SCHUTZ; P. BERMEJO, P.M. Indicadores de Saúde Ambiental: uma Ferramenta para a Gestão Integrada de Saúde e Ambiente. Cadernos de Saúde Pública, vol. XIII, n.1, jan - mar NESC/UFRJ, p.45-66, 2005.

HACON, S. S.; DÓREA, J. G.; FONSECA, Marlon F; OLIVEIRA, B. A.; MOURAO, D. S.; RUIZ, C. M. V.; GONCALVES, R. A.; MARIANI, C. F.; BASTOS, W. R. The Influence of Changes in Lifestyle and Mercury Exposure in Riverine Populations of the Madeira River (Amazon Basin) near a Hydroelectric Project. International Journal of Environmental Research and Public Health, v. 11, p. 2437-2455, 2014.

HAESBAERT, R. Territórios alternativos. EdUFF. Contexto. 186 p. São Paulo, 2002.

HARVEY, David. A condição pós-moderna. São Paulo: Ed. Loyola, 1993.

HARVEY D. A Produção Capitalista do Espaço. Ed.: Annablume, $2^{a}$ edição. São Paulo, 2005. 
HAUGHTON, G.; HUNTER, C. Urban growth and the urban environment. In: Sustainable cities: regional development and public policy. London: Routledge, n. 2, p. 357, 2004.

IAIA. International Association for Impact Assessment. Avaliação de Impactos na Saúde: princípios internacionais da melhor prática. Edições Especiais n. 5, 2006.

IBGE. Instituto Brasileiro de Geografia e Estatística. Pesquisa de informações básicas municipais: perfil dos municípios brasileiros. Gestão 2005. Rio de Janeiro: Instituto Brasileiro de Geografia e Estatística, 2006.

IBGE. Instituto Brasileiro de Geografia e Estatística. Cadastro de Municípios localizados na Amazônia Legal.

Disponível: http://www.ibge.gov.br/home/geociencias/geografia/amazonialegal.shtm?c=2 Acesso 02/03/2015.

IHU. Instituto Humanitas Unisinos. Disponível: http://www.ihu.unisinos.br/entrevistas/ 40735belo-monte-e-seus-impactos-sobre-os-povos-indigenas-entrevista-especial-com-ricardoverdum. Acesso em: 26/01/2012.

ISA. Instituto Socioambiental. Notícias Socioambientais. Semana começa com protestos no canteiro de obras de Belo Monte e em Altamira, 8 de maio de 2013. Disponível em: http://www.socioambiental.org/pt-br/noticias-socioambientais/semana-comeca-comprotestos-no-canteiro-de-obras-de-belo-monte-e-em. Acesso em: 15/12/2015

O Dossiê Belo Monte - Não há condições para a Licença de Operação. Junho de 2015. Disponível: https://www.socioambiental.org/sites/blog.socioambiental.org/files/dossiebelo-monte-site.pdf Acesso em:

- Programa de Monitoramento de Áreas Protegidas. 2010. Disponível em: http://uc.socioambiental.org. Acesso em: 15/12/2015.

JACOBI P.R. Brasil depois da Rio+10. Revista do Departamento de Geografia [Internet]. 2002; (15):19-29. Disponível em: http://www.geografia.fflch.usp.br/ publicacoes/RDG/RDG_15/1929.pdf. Acesso em: 02/03/2012.

JATOBÁ, S.U. S. Gestão do território e a produção da socionatureza nas ilhas do Lago de Tucuruí na Amazônia brasileira. 2006. 318f. Tese (Doutorado em Desenvolvimento Sustentável) - Centro de Desenvolvimento Sustentável, Universidade de Brasília-UnB, Brasília, 2006.

KATSURAGAWA, T. H. et al. Malária e aspectos hematológicos em moradores da área de influência dos futuros reservatórios das hidrelétricas de Santo Antônio e Jirau, Rondônia-Brasil. Caderno de Saúde Pública, n.25(7), p. 1486-1492, 2009.

KLIGERMAN D. C.; VILELA, H.; CARDOSO, O.T.A.; COHEN, S.C. SOUSA, D.; LA ROVERE, E. Sistemas de indicadores de saúde e ambiente em instituições de saúde. Ciência e Saúde Coletiva, vol.12, n.1, 2007.

KOIFMAN, S. Geração e transmissão da energia elétrica: impacto sobre os povos indígenas no Brasil. Caderno de Saúde Pública, n. 17(2), p. 413-423, 2001. 
LEFEBVRE, H. La production de l'espace. Paris: Ed anthropos, 1974.

LEPPO, K.; OLLILA, E.; SEBATIÁN, P.; WISMAR, M.; COOK, S. Health in All Policies: Seizing opportunities, implementing policies. Finland: Ministry of Social Affairs and Health, 2013.

LUCENA IG. Gestão ambiental empresarial e certificação ISO 14001: alcances e limites. In: RIBEIRO H. Olhares Geográficos: meio ambiente e saúde. São Paulo: Senac, 2005.

MAGALHÃES SANTOS, S. M. S. B.; HERNANDEZ F. M. (Orgs.). Análise Crítica do Estudo de Impacto Ambiental do Aproveitamento Hidrelétrico de Belo Monte (Painel de Especialistas). Belém, 2009.

MAGALHAES, M. A. F. M.; SANTOS, S. M.; GRACIE, R.; BARCELlOS, C. Sistemas de Informações Geográficas em Saúde. In: SANTOS, S. M.; BARCELLOS, C (Orgs). Abordagens espaciais na saúde pública. Brasília: Ministério da Saúde/Fundação Oswaldo Cruz, 2006.

MALAGUTI, G. A. Regulação do setor elétrico brasileiro: da formação da indústria de energia elétrica aos dias atuais. Textos para discussão. Universidade Federal Fluminense. Faculdade de Economia. Niterói (RJ), 2009.

MANYARI, W. V. Impactos ambientais a jusante de hidrelétricas, o caso da usina de Tucuruí, PA. 2007. 211f. Tese (Doutorado em Planejamento Energético e ambiental) - COPPE, Universidade Federal do Rio de Janeiro, Rio de Janeiro, 2007.

MASSEY, D. Pelo Espaço: uma nova política de espacialidade. Rio de Janeiro: Bertrand Brasil, 2008.

MILARÉ, E. Estudo Prévio de Impacto Ambiental no Brasil. In: AB'SABER, A.N; MULLERPLANTENBERG, C (Orgs.). Previsão de Impactos: o Estudo de Impacto Ambiental no Leste, Oeste e Sul. Experiências no Brasil, na Rússia e na Alemanha 2a ed. São Paulo: Editora da Universidade de São Paulo, 2006.

MIRANDA, A.C.; BARCELLOS, C.; MOREIRA, J.C.; MONKEN, M. (Orgs). Território, ambiente e saúde. Rio de Janeiro: Fiocruz; 2008.

MITCHELL, B. Geography and Resources Analysis. New York: Longemans, 1979.

MONKEN, M.; PEITER, P.; BARCELLOS, C.; ROJAS, L. I.; NAVARRO, M. A.; GODIM, G. M. M.; GRACIE, R. O Território na Saúde: construindo referencias para análises em saúde e ambiente. In: MIRANDA, A.C.; BARCELLOS, C.; MOREIRA, J.C.; MONKEN, M. (Orgs.). Território, ambiente e saúde. Rio de Janeiro: Editora Fiocruz, 2008.

MORETTO, E. M; GOMES, C. S; ROQUETTI, D. R; JORDAO, C.O. Histórico, tendências e perspectivas no planejamento espacial de usinas hidrelétricas brasileiras: a antiga e atual fronteira Amazônica. Ambiente \&Sociedade, São Paulo, v.15, n.3, p.141-164, Dec.2012. Disponível em: http://www.scielo.br/scielo.php?script= sci_arttex\&pid=S1414753X2012000300009\&lng=em \&nrm=iso . Acesso em 02/11/2014. 
MOREIRA, C.G.Q. Geografia da Produção de Energia Hidroeletrica no Brasil. 2015. 172 f. Dissertação (Mestrado em Geografia) - Departamento de Geografia, Universidade de São Paulo- USP, São Paulo, 2015.

MAB. Movimento dos Atingidos por Barragens. Água e energia não são mercadorias! ". Entrevista especial: "Falta clareza nas licenças ambientais de Belo Monte, 23/02/2011. Disponível em: http://www.mabnacional.org.br/search/node/Belo\%20Monte Acesso em: 23/08/2014.

NOBLE, B. F.; BRONSON, J. E. Integrating Human Health into Environmental Impact Assessment: Case Studies of Canada's Northern Mining Resource Sector. Arctic, vol. 58, n. 4, 2005 .

NORTE ENERGIA. Investimentos melhoram a vida de indígenas no Xingu. Disponível em: http://norteenergiasa.com.br/site/2015/ 10/16/investimentos-melhoram-vida-de-indigenas-noxingu/. Acesso em: 18/10/2015.

. UHE de Belo Monte. Disponível em: http://norteenergiasa. com.br/site/wpcontent/uploads/2015

/01/Paper-Belo-Monte-Dezembro.pdf. Acesso em: 10/04/2014.

OCDE. Organisation de Coopération et de Développement Économiques. L'évaluation environnementale stratégique. Guide de Bonnes Pratiques Dans le Domaine de la Coopération pour le Développement. Paris, 2006.

OLIVEIRA, S.S.; CÂMARA, V.M. O Desenvolvimento do Curso Básico de Vigilância Ambiental no Estado da Bahia. Revista Baiana de Saúde Pública, n. 28(2), p. 267-279, 2004.

OLIVEIRA, F.A.S.; HEUKELBACH, J.; GOMIDE, M.; MOURA, R.C.S. Grandes represas e seu impacto em saúde pública: II. Efeitos a jusante. Cadernos de Saúde Coletiva. Rio de Janeiro, 2006.

OLIVEIRA, J. P.; COHN, C. (Orgs.). Belo Monte e a questão indígena. Brasília: ABA, 2014.

ORDÓÑEZ, G.A. Salud ambiental: conceptos y atividades. Revista Panamericana de Salud Publica (Pan Am J Public Health), n. 7(3), 2000.

OPAS/OMS. Organizacion Panamericana de la Salud. Organizacion Mundial de la Salud. Nuestro planeta, nuestra salud. Informe de la Comisión de Salud y Medio Ambiente de la OMS. Washington, DC: OPS/ OMS, 1993.

OPAS. Organização Pan-Americana da Saúde. Representação Brasil. Ecossistema e saúde humana: alguns resultados da Avaliação Ecossistêmica do Milênio. Brasília, 2005.

Representação Brasil. Vigilância em Saúde Ambiental. http://www.paho.org /bra/index.php?option=com_content $\&$ view=category\&layout=blog\&id=1228\&Itemid=768.

Acesso em: 23/09/2014.

OMS. Organização Mundial da Saúde. Indicadores para o estabelecimento de políticas e a tomada de decisão em saúde ambiental. Genebra, 2001. 
Diminuindo diferenças: a prática das políticas sobre determinantes sociais da saúde: documento de discussão. 2011.

PARLAMENTO EUROPEU. Relatório: Reduzir as desigualdades no domínio da saúde na EU. Comissão do Ambiente, da Saúde Pública e da Segurança Alimentar. A7-0032/2011. (2009/2014). Disponível em: http://www.europarl. europa.eu/sides/getDoc.do?pubRef=-//EP// NONSGML+REPORT+A7-2011-0032+0+DOC+PDF+V0//PT. Acesso em: 12/12/2015.

PAZ, L. R. L. Hidrelétricas e Terras Indígenas na Amazônia: Desenvolvimento Sustentável? 232p. Tese (Doutorado em Planejamento Energético) - COPPE, Universidade Federal do Rio de Janeiro-UFRJ, Rio de Janeiro, 2006.

PEITER, P. C.; BARCELLOS, C.; ROJAS, L. B. I.; GONDIM, G. M. M. Espaço Geográfíco e Epidemiologia. In: SANTOS, S. M.; BARCELLOS, C. (Orgs.). Abordagens espaciais na saúde pública. Brasília: Ministério da Saúde/Fundação Oswaldo Cruz, 2006.

PELLEGRINI, M. Energia: fontes limpas e eficiência são as soluções. In: Diálogos Capitais. Publicado em 31/08/2015. Disponível em: http://www.cartacapital.com.br/dialogoscapitais/energia-fontes-limpas-e-eficiencia-sao-as-solucoes-1304.html. Acesso em: 10/10/2015.

PEREIRA, A. F. S. Planejamento da operação energética e da manutenção no sistema hidrotérmico de potência brasileiro. 2006. 214f. Dissertação (Mestrado em Planejamento de Sistemas Energéticos), Universidade Estadual de Campinas-Unicamp, Campinas, 2006.

PHILIPPI J.A.; MALHEIROS, T. F. Saneamento, saúde e ambiente: fundamentos para um desenvolvimento sustentável. São Paulo: Manole, 2005.

PNUMA. Programa das Nações Unidas para o Meio Ambiente. Metodologia para a elaboração de Relatórios GEO Cidades. Manual de Aplicação Versão 2. Programa das Nações Unidas para o Meio Ambiente e Consorcio Parceria 21, 2004.

PORTO, M.F.S; FREITAS C.M. Análise de riscos tecnológicos ambientais: perspectivas para o campo da saúde do trabalhador. Cad. Saúde Pública, Rio de Janeiro, v.13, No 1.2, p.59-72, 1997.

PORTO M.F., MILANEZ B. Eixos de desenvolvimento econômico e geração de conflitos socioambientais no Brasil: desafios para a sustentabilidade e a justiça social. Ciência e Saúde Coletiva, n.14(6), p. 1983-94, 2009.

PORTO M.F., FINAMORE R. Riscos, saúde e justiça ambiental: o protagonismo das populações atingidas na produção de conhecimento. Ciência \& Saúde Coletiva, n. 17(6), p. 1493-1501, 2012.

QUEIROZ, A.R.S.; MOTTA-VEIGA, M. Análise dos impactos sociais e à saúde de grandes empreendimentos hidrelétricos: lições para uma gestão energética sustentável. Ciência \& Saúde coletiva, n. 17(6), p. 1387-1398, 2012.

RAMOS, R.R.; MACHADO, C. J. S. Contribuições teórico-metodológicas para o estudo das relações entre saúde, meio ambiente e território. Hygeia, Revista Brasileira de Geografia Médica e da Saúde, n.6 (11), p.80-90, 2010. 
RADICCHI, A.L.A. E LEMOS, A.F. Saúde Ambiental. Núcleo de Educação em Saúde Coletiva da Faculdade de Medicina. Belo Horizonte: Nescon/UFMG, Coopmed, 2009.

REPÓRTER BRASIL. O BNDES e sua política socioambiental: Uma crítica sob a perspectiva da sociedade civil organizada. Centro de Monitoramento de Agrocombustíveis. Fevereiro de 2011. http://reporterbrasil.org.br/documentos/BNDES_Relatorio_CMA_ReporterBrasil_2011.pdf. Acesso em: 10/10/2015.

ROSA, L.P.; SIGAUD, L; MIELNIK, O. Impactos de grandes projetos hidrelétricos e nucleares: aspectos econômicos e tecnológicos, sociais e ambientais. São Paulo. AIE/COPPE; Marco Zero, CNPQ, 199p., 1988.

ROSA, L. P. Hidrelétricas e meio ambiente na Amazônia: análise crítica do Plano 2010. Revista Brasileira de Energia, vol. 1, n.1, 1989.

ROVERE, E.L.L., SILVA, H.V.O., BULCAO, J.A.S., SANTOS, S., BARCELOS, C., LUIGI, G., SOUSA, D.S., MOURA, F.H.S.; NIEMEYER, L.F. Mapa de risco epidemiológico de projetos hidrelétricos no Brasil - Produto 1. Rio de Janeiro: LIMA/COPPE/UFRJ, 2009.

SABBAG, O. J. Impactos da construção da UHE "Três Irmãos" sobre a atividade de mineração: importância de uma gestão ambiental. 2006. 136 f. Tese (doutorado). Universidade Estadual Paulista, Presidente Prudente, 2006.

SANTO, A. H. Causas mal definidas de morte e óbitos sem assistência. Revista Associação Médica Brasileira, n. 54 (1), p. 23-28, $2008 . \quad$ Disponível em: http://www.scielo.br/pdf/ramb/v54n1/16.pdf . Acesso em 12/04//2014.

SANTOS, Milton. Espaço e Método. São Paulo: Nobel, 1985.

SANTOS, M. C. O conceito de "atingido" por barragens - direitos humanos e cidadania. Revista Direito \& Praxis. Vol. 06, n. 11, p. 113-140. Rio de Janeiro, 2015.

SÁNCHEZ, L. E. Avaliação de impacto ambiental: conceitos e métodos. $1^{a}$ Edição. São Paulo: Oficina de Textos, 2006. 495p.

SÁNCHEZ L.E. Avaliação Ambiental Estratégica e sua aplicação no Brasil. "Rumos da Avaliação Ambiental Estratégica no Brasil". Instituto de Estudos Avançados da Universidade de São Paulo [internet]. 2008. Disponível em: http://www.iea.usp.br/ publicações/textos/aaeartigo./at_/file. Acesso em: 03/01/2014.

SÁNCHEZ, L.E. Avaliação de impacto ambiental: conceitos e métodos. 2a . Edição. São Paulo: Oficina de Textos, 2013.

SCHAEFFER, R. Impactos Ambientais de Grandes Usinas Hidrelétricas no Brasil. 1986. $194 \mathrm{f}$. Dissertação (Mestrado em Engenharia Nuclear e Planejamento Energético) - COPPE, Universidade Federal do Rio de Janeiro - UFRJ, Rio de Janeiro, 1986.

SILVEIRA, M. Interface entre saúde e meio ambiente: aspectos da saúde na Avaliação de Impacto Ambiental de empreendimentos. In: V ENCONTRO NACIONAL DA ANPPAS. 
Anais. Florianópolis, 2010. Disponível em: http://www.anppas.org.br/encontro5/ cd/artigos/GT4-270-187-20100903230338.pdf. Acesso em: 21/10/2011.

. A contribuição do setor saúde aos processos de licenciamento ambiental: primeiras aproximações. 2008. 129f Dissertação (Mestrado em Geografia) - Pós-Graduação em Geografia, Universidade de Brasília-UnB, 2008.

SILVEIRA, M.; ARAUJO NETO, M. Diniz. Licenciamento ambiental de grandes empreendimentos: conexão possível entre saúde e meio ambiente. Ciência Saúde Coletiva, v. 19, n. 9, p. 3829-3838, Sept. 2014. Disponível em: http://www.scielo.br/scielo.php? script=sci_arttext\&pid=S1413-81232014000903829\&lng=en\& $\mathrm{nrm}=$ iso. Acesso em $15 / 12 / 2015$.

SILVEIRA, M., PADILHA, J.D.; SCHNEIDER, M.; AMARAL, P.S.T.; CARMO, T.F.M.; NETTO, G.F.; ROHLFS, D.B. Perspectiva da avaliação de impacto à saúde nos projetos de desenvolvimento no Brasil: importância estratégica para a sustentabilidade. Caderno de Saúde Coletiva, n. 20 (1), p. 57-63, 2012.

SOARES, W.L.; PORTO, M.F. Atividade agrícola e externalidade ambiental: uma análise a partir do uso de agrotóxicos no cerrado brasileiro. 2007. Disponível em: http://www.scielo.br/scielo.php?pid=S1413-

1232007000100016\&script=sci_abstract\&tlng=pt. Acesso em: 24/8/2013.

SOBRAL, A; FREITAS, C.M. Modelo de organização de indicadores para operacionalização dos determinantes socioambientais da saúde. Saúde Social, vol. 19, n. 1, Mar./2010. Disponível em: http://www.scielo.br/scielo.php?script+sci_arttext\&pid+S0104-1290010000100004 \&lng= en\&nrm=iso. Acesso em: 04/02/2014.

SOBRAL, A; FREITAS, CM; GURGEL, H; PEDROSO, MM. Modelos de organização e análise dos indicadores. In: FREITAS, C. M. Saúde Ambiental - Guia Básico para Construção de Indicadores. Brasília-DF, 2011.

STAMM, H. R. Método para Avaliação de Impacto Ambiental (AIA) em projetos de grande porte: estudo de caso de uma usina termelétrica. 2003. 284f. Tese (Doutorado em Engenharia de Produção) - Programa de Pós-Graduação em Engenharia Industrial, Universidade Federal de Santa Catarina, Florianópolis, 2003.

THÉRY, H. Situações da Amazônia no Brasil e no continente. Revista Estudos Avançados n.53, Instituto de Estudos Avançados da Universidade de São Paulo, 2005.

TUNDISI, J. G. Exploração do potencial hidrelétrico da Amazônia. Estudos Avançados, v. 21 (59), p. 109-17, São Paulo, 2007.

VAN BELLEN, H. M. Desenvolvimento sustentável: uma descrição das principais ferramentas de avaliação. Ambiente e sociedade, v. 7, n. 1, jun/2004.

VARGAS, G.M. Amazônia: novas dinâmicas e territorialidades. Hist. cienc. saúdeManguinhos, Rio de Janeiro , v. 13, n. 1, p. 193-197, Mar. 2006. Disponível em: 
http://www.scielo.br/scielo.php?script=sci_arttext\&pid=S0104-

59702006000100015\&lng=en\&nrm=iso Acesso em: 10/03/2014

VASCONCELOS, C. H.; NOVO, E.M.L.M.; DONALISIO, M.R. Uso do sensoriamento remoto para estudar a influência de alterações ambientais na distribuição da malária na Amazônia brasileira. Caderno de Saúde Pública, n. 22(3), p. 517-526, 2006.

VERDUM, R. As obras de infraestrutura do PAC e os Povos Indígenas na Amazônia brasileira. Observatório de Investimentos na Amazônia. Inesc, 2012. Disponível em: http://amazonia.web1325.kinghost.net/wp-content/uploads/2012/10/Obras-de-Infraestruturado-PAC-e-Povos-Indigenas.pdf. Acesso em 13/07/2015.

WCD. World Comission on Dams. Dams and development. A new framework for decisionmaking. The Report of the World Commission on Dams. London: Earthscan Publications, 2000.

WHEED, B.; KHAN, F.; VEITCH, B. Linkage-Based Frameworks for Sustainability Assessment: Making a Case for Driving Force-Pressure-State-Exposure - Effect-Action (DPSEEA) Frameworks. Sustainability, n. 1(3), p.441-463, 2009.

WHO. World Health Organization. European Centre for Health Policy. Health Impact Assessment: mains concepts and suggested approach. Gothenburg Consensus paper. WHO: Regional Office for Europe, 1999.

Malaria Report 2014. Global Malaria Programme. Geneva, 2014. http://www.who.int/malaria/publications/world_malaria_report_2014/wmr-2014-no-profiles. pdf. Acesso em: 21/11/2015.

Public health, environmental and social determinants of health (PHE). http://www.who.int/phe/about_us/en/. Acesso em: 10/10/2014.

United Nations Conference on Sustainable Development Rio+20. Executive Board.

Rio de Janeiro, 2012.

WINKLER, M. S. Health impact assessment in complex eco-epidemiological settings in the humid tropics. 2011. 173p. Thesis. Basel, 2011.

WWF. Construção de hidrelétricas ameaça o rio Tapajós. 2012. Disponível em: http://www.wwf.org.br/informacoes/sala_de_imprensa/?30562/ construo-de-hidreltricasameaa-rio-tapajs. Acesso em: 10/12/2012.

YHEC. York Health Economics Consortium. Cost Benefit Analysis of Health Impact Assessment. Final Report. York: University of York, Department of Health, 2006.

ZHOURI A.; OLIVEIRA, R. Desenvolvimento, Conflitos Sociais e Violência no Brasil Rural: o caso das usinas hidrelétricas. Ambiente \& Sociedade, v. X, n. 2 p. 119-135, 2007.

ZHOURI, A.; LASCHEFSK, K.; PEREIRA, D.B. Desenvolvimento, sustentabilidade e conflitos socioambientais. In: ZHOURI, A. (Org.). A insustentável leveza da política ambiental: desenvolvimento e conflitos socioambientais. Belo Horizonte: Ed. Autêntica, 2005. 


\begin{abstract}
ANEXO 1
SILVEIRA, M., PADILHA, J.D.; SCHNEIDER, M.; AMARAL, P.S.T.; CARMO, T.F.M.; NETTO, G.F.; ROHLFS, D.B. Perspectiva da avaliação de impacto à saúde nos projetos de desenvolvimento no Brasil: importância estratégica para a sustentabilidade. Caderno de Saúde Coletiva, n. 20 (1), p. 57-63, 2012.
\end{abstract}

Artigo Original

\title{
Perspectiva da avaliação de impacto à saúde nos projetos de desenvolvimento no Brasil: importância estratégica para a sustentabilidade
}

Perspective of the health impact assessment in development projects

in Brazil: strategic importance for sustainability

Missifany Silveira', José Braz Damas Padilha', Mariana Schneider', Pablo Sebastian Tavares Amaral', Thenille Faria Machado do Carmo', Guilherme Franco Netto², Daniela Buosi Rohlfs ${ }^{3}$

\begin{abstract}
Resumo
Diante de questoes relacionadas aos falores de degradaçao socioambiental decorrentes do modelo de desanwolvimento vigente, o presente artigo propos uma reflexas sobog o papel do deservivivimento sustentavel e o seu entrentamento diante das

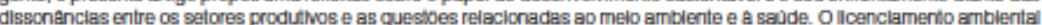
de empreendimantos, alam de represantar um marco h'storico importante e de externa necessidade en relacao a prevençao

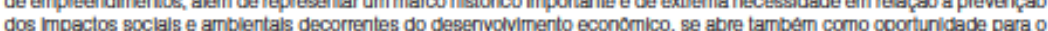

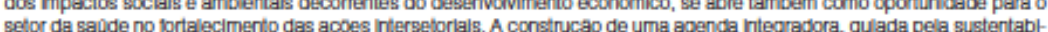
elar ta promoca a

Palavras-chave: desenvolvimento sustentavel; lloença; impacto ambiental; avallaçao.

Abstract

Considering the development model which affects the errvironment and human health this paper proposes a reflection on the cole of sustainable doveloprnent and solveng them to envirciment and health. The and solvng them before the dissonance between the productlve sectiors and issues relaied Intersectoral action. The construction of aganda ditven by integrating gustainablithy and health promotion can contribute to the construction of tools or methodologles to assess the health impacts arising from production processes, such as the Health Impact Assessment (SIA).

Keywords: sustainabla development; Ilcensure; ervironmental impact; evaluation.
\end{abstract}

2 Drebor do DSAST/SVS; Mintstarlo di Salde - Bras/la (DF) Bras.

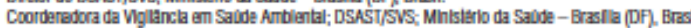

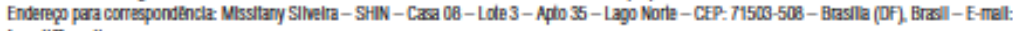

Fonle de thanclamento: rentuma.

Cont lo de hleresse nacta a declars.

Fiecobloso ent 17/08/2011

Aprovaso ent 14/12/201

Ca1. Saúde Colst, 2012, Rio de Janeko, 20 (1): $57-6357$ 


\begin{abstract}
ANEXO 2
SILVEIRA, M.; ARAUJO NETO, M. Diniz. Licenciamento ambiental de grandes empreendimentos: conexão possível entre saúde e meio ambiente. Ciência Saúde Coletiva, v. 19, n. 9, p. 3829-3838, Sept. 2014. Disponível em: http://www.scielo.br/scielo.php? script=sci_arttext\&pid=S14131232014000903829\&lng=en\&rm=iso.
\end{abstract}

Licenciamento ambiental de grandes empreendimentos: conexão possível entre saúde e meio ambiente

Environmental licensing of major undertakings: possible connection between health and environment
Abstract The prospect of multidisciplinary assessment that considers the environmental im pacts on the health of the population during the implementation of potentially polluting projecs is incipient in Brazil. Considering the scenario of major undertakings in the country, broadening the outlook on the health and environment relationship based on social and economic development processes striving for environmentally sustainable projects is a key strategy. This article examines the debate on the relationship between the current development model, the risks, the environment and health and discusses the importance of the participarion of the health sector in the environmental licensing procedures, which the instrument of the Environmental Impact As sessment (ELA). Seeking to create more environmentally and socially sustainable territories, the health sector has been looking for opportunities to participate in the licensing processes of major undertakings from the EIA standpoint. Results of research conducted by the Ministry of Health have demonstrated the form of participation in these processes, highlighting the strengths and weaknesses that finor or hinder the increase of preventive actions in public health in the implementation of major undertakings in Brazil. Key words Environmental licensing, Health, Major undertakings, Sustainability
Resumo A perspectiva de uma avaliacáo mulidisciplinar, que considere os impactos da modificaçato do meio ambiente sobre a saúde da populacha, durante a implantacalo de projetos de desenvalvimento potencialmente poluidores $e$ incipiente no Brasil Considerando o cenário de grandes empreendimentos no pais, ampliar o olhar sobre a relaçato saúde-ambiente a partir dos processos saciais e econômicos de desenvolvimento, visando projetos ecologicamente sustentáveis, $e$ uma estratégia fundamental. $O$ artigo explora o debate sobre as relapoes entre o modelo de desenvolvimento vigente, os riscos, o ambiente $e$ a saúde e discute a importancia da participaralo do setor saúde nos processos de licenciamento ambiental instrumento da Avaliapao de Impacto Ambiental (AIA). Visando à construçáo de territórios mais sustentáveis, ambientalmente $e$ socialmente, o setor saúde vem buscando oportunidades para participar dos processos de licenciamento de gramdes empreendimentos, na perspectiva da AIA. Resultados de uma pesquisa realizada no ambito do Ministério da Saúde demonstrou a forma de participacalo nesses processos, apontando para as potencialidades $e$ fragilidades que favorecem ou dificultam o fortalecimento de apoes preventivas em saúde pública, na implementacao de grandes projetos de desenvolvimento no Brasil.

Palavras-chave Licenciamento ambiental, Saúde, Grandes empreendimentos, Sustentabilidade 